\title{
Pressure Behavior of Horizontal Wells With Multiple Hydraulic Fractures Completed In Shale
}

Corinne Melissa Akoun

West Virginia University

Follow this and additional works at: https://researchrepository.wvu.edu/etd

\section{Recommended Citation}

Akoun, Corinne Melissa, "Pressure Behavior of Horizontal Wells With Multiple Hydraulic Fractures Completed In Shale" (2011). Graduate Theses, Dissertations, and Problem Reports. 3380.

https://researchrepository.wvu.edu/etd/3380

This Thesis is protected by copyright and/or related rights. It has been brought to you by the The Research Repository @ WVU with permission from the rights-holder(s). You are free to use this Thesis in any way that is permitted by the copyright and related rights legislation that applies to your use. For other uses you must obtain permission from the rights-holder(s) directly, unless additional rights are indicated by a Creative Commons license in the record and/ or on the work itself. This Thesis has been accepted for inclusion in WVU Graduate Theses, Dissertations, and Problem Reports collection by an authorized administrator of The Research Repository @ WVU. For more information, please contact researchrepository@mail.wvu.edu. 
Pressure Behavior of Horizontal Wells With Multiple Hydraulic Fractures Completed In Shale

\author{
Corinne Melissa Akoun
}

Thesis submitted to the

Benjamin M. Statler College of Engineering and Mineral Resources

At West Virginia University

In partial fulfillment of the requirements

For the degree of

Master of Sciences

In

Petroleum and Natural Gas Engineering

Khashayar Aminian, Ph.D., Chair

Samuel Ameri, M.S.

Alan W. Brannon

Morgantown, West Virginia

2011

Keywords: Shale gas, Flow regimes, Hydraulic fracturing, Dual porosity

Copyright 2013 Corinne Melissa Akoun 


\section{Abstract \\ Pressure Behavior of Horizontal Wells with Multiple Hydraulic Fractures \\ Completed in Shale}

\section{Corinne Melissa Akoun}

The purpose of this study was to investigate and identify the pressure behavior of a horizontal well with multiple hydraulic fractures completed in an ultra-low permeability formation. These formations are also referred to as unconventional gas reservoirs. Unconventional gas reservoirs such as shales and tight gas sands have extremely low permeability that requires massive simulation treatments in order to produce at an economic flow rate. Horizontal drilling and hydraulic fracturing are proven technologies for achieving economic production from unconventional gas reservoirs.

A dual porosity reservoir model was employed in this research study to simulate the pressure behavior of horizontal well containing multiple hydraulic fractures. The flow regimes were determined using the diagnostic plot. The impact of the reservoir and the hydraulic fracture

properties on the various flow regimes were also investigated. The flow regimes were found to be influenced by the number and conductivity of the hydraulic fractures and natural fracture permeability. 


\section{ACKNOWLEDGEMENTS}

I would like to take this opportunity to express my gratitude to all the people that have been helping in my research and the completion of my thesis.

My sincere gratitude is to my academic and research advisor, Dr. Kashy Aminian, for his support during my studies at WVU. I really appreciate his guidance, help and availability to answer my questions.

In addition, my appreciation goes to Professor Sam Ameri and to Dr. Ilkin Bilgesu for their guidance of my work here at West Virginia University. I am also grateful to Sir Alan W. Brannon for being part of my committee.

My special thanks to my sisters and brothers for their support and prayers. 


\section{DEDICATION}

This thesis is dedicated to The Lord Almighty for is guidance, strength and protection during this research.

I also dedicate this thesis to my lovely parents, Gisele and Laurent Akoun. Mom and dad, thank you very much for all you have done for me. I love you very much. 


\section{Table of Contents}

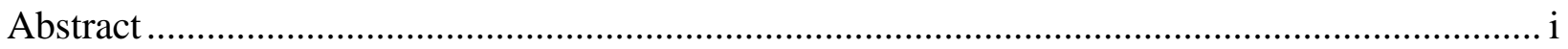

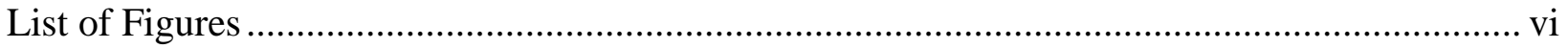

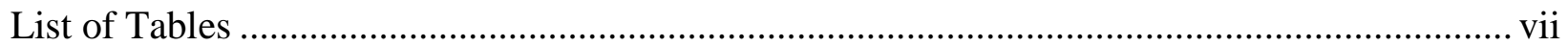

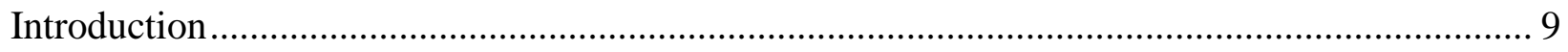

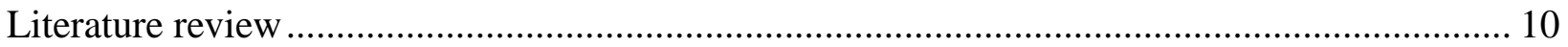

2.1 Naturally Fractured Reservoir ............................................................................... 10

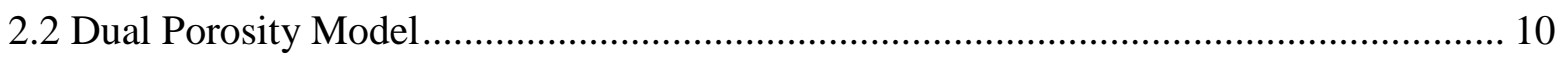

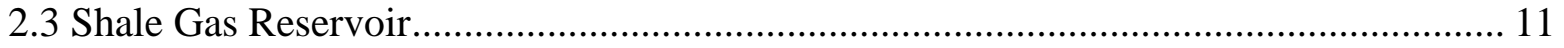

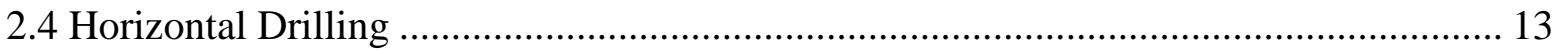

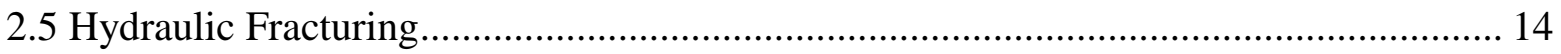

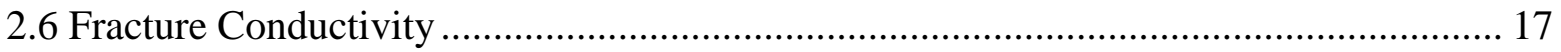

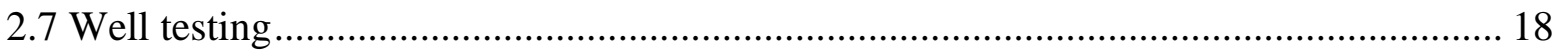

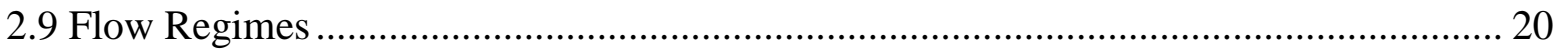

2.10 Flow Regimes for Fractured Horizontal Well ........................................................ 23

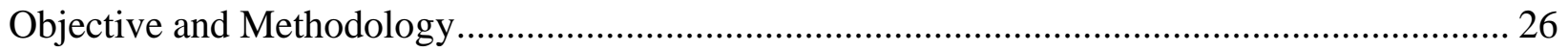

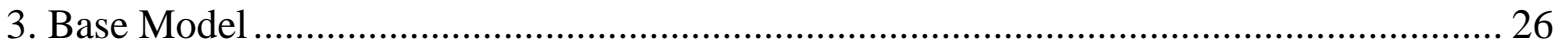

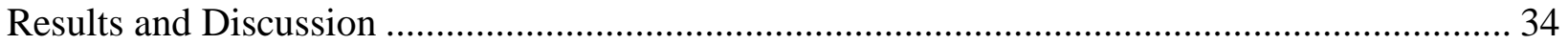

1. The effect of the number of hydraulic fractures ....................................................... 34

2. The impact of fracture properties on flow regimes was investigated ........................... 35

3. The impact of reservoir characteristics on flow regimes was investigated ..................... 38

5. The impact of the horizontal well length on the flow regimes was determined ............ 40

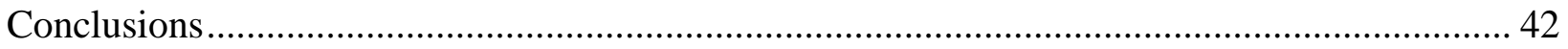

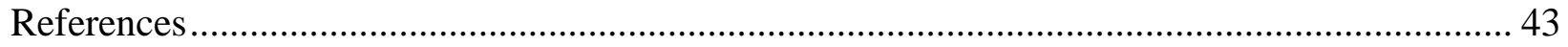

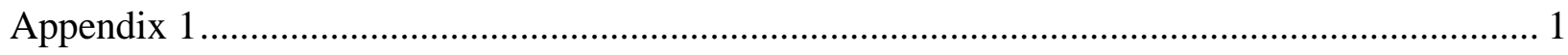

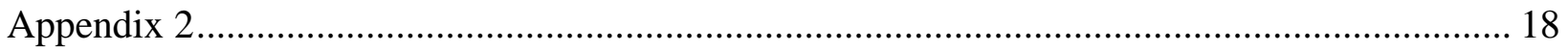

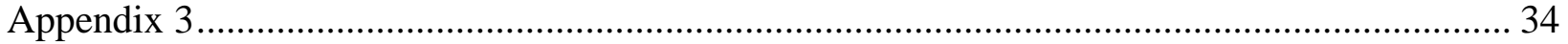

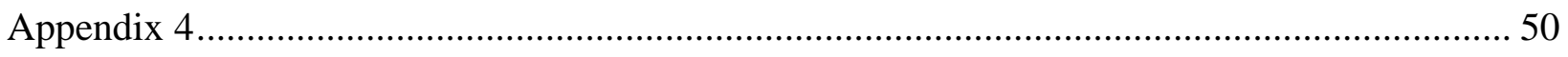




\section{List of Figures}

Figure 1: Dual Porosity Realistic and Conceptual Grid models (Grid block, www.dcs.gla.ac.uk,

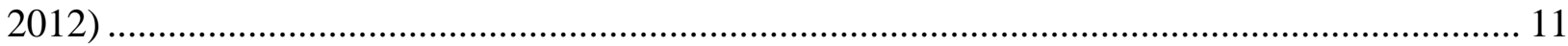

Figure 2: Shale Gas resources (Energy Information Administration, 2010) .............................. 12

Figure 3: More prominent Shale Field in USA (Perry Management, 2010) .............................. 12

Figure 4: Horizontal Drilling (Josh Corey, 2011) ................................................................. 13

Figure 5: PKN Hydraulic Fracture Model (J. Adachi, E. Siebrits, A. Peirce, July 2007) ............. 15

Figure 6: KGD Hydraulic Fracture Model (J. Adachi, E. Siebrits, A. Peirce, July 2007)............ 16

Figure 7: Radial Hydraulic Fracture Model (McLennan and Rob Jeffrey May 2013) ................. 16

Figure 8: Schematic of a Vertical Mini-Frac (Powless K.R. 2012) ………................................ 20

Figure 9: Schematic of a Horizontal Mini-Frac (Powless K.R. 2012)………………………...... 20

Figure 10: Early linear flow ................................................................................................. 21

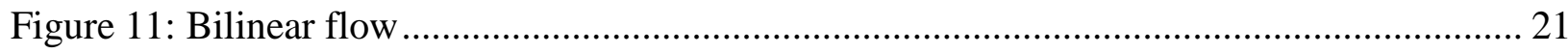

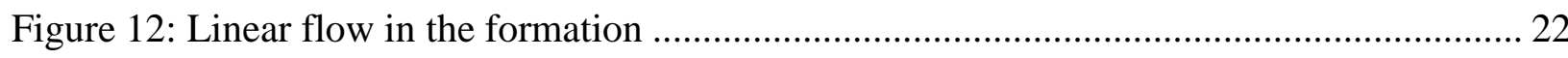

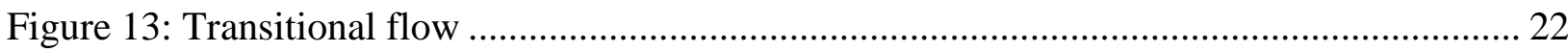

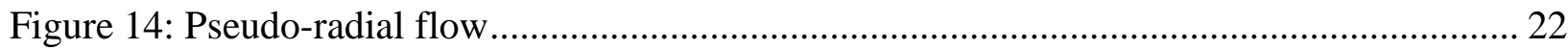

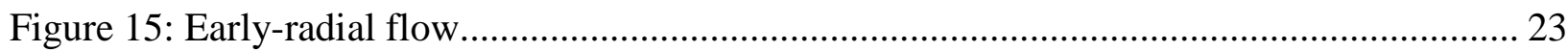

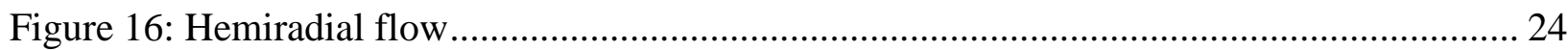

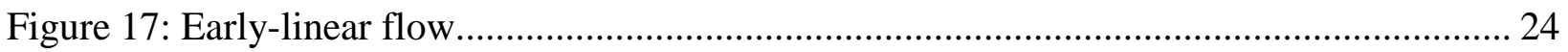

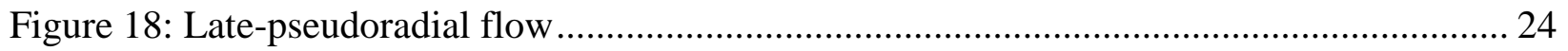

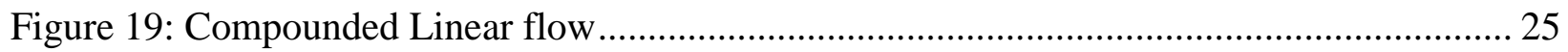

Figure 20: Reservoir pressure changes near the hydraulic fracture for the based model ............. 28

Figure 21: A Diagnostic plot illustrating various flow regimes associated with a hydraulically

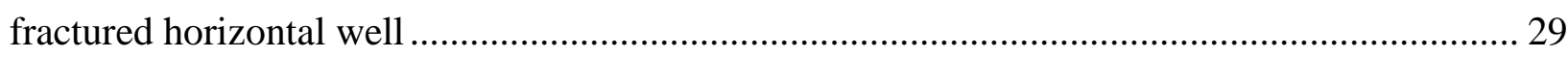

Figure 22: Diagnostic plot for Case 4.6 (1,2and3 Hydraulic Fractures)...................................... 34

Figure 23: Diagnostic plot for Case 4.6 (4, 7 and 11 Hydraulic Fractures)................................. 35

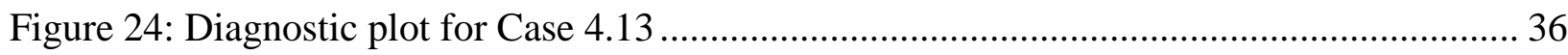

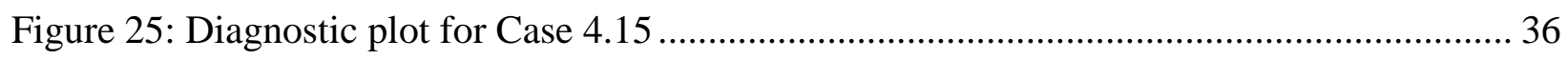

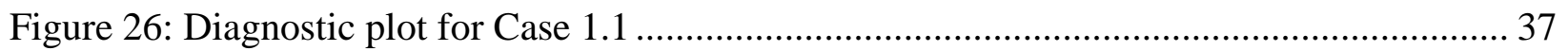

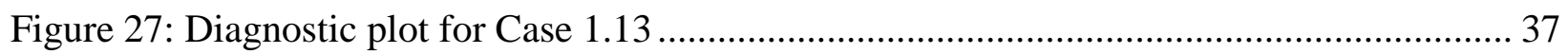

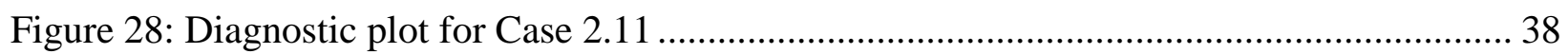

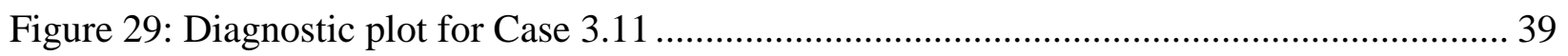

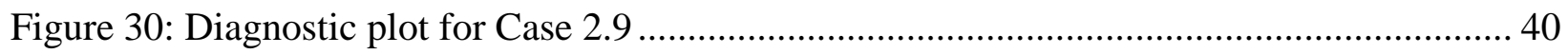

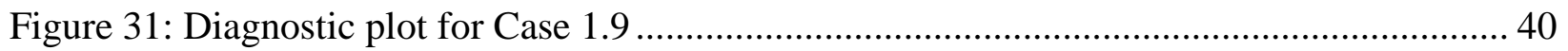

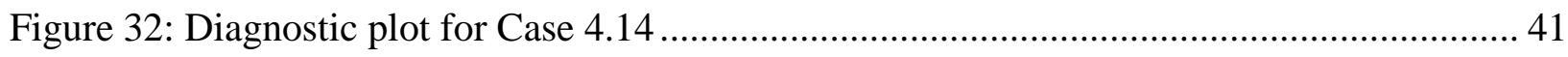

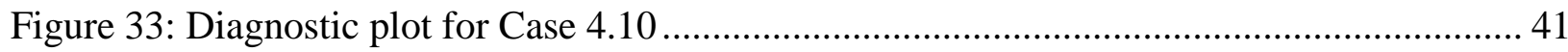




\section{List of Tables}

Table 1: Base Model Parameters ................................................................................................ 27

Table 2: List of the Parameters that were varied for Case 1 .................................................... 30

Table 3: List of the Parameters that were varied for Case 2 ............................................... 31

Table 4 : List of the Parameters that were varied for Case 3 ................................................. 32

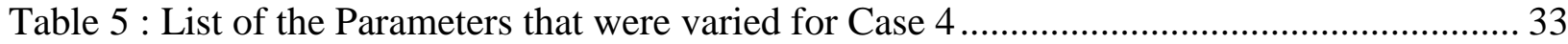




\section{List of Symbols/ Nomenclatures}

$L=$ fracture spacing

$h=$ thickness, $\mathrm{ft}$.

$\mu=$ viscosity, $\mathrm{cp}$

$k=$ permeability, md

$k_{f}=$ hydraulic fracture permeability, md

$k_{F}=$ natural fracture (fissure) permeability, md

$r_{f}=$ fracture radius, $\mathrm{ft}$

$w_{f}=$ fracture width, in

$x_{f}=$ fracture half length, $\mathrm{ft}$

$\beta=$ shape factor

$\Delta p=$ pressure change, psia

$c=$ reservoir diffusivity coefficient

$E=$ the Young's modulus of the material

$H=$ fracture height, $\mathrm{ft}$ 


\section{Introduction}

Unconventional reservoirs, such as shale gas, contain two pore structures, matrix and the natural fractures, and are more accurately represented by the dual porosity model.

Vertical and horizontal completions can be used in the low permeability formations, horizontal wells with multiple hydraulic fractures are considered to be most effective in achieving commercial production. Pressure transient test are commonly conducted both in

vertical and horizontal wells to evaluate the formation and hydraulic fracture properties. In order to analyze the results of the pressure transient tests, it is necessary to identify the flow regimes during the test. The flow regimes associate with horizontal wells containing multiple hydraulic fractures completed in naturally fractured formations has not been previously investigated. Previous studies have utilized This research was conducted using a dual porosity reservoir model to investigate the pressure behavior of the horizontal wells, containing multiple hydraulic fractures, completed in ultra-low permeability naturally fractured formations. The investigation focused on understanding how the reservoir properties and the hydraulic fractures characteristics affected the flow regimes. 


\section{Literature review}

\subsection{Naturally Fractured Reservoir}

Naturally fractured reservoir make up a large and increasing number of the world's underground hydrocarbon reserves. They are heterogeneous porous media where the fissures (or the natural fractures) are different in size based on where they are located. Fractures and opening of large size are form vugs and interconnected channels while the fine cracks are form block systems which are the main body of the reservoir. Usually the porous block store most of the fluid in the reservoir and are very low in permeability. The fissures have a low storage capacity and high in permeability. Natural fracture systems can have a variety of effects on reservoir performance in primary, secondary, and tertiary recovery and because of these effect must often be predicted long before they are evidenced in production data. Naturally occurring fracture classification:

1. Tectonic fractures (due to surface forces)

2. Regional fractures (due to surface or body forces)

3. Contractional fracture( due to body forces)

4. Surface-related fractures(due to body forces)

\subsection{Dual Porosity Model}

Dual porosity reservoir models are often used to represent the naturally fractured reservoirs. A rock defined by primary porosity is interganular and controlled by deposition and lithification. This porosity is mainly interconnected and usually can be correlated with permeability since it is largely dependent on the geometry size distribution and spartical distribution of the grains. In contrast, the secondary porosity is controlled by fracturing and jointing and is not highly interconnected. The secondary porosity cannot be correlated with 
permeability because it is created though alteration of rock by the processes such as dolomitization and dissolution. Figure 1 shows a naturally fractured reservoir and how it is represented by dual porosity model.

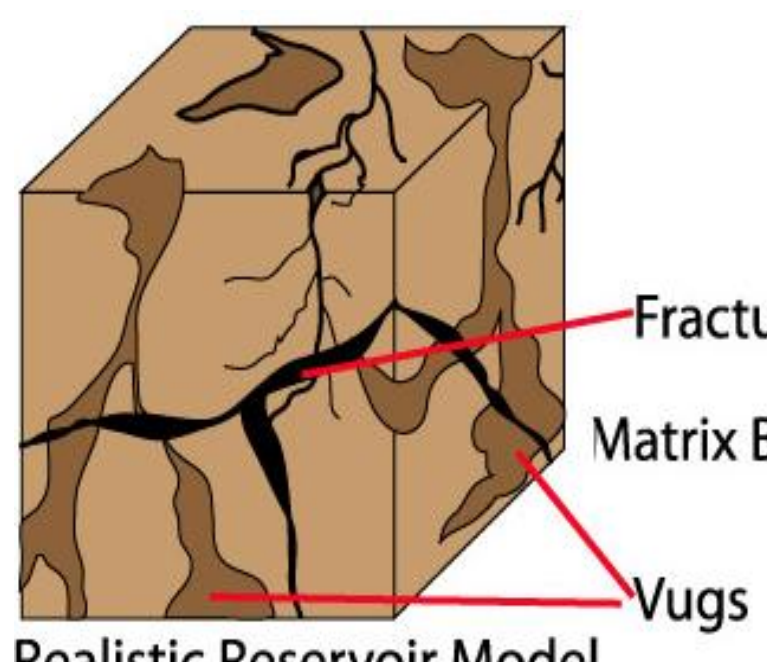

Realistic Reservoir Model

Figure 1: Dual Porosity Realistic and Conceptual Grid models (Grid block, www.dcs.gla.ac.uk, 2012)

\subsection{Shale Gas Reservoir}

Shale gas reservoirs are made of organic rich, fine grained rocks with very low permeability due to both very small grain size and clay content. The organic matter in the shale may contain as much as $60 \mathrm{scf}$ of natural gas per ton of rock. The organic matter preserved in the rocks is derived largely from bacteria and blue-green algae, marine green-algae or higher woody plants. Figure 2 shows the distribution of shale gas resources around the world 


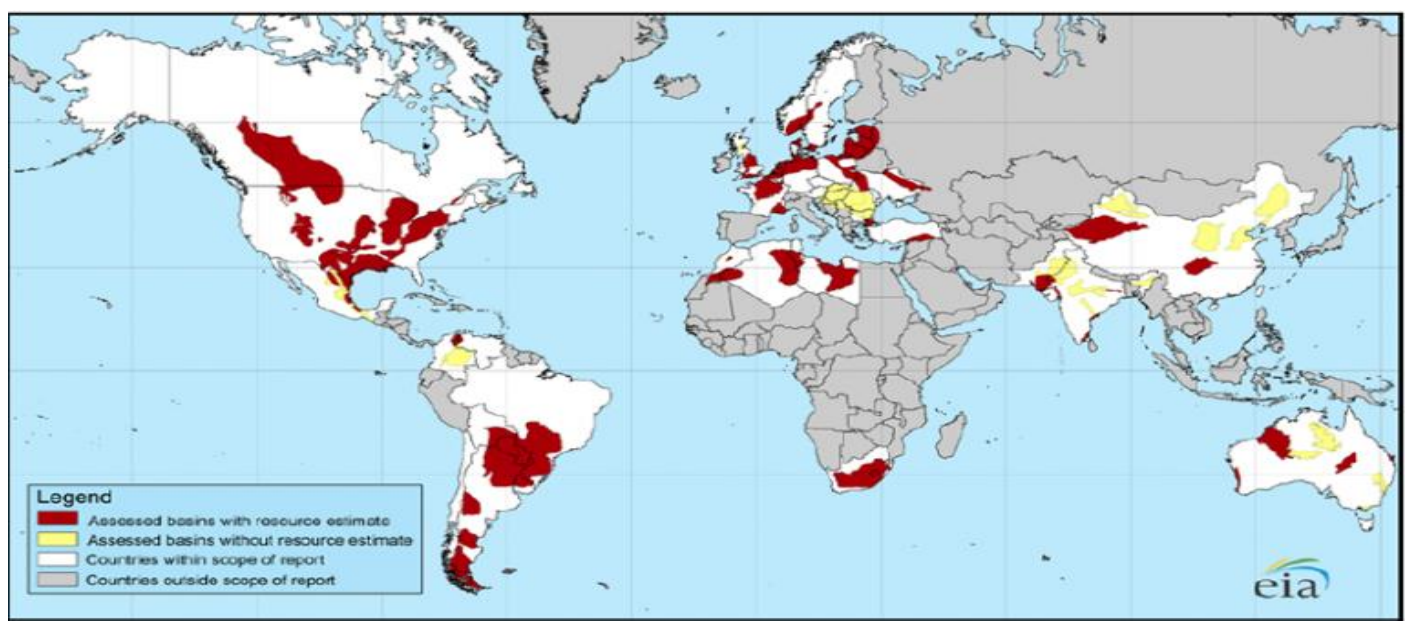

Figure 2: Shale Gas resources (Energy Information Administration, 2010)

Figure 3 illustrates the key characteristics of various shale formations in United States.

Figure 3: More prominent Shale Field in USA (Perry Management, 2010)

\begin{tabular}{|c|c|c|c|c|c|}
\hline $\begin{array}{c}\text { Shale } \\
\text { Reservoir }\end{array}$ & Location & $\begin{array}{l}{ }^{*} \text { Est. } \\
\text { Breakeven } \\
\text { Price, \$/mmbtu }\end{array}$ & $\begin{array}{l}\text { Ave. Well } \\
\text { Depth, ft. }\end{array}$ & $\begin{array}{l}\text { Ave. Well } \\
\text { Production, } \\
\text { mmatd }\end{array}$ & $\begin{array}{l}\text { Ave. Carbon } \\
\text { Dioxide \% }\end{array}$ \\
\hline Barnett & Nor. Tex. & $\$ 4.50-\$ 5.50$ & $6,500-9,500$ & $0.5-4.0$ & $0.3-2.7$ \\
\hline Haynesville & E. Tex./W. La. & $\$ 3.50-\$ 4.50$ & $10,000+$ & $2.5-20+$ & 4.8 \\
\hline Fayetteville & Cen Ark. & $\$ 4.50-\$ 5.50$ & $1,500-6,500$ & $1.0-3.5$ & 1.0 \\
\hline Marcellus & Pa., Oh., N.Y. & $\$ 5.00-\$ 5.50$ & $2,000-8,000$ & $0.5-4.0$ & $0.1-0.9$ \\
\hline Woodford & Okla. & $\$ 4.50-\$ 5.50$ & $6,000-11,000$ & $1.0-3.0$ & $?$ \\
\hline Eagle Ford & Sou. Tex. & $\$ 4.00-\$ 5.00$ & $11,000-14,000$ & $6.0-10.0$ & $?$ \\
\hline \multicolumn{3}{|c|}{$\begin{array}{l}\text { Copyright } 2010 \\
\text { Perry Management, inc. } \\
\text { Midland, Texas }\end{array}$} & \multicolumn{3}{|c|}{ Estimates by Perry Management, Inc. } \\
\hline
\end{tabular}

Methane and associated natural gas liquids are stored primarily within three sites within the shale: matrix pore space, adsorbed on organic matter, and within the network of natural fractures. Both micro and macro-fractures network enhances the gas storage and deliverability of the kerogen rich shales. 
Developing shale gas reservoirs in currently producing regions of the United States provides the best guide for exploration and exploitation of additional shale gas resources worldwide.

\subsection{Horizontal Drilling}

The first recorded true horizontal oil well drilled near Texon, Texas, was completed in 1926. This method of drilling is very costly but efficient for development of unconventional reservoir around the world. As shown in Figure 4, a horizontal well is drilled such that the borehole is deviated at least 80 degree from vertical. As a result, the horizontal borehole contacts a large section of the reservoir.

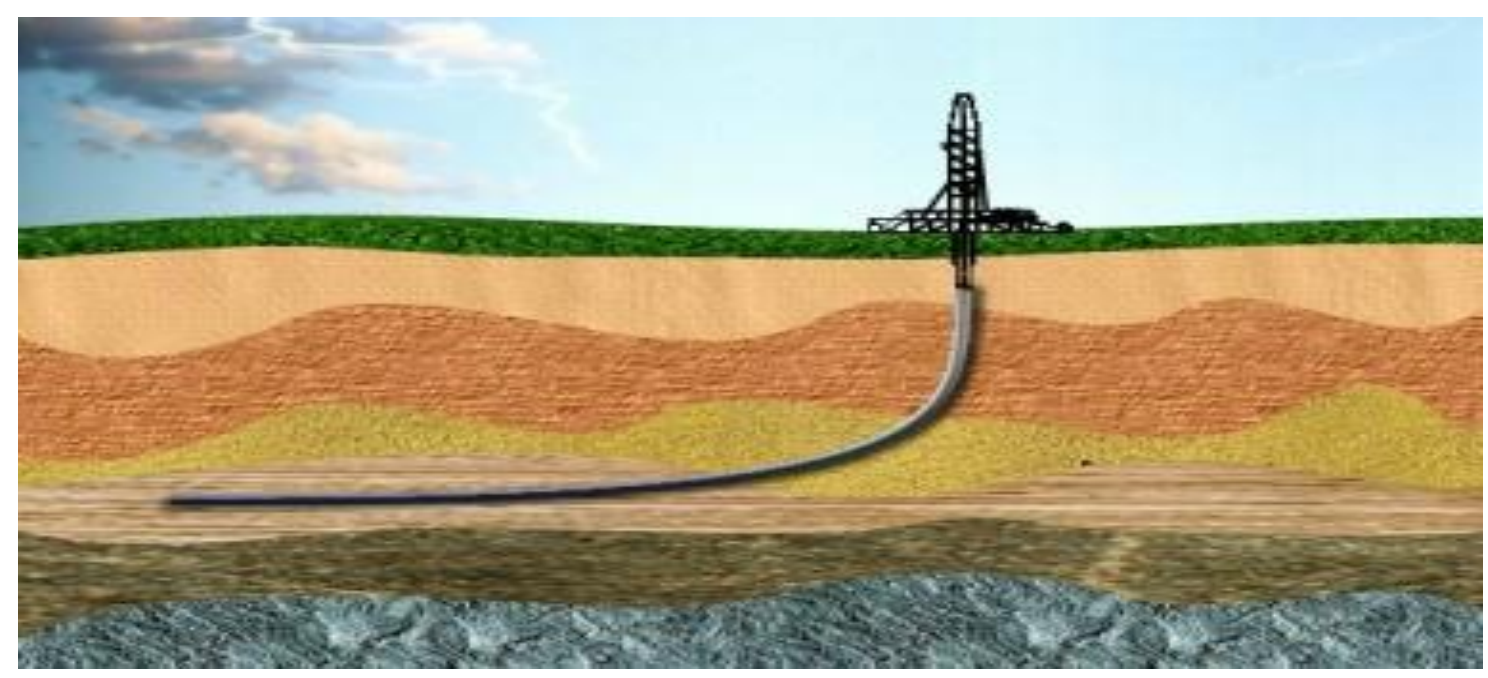

Figure 4: Horizontal Drilling (Josh Corey, 2011)

This drilling process utilizes whipstocks, bottomhole assembly configurations, instruments to measure the path of the wellbore in three-dimensional space, data links to communicate measurements taken downhole to the surface, mud motors and special BHA components and drill bits, including rotary steerable systems, and drill bits. The engineer in 
charge of this task exploits drilling parameters such as weight on bit and rotary speed to deflect the bit away from the axis of the existing wellbore.

Thin beds reservoirs are usually drilled horizontally in order to enhance oil or gas recovery. Horizontal drilling is commonly applied to the shale reservoirs in order to place the borehole in extended contact with the formation.

\subsection{Hydraulic Fracturing}

Hydraulic fracturing is a widely used stimulation technology for achieving production from unconventional reservoirs. For any fracturing operation, basic information such as direction of fracture, impact of the natural fractures on propagation of the hydraulic fracture created and the rate of production have to be estimated prior to the stimulation job. Different studies as well as the experience with the hydraulic fracturing, have revealed that hydraulic fractures always initiates in the direction of the minimum principal stress and propagate perpendicularly to this direction. However, recent studies have proved that hydraulic fractures might be more complex where the natural fractures are present.

A significant amount of force is required for fracturing (Daneshy A.A, 2007). The total amount of force required to keep a relatively small fracture $(50 \mathrm{ft} . \times 100 \mathrm{ft}$. $)$ with an in-situ principal stress of about $5000 \mathrm{psi}$, open is $7.2 \times 10^{9} \mathrm{lb}(50 \times 100 \times 5000 \times 2 \times 144)$. Daneshy further states that a small pressure increase of about 100 psi, if active over the entire length of the fracture, will exert about $1.44 \times 108(50 \times 100 \times 100 \times 2 \times 144) \mathrm{lb}$ of force on the fracture faces. The amount of stress that develops at fracture tips is large enough to cause fracture extension in any formation. Pressure drop inside fractures should be accounted for by frictional resistance along the fracture length. In order to create larger pressure differences the fracture width over a 
significant part of the fracture length should be narrow. The variations of pressure seen while fracturing have been complex; the fluid pressure is relatively constant inside the fracture the only pressure difference observed is at the tip of the fracture.

Fracture pressure analysis accepts three basic types of fracture geometry (Guo.F.et al, 2007) they are PKN, KGN and radial models.

Both PKN and KGD models have a rectangular extension mode but Figure 5 shows that the PKN model uses an elliptical cross section while Figure 6 shows that the KGD model uses a rectangular cross section.

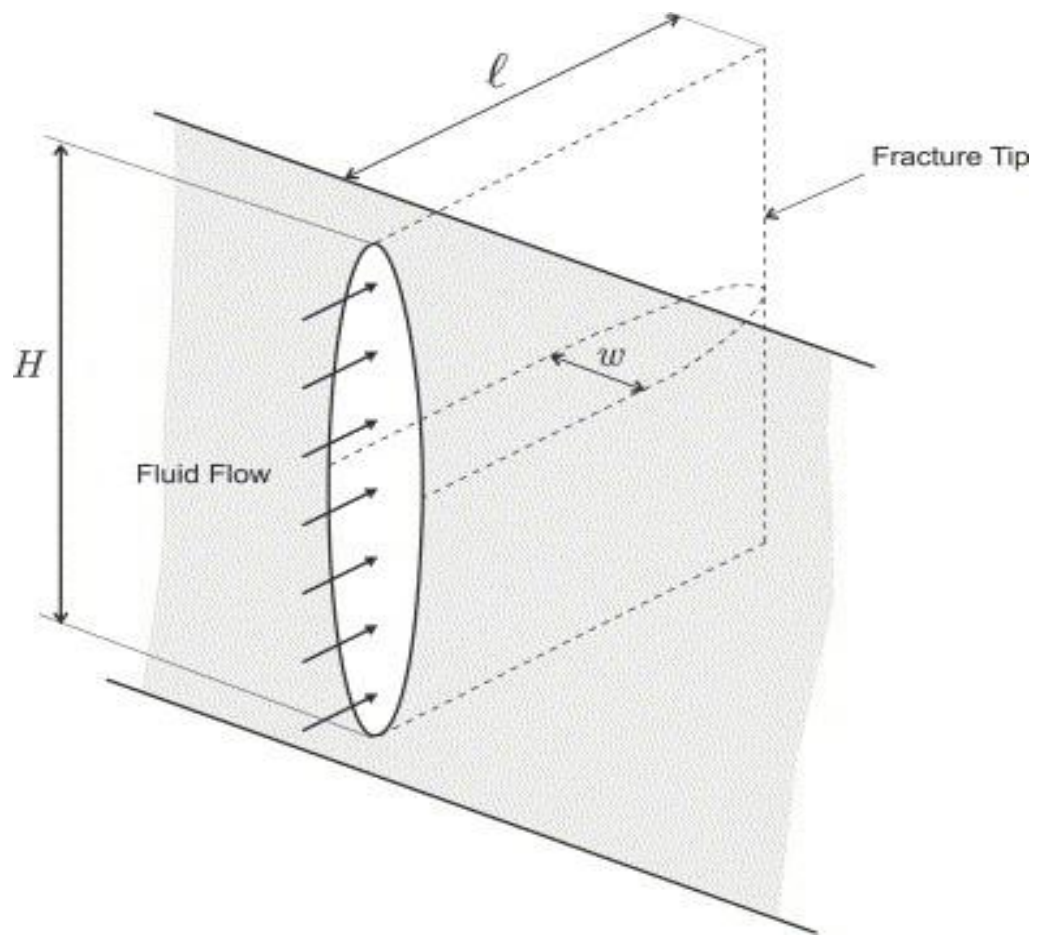

Figure 5: PKN Hydraulic Fracture Model (J. Adachi, E. Siebrits, A. Peirce, July 2007) 


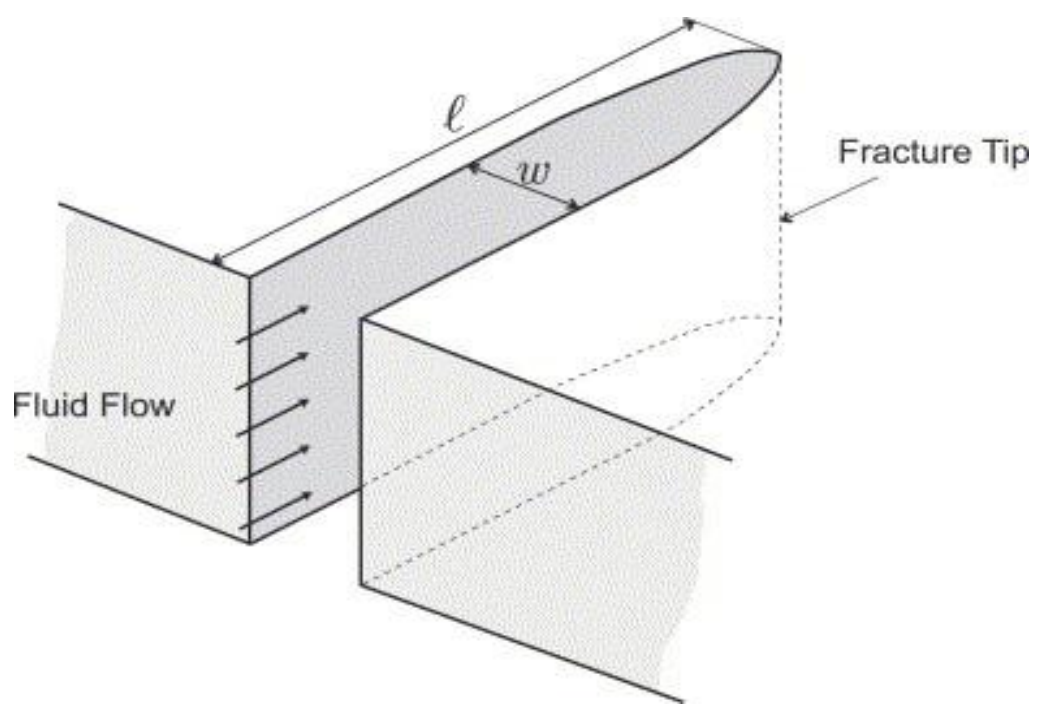

Figure 6: KGD Hydraulic Fracture Model (J. Adachi, E. Siebrits, A. Peirce, July 2007)

The radial model however is characterized with a circular shape and propagates in the radial direction as shown in Figure 7.

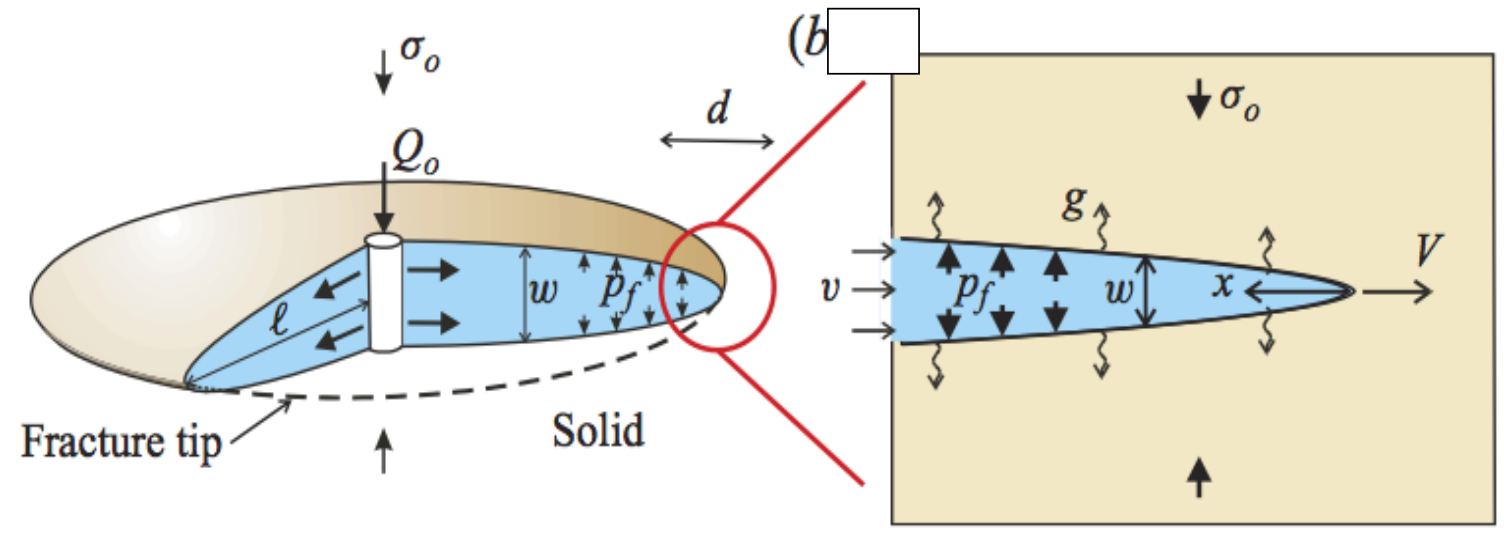

Figure 7: Radial Hydraulic Fracture Model (McLennan and Rob Jeffrey May 2013) 
Fracture width can be expressed in explicit function of fracture pressure and fracture length.

$$
\begin{aligned}
& w=c \Delta p \\
& c=\frac{\beta \pi\left(1-\mu^{2}\right) h}{2 E} \text { PKN Model } \\
& c=\frac{\beta \pi\left(1-\mu^{2}\right) L}{2 E} \text { KGD Model } \\
& c=\frac{\beta 16\left(1-\mu^{2}\right) r_{f}}{3 \pi E} \quad \text { Radial Model }
\end{aligned}
$$

Different factors generate the final result or output of the hydraulic fracturing process; among these are fracture dimensions in fracture half length, fracture width and height with also rock and fluid properties. It is usually preferred that fracture height is equal to formation height to create fully penetrating fractures but fractures always do not fully penetrate these formation and in most cases, partial penetration are mostly produced. Partial penetration of fractures into producing formations is not always desired as these always lead to reduction in production rate. However, fully penetrating hydraulic fractures may also lead to early or immediate water production.

\subsection{Fracture Conductivity}

Dimensionless fracture conductivity is a major design parameter for well stimulation used in the comparing of the capacity of fractures to transmit fluids down the fracture and into the wellbore to the ability of the formation to deliver fluid into the fractures.

Dimensionless fracture conductivity, $\mathrm{C}_{\mathrm{fd}}$ can be expressed as

$$
C_{f D}=k_{f} w_{f} / k_{F} x_{f}
$$


Of recent, it has become evident that conductivity of the fracture had to be matched with potential deliverability of the reservoir. For different analytical solutions that have been used to estimate fractured-well productivity, fracture conductivity has been a major factor that has been put into consideration. Fracture conductivity is the product of fracture permeability and propped fracture width left the fracture has closed (Pearson, C.M, 2001). They are two types of fracture conductivity, infinite and finite. The infinite fracture conductivity is experience when during the simulation there is no considerable pressure drop along the fracture during production in opposition the finite fracture conductivity is observe when during the well test there is a considerable pressure drop along the fracture during production.

$$
\begin{aligned}
& C_{f D}>100 \text { infinite conductivity } \\
& C_{f D}<100 \text { finite conductivity }
\end{aligned}
$$

\subsection{Well testing}

Well testing in general refers to both pressure drawdown and buildup tests. It is done to achieve basically reservoir evaluation, reservoir description and reservoir management (monitoring). Well test for reservoir evaluation include test for flow capacity or productivity, initial reservoir pressure, fluid sampling for PVT analysis. Test for reservoir description is always done to determine reservoir anisotropy, heterogeneity, drainage geometry as well as boundary conditions which include constant pressure, no-flow and closed reservoir boundaries. Test for reservoir management however can be subdivided into three basic ways the first include test for the future monitoring of the reservoir which includes systematic test design, operation analysis and interpretation at appraisal phase, the second is extended well testing which uses long-term pressure drawdown and build-up data from permanent down hole gauge. This is done 
to achieve to determine hydrocarbon reserve, reservoir drive mechanism, reservoir boundary or compartmentalization as well as geological structure or heterogeneity.. For the particular case of hydraulically fractured reservoir the properties of the fracture can be found from a poststimulation test that requires an estimation of the permeability.

Pressure transient analysis is an important tool used in the characterization of any reservoir as this helps in the determination of the reservoir fluid behavior and their interaction with reservoir rock, completion and production systems. This characterization is achieved with the use of reservoir modeling with well test data providing a force for running model simulations. Reservoir models are basically built using geophysical, geological and petrophysical data. After the reservoir model has been built, it is calibrated by a process of comparison of test simulation results with that of measured data to check for accuracy. To achieve a good match between the real and modeled data, there may be the need to adjust certain parameters from the well to the reservoir such as permeability, distance to fault etc. Production histories from well and field are then entered into the model and results from this are compared to that from actual field measurements. For large reservoirs, Drill-Steam Test (DST) is majorly used which test a large volume of the reservoir for flow assurance purposes.

Pressure transient analysis always starts with the creation of a sketch of the physical layout of the well as well as formation with the analyst stepping sequentially through expected flow regimes. Figure 8 and 9 show respectively a vertical mini- fracture and a horizontal mini-fracture and the pressure transient path from the wellbore out into the reservoir. 


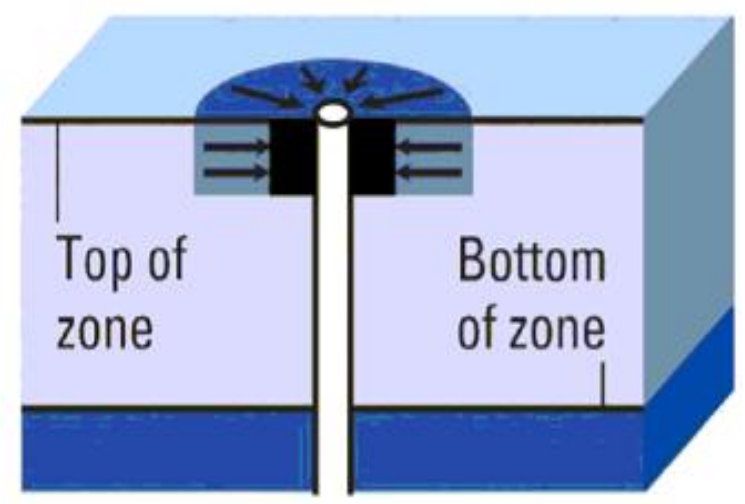

Figure 8: Schematic of a Vertical Mini-Frac (Powless K.R. 2012)

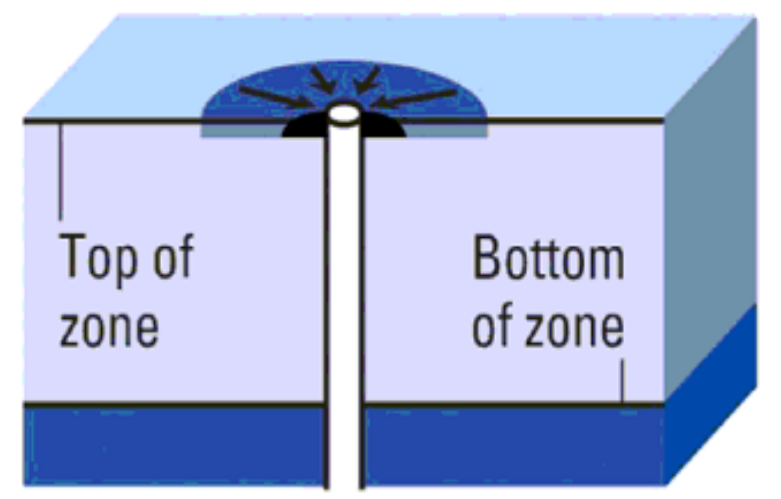

Figure 9: Schematic of a Horizontal Mini-Frac (Powless K.R. 2012)

\subsection{Flow Regimes}

Flow regimes represent the geometry of the flow obtained in the pressure transient test. The flow regimes are easily recognized in the log-log plot of the pressure derivative versus the change of time. Flow regimes that occur during the test are based on the conductivity of the hydraulic fracture.

Infinite conductivity fractures can have 3 types of flow period (1) linear flow (2) transitional flow and pseudo-radial flow. 
Finite or low conductivity fracture can encounter 4 types of flow period (1) linear flow in fracture (2) bilinear flow (3) linear flow in the formation (4) transition flow (5) pseudo-radial flow.

- Fracture Linear flow: This flow is illustrated in Figure 10 occurs within the hydraulic fracture and because of the high permeability of the hydraulic fracture is extremely short in duration. This flow is often not observed during well test.

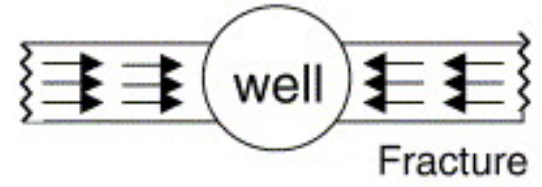

Figure 10: Early linear flow

- Bilinear flow: This flow is illustrated in Figure 11and it consists of two simultaneous linear flows; one in the formation and one within the hydraulic fracture. This flow is characterized by a slope of $1 / 4$ on a diagnostic plot of the pressure derivative versus the change in time.

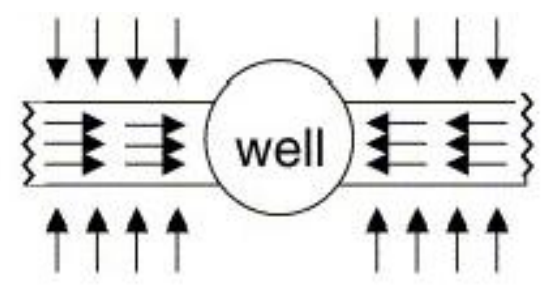

Figure 11: Bilinear flow

- Formation Linear Flow: This flow is illustrated in Figure 12. This flow is characterized by a slope of $1 / 2$ on the log-log plot of the pressure derivative versus the change in time. 


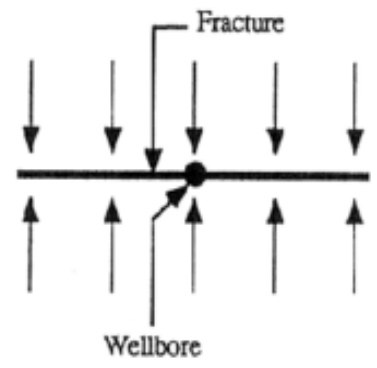

Figure 12: Linear flow in the formation

- Transitional flow: This flow occurs as flowlines deviate from linear geometry as shown in Figure 13. This flow has no solution.

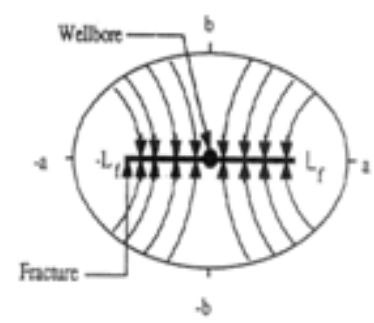

Figure 13: Transitional flow

- Pseudo-radial flow: As seen in Figure 14 the pseudo-radial flow occurs when the reservoir boundaries control the pressure response.

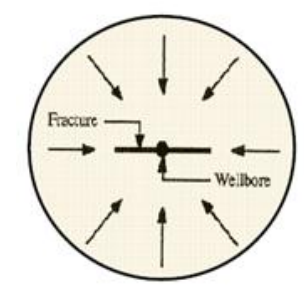

Figure 14: Pseudo-radial flow 


\subsection{Flow Regimes for Fractured Horizontal Well}

In horizontal wells unlike in vertical wells, it is more complicated to understand and estimate the flow regimes. The flow geometry in the horizontal wells is in three dimensions and this is one of the main concerns. Wellbore storage effect can be more important in a horizontal well than in vertical wells. Partial penetration and end effects make the interpretation more difficult. In horizontal wells five distinct flow regimes occur: (1) early radial, (2) hemiradial, (3) early linear, (4) late pseudoradial, and (5) compounded linear.

- Early- radial flow: is seen before the drainage area or the pressure transient caused by this production encounters either boundaries of the reservoir. Figure 15 shows the flow pattern of the early radial flow which looks like elliptical, and occurs when in the higher permeability is in the $\mathrm{x}$-direction and the lower permeability is in the z-direction.

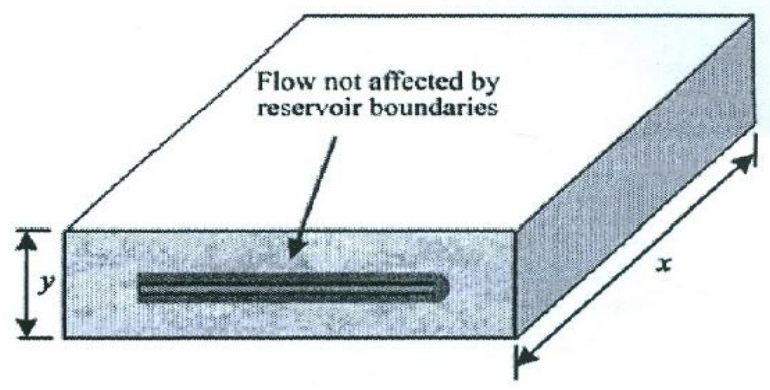

Figure 15: Early-radial flow

- Hemiradial flow: As shown in Figure 16, the hemiradial flow usually takes place after the early radial flow, if the horizontal well is closer to one of the vertical boundaries. 


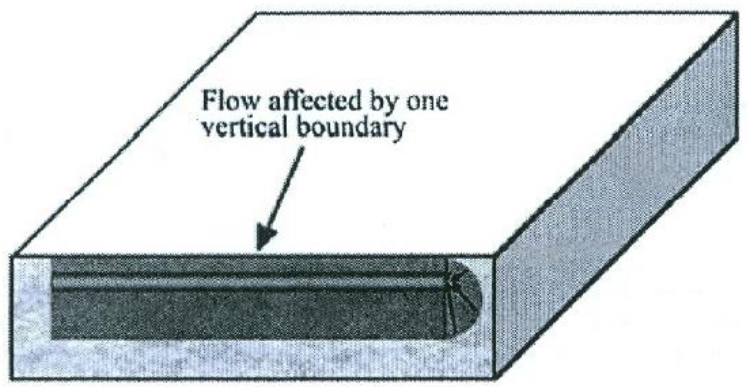

Figure 16: Hemiradial flow

- Early linear flow: Figure 17 shows that the early linear flow takes place when the production comes from the entire reservoir thickness. The fluid will begin flowing in a linear manner from the top and the bottom of the reservoir into the well.

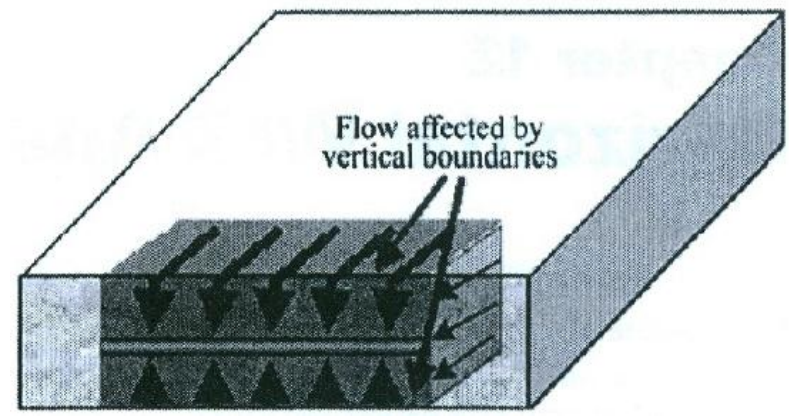

Figure 17: Early-linear flow

- Late-pseudoradial flow: Figure 18 shows that once the entire thickness of the reservoir is affected the reservoir keeps on being depleted this is a transition phase which happens right before one side of the reservoir is touched.

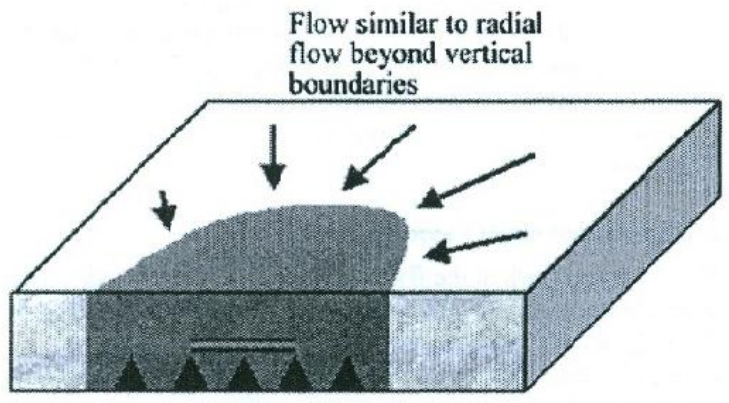

Figure 18: Late-pseudoradial flow 
- Compounded Linear flow: This flow regime occurs in hydraulically fractured horizontal wells. The compounded flow as shown in Figure 19 arises when three linear flows coincide. They include the flow from the inner reservoir between hydraulic fractures, the flow from the outer reservoir beyond the tips of the hydraulic fracture, and the flow within the hydraulic fractures. This flow is characterized by a slope of $1 / 2$ on the log-log plot of the pressure derivative versus the change in time.

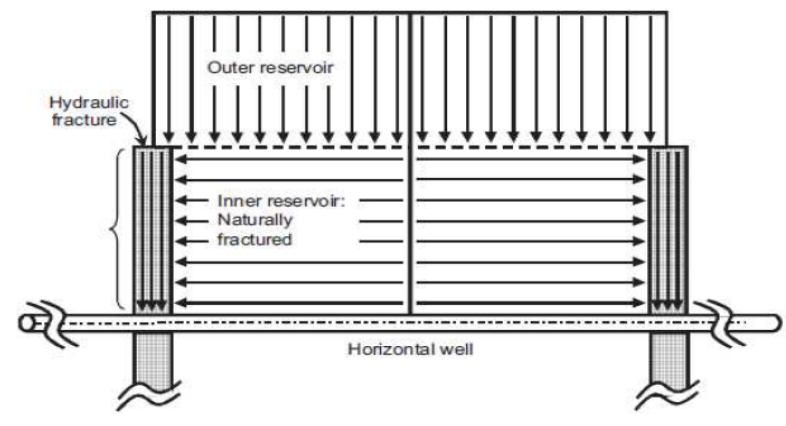

Figure 19: Compounded Linear flow 


\section{Objective and Methodology}

The primary objective of the research was to understand the pressure behavior of a horizontal well with multiple hydraulic fractures completed shale gas reservoir. This was achieved by investigating the implication of the reservoir characteristics and the hydraulic fractures properties on the flow regimes. The following methodology was applied.

1. A base reservoir model was built, using a dual porosity numerical reservoir simulator, to simulate the pressure response of a horizontal well completed in shale.

2. The simulated pressure response of the horizontal well was utilized to identify the flow regimes with the aid of diagnostic plot.

3. The impact of the number of hydraulic fractures on the flow regimes was determined.

4. The impact of fracture properties on flow regimes was investigated.

5. The impact of reservoir characteristics on flow regimes was investigated.

6. The impact of the horizontal well length on the flow regimes was determined.

\section{Base Model}

For this research study the commercial simulator, Eclipse, was used following a similar approach as the previous study conducted at West Virginia University Department of Petroleum and Natural Gas Engineering by E. M. Tabar "Analysis of data from horizontal well with multiple hydraulic fractures in Shale gas". Tabar studied hydraulically fractured horizontal well completed in a single porosity reservoir. The current study modifies the Tabar's work by using a dual porosity model. The reservoir model was designed to produce at a constant rate from a single layer; Table 1 shows the used parameters. To investigate the impact of the reservoir 
properties and fracture characteristics on the flow regimes, various parameters were varied. The numerical reservoir model represents a drainage area $(4000 \mathrm{ft} . \times 2000 \mathrm{ft}$.).

Table 1: Base Model Parameters

\begin{tabular}{|c|c|}
\hline \multicolumn{2}{|c|}{ Base Model Parameters } \\
\hline \multicolumn{2}{|c|}{ Reservoir Parameters } \\
\hline Production time, year & 10 years \\
\hline Depth, ft. & 7000 \\
\hline Thickness, ft. & 100 \\
\hline \multicolumn{2}{|c|}{ Rock Properties } \\
\hline Porosity Type & Dual \\
\hline Fissure Porosity, fraction & 0.005 \\
\hline Matrix Porosity, fraction & 0.05 \\
\hline Bulk permeability $i, j, k, m d$ & $0.001,0.001,0.0001$ \\
\hline Matrix permeability $i, j, k, m d$ & $0.0003,0.0003,0.00003$ \\
\hline Fracture spacing, $1 / f t^{2}$ & 0.007300003 \\
\hline Compressibility, 1/psia & $1 * 10^{-6}$ \\
\hline Density, $l b / f t^{3}$ & 150 \\
\hline \multicolumn{2}{|c|}{ Initial Conditions } \\
\hline Reservoir Pressure, psia & 3000 \\
\hline Water Saturation, fraction & 0.15 \\
\hline \multicolumn{2}{|c|}{ Hydraulic Fractures Properties } \\
\hline Half length, $f t$. & 300 \\
\hline Width, in & 0.01 \\
\hline Top of fracture, $f t$. & 7000 \\
\hline Bottom of fracture, $f t$. & 7100 \\
\hline Permeability, md & 10000 \\
\hline Porosity, fraction & 0.2 \\
\hline \multicolumn{2}{|c|}{ Well Production Controls } \\
\hline Gas flow rate, mscfd & 100 \\
\hline Pwf, psia & 300 \\
\hline \multicolumn{2}{|c|}{ Fluid Properties } \\
\hline Standard Pressure, psia & 14.7 \\
\hline Standard Temperature, $\circ \mathrm{F}$ & 60 \\
\hline Reference Temperature, $\circ F$ & 120 \\
\hline \multicolumn{2}{|c|}{ Adsorption } \\
\hline Diffusion coefficient, $f t^{2} /$ day & 1 \\
\hline Sorption Time, day & 62 \\
\hline Langmuir Pressure, psia & 635 \\
\hline Langmuir Concentration, mscf/ton & 0.08899 \\
\hline
\end{tabular}


Using the above parameters a based model was constructed using the commercial simulator (Schlumberger Eclipse). The Figure 20 below shows how the reservoir pressure changes near the hydraulic fracture for the base model. The red color describes a high pressure zone and the blue color describes a low pressure zone. In this case the reservoir simulation provides a method in which the pressure change of a horizontal well can be predicted. The model was contructed based on a dual porosity system including the shale properties, instant adsorption and by coal defineding on unit weight basis with ash and moisture content. The Shlumberger sotfware Eclipse is a very usefull tool for having the ability to model any horizontal well with or without hydraulic fractures.

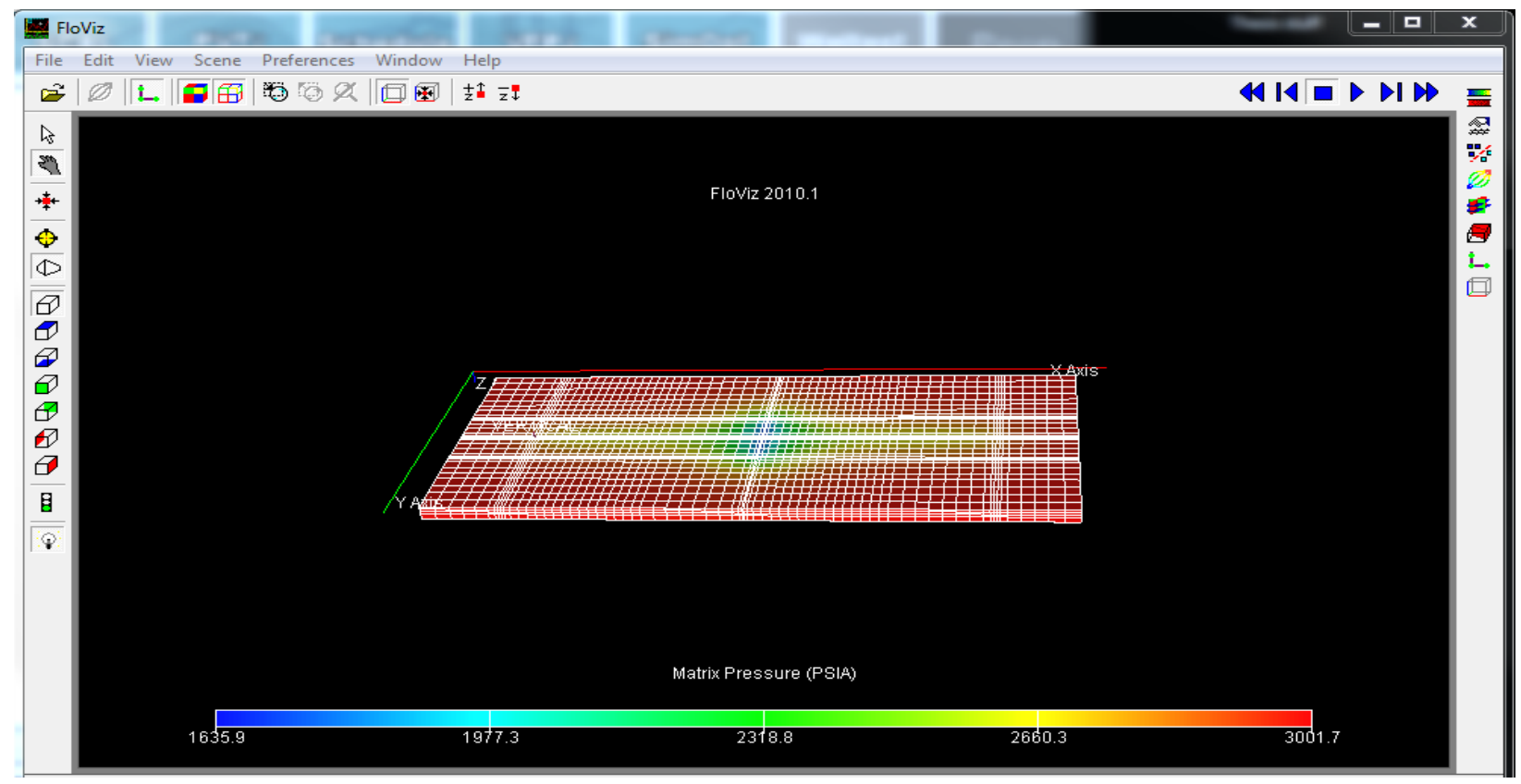

Figure 20: Reservoir pressure changes near the hydraulic fracture for the based model

Figure 21 shows a dignostic plot for a horizontal well with one hydraulic fracture in $3500 \times 2000$ $\mathrm{ft}^{2}$ dranaige area. The valley at the beginning of the plot is the indication of the dual porosity behavior which is in accordance with the model. The dual porosity valley is followed by an early 
linear flow, as indicated by the slope of $1 / 2$ on Figure 21 . The duration of the early linear flow will depend on the spacing of the hydraulic fractures. Following the early linear flow, a bilinear flow can be present, as indicated by the slope of $1 / 4$ on Figure 21 . The presence of the bilinear flow will also depend on the spacing of the hydraulic fractures. As the fracture spacing is reduced the bilinear flow disappears. For example, when the number hydraulic fracture is more than 4 , the bilinear flow is no longer present. Finally the compounded linear flow is encountered, as indicated by the slope of $1 / 2$ on Figure 21. This flow period is the result of production from areas beyond the tip of the hydraulic fracture.

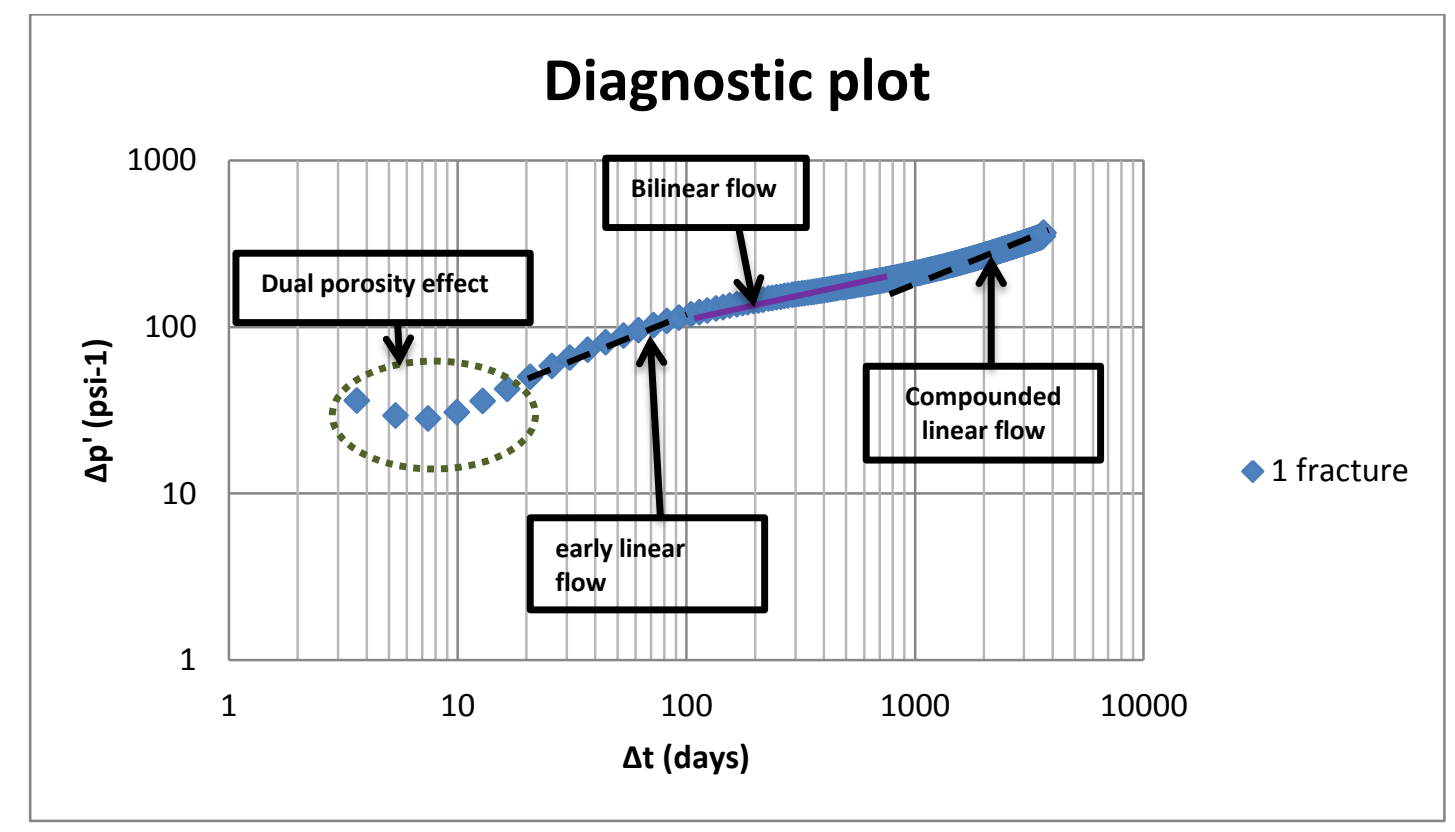

Figure 21: A Diagnostic plot illustrating various flow regimes associated with a hydraulically fractured horizontal well

Using the base model four cases were simulated. Each of the cases included models with 1, 2,3,4,7 and 11 hydraulic fractures. 


\section{Case 1}

Table 2 summarizes the key parameters that were varied in this case.

Table 2: List of the Parameters that were varied for Case 1

\begin{tabular}{|c|c|c|c|c|c|c|}
\hline Case 1 & $\begin{array}{c}\text { Lateral } \\
\text { Length, ft. }\end{array}$ & $\begin{array}{l}\mathbf{x}_{\mathrm{f}}, \\
\mathrm{ft} .\end{array}$ & $\begin{array}{l}w_{f}, \\
\text { in. }\end{array}$ & $\begin{array}{l}\mathbf{k}_{\mathbf{f}}, \\
\mathbf{m d}\end{array}$ & $\begin{array}{c}\text { Fissure } \\
\text { Permeability } \\
\end{array}$ & $\begin{array}{c}\text { Fissure } \\
\text { Porosity } \\
\end{array}$ \\
\hline Case 1.1 & 4000 & 300 & 0.01 & 10000 & 0.001 & 0.005 \\
\hline Case 1.2 & 4000 & 300 & 0.1 & 10000 & 0.001 & 0.005 \\
\hline Case 1.3 & 4000 & 300 & 0.01 & 40000 & 0.001 & 0.005 \\
\hline Case 1.4 & 4000 & 300 & 0.1 & 40000 & 0.001 & 0.005 \\
\hline Case 1.5 & 3500 & 300 & 0.01 & 10000 & 0.001 & 0.005 \\
\hline Case 1.6 & 3500 & 300 & 0.1 & 10000 & 0.001 & 0.005 \\
\hline Case 1.7 & 3500 & 300 & 0.01 & 40000 & 0.001 & 0.005 \\
\hline Case 1.8 & 3500 & 300 & 0.1 & 40000 & 0.001 & 0.005 \\
\hline Case 1.9 & 4000 & 500 & 0.01 & 10000 & 0.001 & 0.005 \\
\hline Case 1.10 & 4000 & 500 & 0.1 & 10000 & 0.001 & 0.005 \\
\hline Case 1.11 & 4000 & 500 & 0.01 & 40000 & 0.001 & 0.005 \\
\hline Case 1.12 & 4000 & 500 & 0.1 & 40000 & 0.001 & 0.005 \\
\hline Case 1.13 & 3500 & 500 & 0.01 & 10000 & 0.001 & 0.005 \\
\hline Case 1.14 & 3500 & 500 & 0.1 & 10000 & 0.001 & 0.005 \\
\hline Case 1.15 & 3500 & 500 & 0.01 & 40000 & 0.001 & 0.005 \\
\hline Case 1.16 & 3500 . & 500 & 0.1 & 40000 & 0.001 & 0.005 \\
\hline
\end{tabular}




\section{Case 2}

Table 3 summarizes the key parameters that were varied in this case. This case was simulated to study the impact of the fissure porosity.

Table 3: List of the Parameters that were varied for Case 2

\begin{tabular}{|c|c|c|c|c|c|c|}
\hline Case 2 & $\begin{array}{c}\text { Lateral } \\
\text { Length, ft. }\end{array}$ & $\begin{array}{l}x_{f}, \\
\text { ft. }\end{array}$ & $\begin{array}{l}\mathbf{w}_{\mathrm{f}}, \\
\text { in. }\end{array}$ & $\begin{array}{r}\mathbf{k}_{\mathrm{f}}, \\
\mathrm{md}\end{array}$ & $\begin{array}{c}\text { Fissure } \\
\text { Permeability } \\
\end{array}$ & $\begin{array}{c}\text { Fissure } \\
\text { Porosity } \\
\end{array}$ \\
\hline Case 2.1 & 4000 & 300 & 0.01 & 10000 & 0.001 & 0.002 \\
\hline Case 2.2 & 4000 & 300 & 0.1 & 10000 & 0.001 & 0.002 \\
\hline Case 2.3 & 4000 & 300 & 0.01 & 40000 & 0.001 & 0.002 \\
\hline Case 2.4 & 4000 & 300 & 0.1 & 40000 & 0.001 & 0.002 \\
\hline Case 2.5 & 3500 & 300 & 0.01 & 10000 & 0.001 & 0.002 \\
\hline Case 2.6 & 3500 & 300 & 0.1 & 10000 & 0.001 & 0.002 \\
\hline Case 2.7 & 3500 & 300 & 0.01 & 40000 & 0.001 & 0.002 \\
\hline Case 2.8 & 3500 & 300 & 0.1 & 40000 & 0.001 & 0.002 \\
\hline Case 2.9 & 4000 & 500 & 0.01 & 10000 & 0.001 & 0.002 \\
\hline Case 2.10 & 4000 & 500 & 0.1 & 10000 & 0.001 & 0.002 \\
\hline Case 2.11 & 4000 & 500 & 0.01 & 40000 & 0.001 & 0.002 \\
\hline Case 2.12 & 4000 & 500 & 0.1 & 40000 & 0.001 & 0.002 \\
\hline Case 2.13 & 3500 & 500 & 0.01 & 10000 & 0.001 & 0.002 \\
\hline Case 2.14 & 3500 & 500 & 0.1 & 10000 & 0.001 & 0.002 \\
\hline Case 2.15 & 3500 & 500 & 0.01 & 40000 & 0.001 & 0.002 \\
\hline Case 2.16 & 3500 . & 500 & 0.1 & 40000 & 0.001 & 0.002 \\
\hline
\end{tabular}




\section{Case 3}

Table 4 summarizes the key parameters that were varied in this case. This case was simulated to study the impact of the fissure porosity and permeability.

Table 4 : List of the Parameters that were varied for Case 3

\begin{tabular}{|c|c|c|c|c|c|c|}
\hline Case 3 & $\begin{array}{c}\text { Lateral } \\
\text { Length, ft. }\end{array}$ & $\begin{array}{l}x_{f}, \\
\text { ft. }\end{array}$ & $\begin{array}{l}\mathbf{w}_{\mathrm{f}}, \\
\text { in. }\end{array}$ & $\begin{array}{r}\mathbf{k}_{\mathrm{f}}, \\
\mathrm{md}\end{array}$ & $\begin{array}{c}\text { Fissure } \\
\text { Permeability } \\
\end{array}$ & $\begin{array}{c}\text { Fissure } \\
\text { Porosity } \\
\end{array}$ \\
\hline Case 3.1 & 4000 & 300 & 0.01 & 10000 & 0.003 & 0.002 \\
\hline Case 3.2 & 4000 & 300 & 0.1 & 10000 & 0.003 & 0.002 \\
\hline Case 3.3 & 4000 & 300 & 0.01 & 40000 & 0.003 & 0.002 \\
\hline Case 3.4 & 4000 & 300 & 0.1 & 40000 & 0.003 & 0.002 \\
\hline Case 3.5 & 3500 & 300 & 0.01 & 10000 & 0.003 & 0.002 \\
\hline Case 3.6 & 3500 & 300 & 0.1 & 10000 & 0.003 & 0.002 \\
\hline Case 3.7 & 3500 & 300 & 0.01 & 40000 & 0.003 & 0.002 \\
\hline Case 3.8 & 3500 & 300 & 0.1 & 40000 & 0.003 & 0.002 \\
\hline Case 3.9 & 4000 & 500 & 0.01 & 10000 & 0.003 & 0.002 \\
\hline Case 3.10 & 4000 & 500 & 0.1 & 10000 & 0.003 & 0.002 \\
\hline Case 3.11 & 4000 & 500 & 0.01 & 40000 & 0.003 & 0.002 \\
\hline Case 3.12 & 4000 & 500 & 0.1 & 40000 & 0.003 & 0.002 \\
\hline Case 3.13 & 3500 & 500 & 0.01 & 10000 & 0.003 & 0.002 \\
\hline Case 3.14 & 3500 & 500 & 0.1 & 10000 & 0.003 & 0.002 \\
\hline Case 3.15 & 3500 & 500 & 0.01 & 40000 & 0.003 & 0.002 \\
\hline Case 3.16 & 3500 . & 500 & 0.1 & 40000 & 0.003 & 0.002 \\
\hline
\end{tabular}




\section{Case 4}

Table 5 summarizes the key parameters that were varied in this case. This case was simulated to study the impact of the fissure permeability.

Table 5 : List of the Parameters that were varied for Case 4

\begin{tabular}{|c|c|c|c|c|c|c|}
\hline Case 3 & $\begin{array}{c}\text { Lateral } \\
\text { Length, ft. }\end{array}$ & $\begin{array}{l}\text { xf, } \\
\text { ft. }\end{array}$ & $\begin{array}{l}\mathbf{w}_{\mathrm{f}}, \\
\text { in. }\end{array}$ & $\begin{array}{l}\mathbf{k}_{\mathbf{f}} \\
\text { md }\end{array}$ & $\begin{array}{c}\text { Fissure } \\
\text { Permeability } \\
\end{array}$ & $\begin{array}{c}\text { Fissure } \\
\text { Porosity } \\
\end{array}$ \\
\hline Case 4.1 & 4000 & 300 & 0.01 & 10000 & 0.003 & 0.005 \\
\hline Case 4.2 & 4000 & 300 & 0.1 & 10000 & 0.003 & 0.005 \\
\hline Case 4.3 & 4000 & 300 & 0.01 & 40000 & 0.003 & 0.005 \\
\hline Case 4.4 & 4000 & 300 & 0.1 & 40000 & 0.003 & 0.005 \\
\hline Case 4.5 & 3500 & 300 & 0.01 & 10000 & 0.003 & 0.005 \\
\hline Case 4.6 & 3500 & 300 & 0.1 & 10000 & 0.003 & 0.005 \\
\hline Case 4.7 & 3500 & 300 & 0.01 & 40000 & 0.003 & 0.005 \\
\hline Case 4.8 & 3500 & 300 & 0.1 & 40000 & 0.003 & 0.005 \\
\hline Case 4.9 & 4000 & 500 & 0.01 & 10000 & 0.003 & 0.005 \\
\hline Case 4.10 & 4000 & 500 & 0.1 & 10000 & 0.003 & 0.005 \\
\hline Case 4.11 & 4000 & 500 & 0.01 & 40000 & 0.003 & 0.005 \\
\hline Case 4.12 & 4000 & 500 & 0.1 & 40000 & 0.003 & 0.005 \\
\hline Case 4.13 & 3500 & 500 & 0.01 & 10000 & 0.003 & 0.005 \\
\hline Case 4.14 & 3500 & 500 & 0.1 & 10000 & 0.003 & 0.005 \\
\hline Case 4.15 & 3500 & 500 & 0.01 & 40000 & 0.003 & 0.005 \\
\hline Case 4.16 & 3500 & 500 & 0.1 & 40000 & 0.003 & 0.005 \\
\hline
\end{tabular}




\section{Results and Discussion}

\section{The effect of the number of hydraulic fractures}

In order to have an efficient treatment and less costly it is important and to study the effect that the numbers of hydraulic fractures have on the pressure of the reservoir. Figure 22 shows that in 1, 2 and 3 fractures three flow regimes are observed the early linear flow, the bilinear flow and the late transient. As the number of hydraulic fractures increases the bilinear flow tempt to decrease. Figure 23 shows that in 4, 7 and 11 fractures only two flow regimes are present: the early linear flow and a the compounded linear flow. In case of 4 fractures, the early linear flow is longer and the compounded linear flown is almost non-existence. The compounded linear flow is only observed for the cases of 7 and 11 fractures.

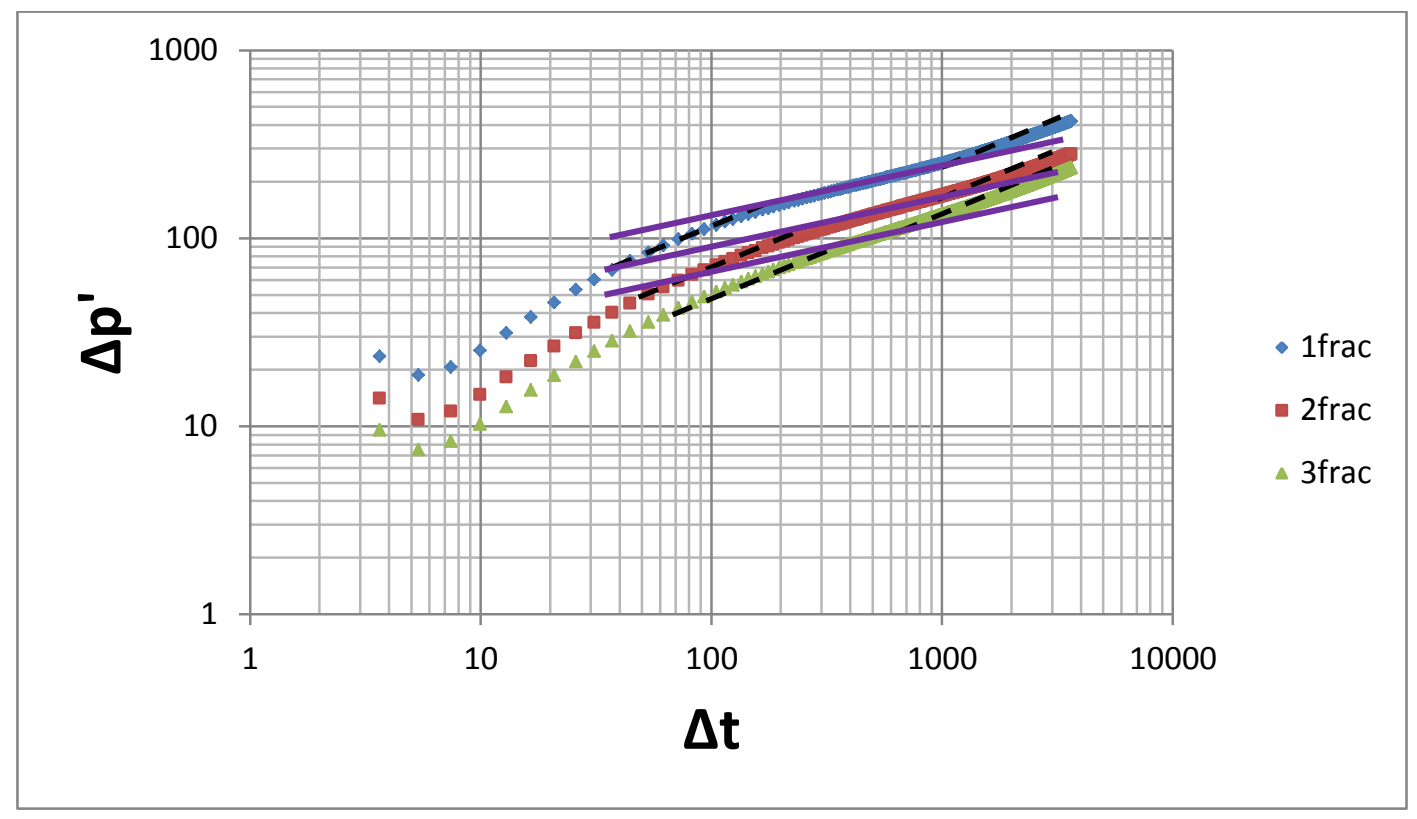

Figure 22: Diagnostic plot for Case 4.6 (1,2and3 Hydraulic Fractures) 


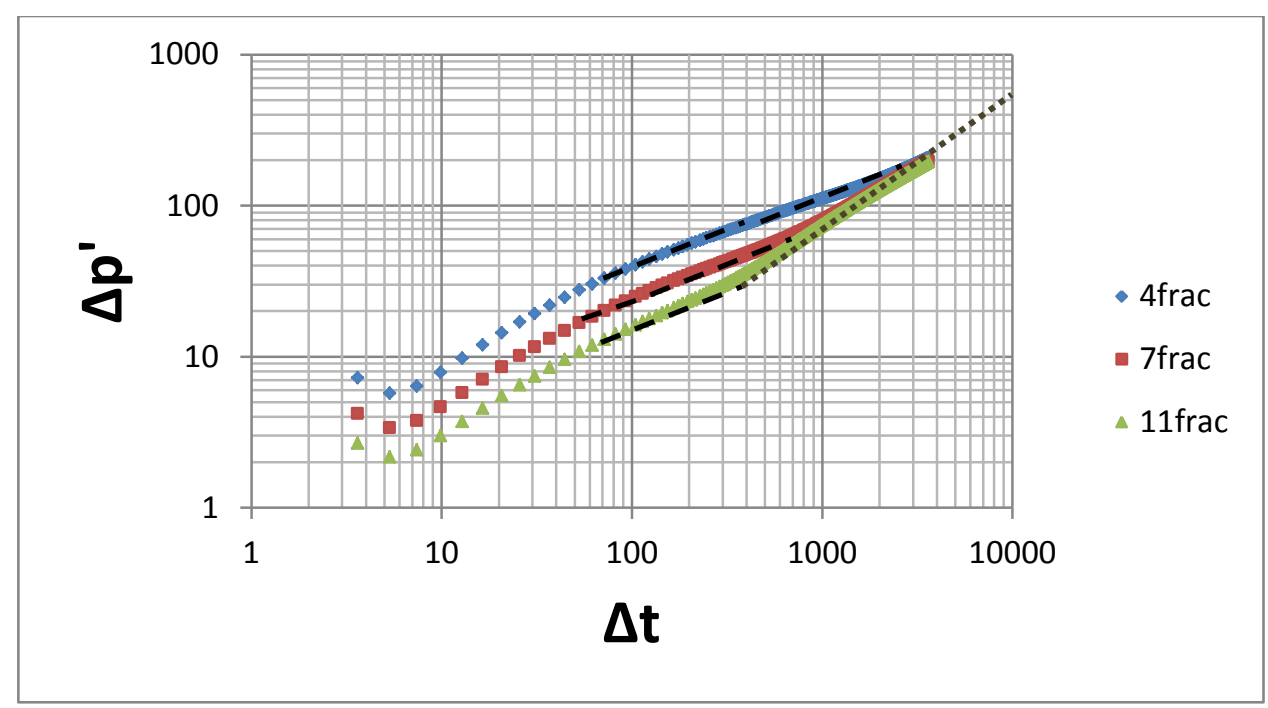

Figure 23: Diagnostic plot for Case 4.6 (4, 7 and 11 Hydraulic Fractures)

2. The impact of fracture properties on flow regimes was investigated

\subsection{Hydraulic fractures permeability}

When the hydraulic fracture permeability is 10000 md as shown in Figure 24, the early linear and late linear flow regimes were detected for all cases except for 1 fracture where a bilinear flow was also observed. When the hydraulic fracture permeability is $40000 \mathrm{md}$ as shown in Figure 25, the early linear, bilinear and late linear for 1 and 2 hydraulic fractures are detected. For cases of 3 or more hydraulic fractures only the early linear and the late linear flow were detected. 


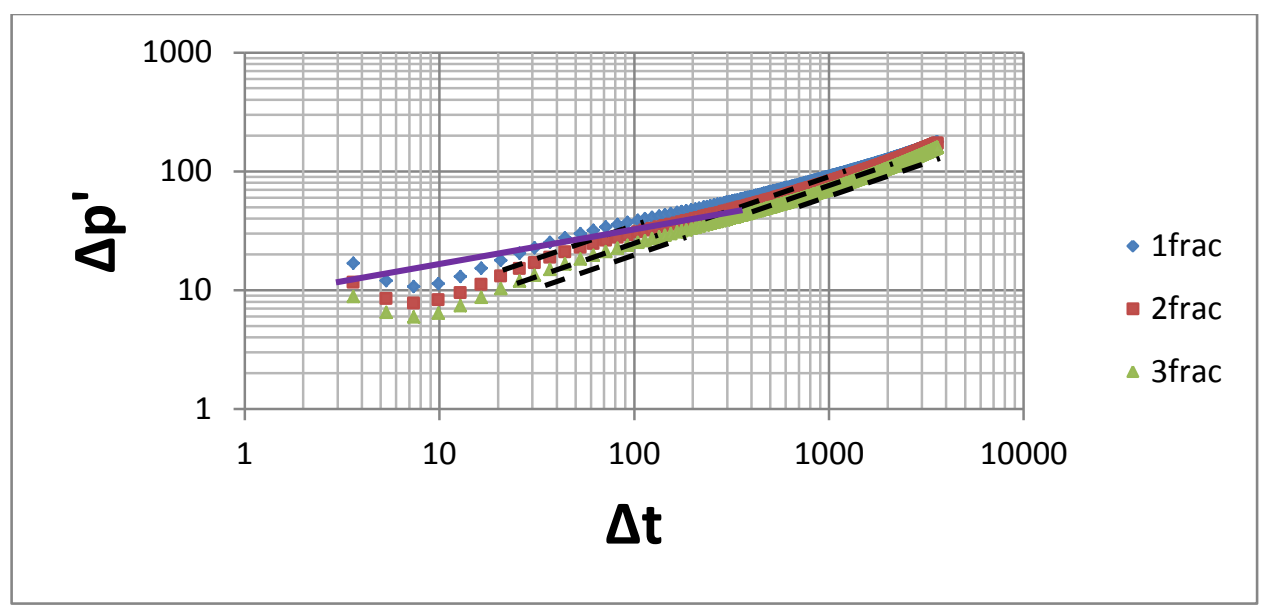

Figure 24: Diagnostic plot for Case 4.13

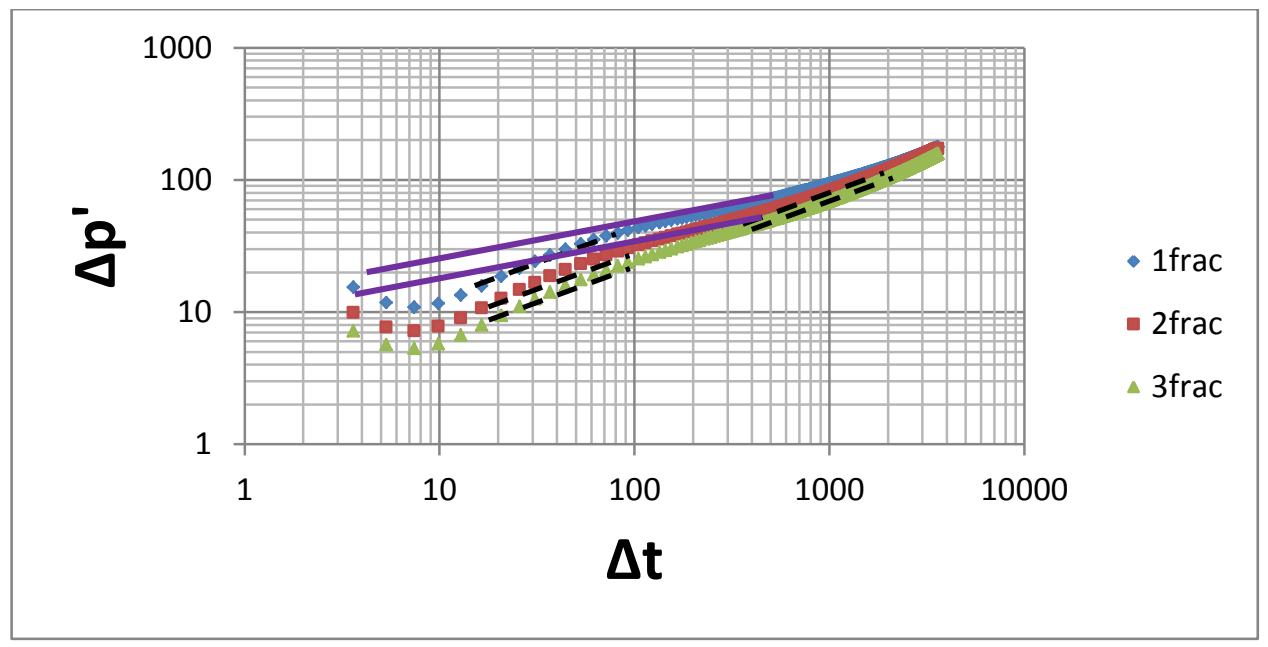

Figure 25: Diagnostic plot for Case 4.15

\subsection{Hydraulic fractures half-length}

With a half-length of $300 \mathrm{ft}$. and half-length of $500 \mathrm{ft}$. three flow regimes are found: early linear, bilinear, and late linear flow. When the half-length is $500 \mathrm{ft}$., a longer late linear flow is observed for 1, 2, and 3 hydraulic fractures and a shorter bilinear flow occurs. This means that the longer the half-length, the smaller the pressure drop along the hydraulic fracture. 


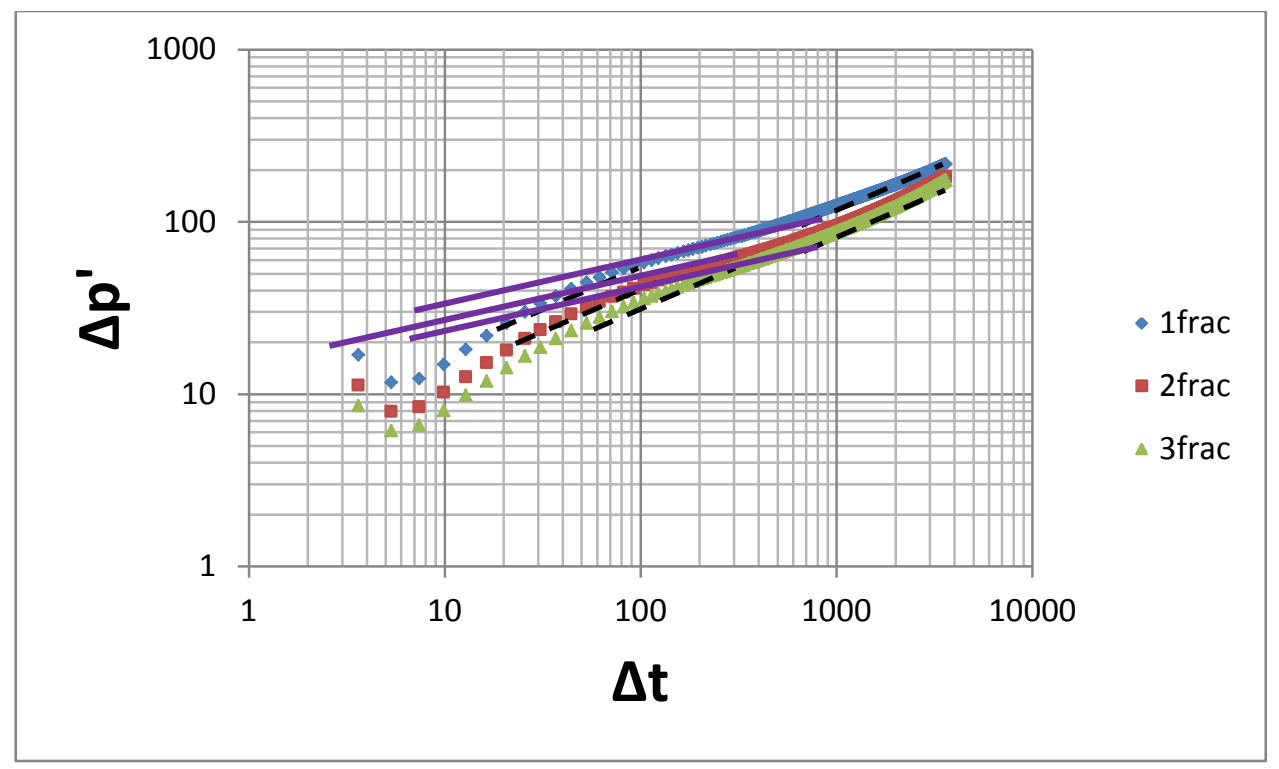

Figure 26: Diagnostic plot for Case 1.1

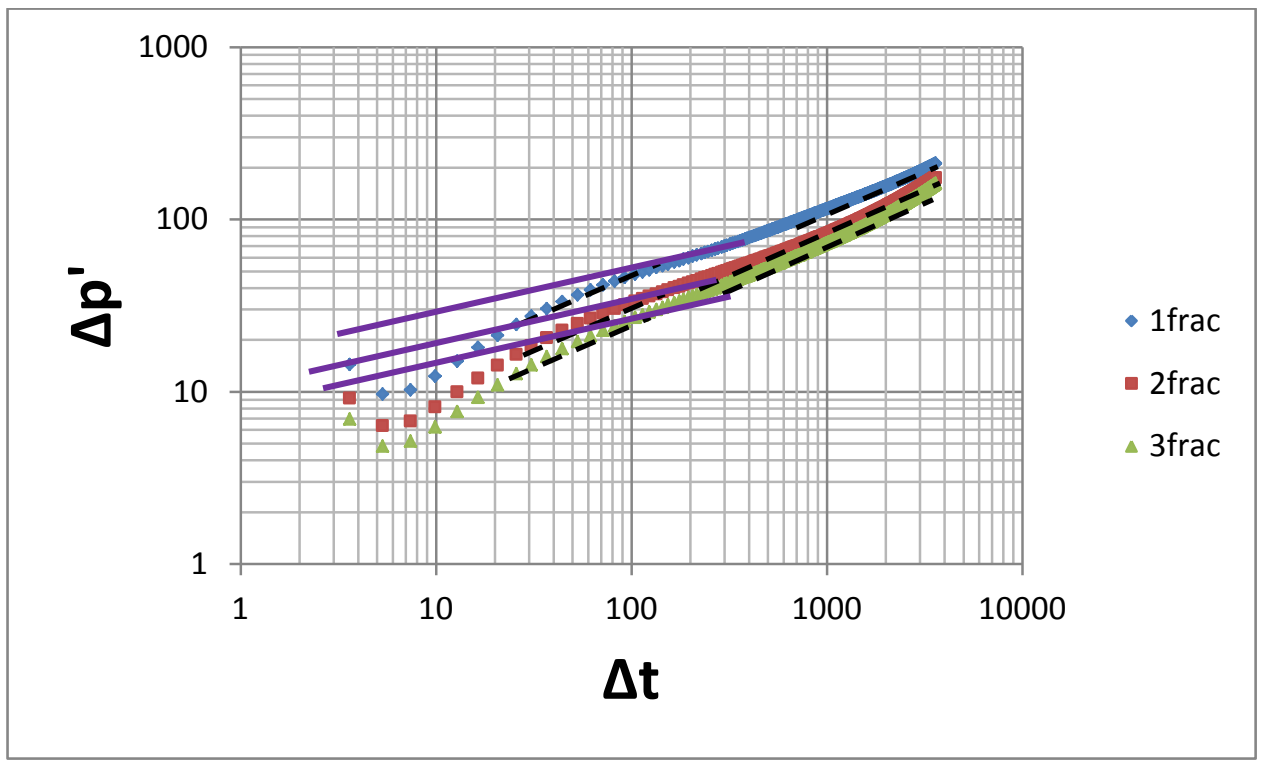

Figure 27: Diagnostic plot for Case 1.13 
3. The impact of reservoir characteristics on flow regimes was investigated

\subsection{The fissure permeability}

As can be seen in Figure 28 (fissure permeability $=0.001$ ) for 1, 23 fractures, three flow regimes are present: the early linear flow the bilinear flow and the late linear flow.

In contrast, as can be seen in Figure 29 (fissure permeability $=0.003$ ) the bilinear flow is only present for 1 fracture. For the 2 and the 3 hydraulic fractures only two flow regimes are observed: the early linear flow and the late linear flow. As the fissure permeability is increased the bilinear flow diminishes. Also as the number of hydraulic fractures is increased the-bilinear flow diminishes.

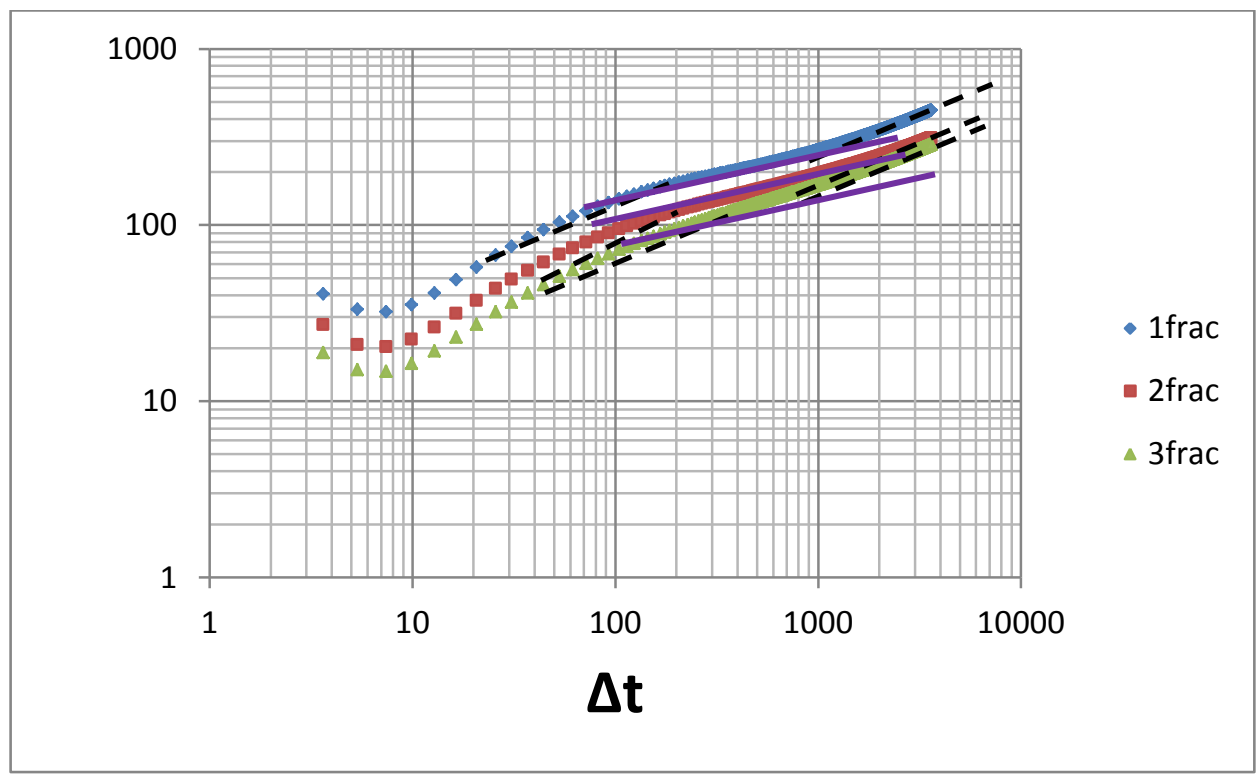

Figure 28: Diagnostic plot for Case 2.11 


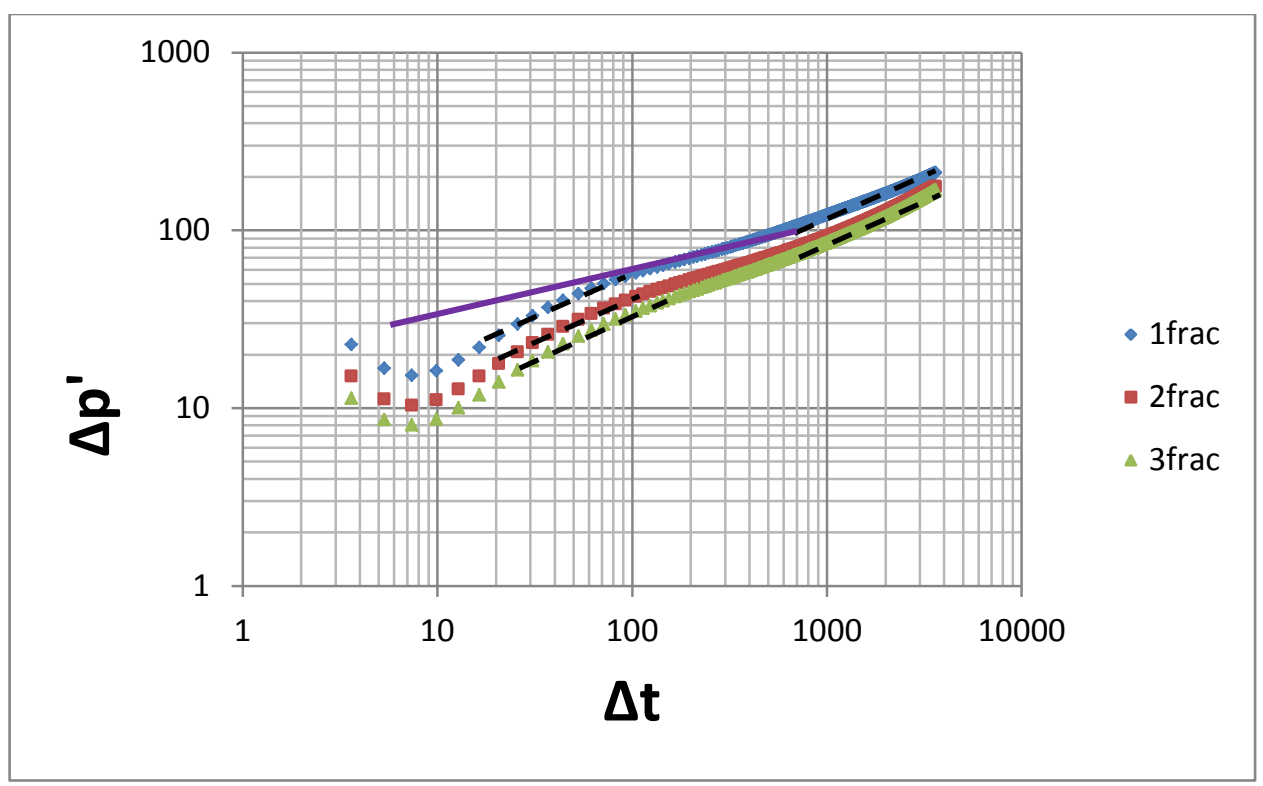

Figure 29: Diagnostic plot for Case 3.11

3.2 The reservoir fissure porosity

Figures 30 and 31 are diagnostic plots for the cases where the fissure porosity values are 0.002 and 0.005 . In these figures three flows regimes are observed: early linear flow, bilinear flow and late linear flow. For 1 and 2 fractures all the three flows are observed but at a different time. For 3 fractures, for both porosity values, only the early linear flow and the late linear flow can be detected. Therefore, it can be concluded that fissure porosity does not have a considerable effect on the flow regimes. 


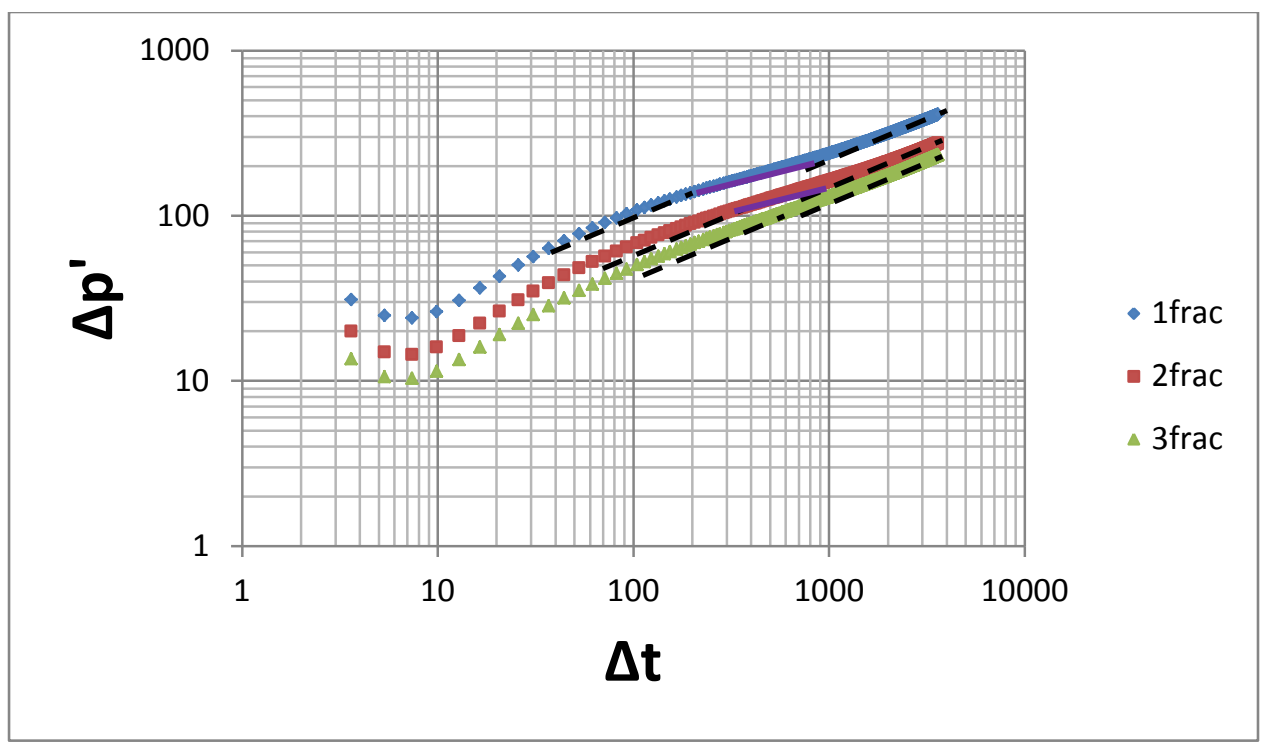

Figure 30: Diagnostic plot for Case 2.9

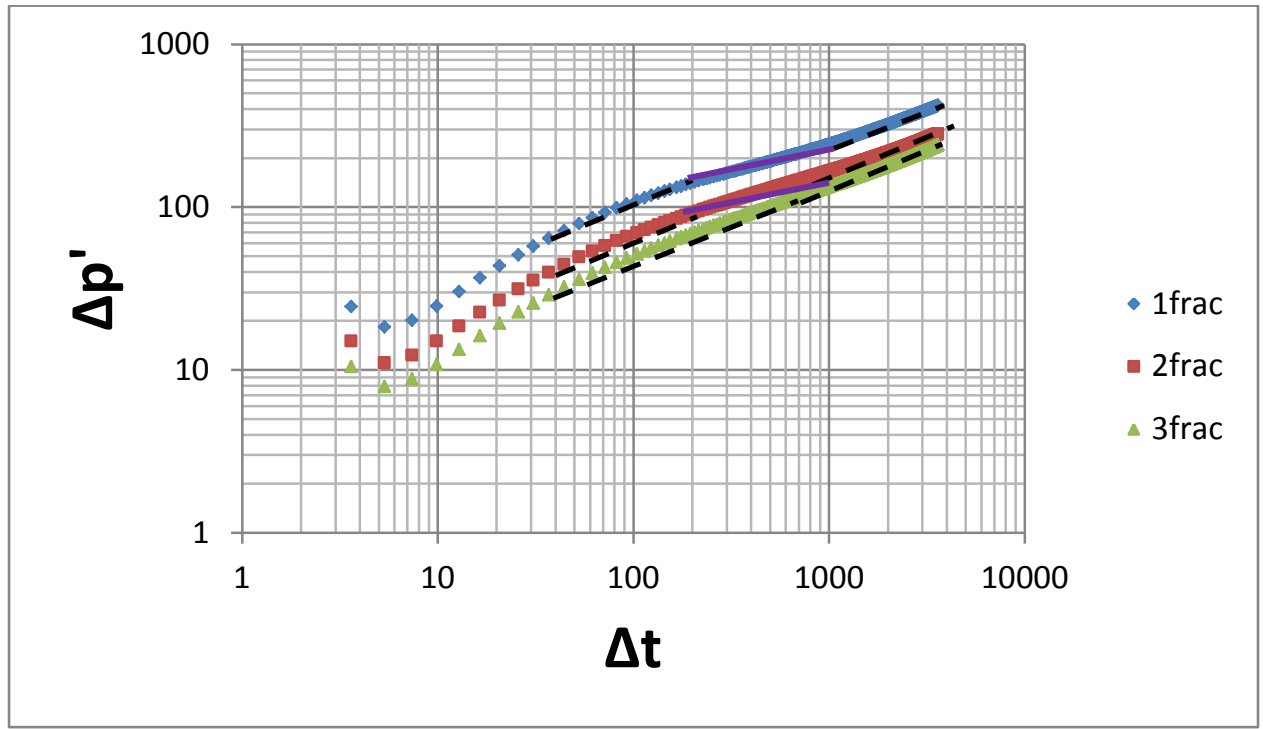

Figure 31: Diagnostic plot for Case 1.9

5. The impact of the horizontal well length on the flow regimes was determined

Figure 32 and 33 show the diagnostic plots for horizontal wells with the length of $4000 \mathrm{ft}$.

and $3500 \mathrm{ft}$. respectively. In both cases, similar flow period including early linear flow, bilinear flow and a late linear flow are observed. 


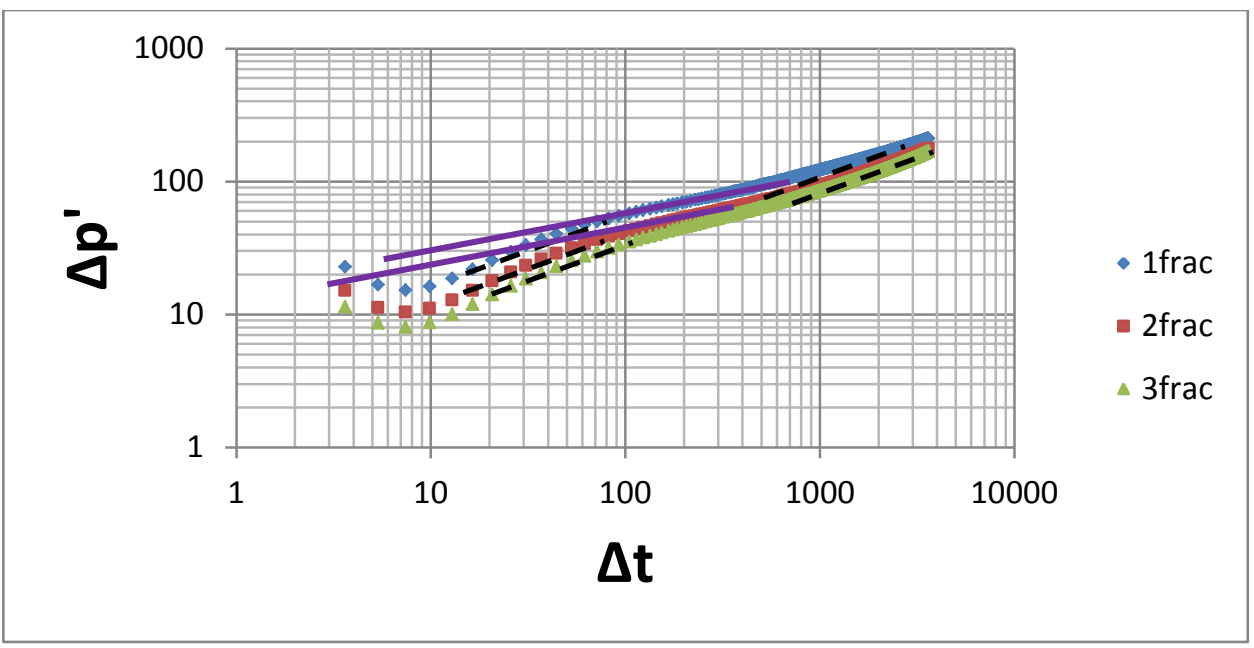

Figure 32: Diagnostic plot for Case 4.14

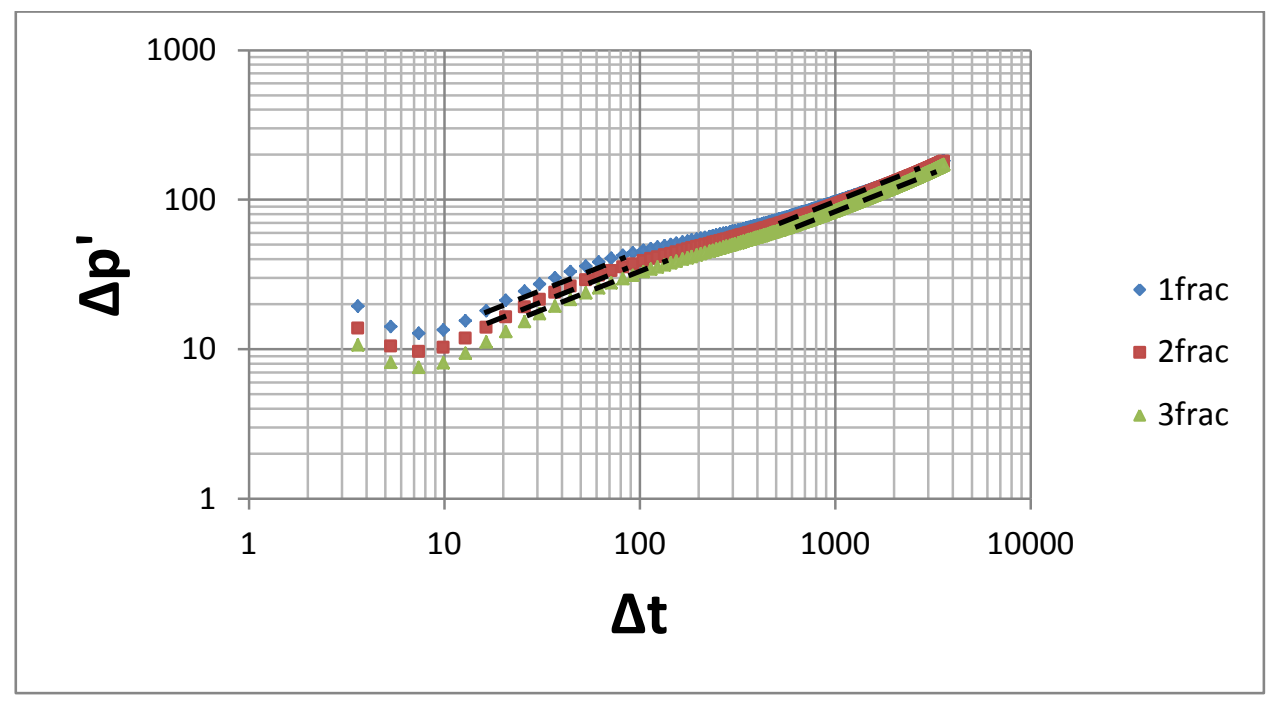

Figure 33: Diagnostic plot for Case 4.10 


\section{Conclusions}

The objective of this research was to understand the pressure behavior of a well with multiple hydraulic fractures completed shale gas reservoir. Besides the impact of the reservoir properties and the fractures properties on the flow regimes were studied. Based on the results, the following conclusions were made:

1. The main flow regimes are the early linear, the bilinear, and the compounded linear flow.

2. As the number of hydraulic fractures increases the bilinear flow diminishes.

3. A reservoir with higher fissure permeability has a longer early linear flow period.

4. The reservoir porosity does not have significant effect on the flow regimes.

5. The length of the horizontal well does not effect on the flow regimes present; it only affects the beginning and end points of each flow regimes.

6. The hydraulic fracture half length affect the time at which the early linear begins and its duration.

7. The hydraulic fracture width and porosity do not have a significant effect on the flow regimes. 


\section{References}

Aminan, K., Lecture 11, Well testing. Morgantown: West Virginia University, 2011

Claudia L. Pinzòn, SPE, Her-Yuan Chen, SPE, and Lawrence W, Teufel, SPE, New Mexico Institute of Mining and Technology. "Complexity of Well Testing Analysis of NaturallyFractured Gas-Condensate Wells in Colombia". SPE 59013, paper presented at 2000 SPE International Conference and Exhibition, Villahermosa, Mexico, 1-3 February 2000.

A. Ali Daneshy, Daneshy Consultants Intl. "Pressure Variations Inside the Hydraulic Fracture and Their impact on Fracture Propagation, Conductivity and Screenout." SPE 95355, paper presented at 2005 SPE Annual Technical Conference and Exhibition, Dallas, Texas, USA, 9-12 October 2005

Chunfang Meng, Delft University of Technology, C.J de Pater, StrataGen Delft. "Hydraulic Fracture propagation in Pre-Fractured Natural Rocks." SPE 140429, paper presented SPE Hydraulic Fracturing Technology Conference, The Woodlands, Texas, USA, 24-26 January 2011

Eclipse Reservoir Engineering Software Manual. 2010 Schlumberger.

Medeiros, F., Petroas, Kurtoglu B., Ozkan E., and Kazemi H. "Pressure- Transient performance of Hydraulically Fractured Horizontal Wells in Locally and Globally Naturally Fractured Formations." IPTC 11781, paper presented at the International Petroleum Technology Conference, Dubai, U.A.E., 4-9 December 2007.

Salam Al Rbeawi, SPE, D. Tiab, SPE, University of Oklahoma. "Partially Penetrating Hydraulic Fractures: Pressure Responses and Flow Dynamics." SPE 164500, paper presented SPE Production and Operations Symposium, Oklahoma City, Oklahoma, USA 23-26 March 2013

Keshavarzi, R., Young Researchers Club, Science and Research Branch, Islamic Azad University, Tehran, Iran, Mohammadi, S. and Bayesteh, H. School of Civil Engineering University of Tehran, Tehran, Iran. "Hydraulic Fracture Propagation in Unconventional Reservoirs: The Role of Natural Fractures." ARMA 12-129, paper presented $46^{\text {th }}$ US Rock Mechanics/ Geomechanics Symposium, Chicago, Illinois, USA, 24-27 June 2012

Y. Cheng, SPE, West Virginia University, W. J. Lee, SPE, and D.A. Mc Vay, SPE, Texas A\&M University. "A New Approach for Reliable Estimation of Hydraulic Fracture Properties Using Elliptical Flow Data in Tight Gas Wells." Journal of SPE Reservoir Evaluation \& Engineering, April 2009, Volume12, Number 12, pp. 254-262

Cinco-Ley, H., and Samananiego, F., "Transient Pressure Analysis For Fractured Wells" Journal of Petroleum Technology. September 1984 
Bettam, Y., Tiab, D., and Zerzar, A., “ A Application of Multi-Hydraulically Fractured Horizontal Wells in Naturally Fractured Reservoirs, SPE 95535, paper presented SPE International Improved Oil Recovery Conference, Kuala Lumpur, Malaysia, 5-6 December 2007

Ammer, J. R and Sawyer, W. K., "Practical Methods for Detecting Production Mechanisms In Tight Gas Reservoirs.” SPE 12864 paper presented SPE Unconventional Das Reservoir Symposium, Pittsburgh, Pennsylvania, 13-15 May 1984 


\section{Appendix 1}

\section{Case 1: Fracture porosity fraction $=0.005$}

\section{Bulk permeability $i, j, k(m d)=0.001,0.001,0.0001$}

Horizontal well length $4000 \mathrm{ft}$

$\checkmark$ Case 1.1: $\mathrm{xf}=300 \mathrm{ft}$, width of fracture $=0.01$ in ,permeability of fracture $=10000$, porosity of fracture $=0.2$

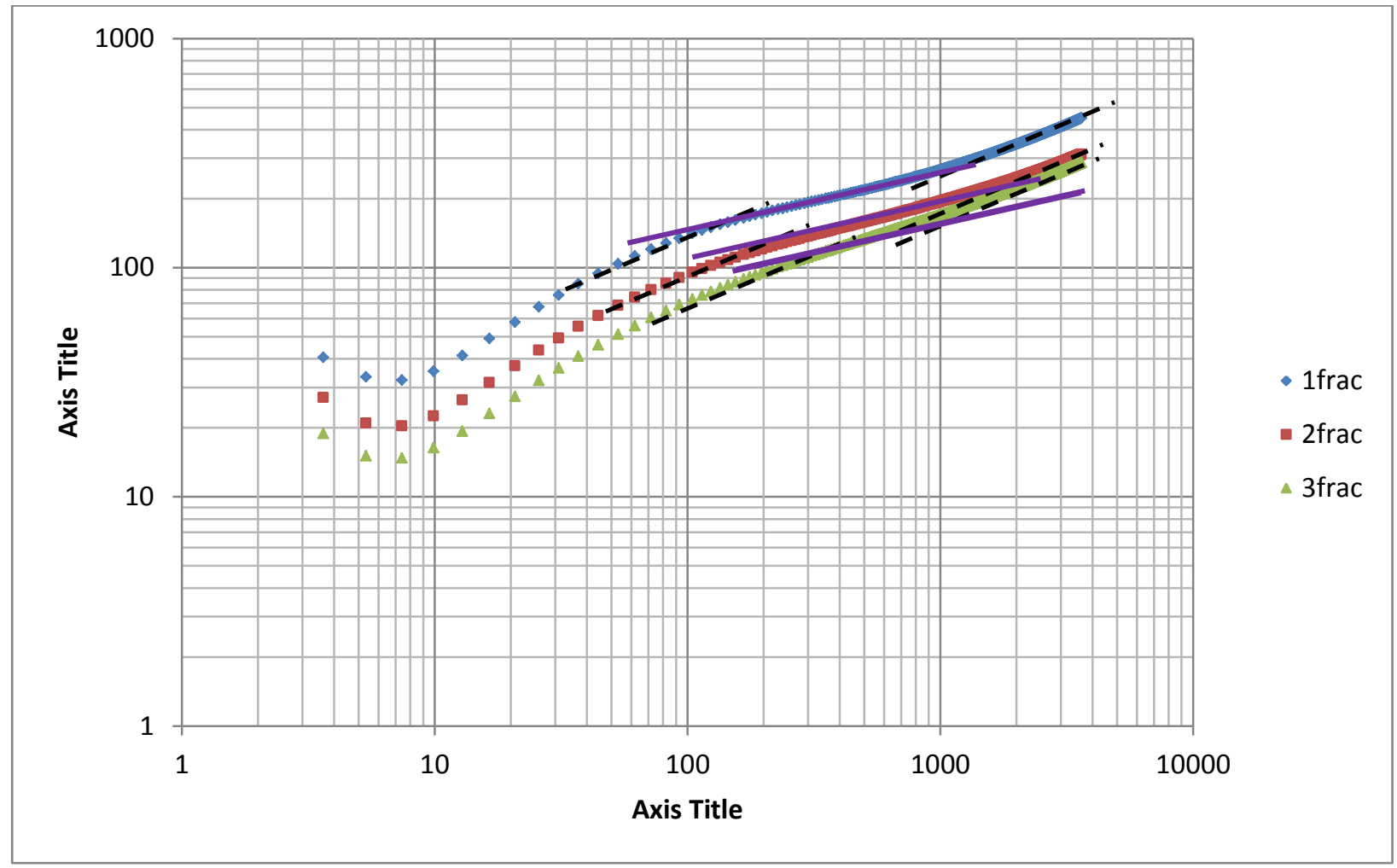




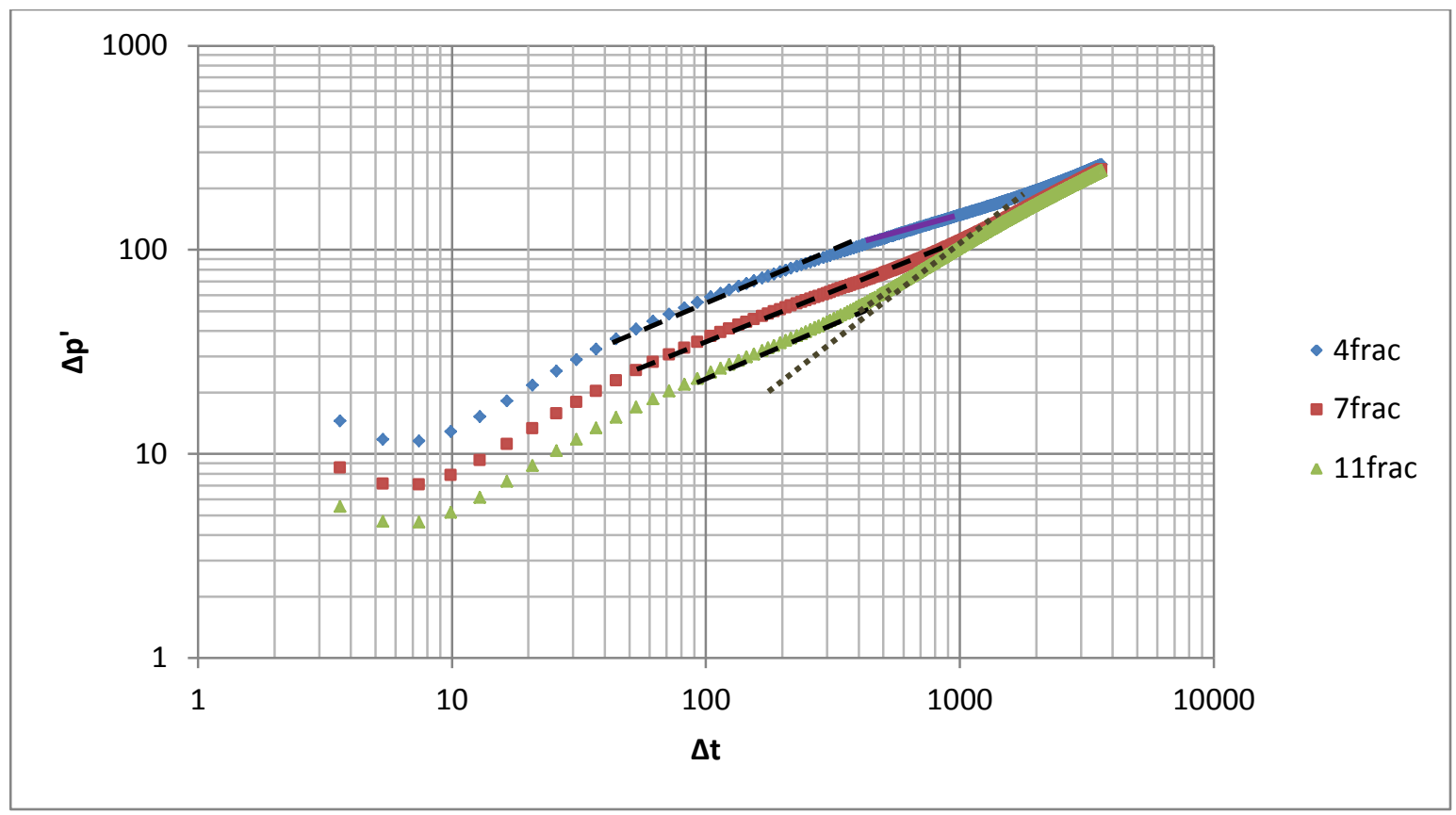

$\checkmark$ Case 1.2: $\mathrm{xf}=300 \mathrm{ft}$, width of fracture $=0.1$ in ,permeability of fracture $=10000$, porosity of fracture $=0.2$

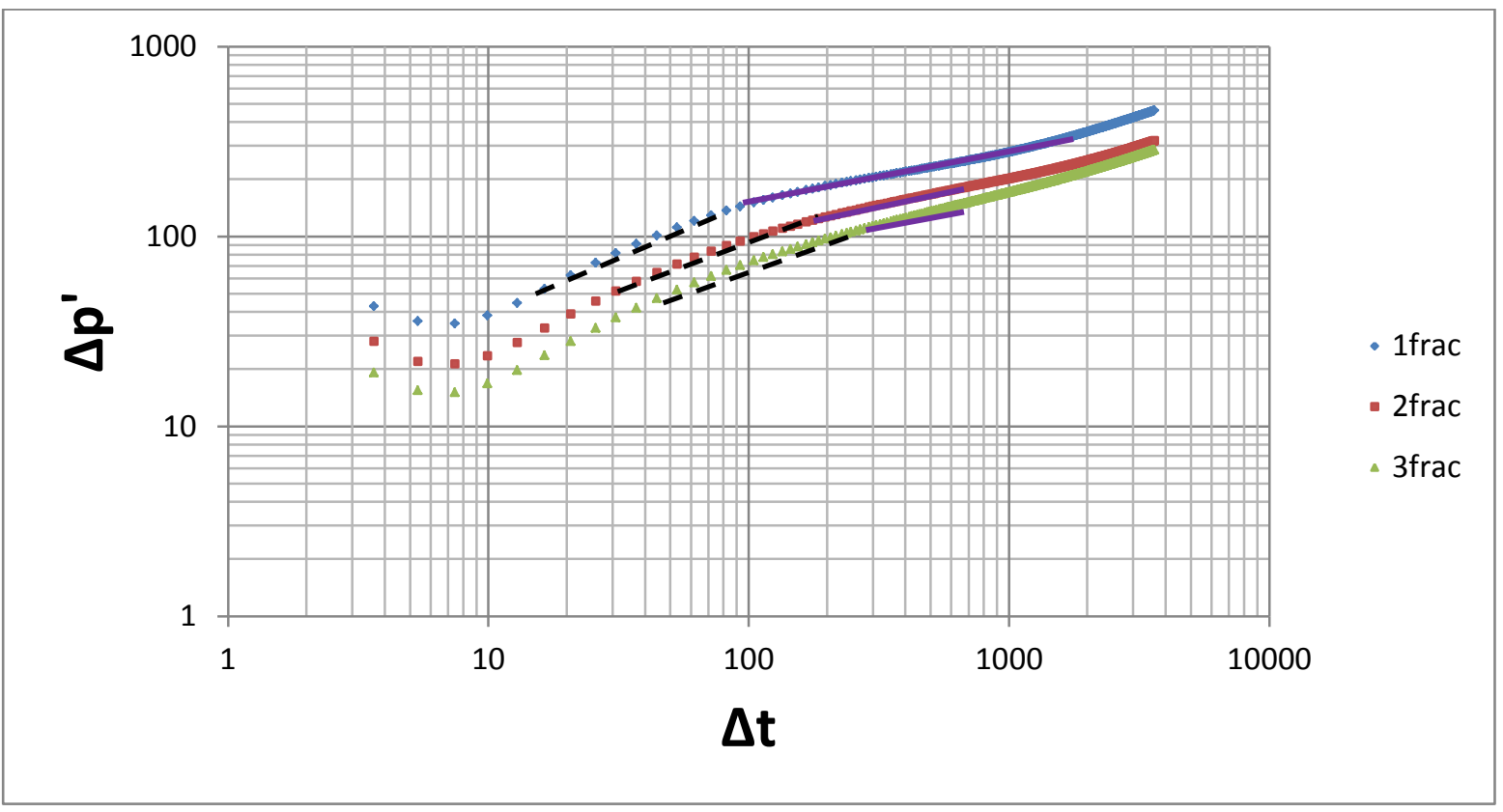




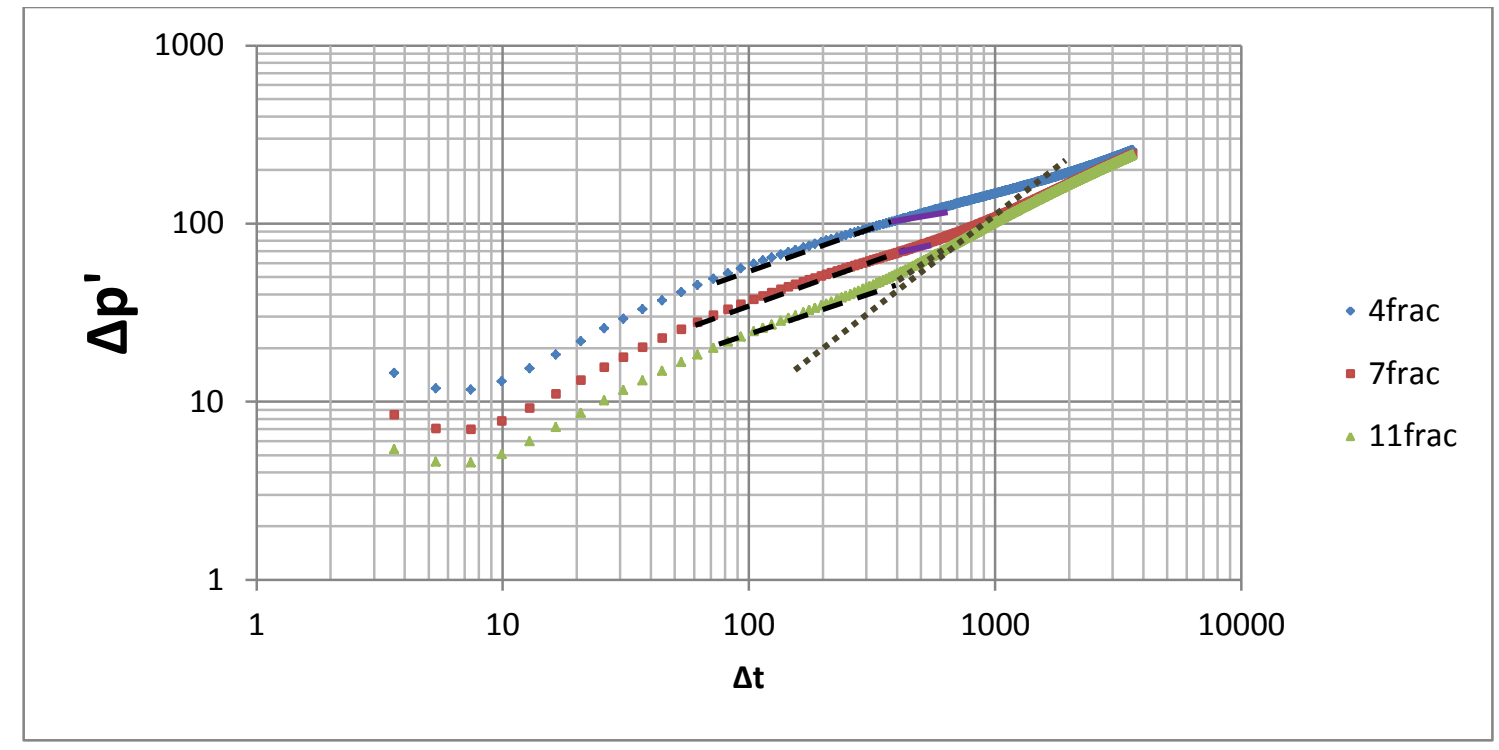

$\checkmark$ Case 1.3: $\mathrm{xf}=300 \mathrm{ft}$, width of fracture $=0.01$ in ,permeability of fracture $=40000$, porosity of fracture $=0.2$

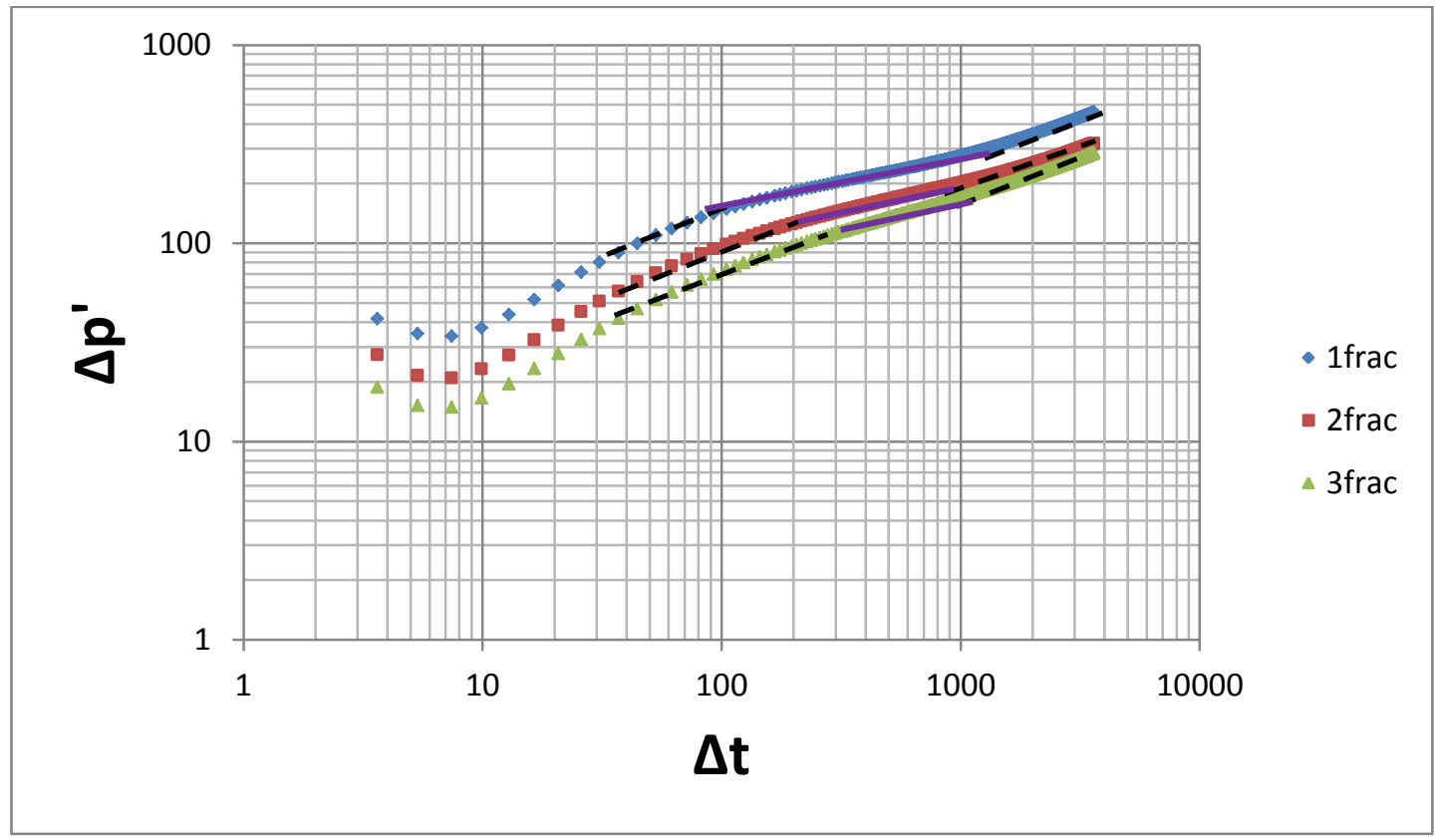




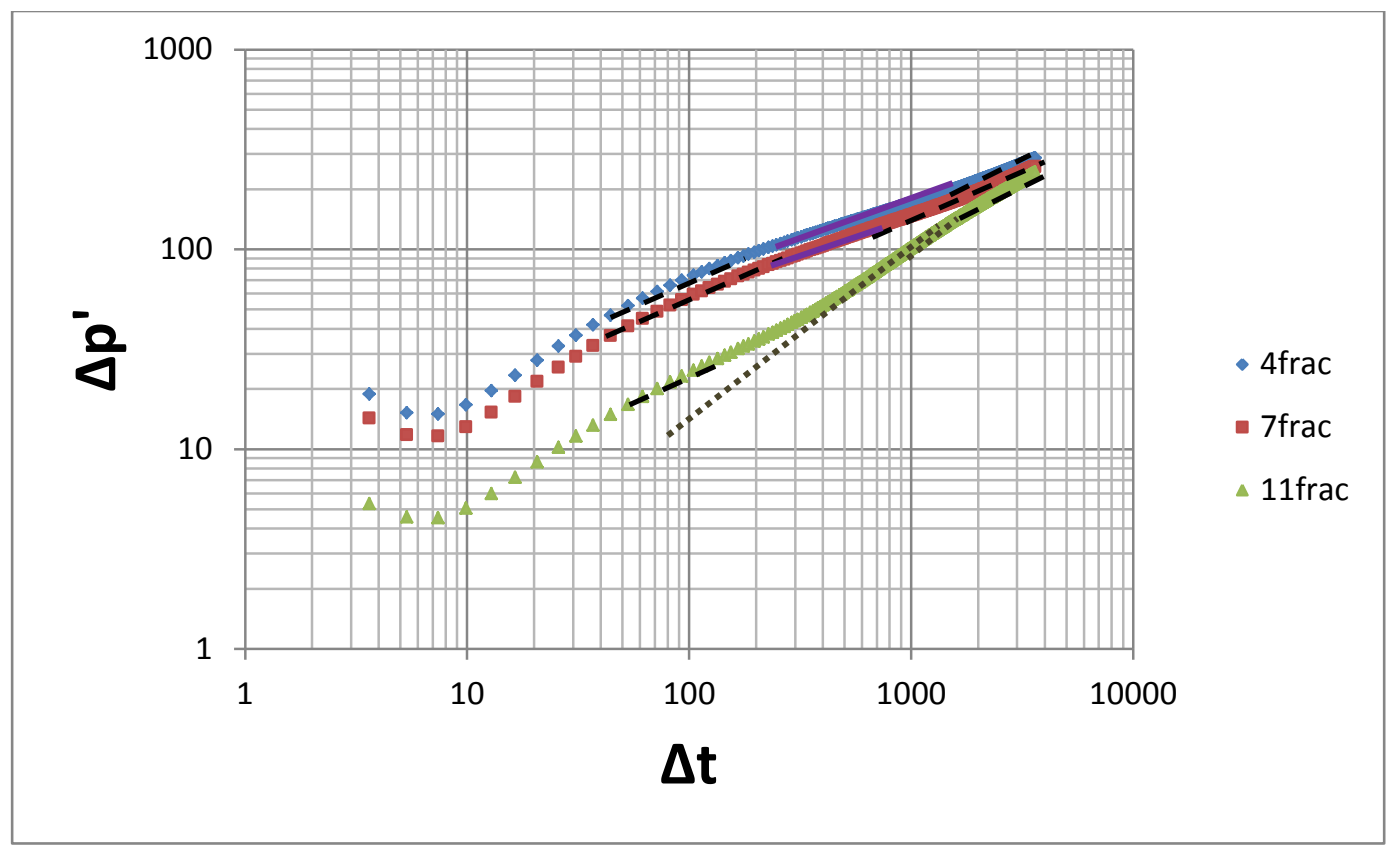

$\checkmark$ Case 1.4: $\mathrm{xf}=300 \mathrm{ft}$, width of fracture $=0.1$ in ,permeability of fracture $=40000$, porosity of fracture $=0.2$

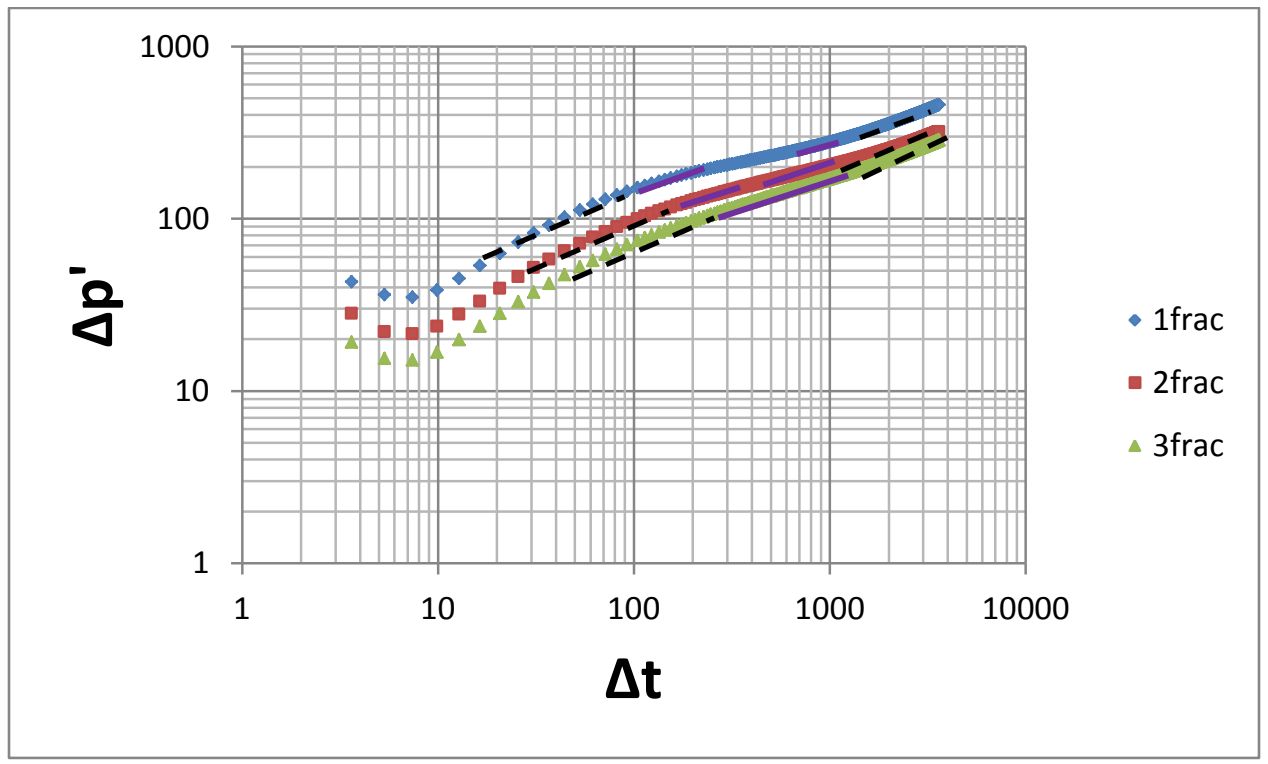




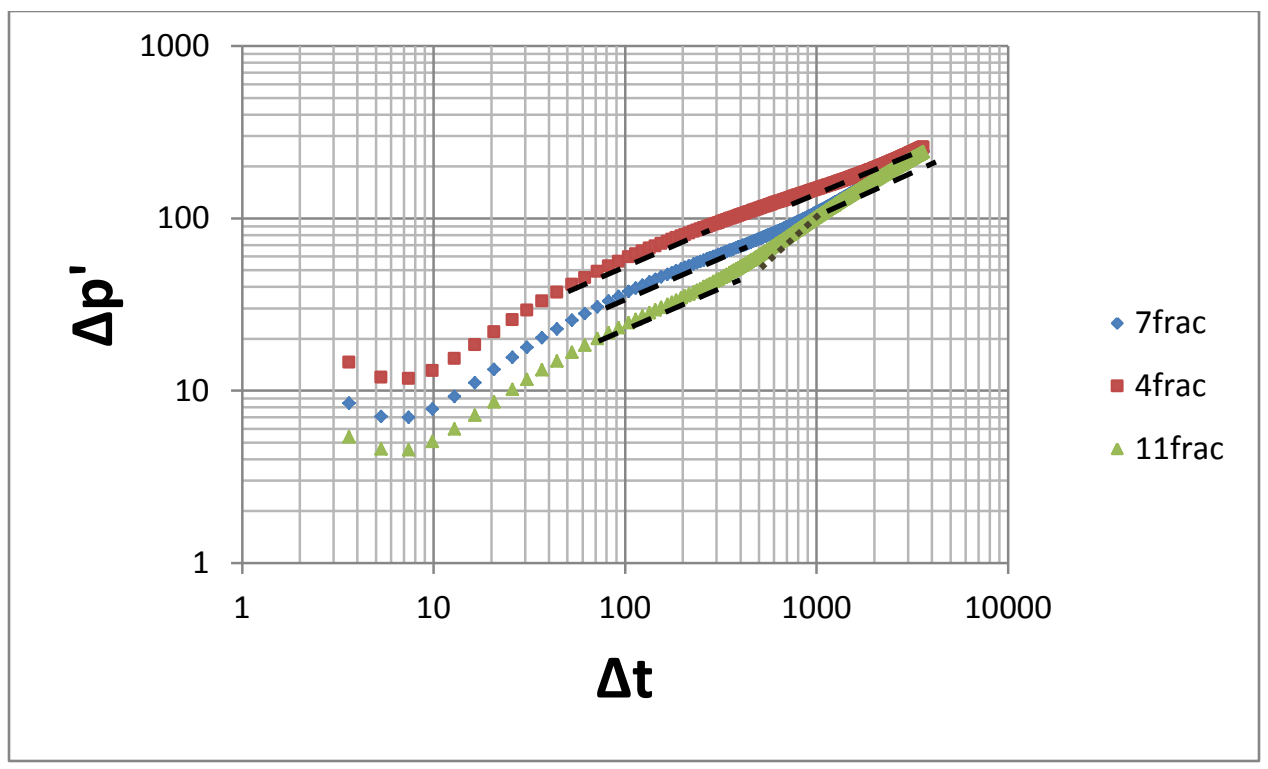

Horizontal well length $3500 \mathrm{ft}$

$\checkmark$ Case 1.5: $\mathrm{xf}=300 \mathrm{ft}$, width of fracture $=0.01$ in ,permeability of fracture $=10000$, porosity of fracture $=0.2$

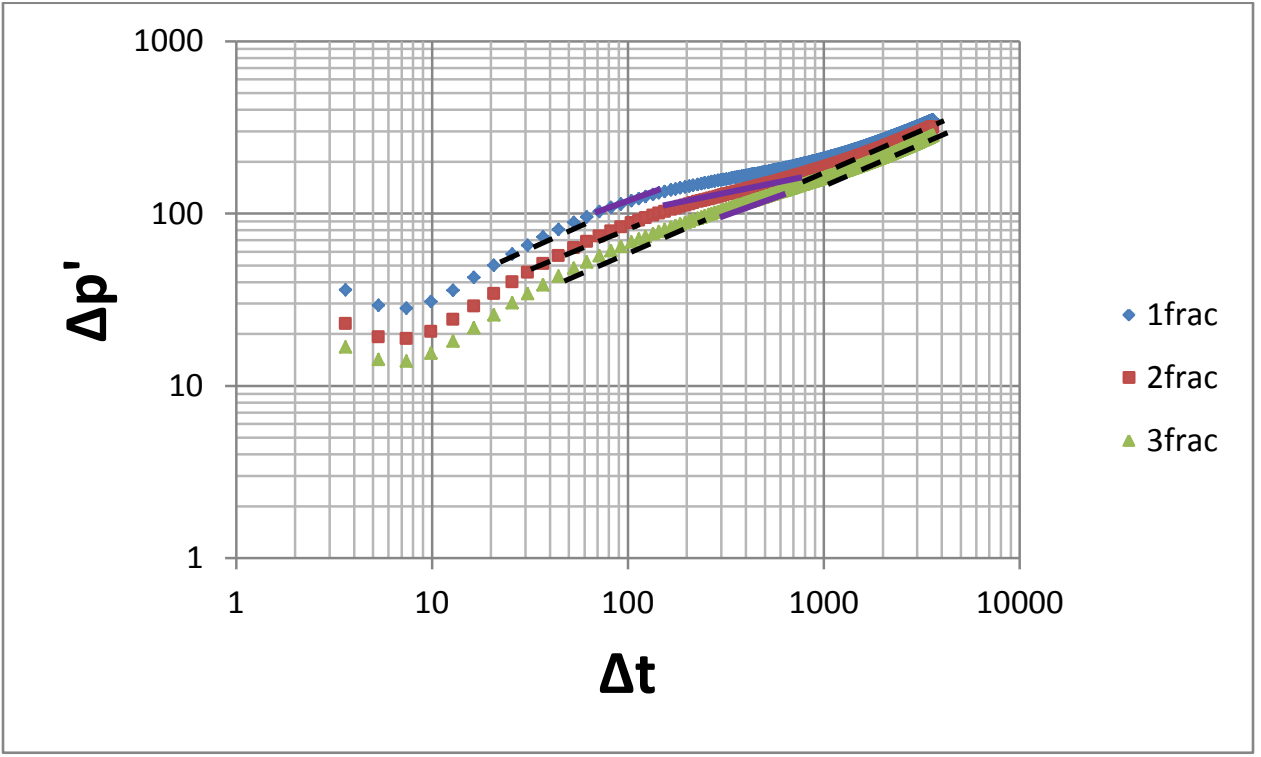




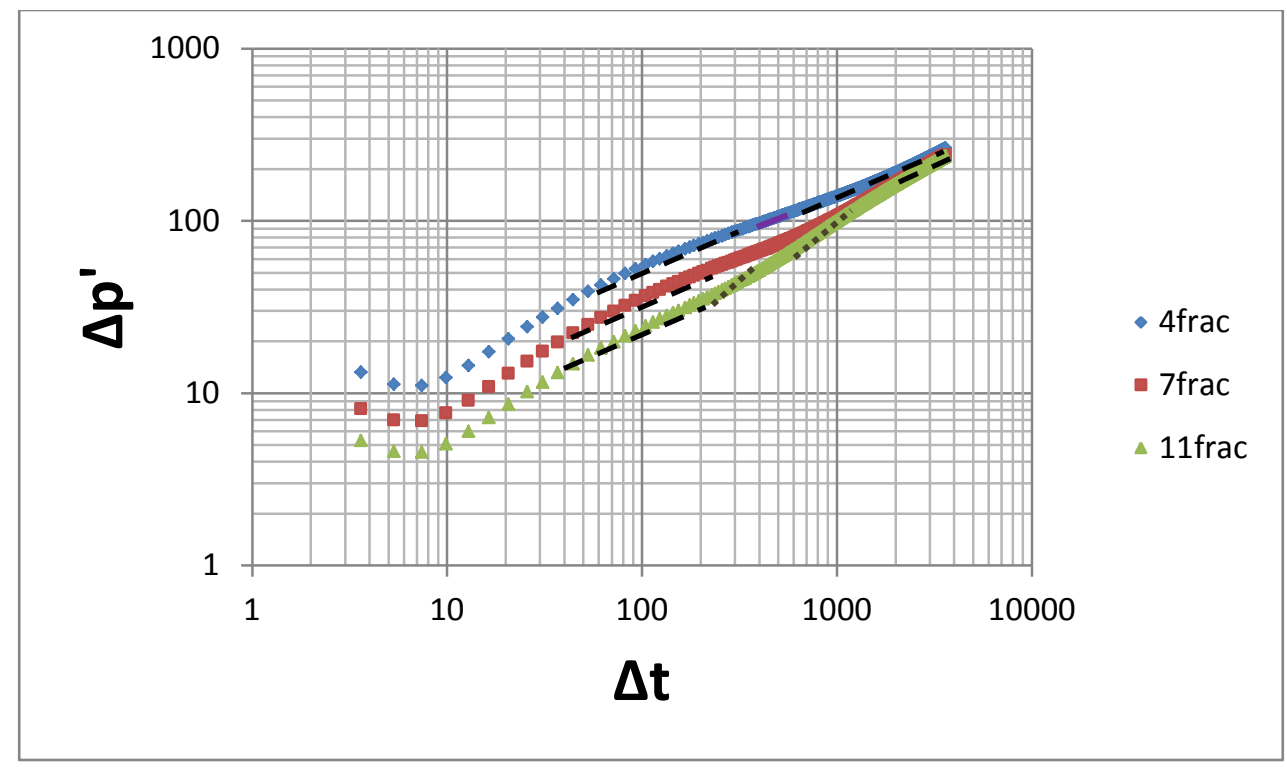

$\checkmark$ Case 1.6: $\mathrm{xf}=300 \mathrm{ft}$, width of fracture $=0.1$ in ,permeability of fracture $=10000$, porosity of fracture $=0.2$

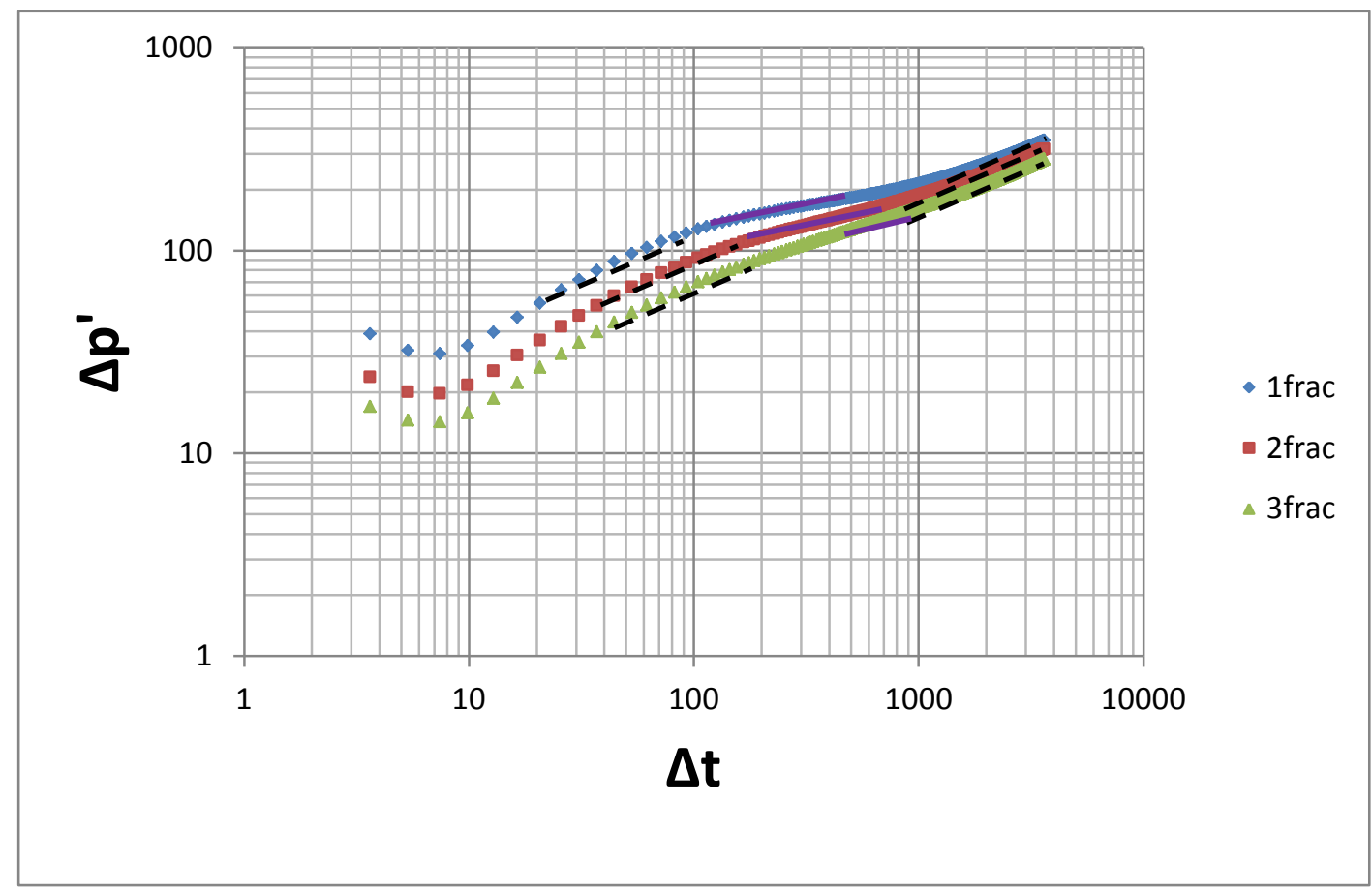




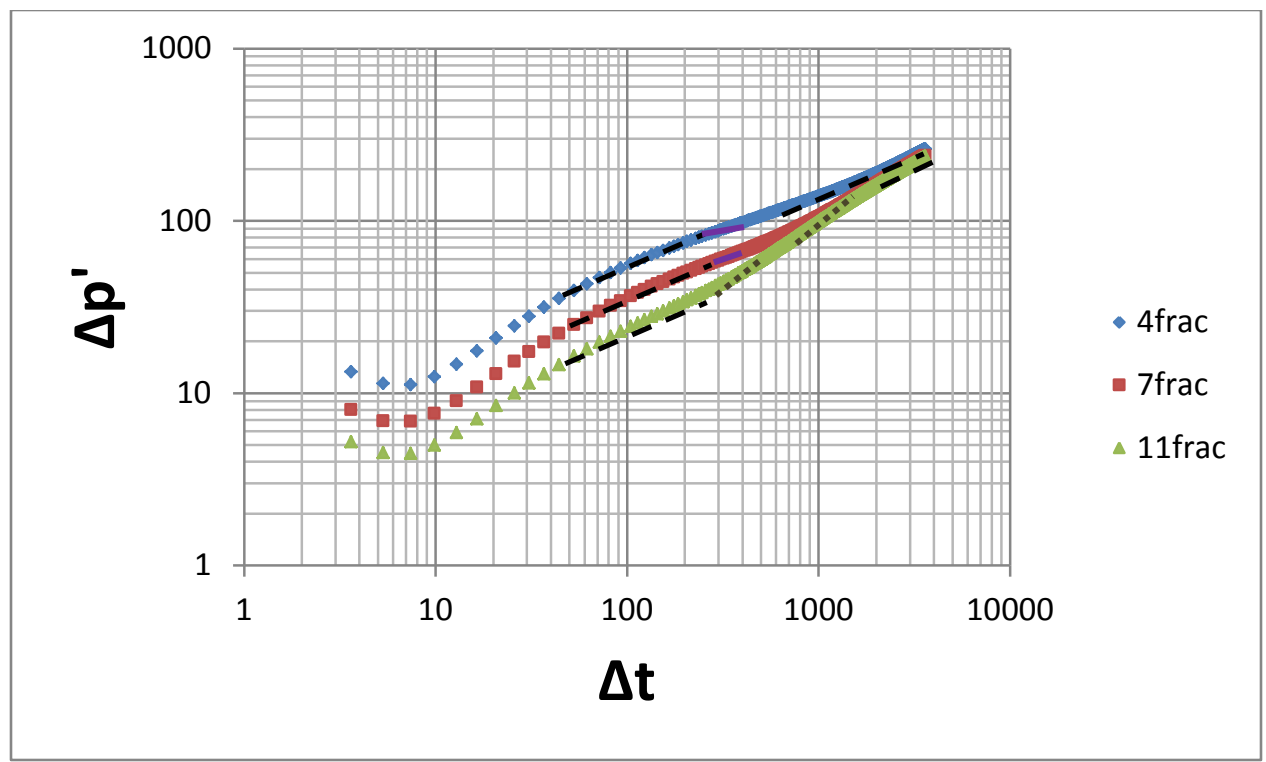

$\checkmark$ Case 1.7: $x f=300 \mathrm{ft}$, width of fracture $=0.01$ in , permeability of fracture $=40000$, porosity of fracture $=0.2$

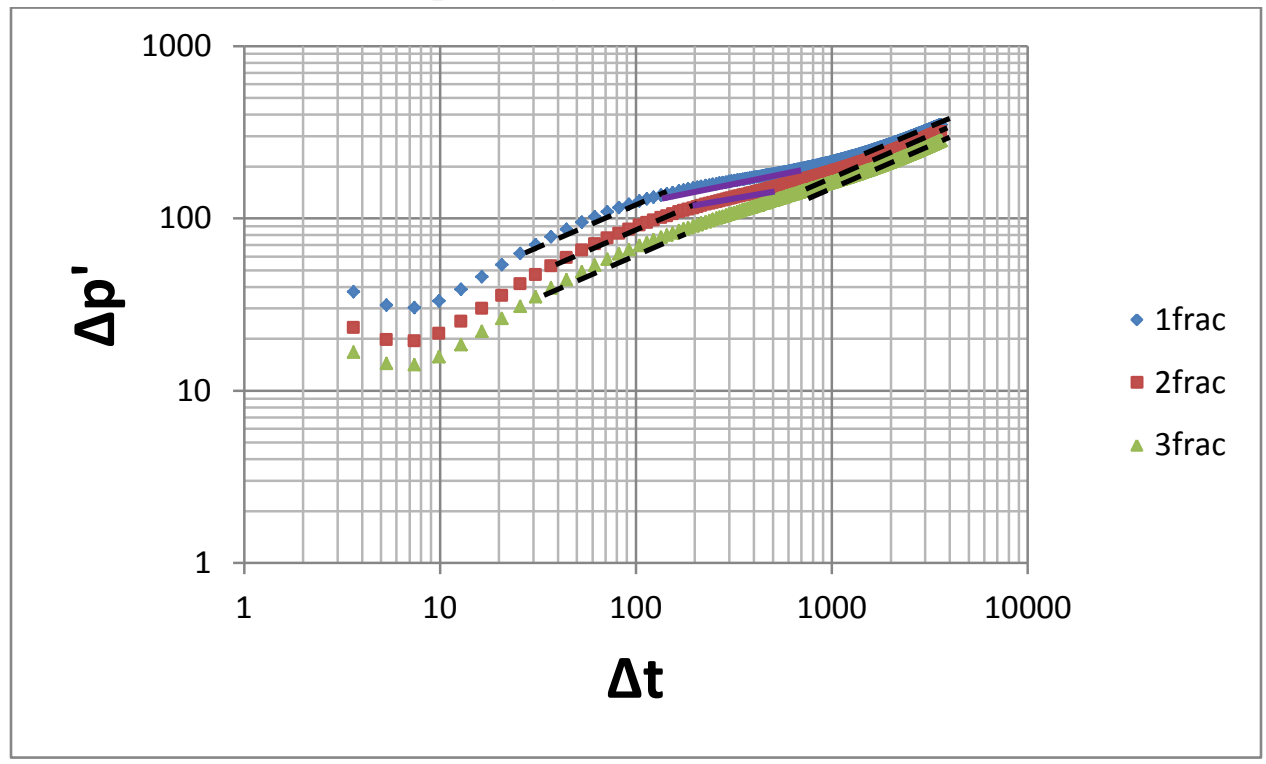




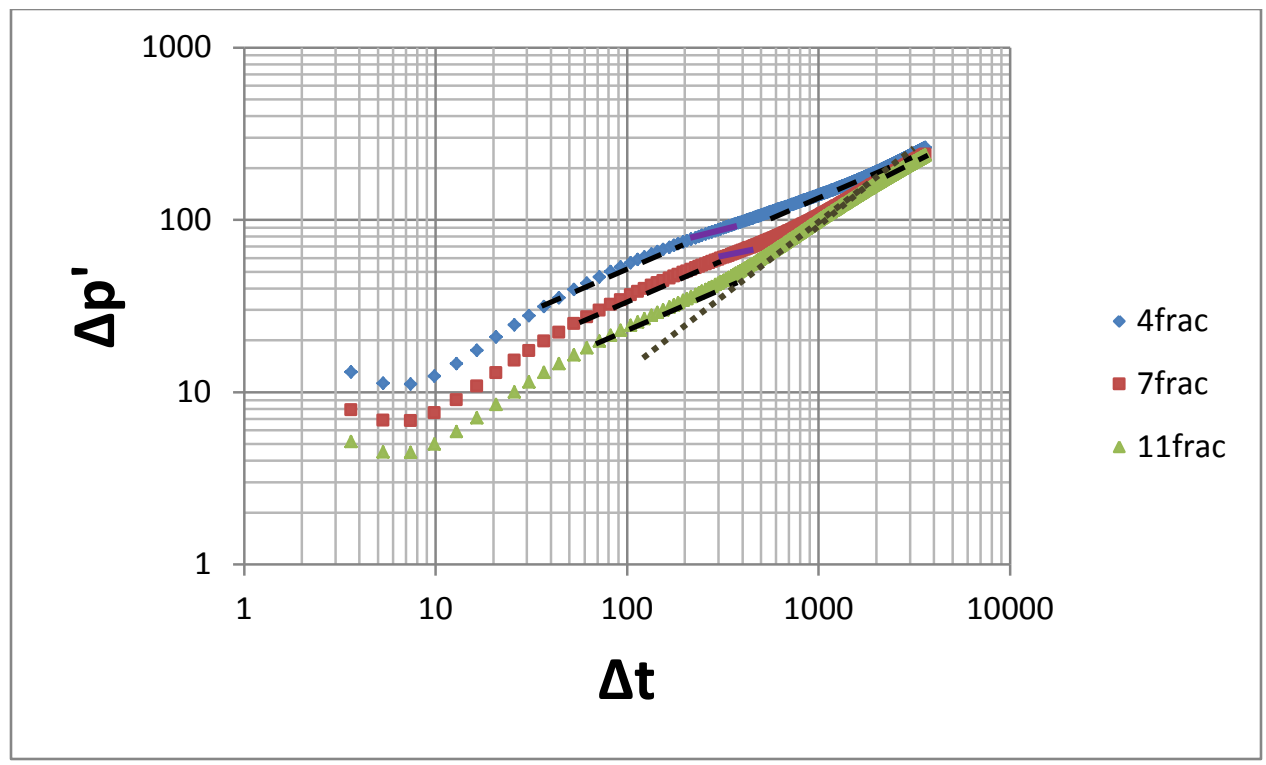

$\checkmark$ Case 1.8: $\mathrm{xf}=300 \mathrm{ft}$, width of fracture $=0.1$ in ,permeability of fracture $=40000$, porosity of fracture $=0.2$

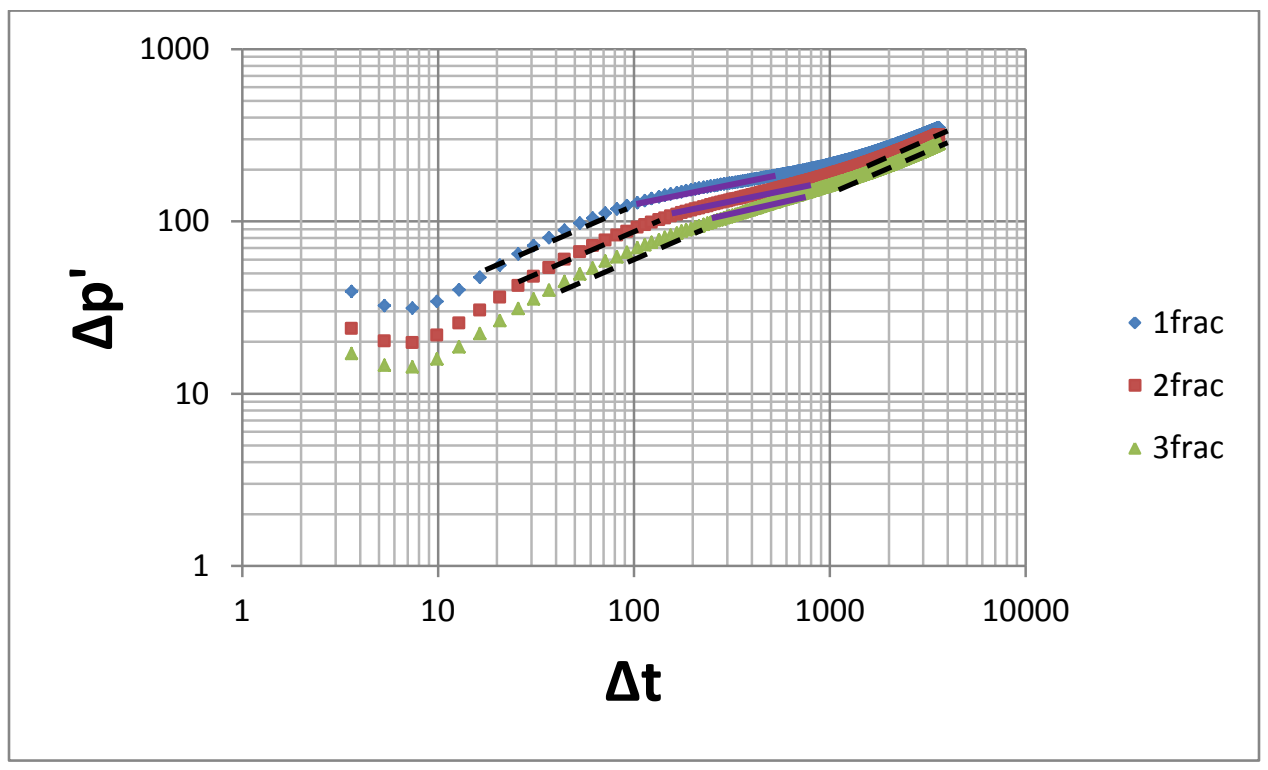




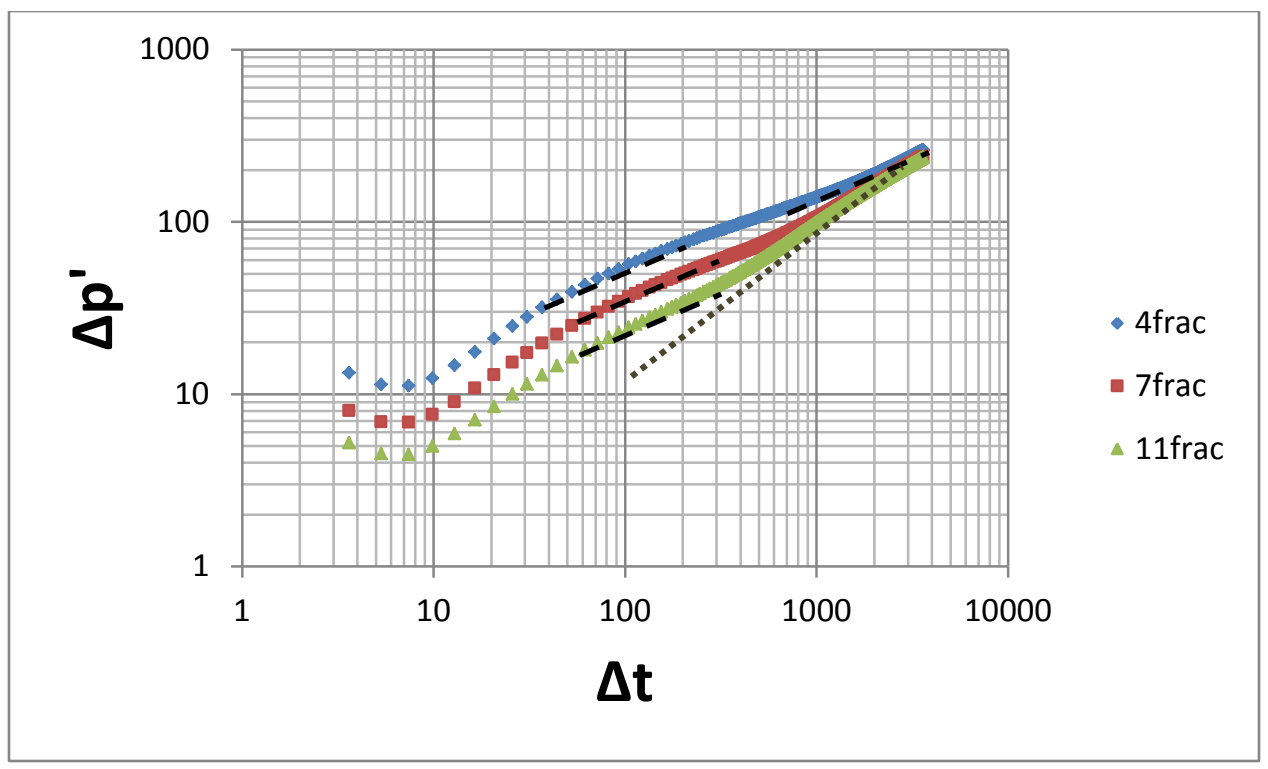

Horizontal well length $4000 \mathrm{ft}$

$\checkmark$ Case 1.9: $\mathrm{xf}=500 \mathrm{ft}$, width of fracture $=0.01$ in ,permeability of fracture $=10000$, porosity of fracture $=0.2$

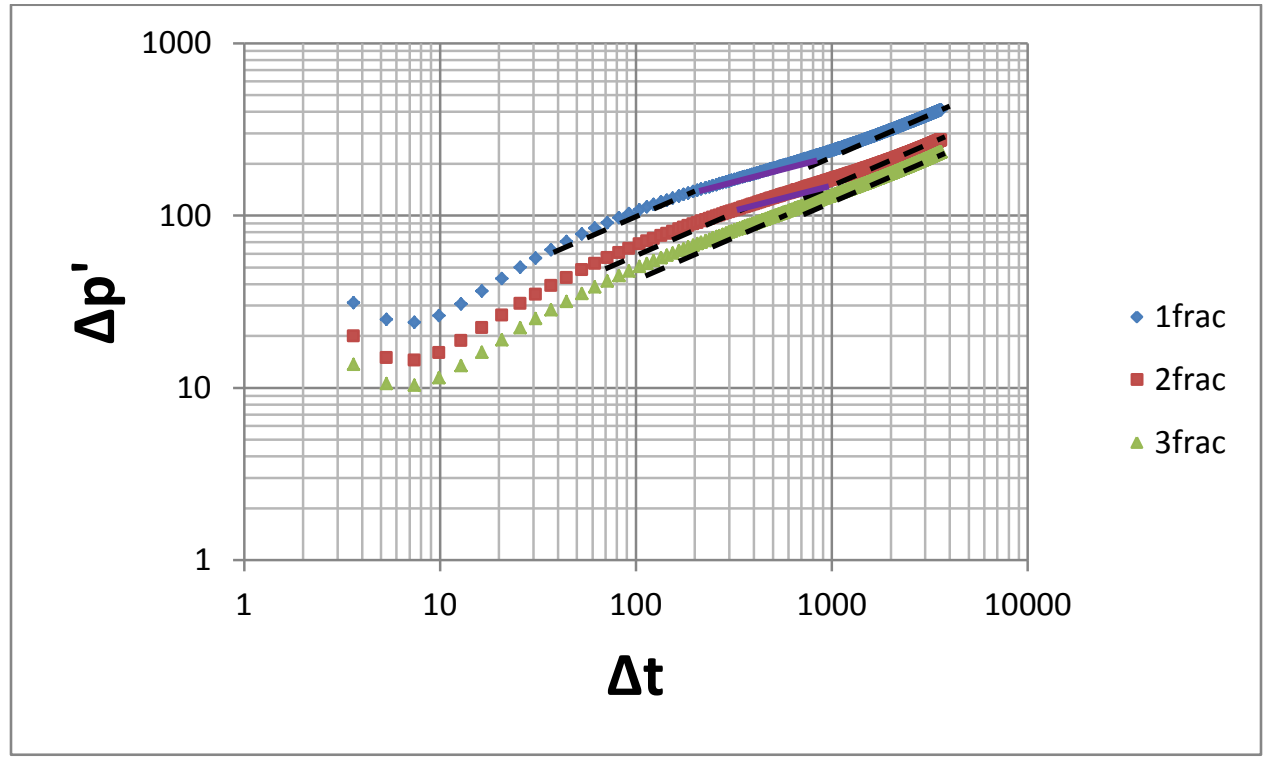




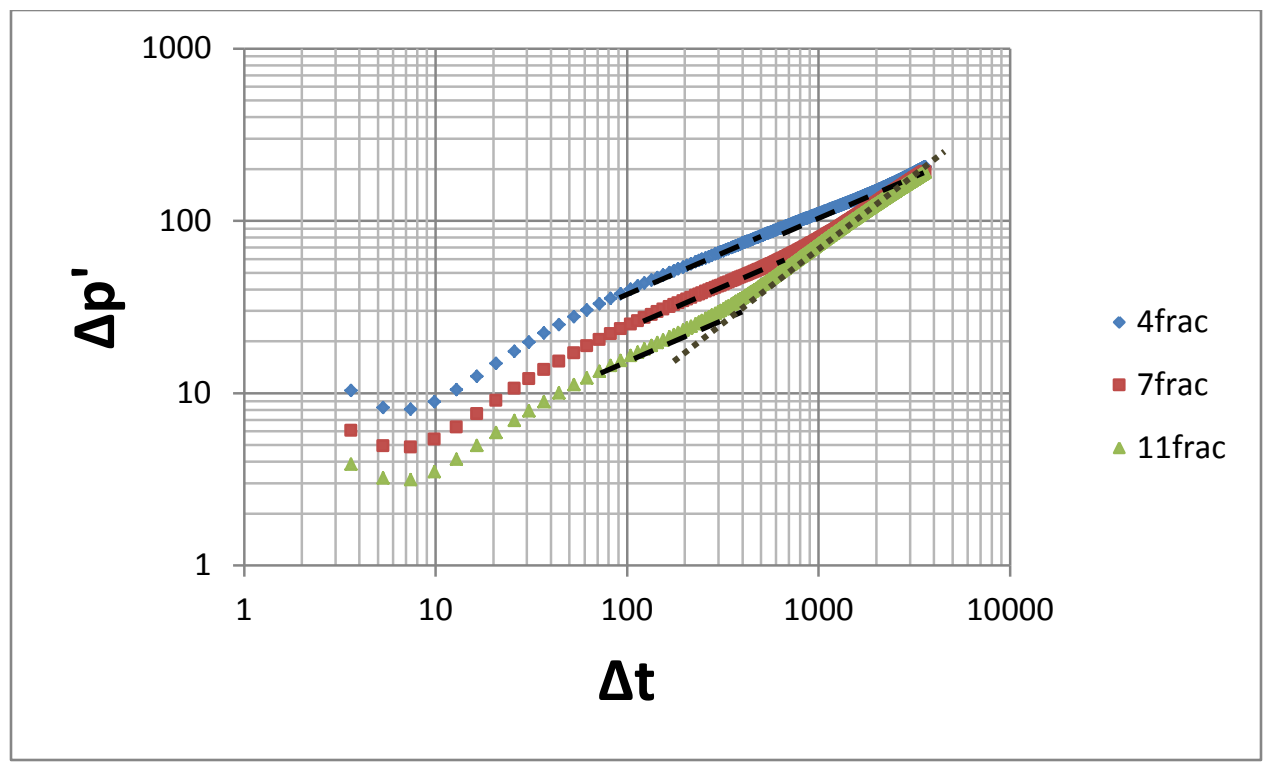

$\checkmark$ Case 1.10: $\mathrm{xf}=500 \mathrm{ft}$, width of fracture $=0.1$ in , permeability of fracture $=10000$, porosity of fracture $=0.2$

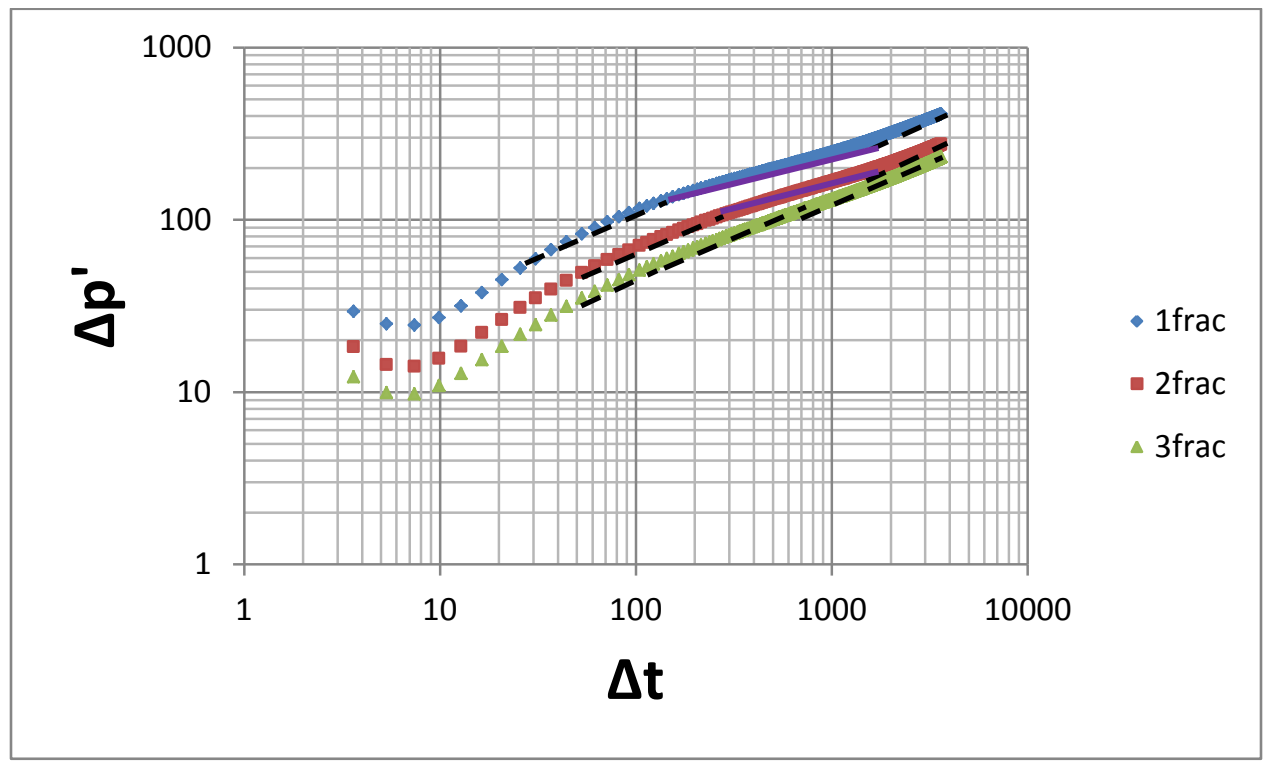




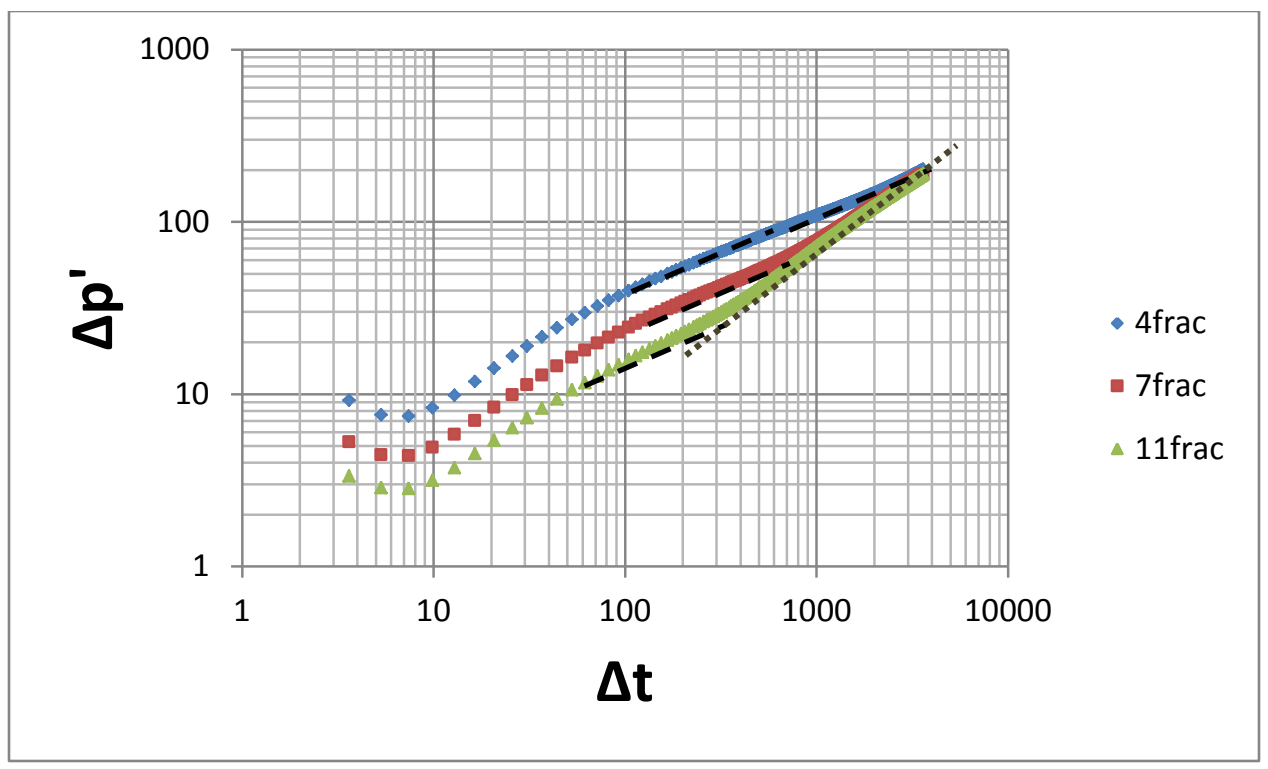

$\checkmark$ Case 1.11: $\mathrm{xf}=500 \mathrm{ft}$, width of fracture $=0.01$ in ,permeability of fracture $=40000$, porosity of fracture $=0.2$

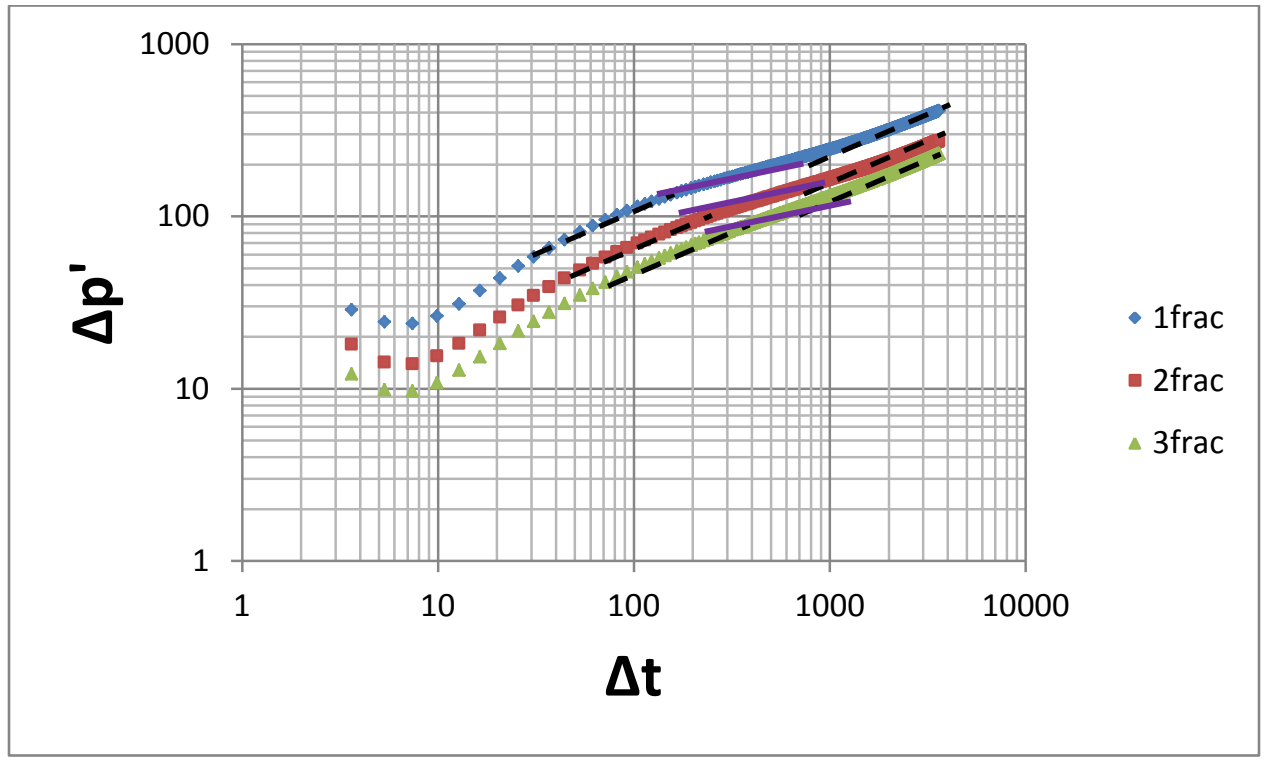




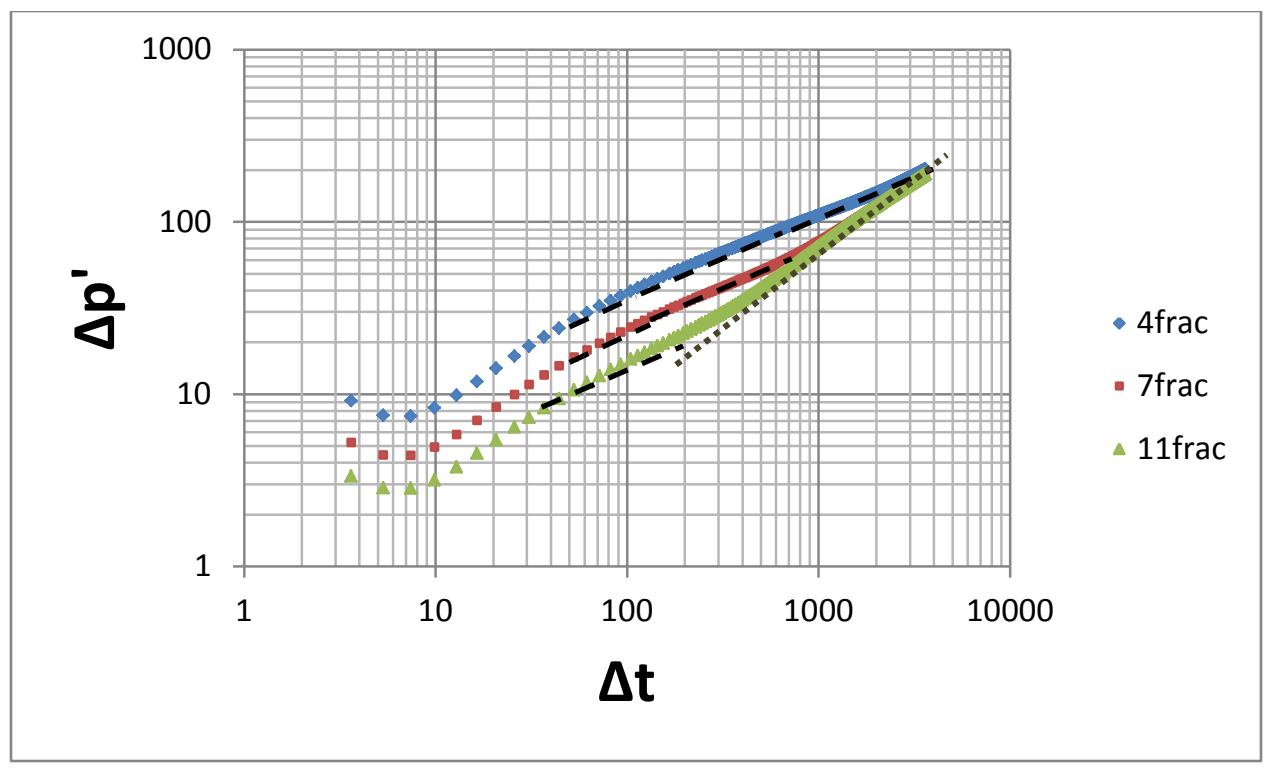

$\checkmark$ Case 1.12: $\mathrm{xf}=500 \mathrm{ft}$, width of fracture $=0.1$ in ,permeability of fracture $=40000$, porosity of fracture $=0.2$

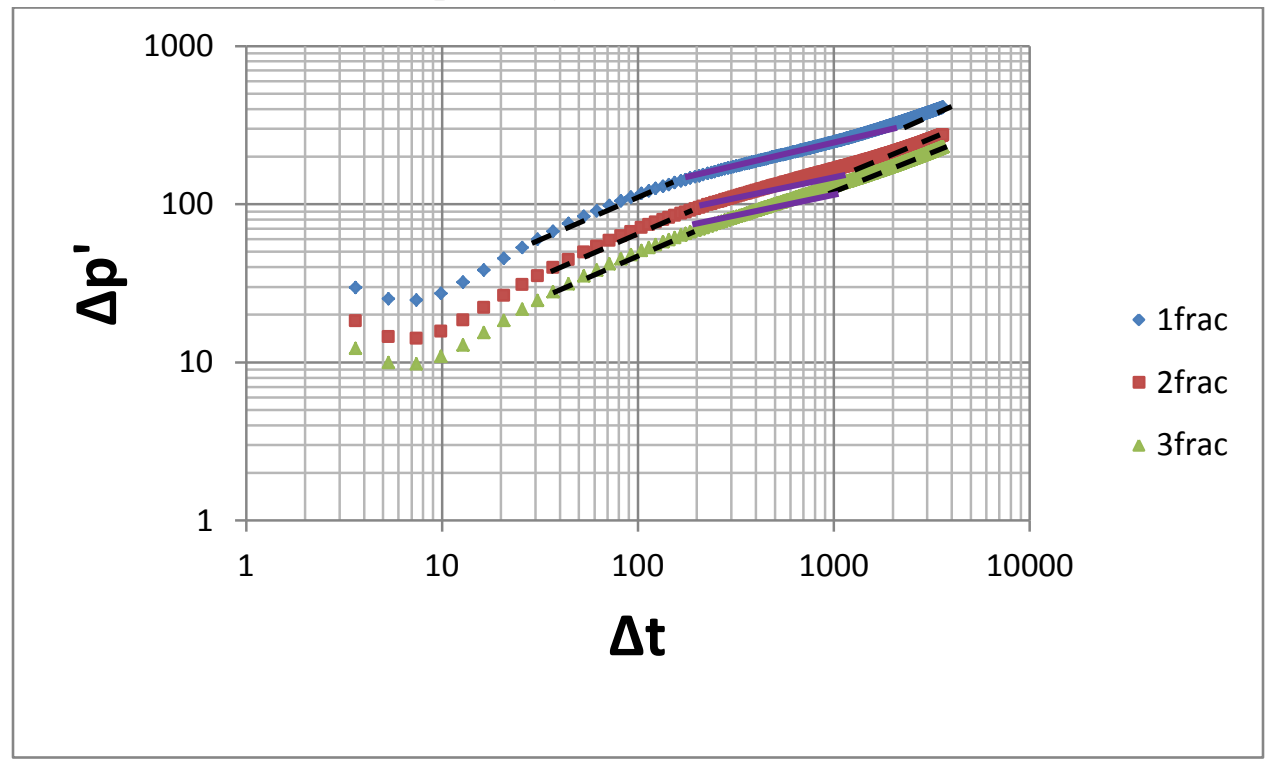




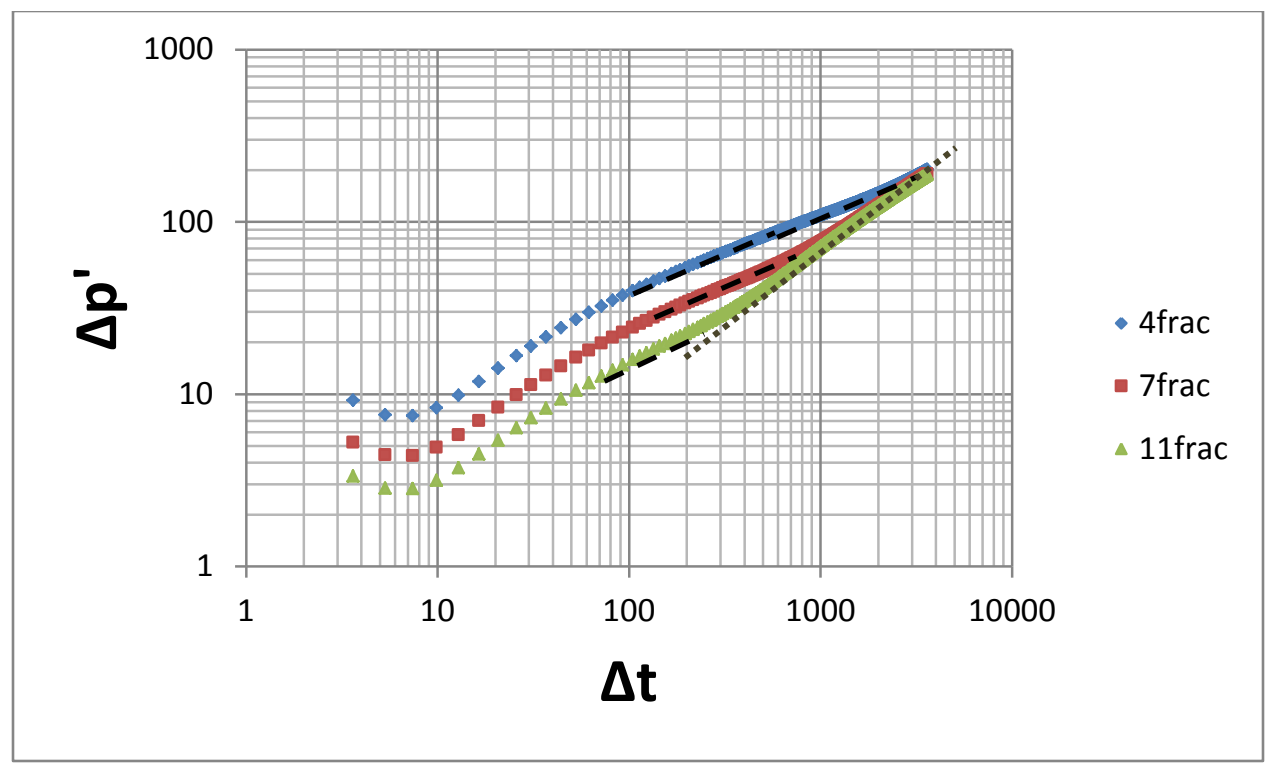

Horizontal well length $3500 \mathrm{ft}$

$\checkmark$ Case 1.13: $x f=500 \mathrm{ft}$, width of fracture $=0.01$ in , permeability of fracture $=10000$, porosity of fracture $=0.2$

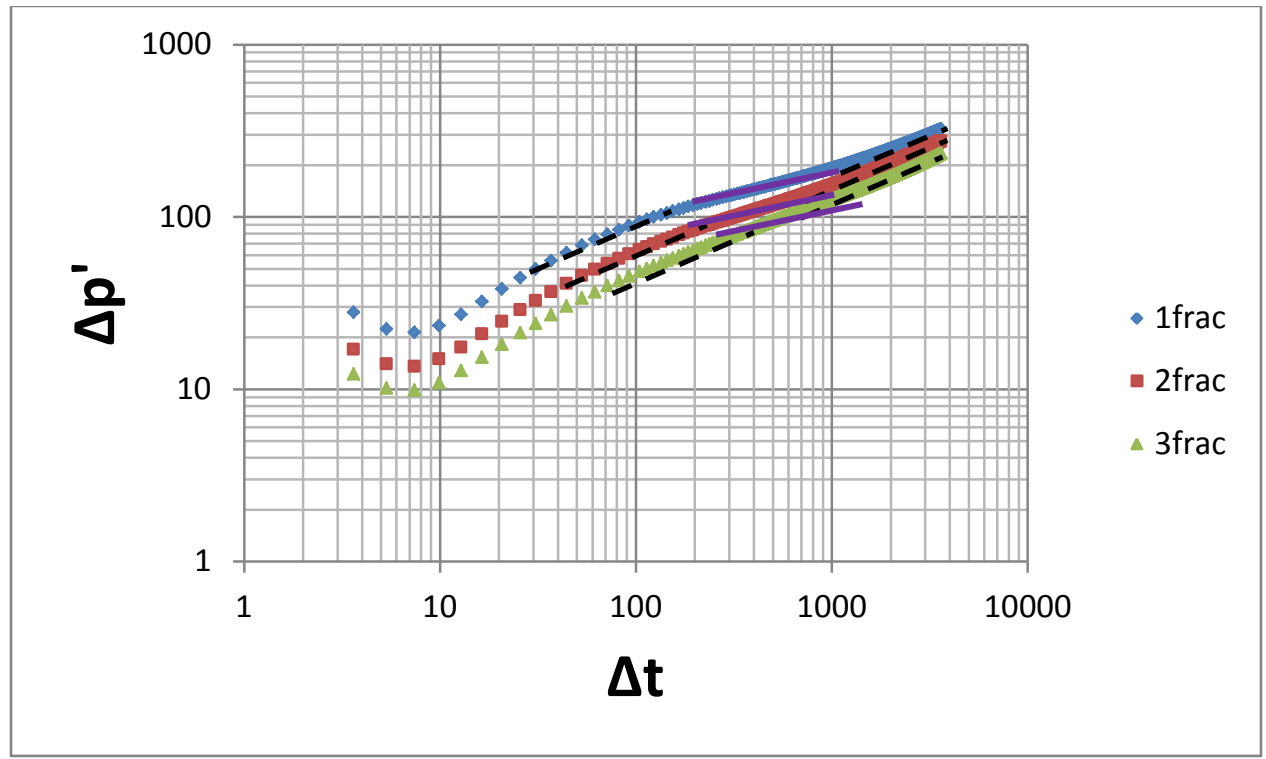




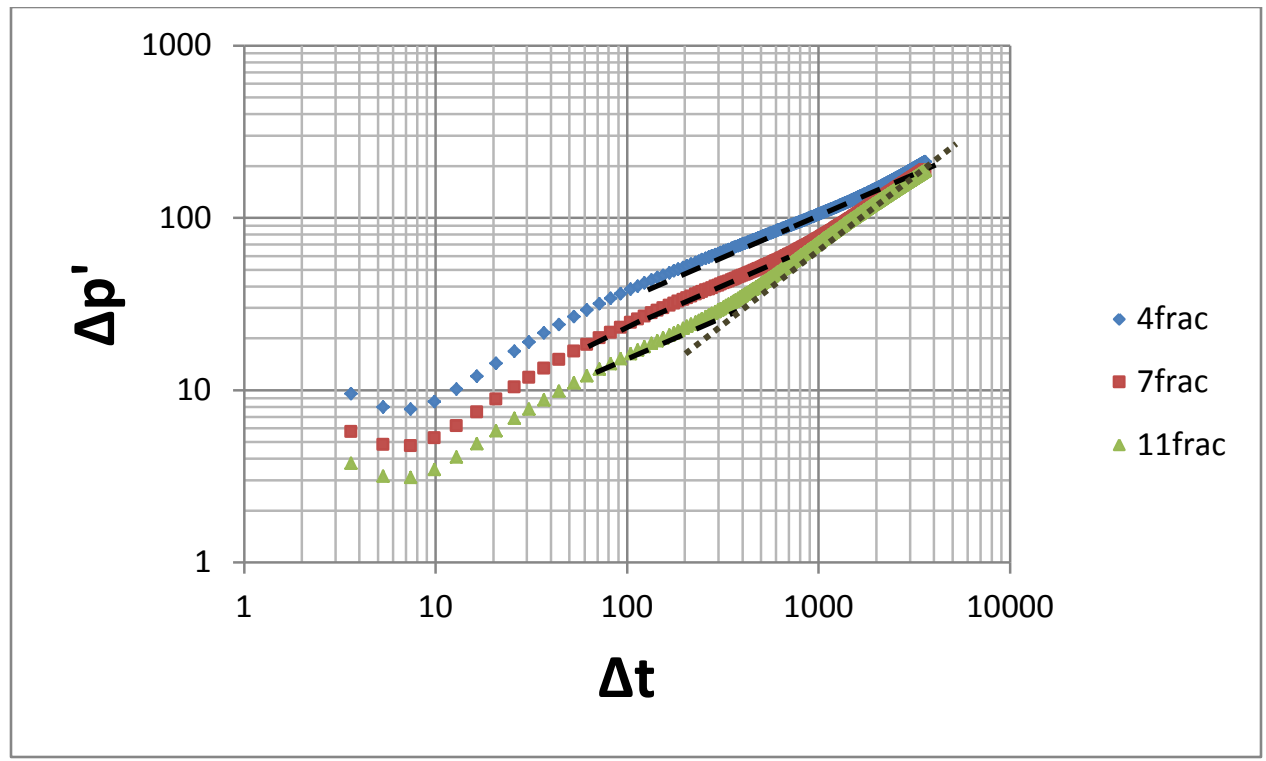

$\checkmark$ Case 1.14: $\mathrm{xf}=500 \mathrm{ft}$, width of fracture $=0.1$ in ,permeability of fracture $=10000$, porosity of fracture $=0.2$

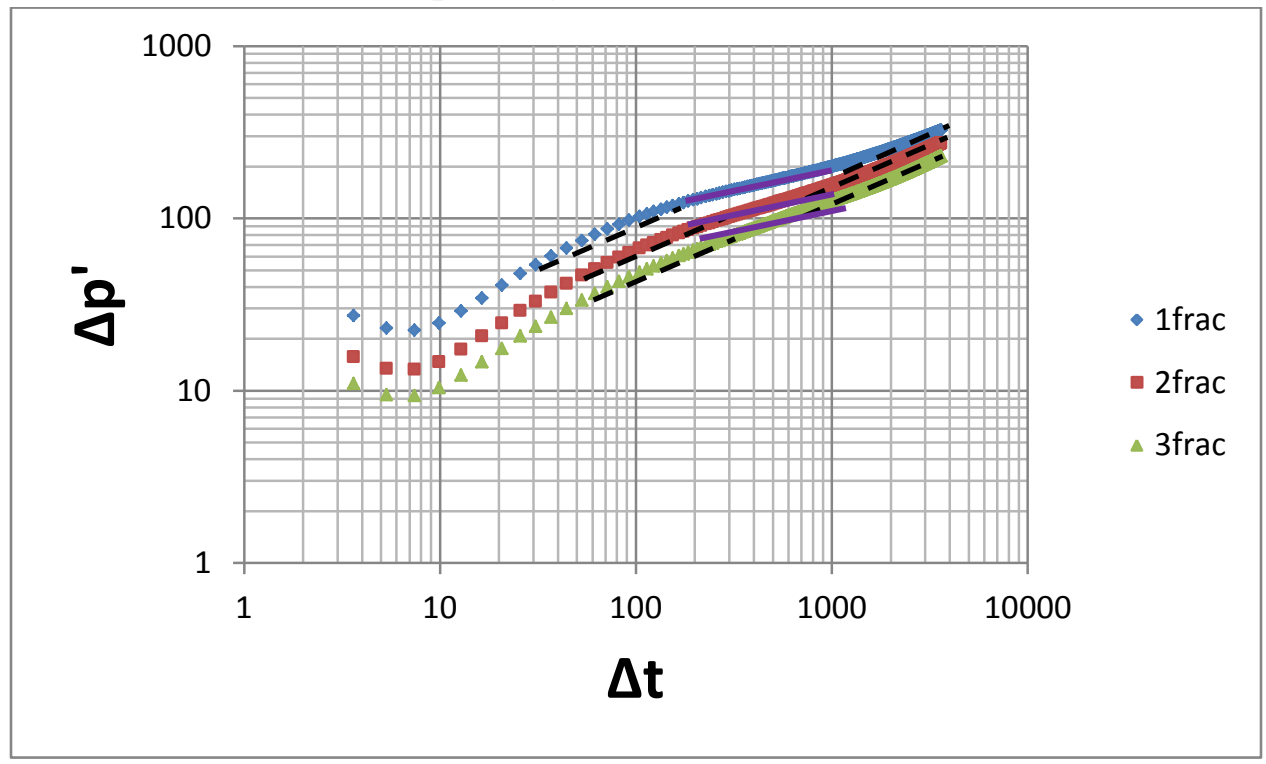




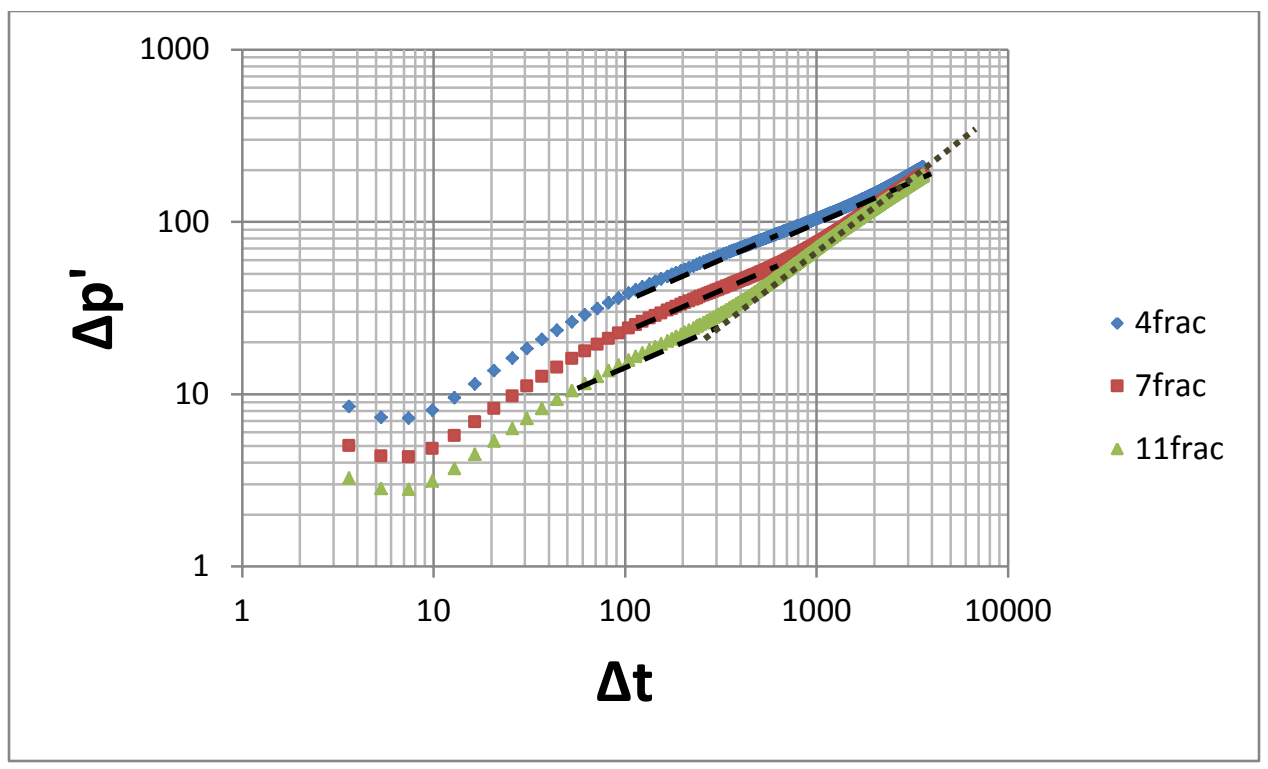

$\checkmark$ Case 1.15: $\mathrm{xf}=500 \mathrm{ft}$, width of fracture $=0.01$ in , permeability of fracture $=40000$, porosity of fracture $=0.2$

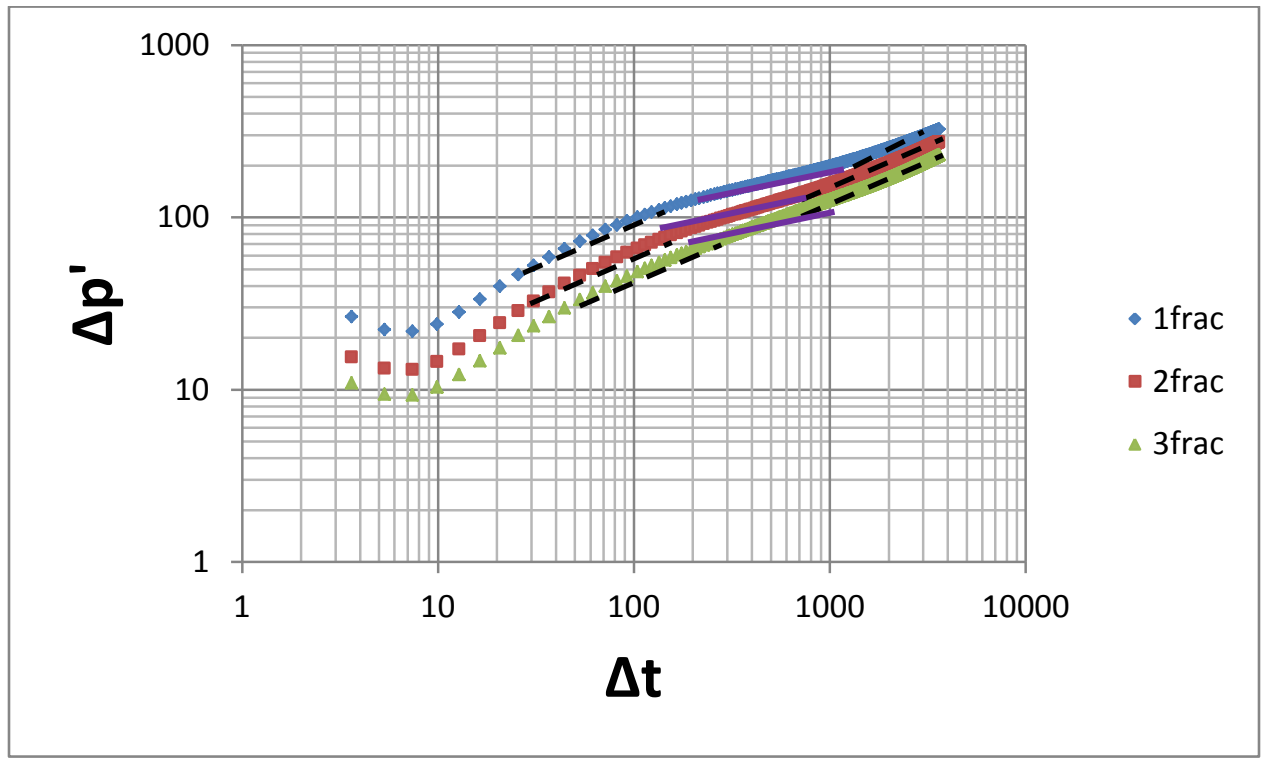




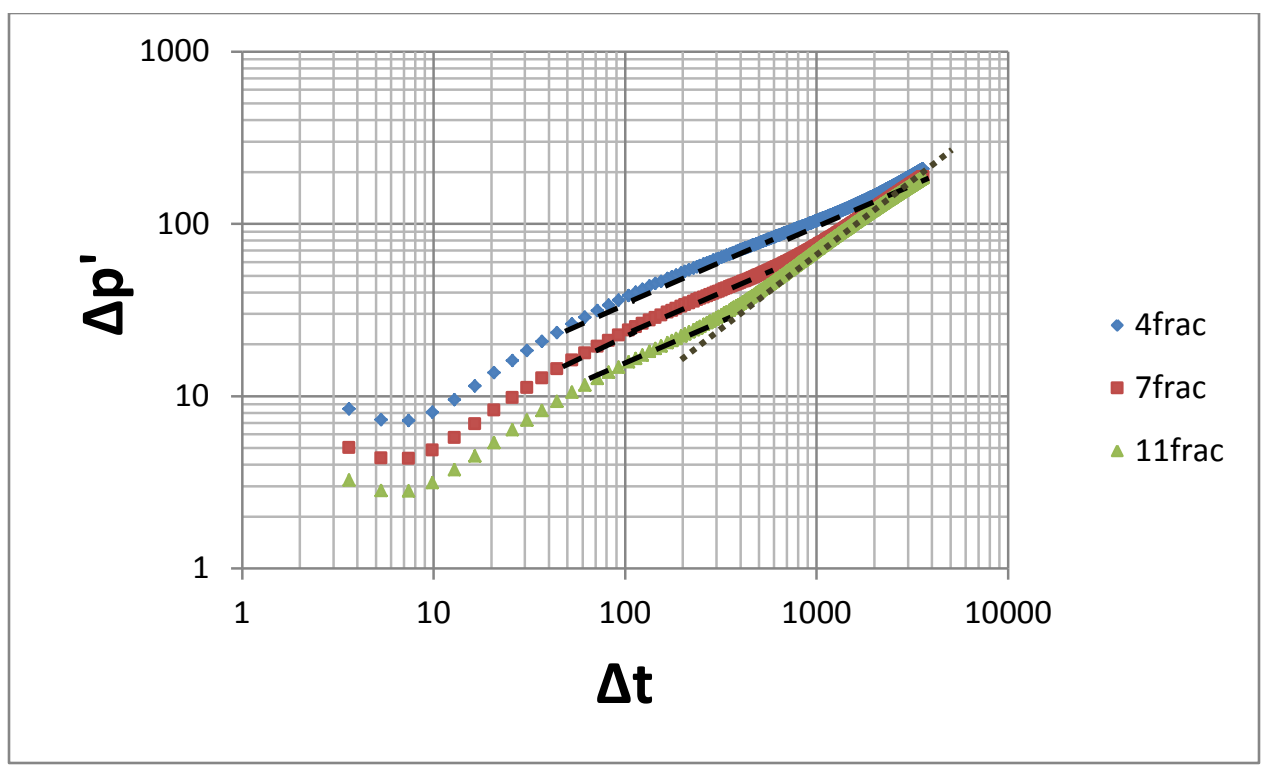

$\checkmark$ Case 1.16: $\mathrm{xf}=500 \mathrm{ft}$, width of fracture $=0.1$ in ,permeability of fracture $=40000$, porosity of fracture $=0.2$

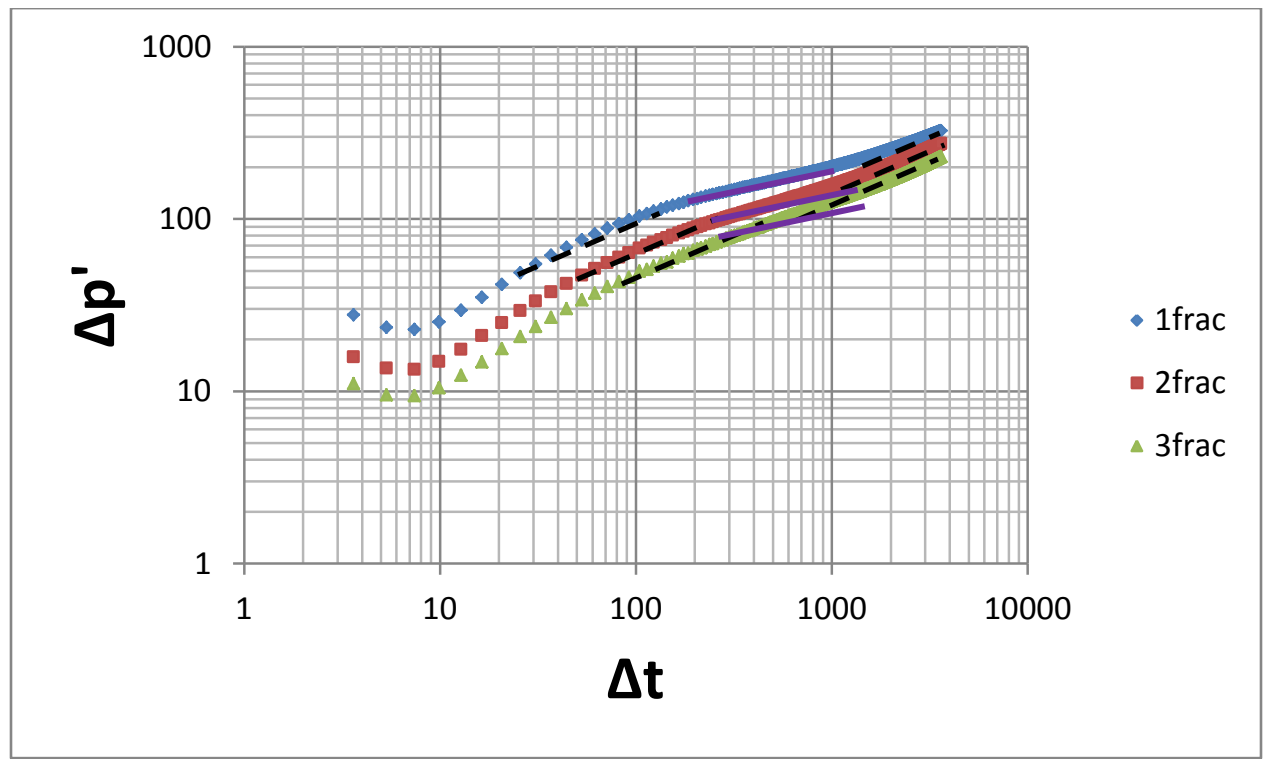




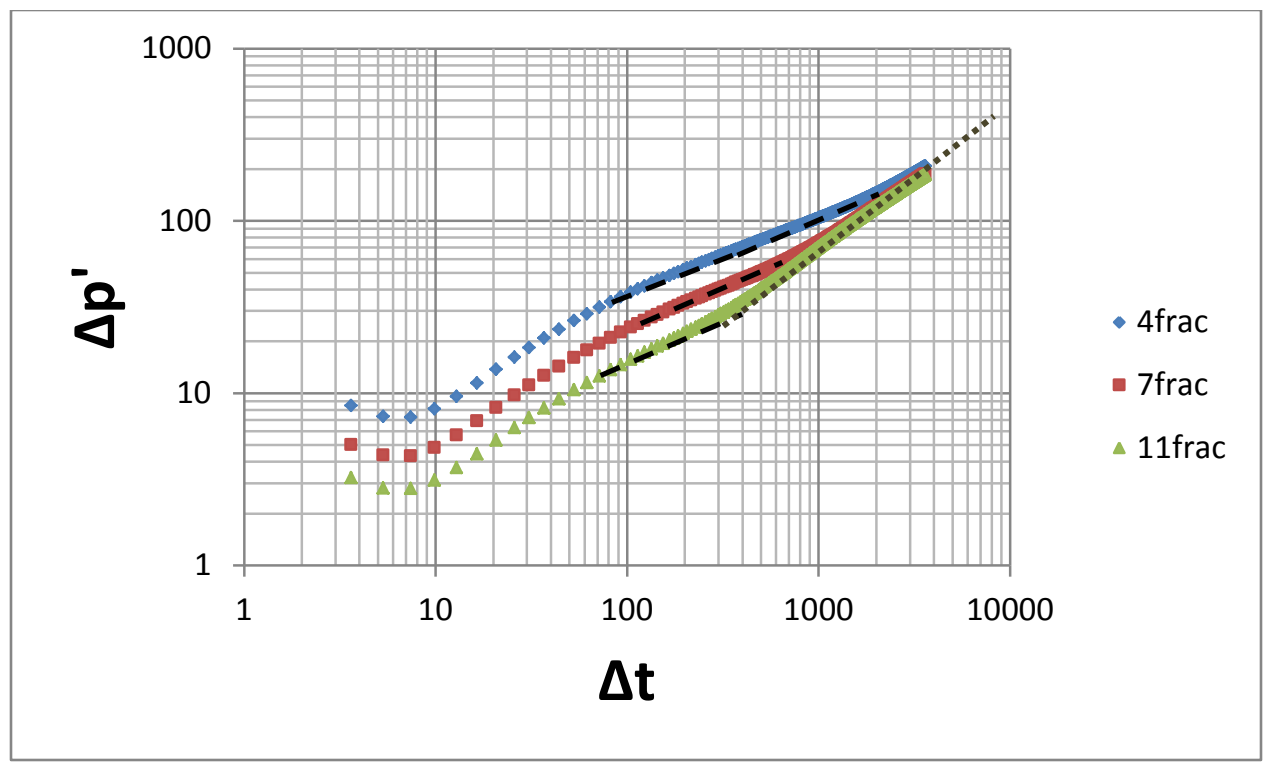




\section{Appendix 2}

\section{Case 2: Fracture porosity fraction $=0.002$}

Bulk permeability $i, j, k(m d)=0.001,0.001,0.0001$

Horizontal well length $4000 \mathrm{ft}$

$\checkmark$ Case $2.1 \mathrm{xf}=300 \mathrm{ft}$, width of fracture $=0.01$ in , permeability of fracture $=10000$, porosity of fracture $=0.2$

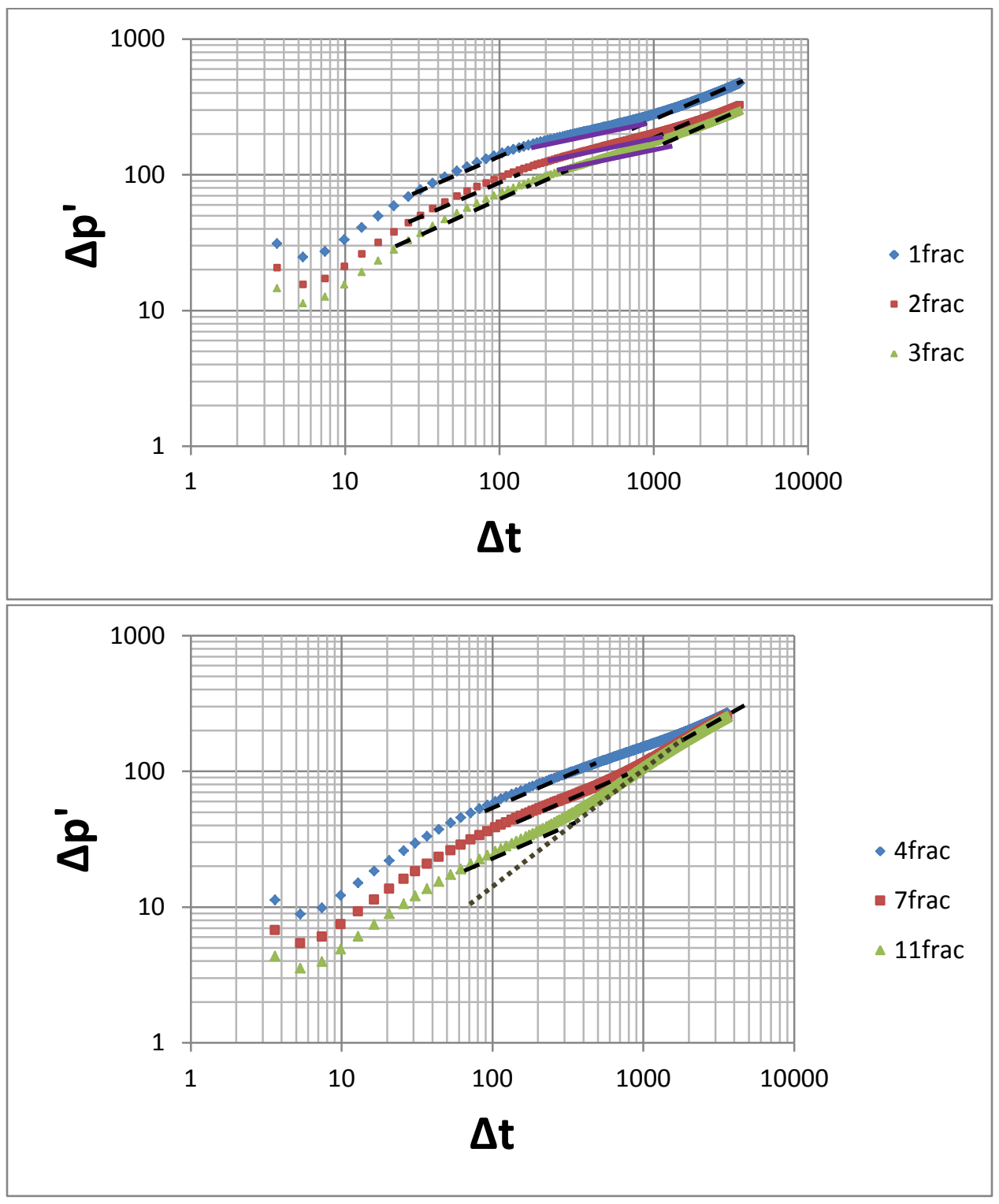


$\checkmark$ Case 2.2: $\mathrm{xf}=300 \mathrm{ft}$, width of fracture $=0.1$ in ,permeability of fracture $=10000$, porosity of fracture $=0.2$

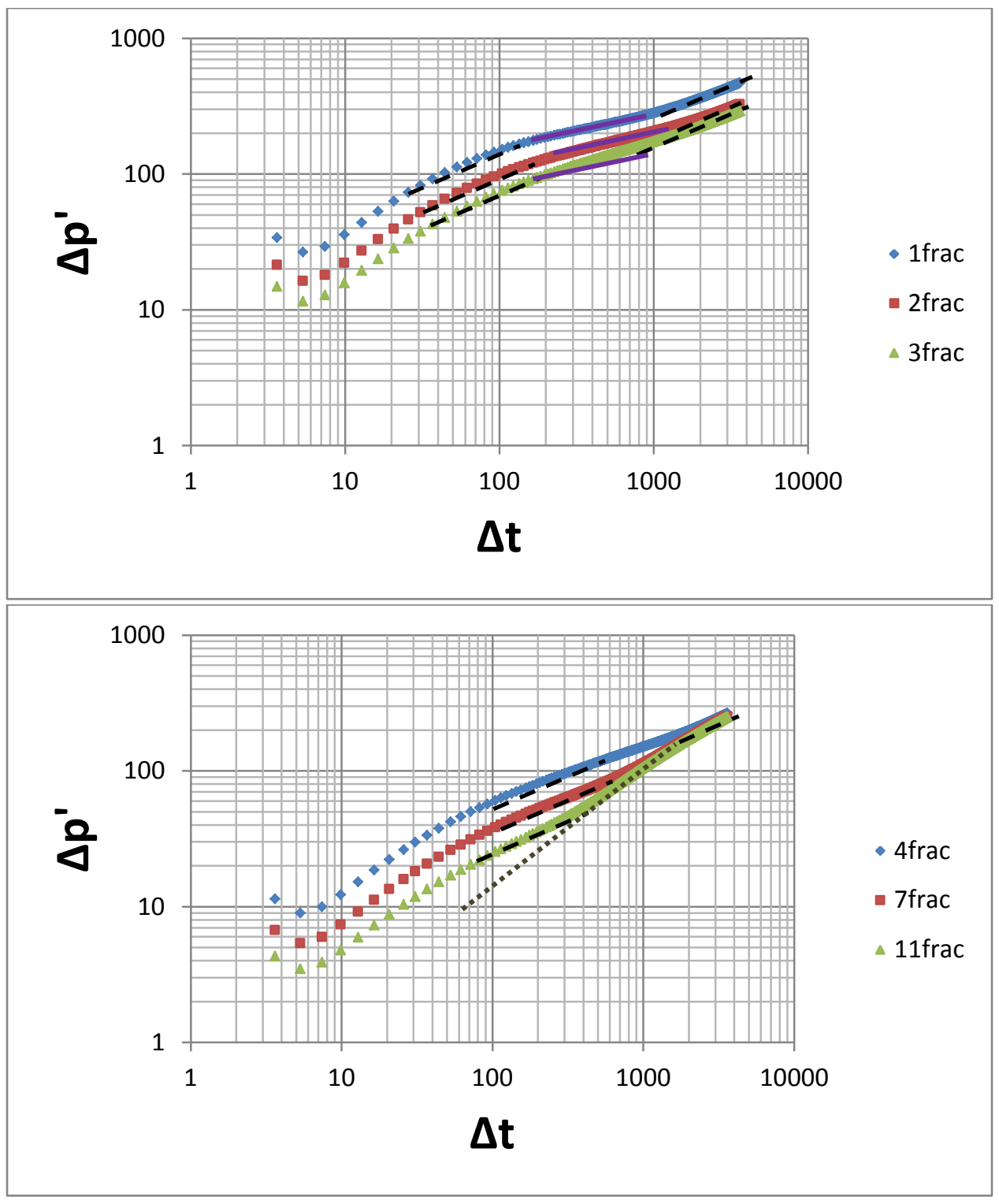

$\checkmark$ Case 2.3: $\mathrm{xf}=300 \mathrm{ft}$, width of fracture $=0.01$ in ,permeability of fracture $=40000$, porosity of fracture $=0.2$ 

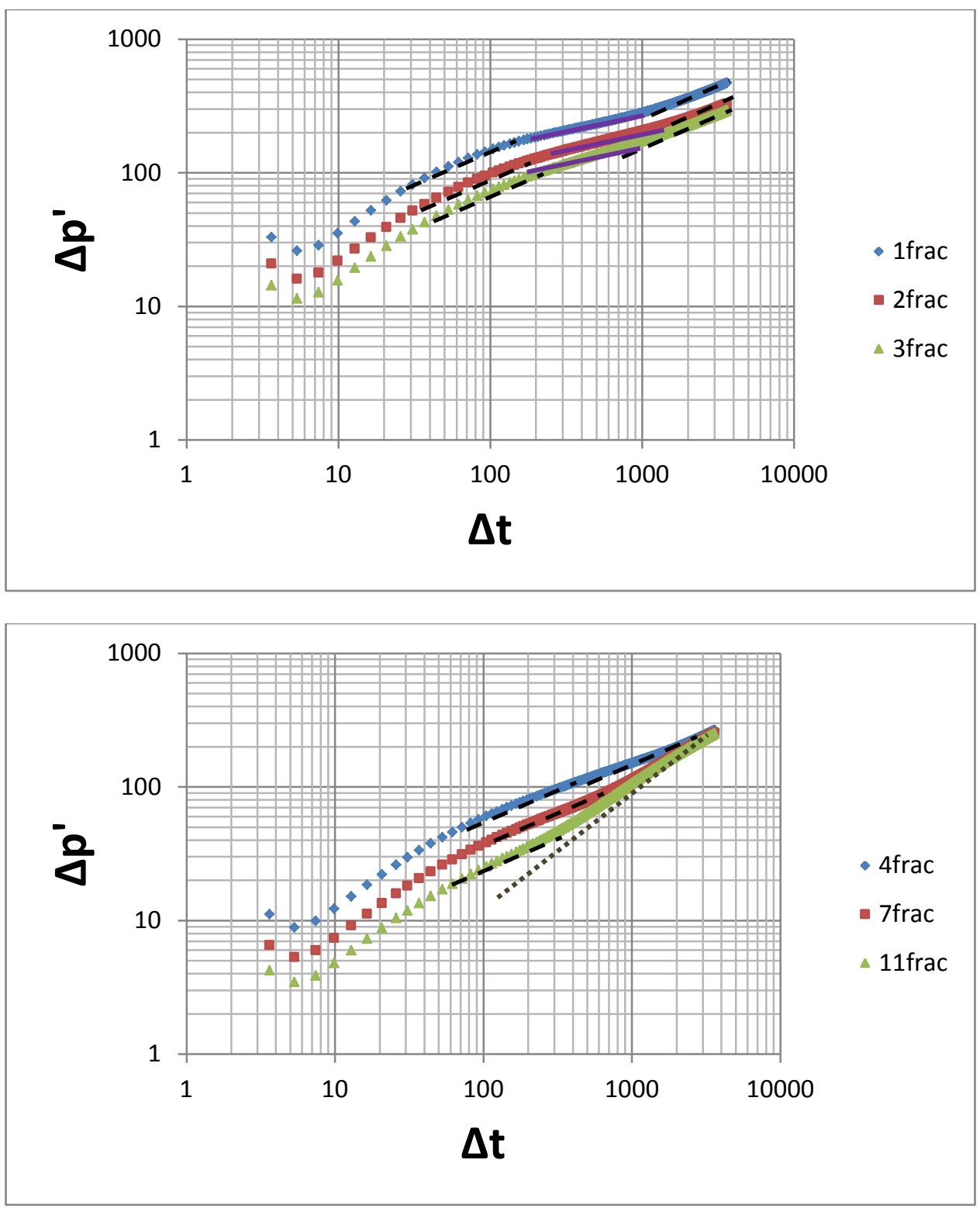

$\checkmark$ Case 2.4: $\mathrm{xf}=300 \mathrm{ft}$, width of fracture $=0.1$ in ,permeability of fracture $=40000$, porosity of fracture $=0.2$ 

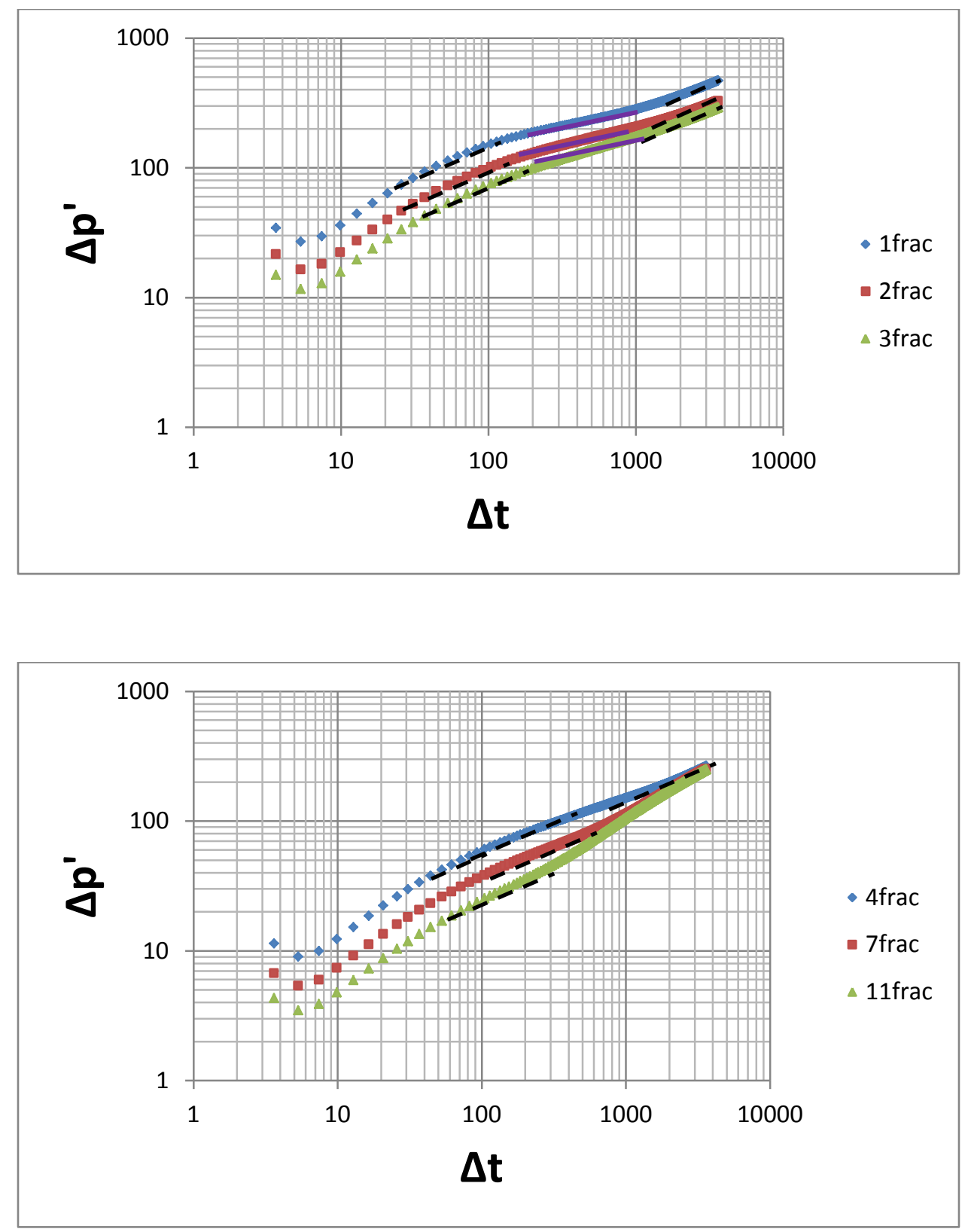

Horizontal well length $3500 \mathrm{ft}$

$\checkmark$ Case 2.5: $\mathrm{xf}=300 \mathrm{ft}$, width of fracture $=0.01$ in ,permeability of fracture $=10000$, porosity of fracture $=0.2$ 

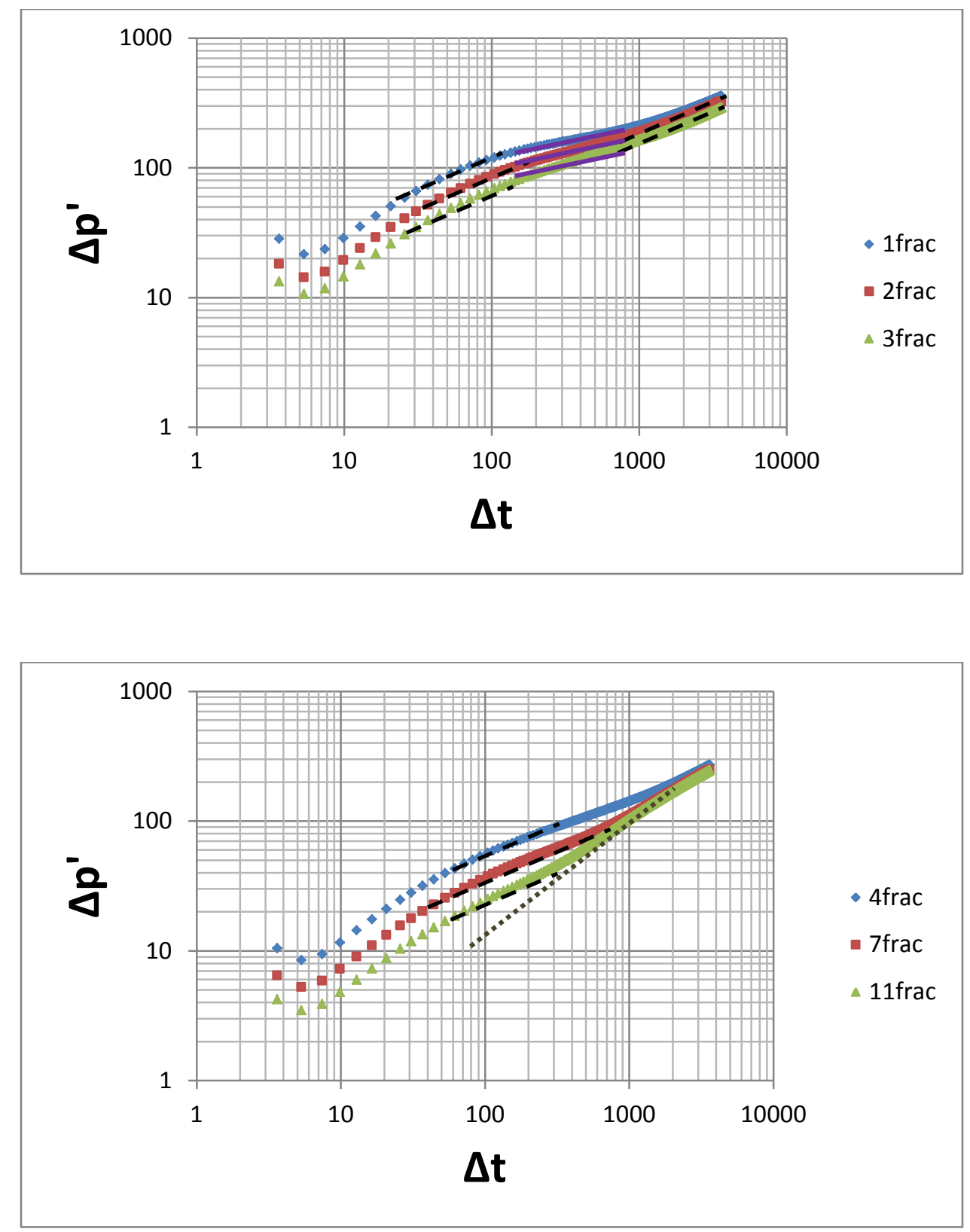

$\checkmark$ Case 2.6: $\mathrm{xf}=300 \mathrm{ft}$, width of fracture $=0.1$ in ,permeability of fracture $=10000$, porosity of fracture $=0.2$ 

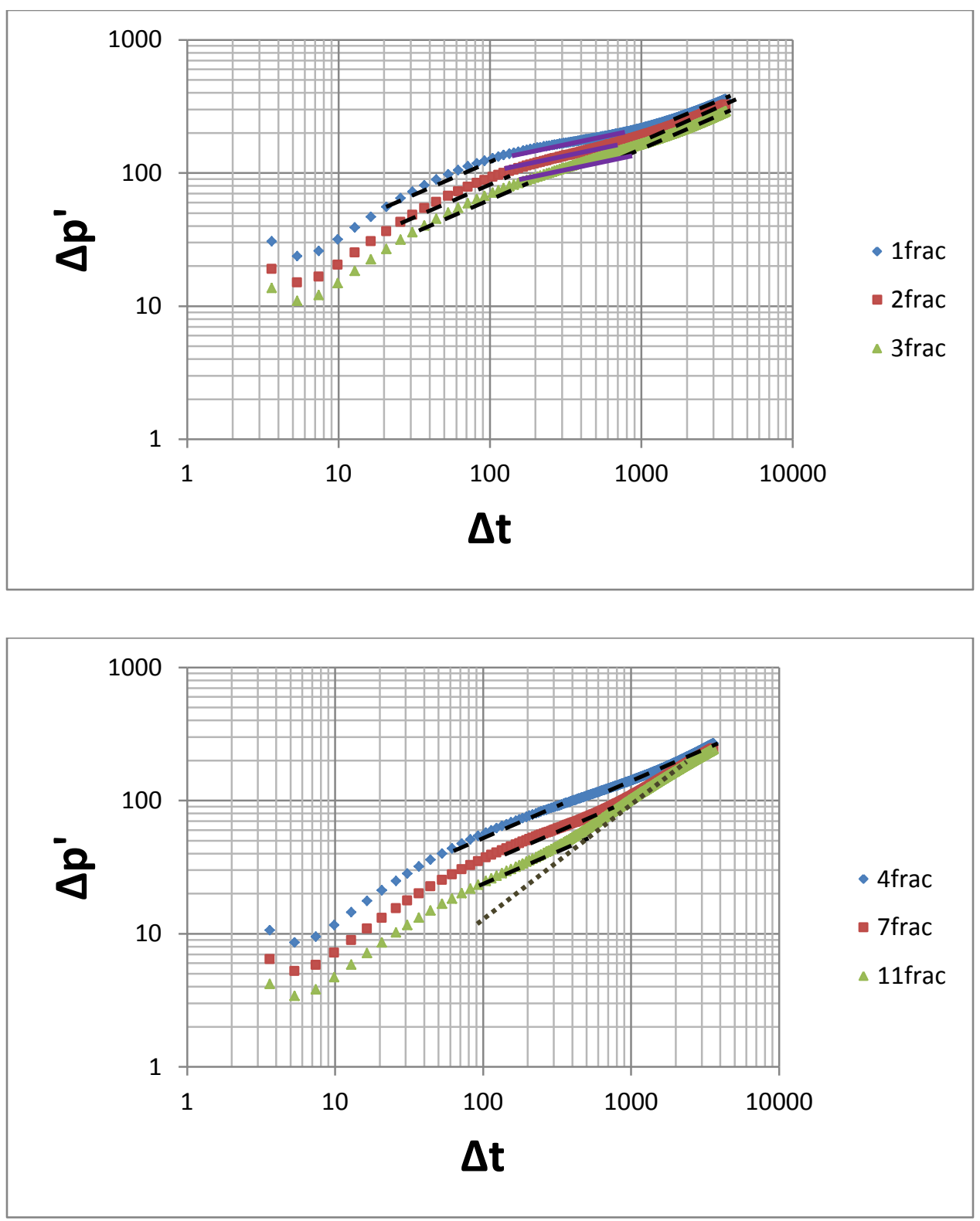

$\checkmark$ Case 2.7: $\mathrm{xf}=300 \mathrm{ft}$, width of fracture $=0.01$ in , permeability of fracture $=40000$, porosity of fracture $=0.2$ 

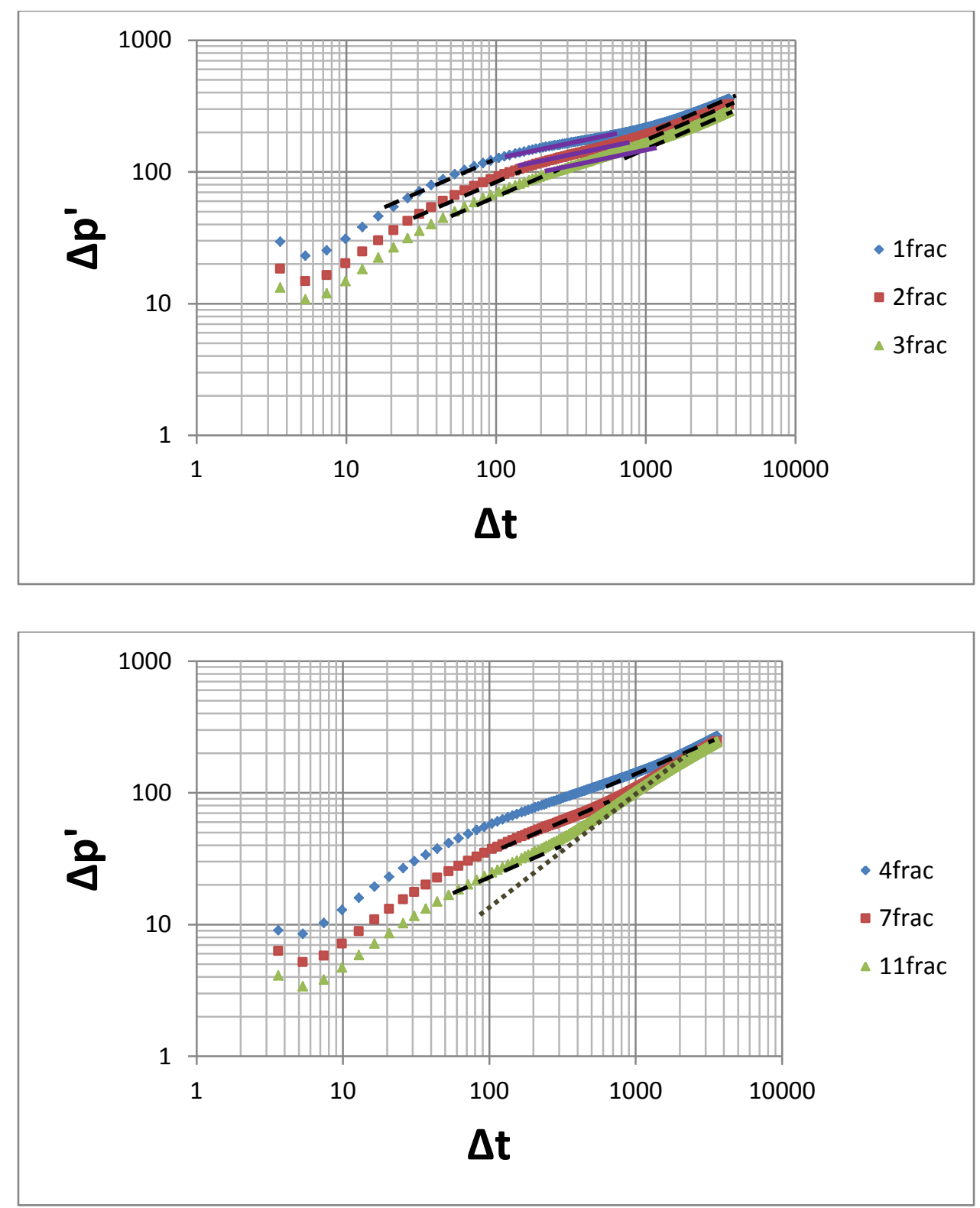

$\checkmark$ Case 2.8: $\mathrm{xf}=300 \mathrm{ft}$, width of fracture $=0.1$ in ,permeability of fracture $=40000$, porosity of fracture $=0.2$ 

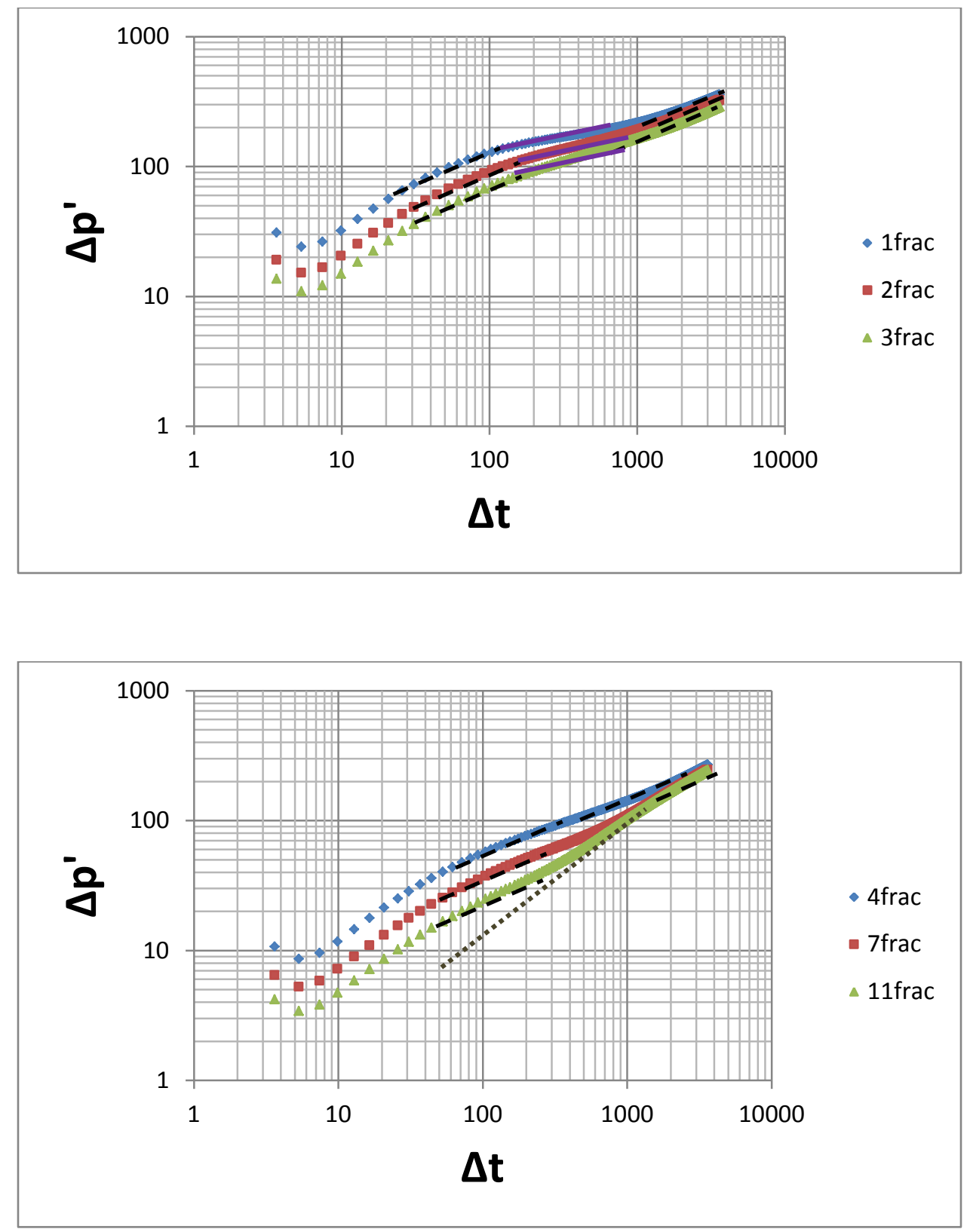

Horizontal well length $4000 \mathrm{ft}$

$\checkmark$ Case 2.9: $\mathrm{xf}=500 \mathrm{ft}$, width of fracture $=0.01$ in , permeability of fracture $=10000$, porosity of fracture $=0.2$ 

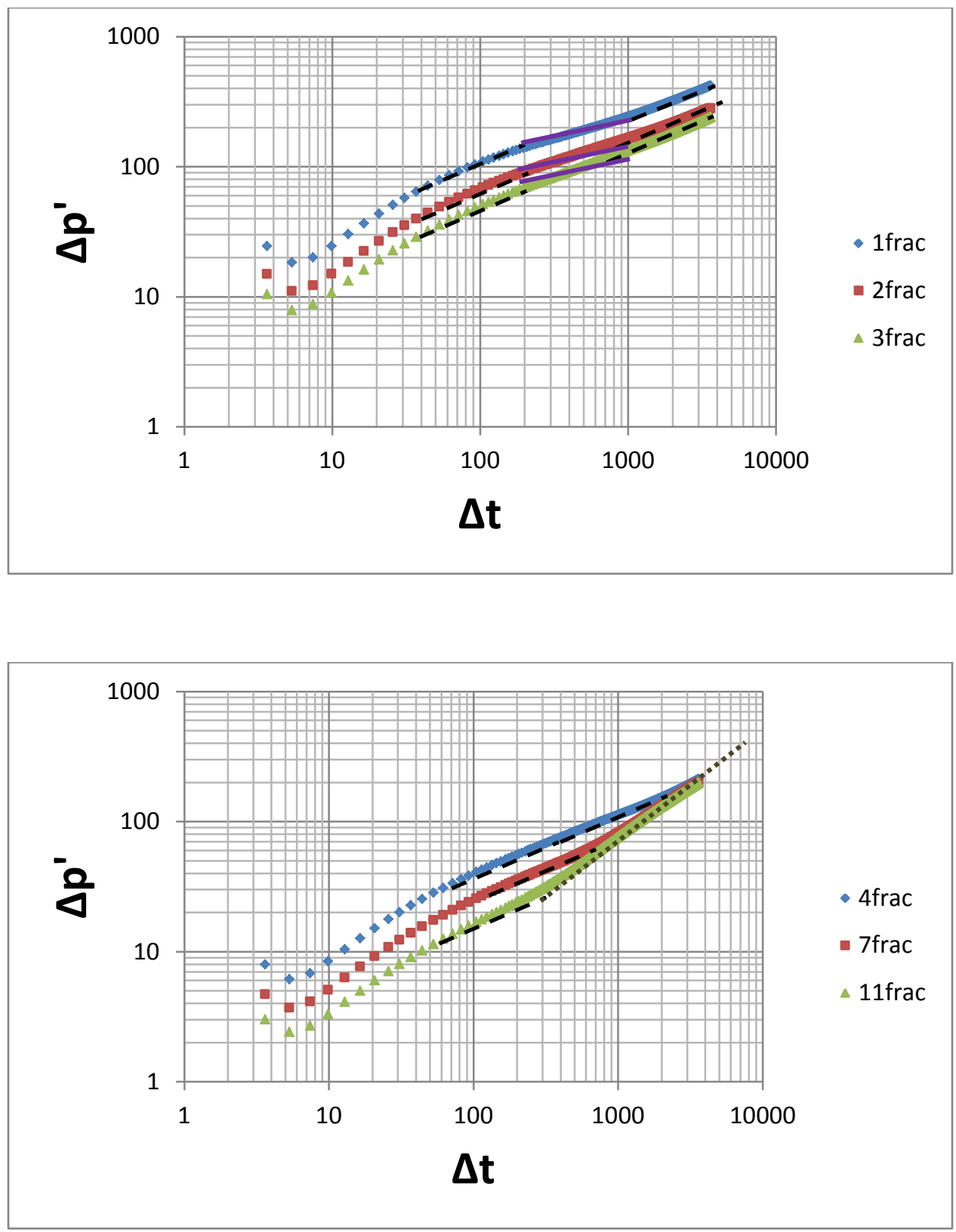

$\checkmark$ Case 2.10: $x f=500 \mathrm{ft}$, width of fracture $=0.1$ in ,permeability of fracture $=10000$, porosity of fracture $=0.2$ 

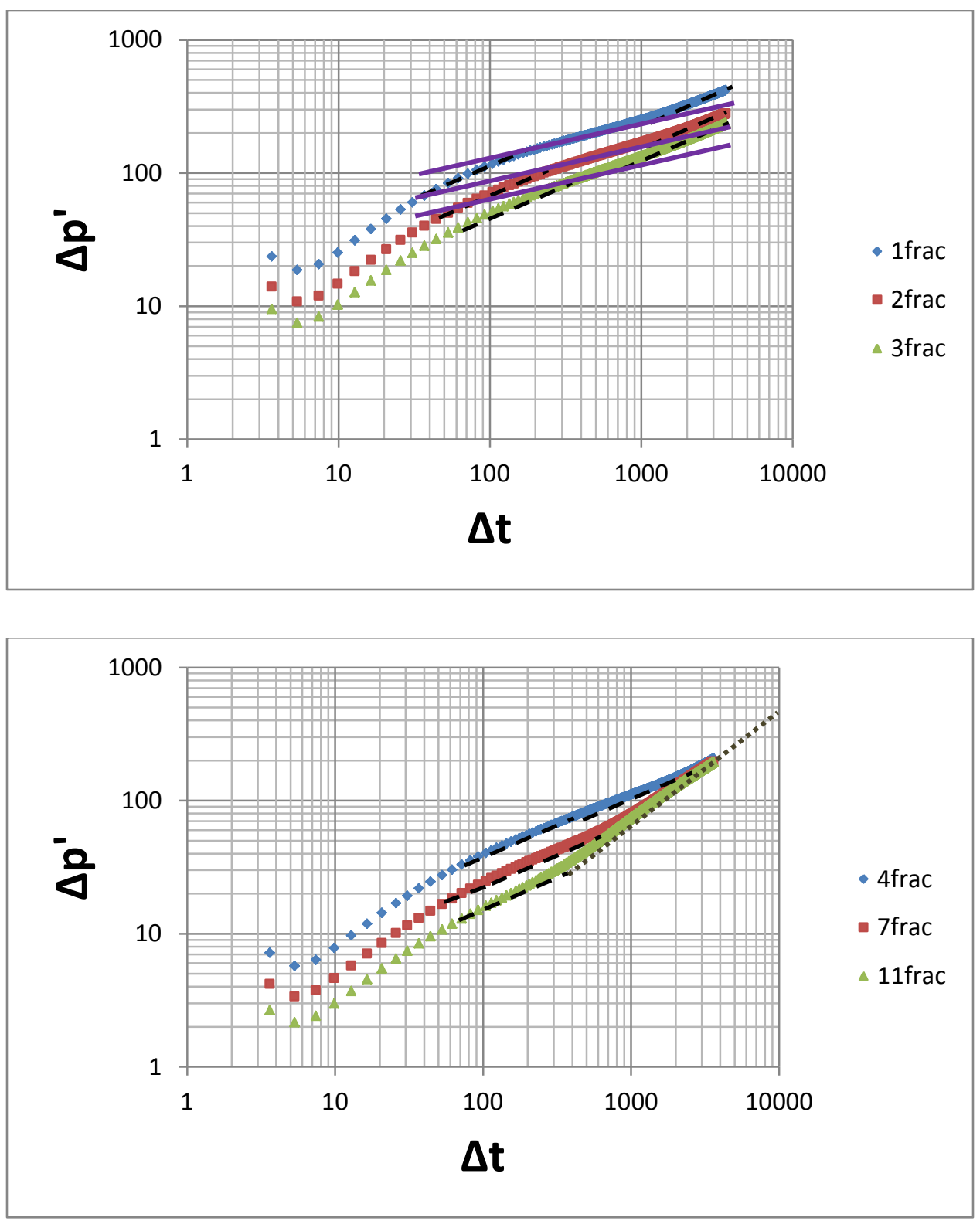

$\checkmark$ Case 2.11: $\mathrm{xf}=500 \mathrm{ft}$, width of fracture $=0.01$ in ,permeability of fracture $=40000$, porosity of fracture $=0.2$ 

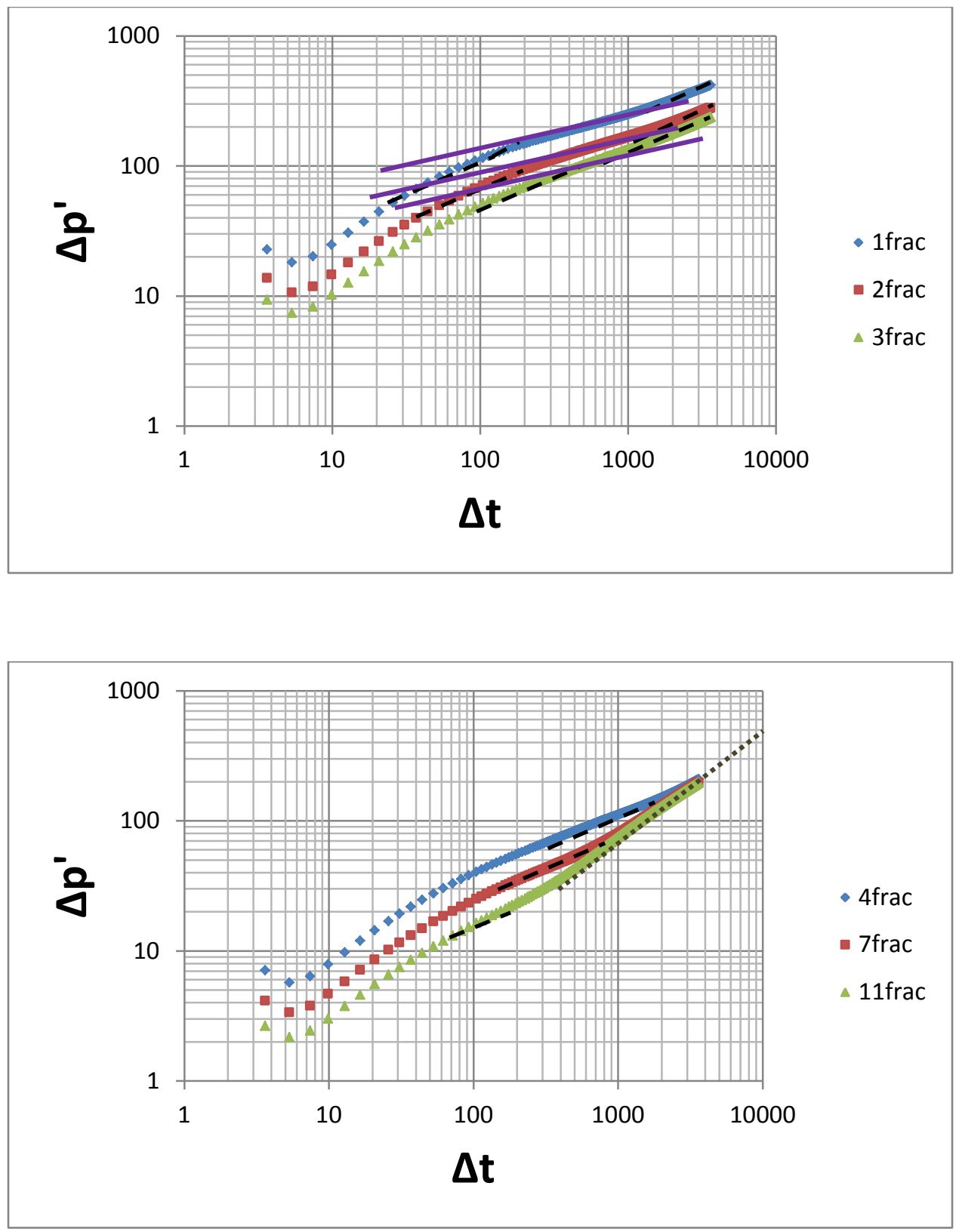

$\checkmark$ Case 2.12: $\mathrm{xf}=500 \mathrm{ft}$, width of fracture $=0.1$ in ,permeability of fracture $=40000$, porosity of fracture $=0.2$ 

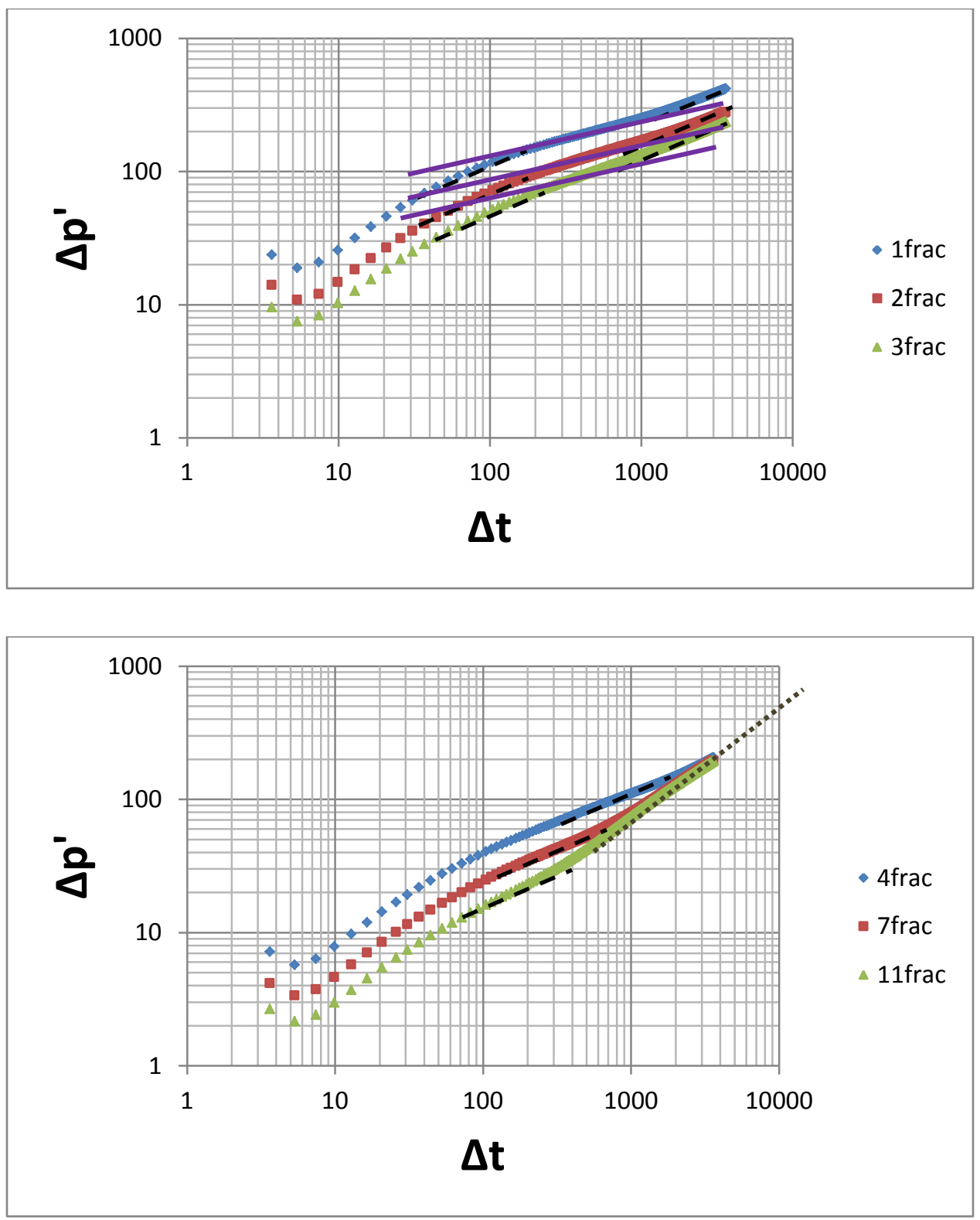

Horizontal well length $3500 \mathrm{ft}$

$\checkmark$ Case 2.13: $\mathrm{xf}=500 \mathrm{ft}$, width of fracture $=0.01$ in , permeability of fracture $=10000$, porosity of fracture $=0.2$ 

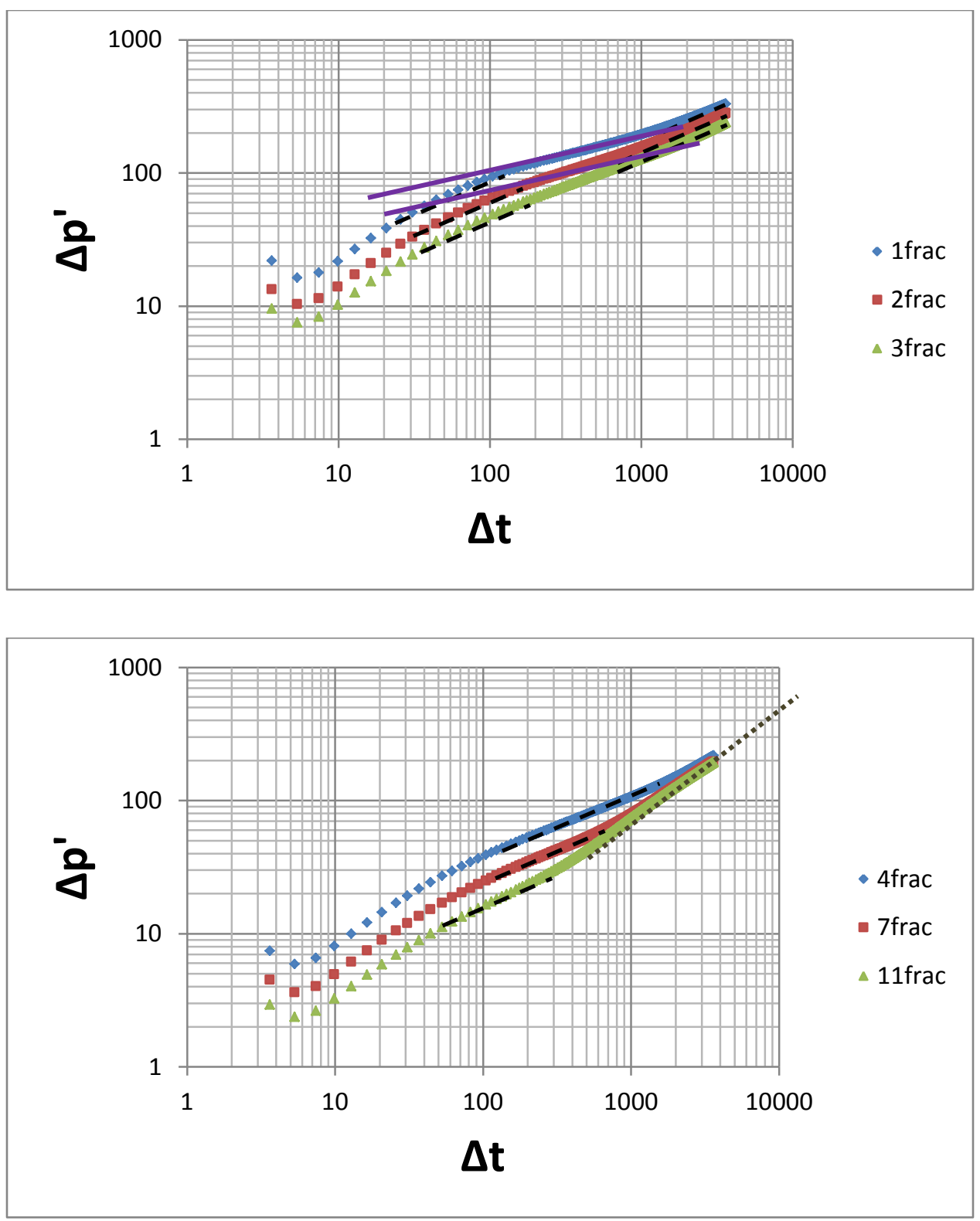

$\checkmark$ Case 2.14: $x f=500 \mathrm{ft}$, width of fracture $=0.1$ in ,permeability of fracture $=10000$, porosity of fracture $=0.2$ 

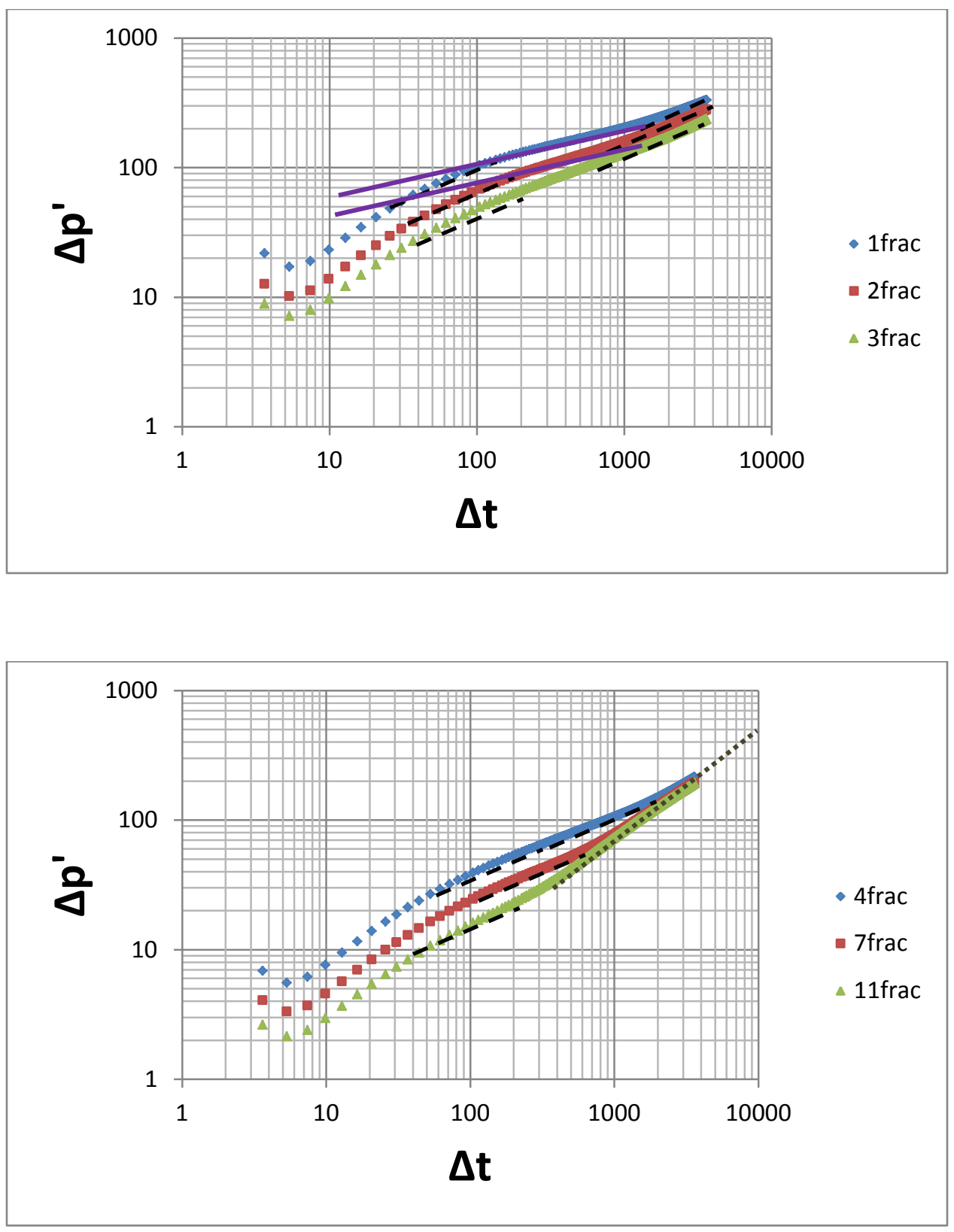

$\checkmark$ Case 2.15: $\mathrm{xf}=500 \mathrm{ft}$, width of fracture $=0.01$ in ,permeability of fracture $=40000$, porosity of fracture $=0.2$ 

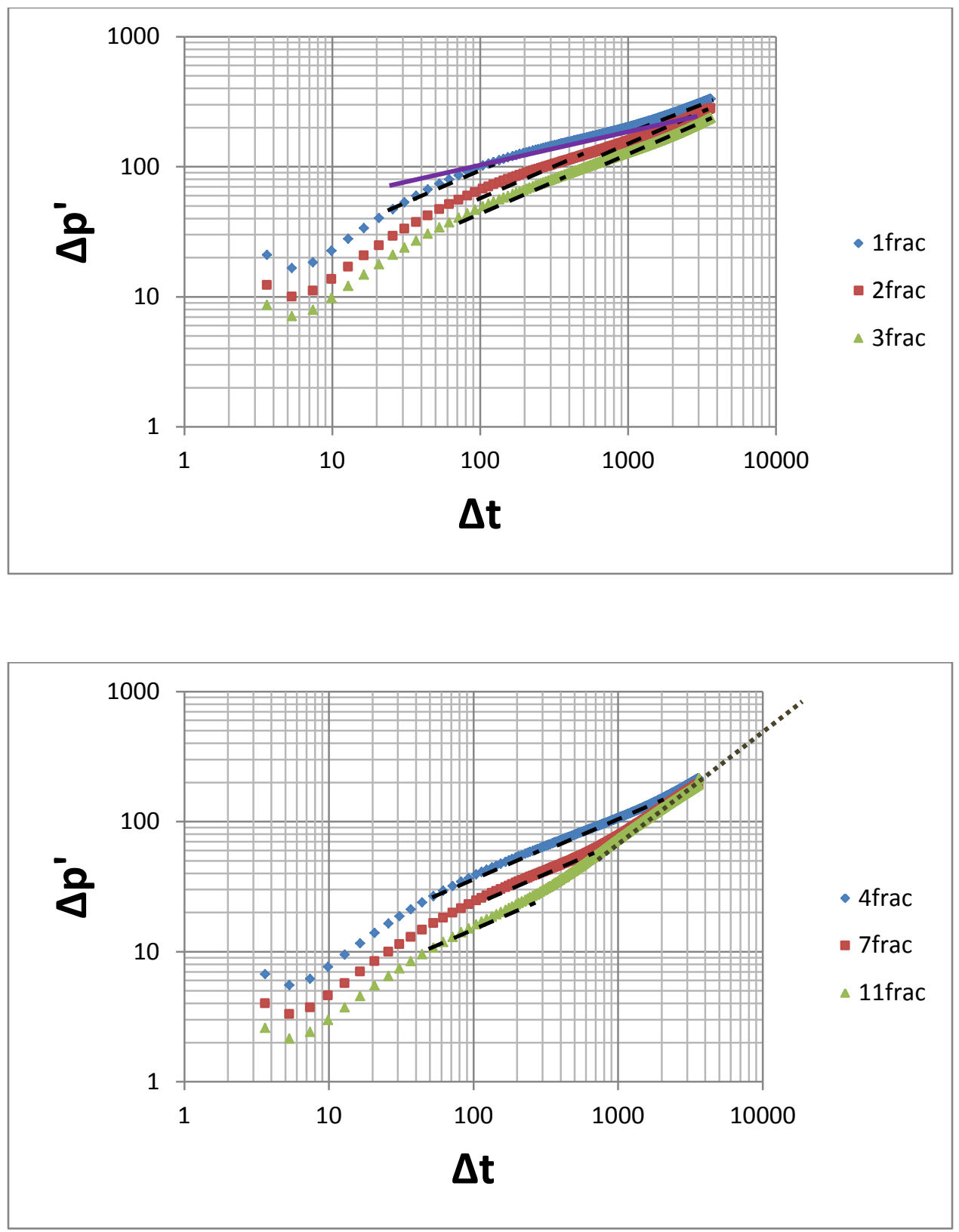

$\checkmark$ Case 2.16: $\mathrm{xf}=500 \mathrm{ft}$, width of fracture $=0.1$ in ,permeability of fracture $=40000$, porosity of fracture $=0.2$ 

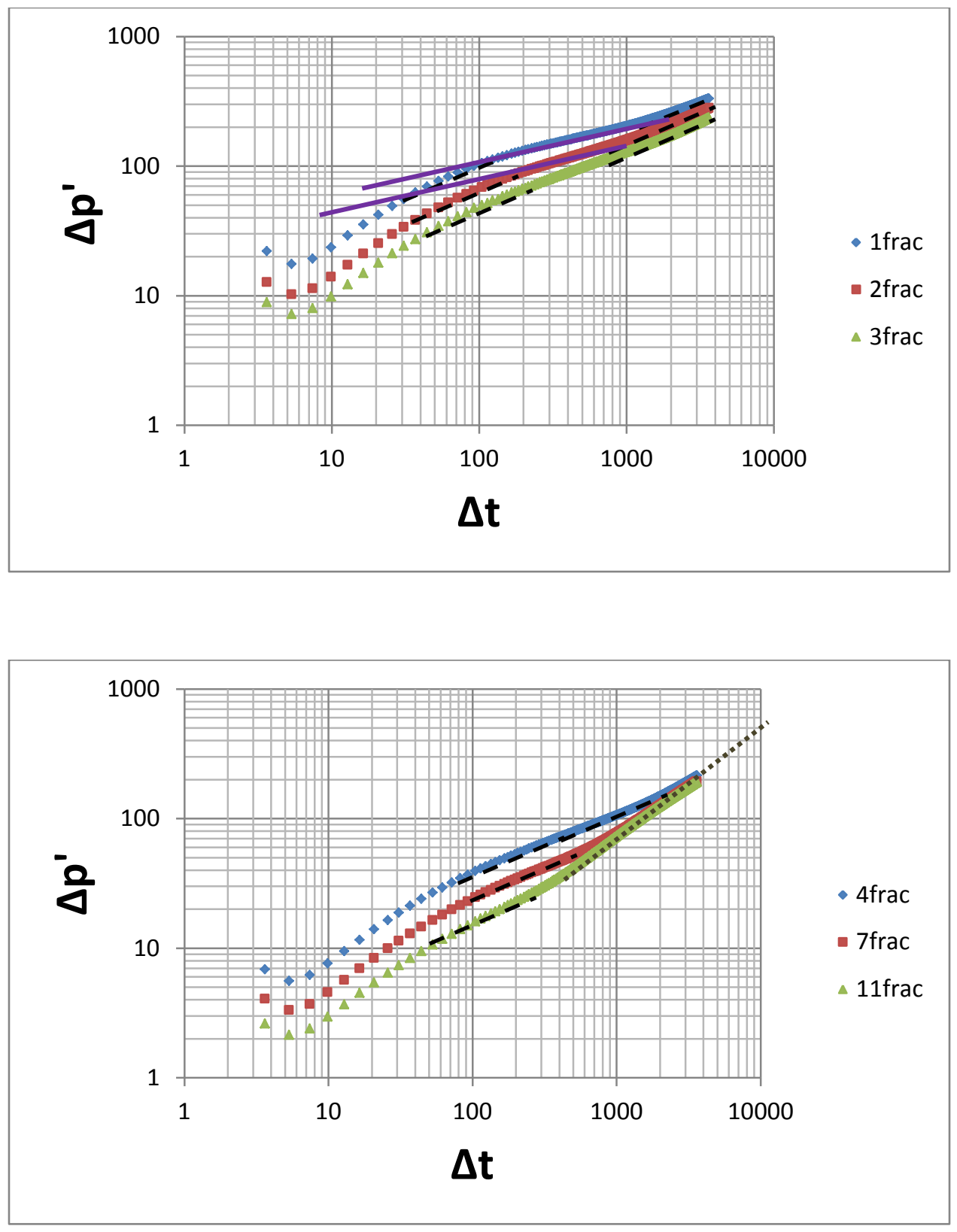


\section{Appendix 3}

Case 3: Fracture porosity fraction $=0.002$

Bulk permeability $i, j, k(m d)=0.003,0.003,0.0003$

Horizontal well length $4000 \mathrm{ft}$

$\checkmark$ Case 3.1: $\mathrm{xf}=300 \mathrm{ft}$, width of fracture $=0.01$ in ,permeability of fracture $=10000$, porosity of fracture $=0.2$
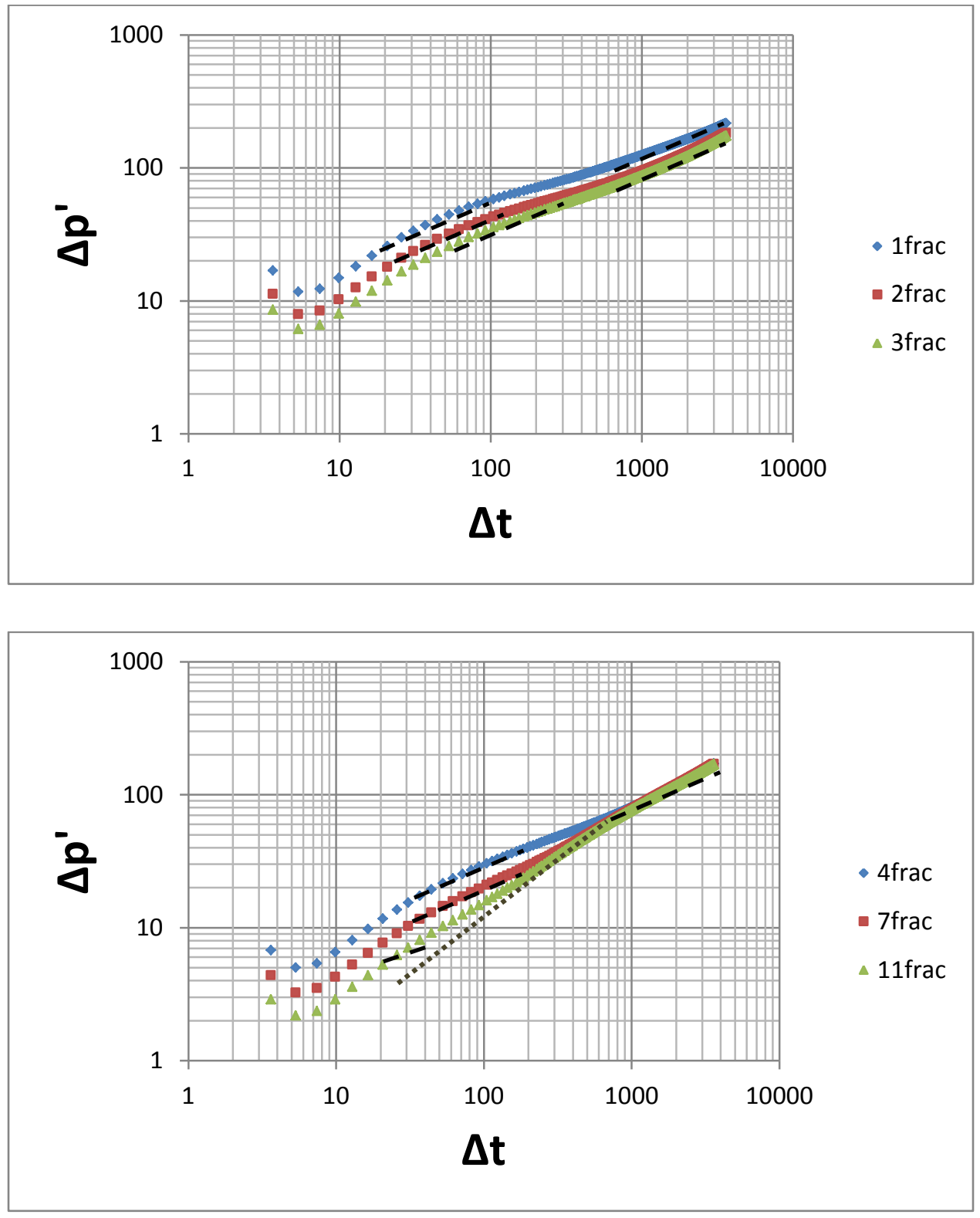
$\checkmark$ Case 3.2: $x f=300 \mathrm{ft}$, width of fracture $=0.1$ in ,permeability of fracture $=10000$, porosity
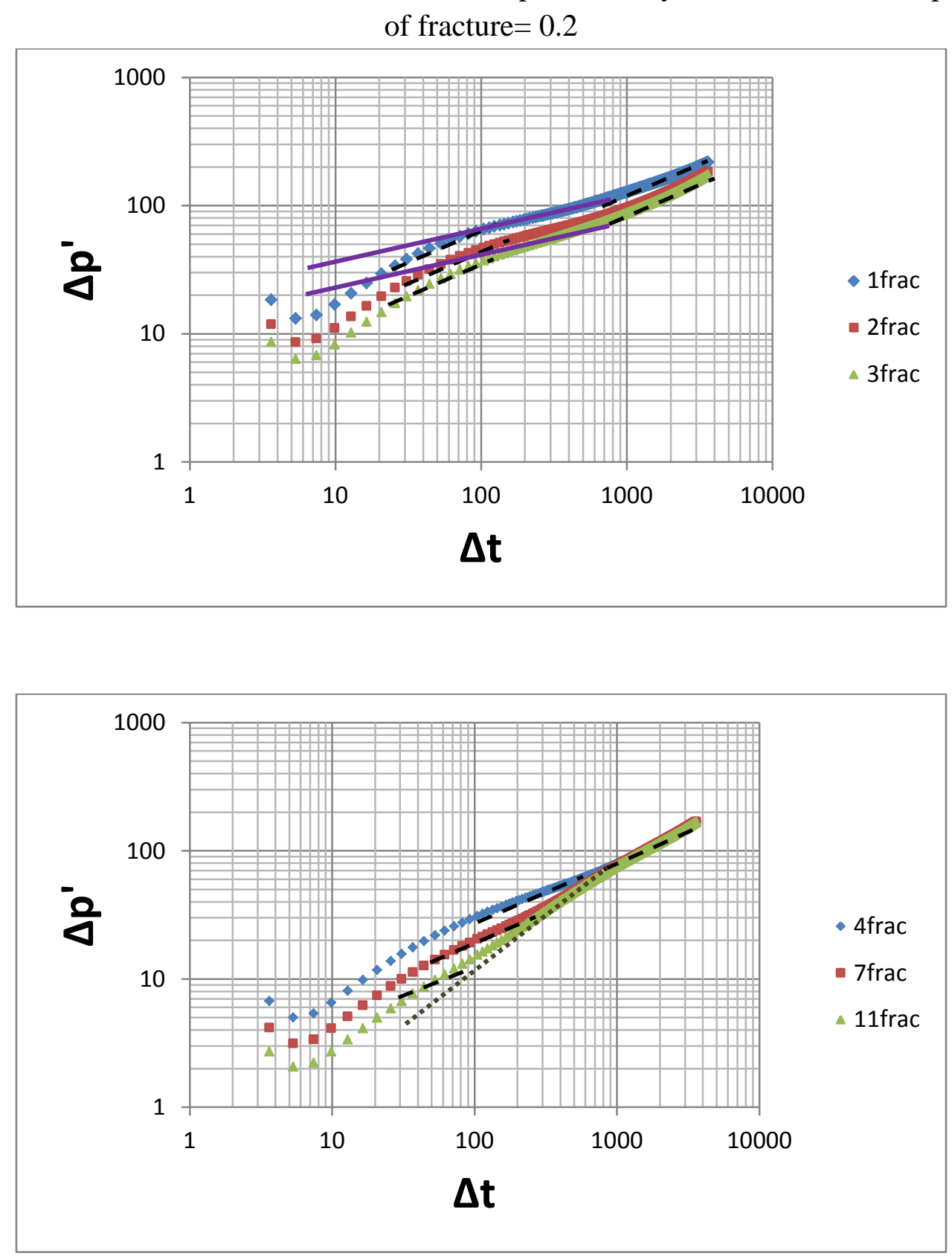

$\checkmark$ Case 3.3: $x f=300 \mathrm{ft}$, width of fracture $=0.01$ in ,permeability of fracture $=40000$, porosity of fracture $=0.2$ 

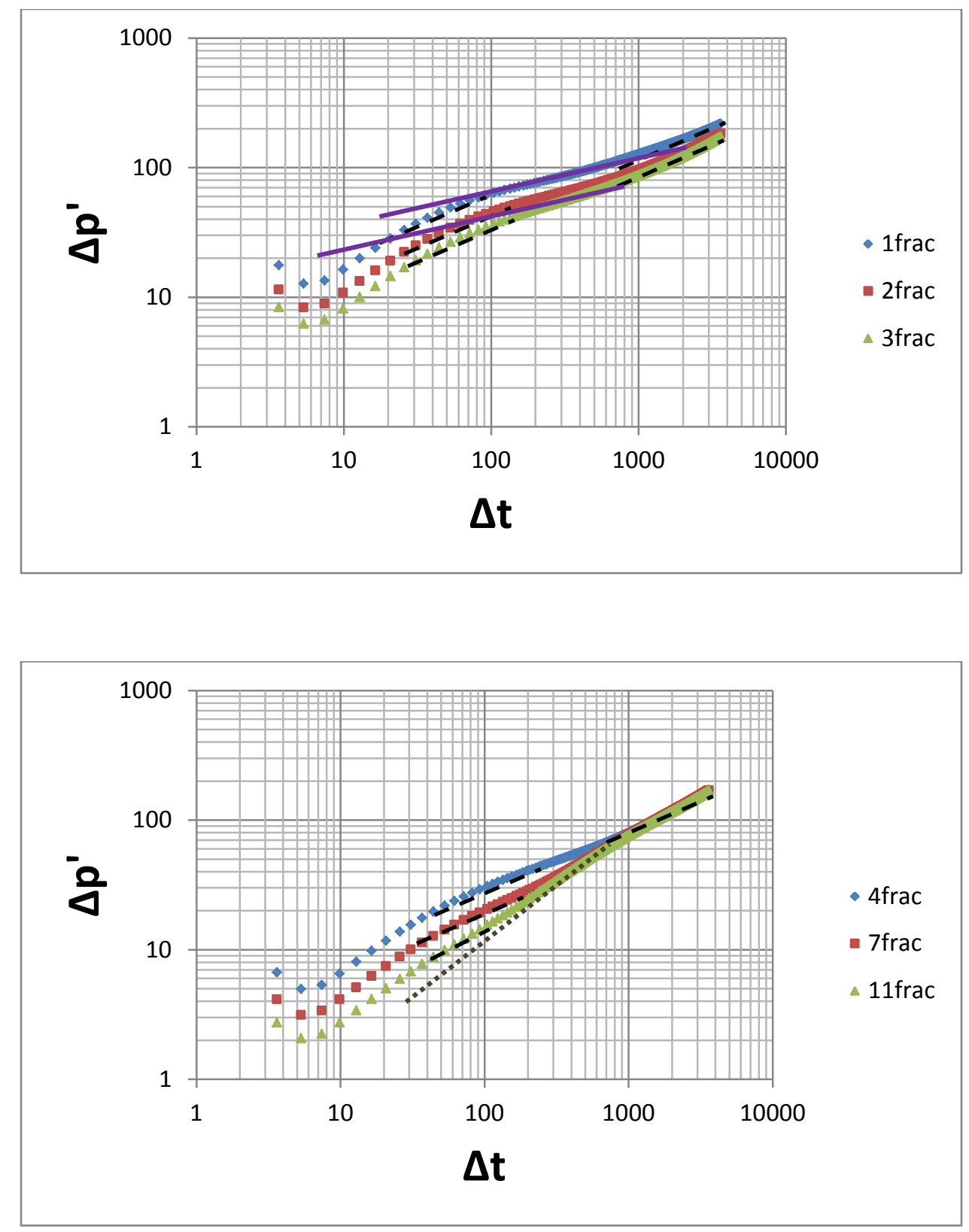

$\checkmark$ Case 3.4: $\mathrm{xf}=300 \mathrm{ft}$, width of fracture $=0.1$ in ,permeability of fracture $=40000$, porosity of fracture $=0.2$ 

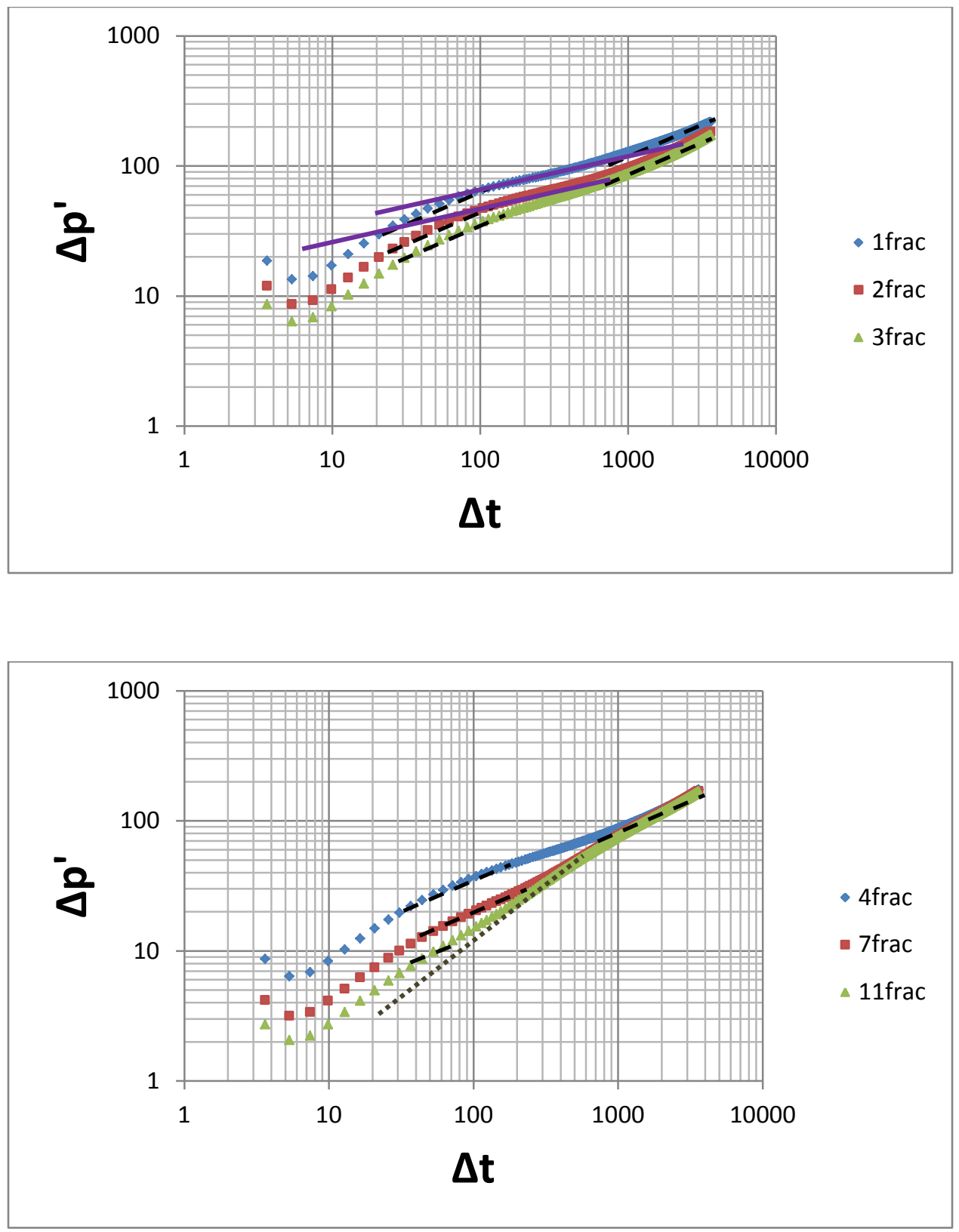

Horizontal well length $3500 \mathrm{ft}$

$\checkmark$ Case 3.5: $\mathrm{xf}=300 \mathrm{ft}$, width of fracture $=0.01$ in ,permeability of fracture $=10000$, porosity of fracture $=0.2$ 

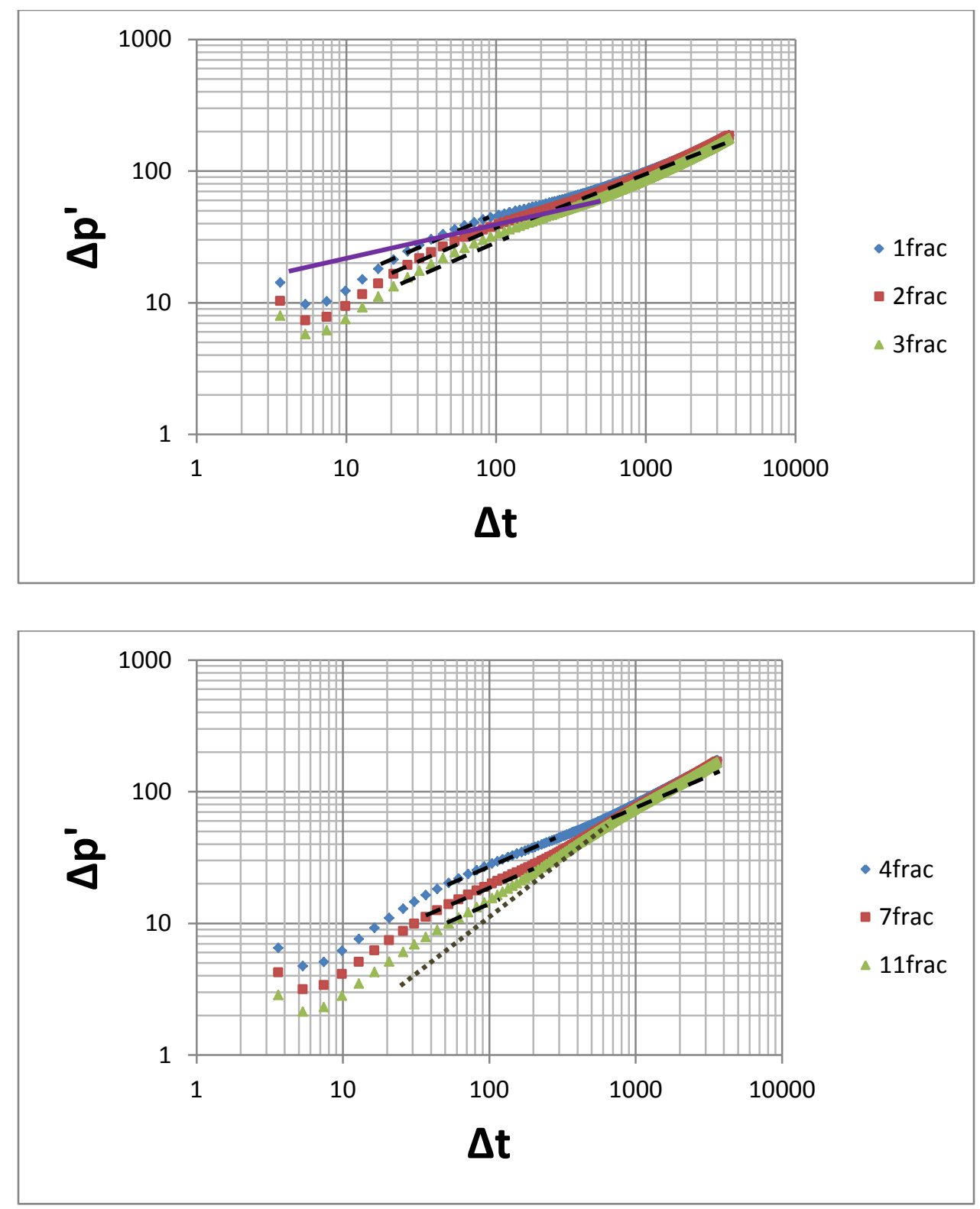

$\checkmark$ Case 3.6: $\mathrm{xf}=300 \mathrm{ft}$, width of fracture $=0.1$ in ,permeability of fracture $=10000$, porosity of fracture $=0.2$ 

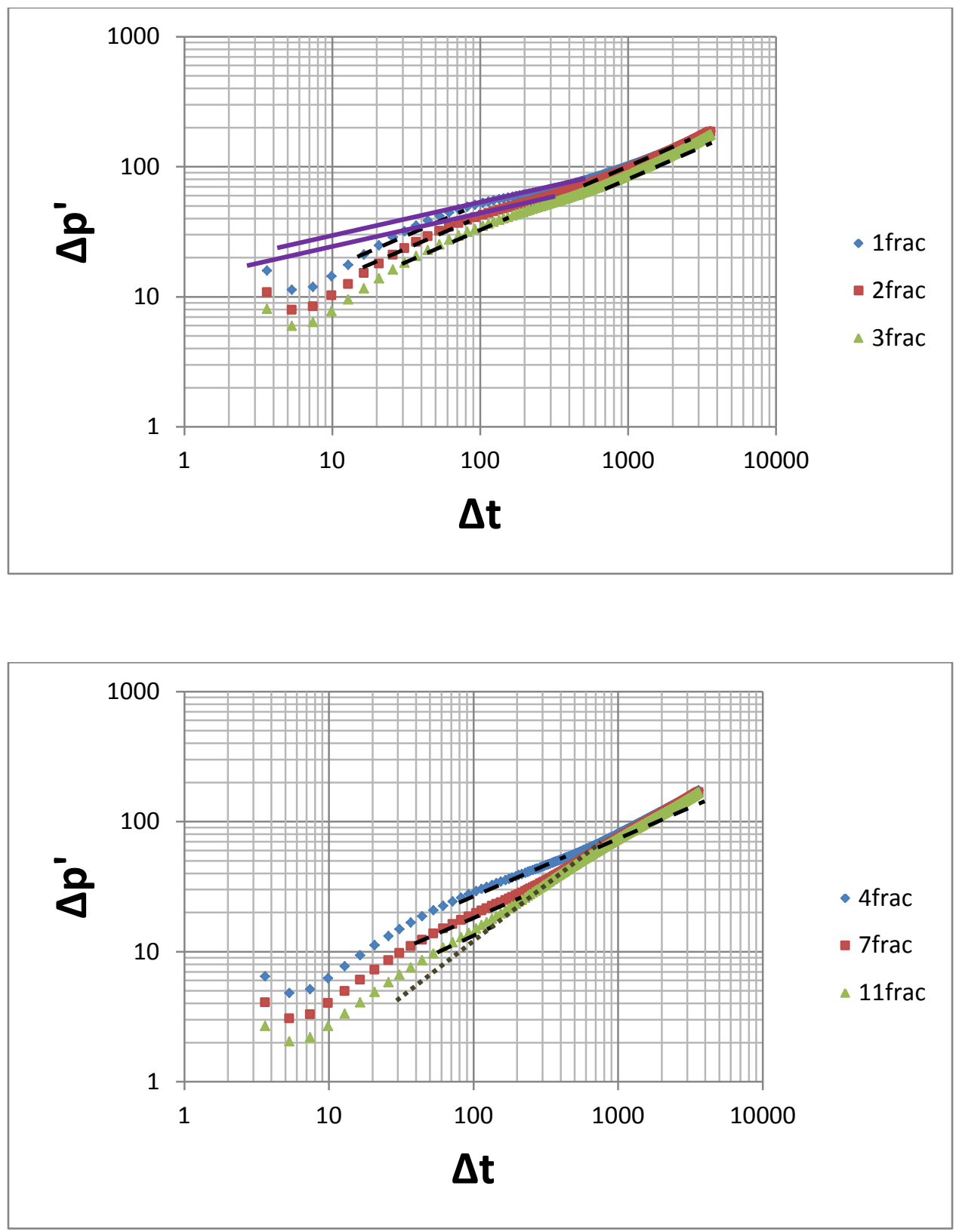

$\checkmark$ Case 3.7: $x f=300 \mathrm{ft}$, width of fracture $=0.01$ in ,permeability of fracture $=40000$, porosity of fracture $=0.2$ 


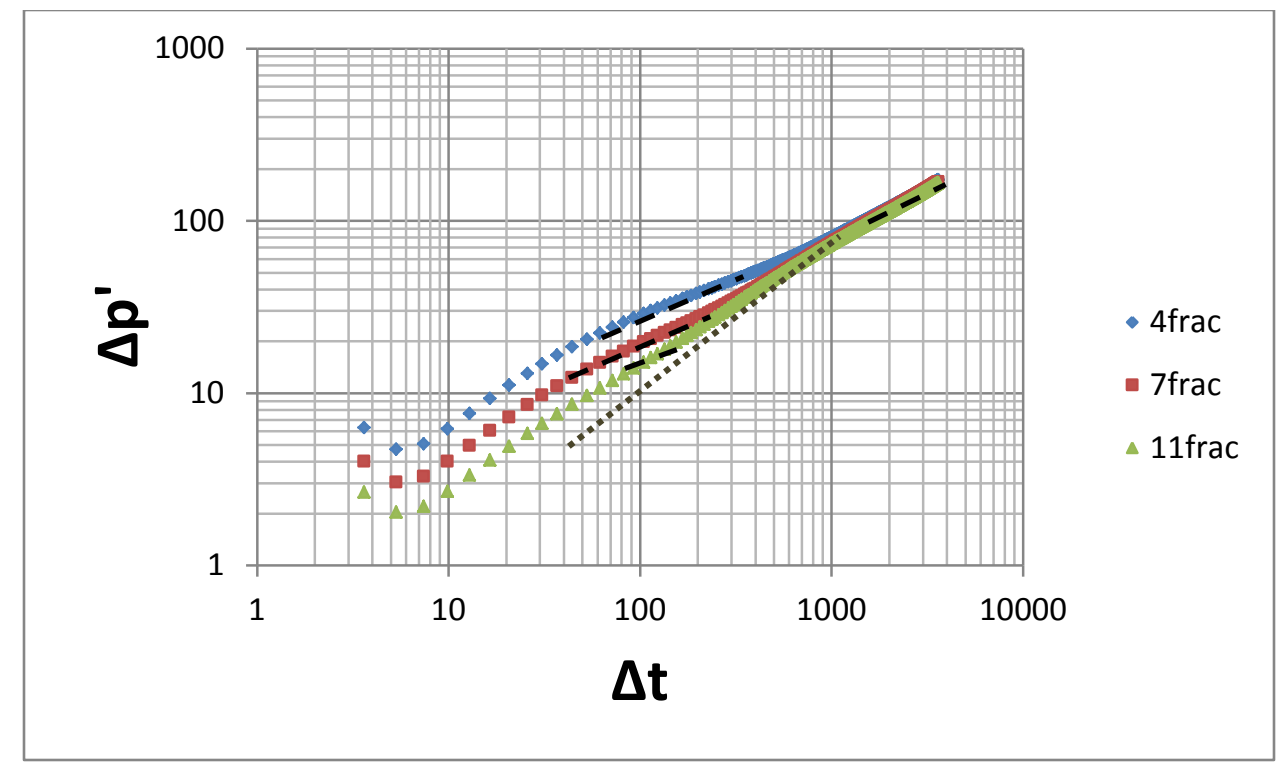

$\checkmark$ Case 3.8: $x f=300 \mathrm{ft}$, width of fracture $=0.1$ in ,permeability of fracture $=40000$, porosity of fracture $=0.2$

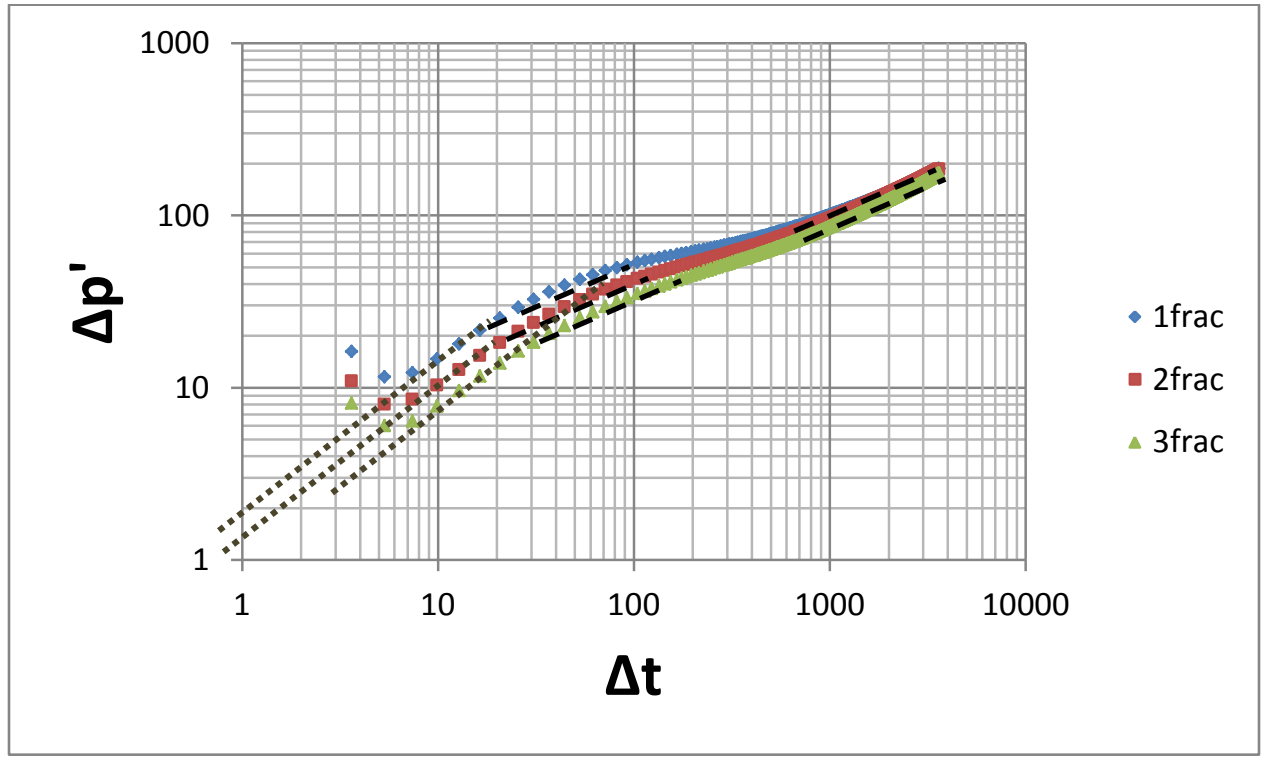




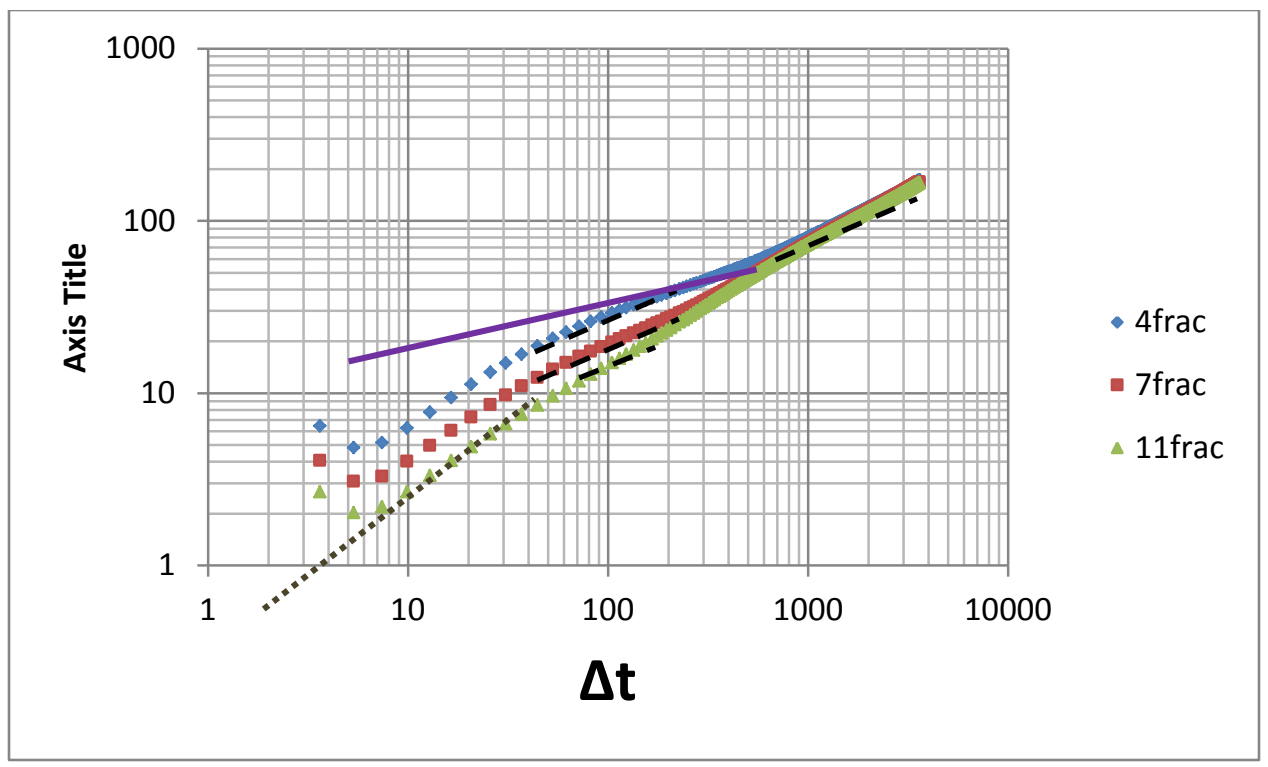

Horizontal well length $4000 \mathrm{ft}$

$\checkmark$ Case 3.9: $\mathrm{xf}=500 \mathrm{ft}$, width of fracture $=0.01$ in ,permeability of fracture $=10000$, porosity of fracture $=0.2$

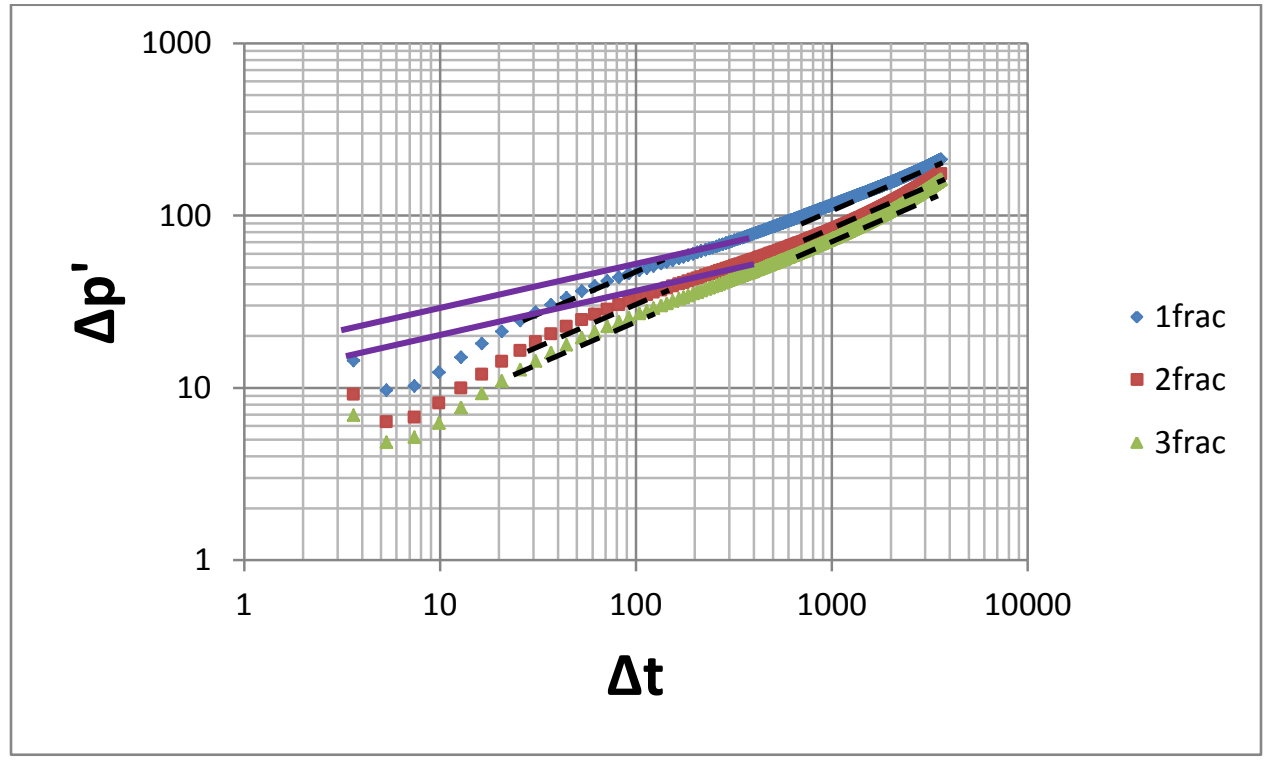




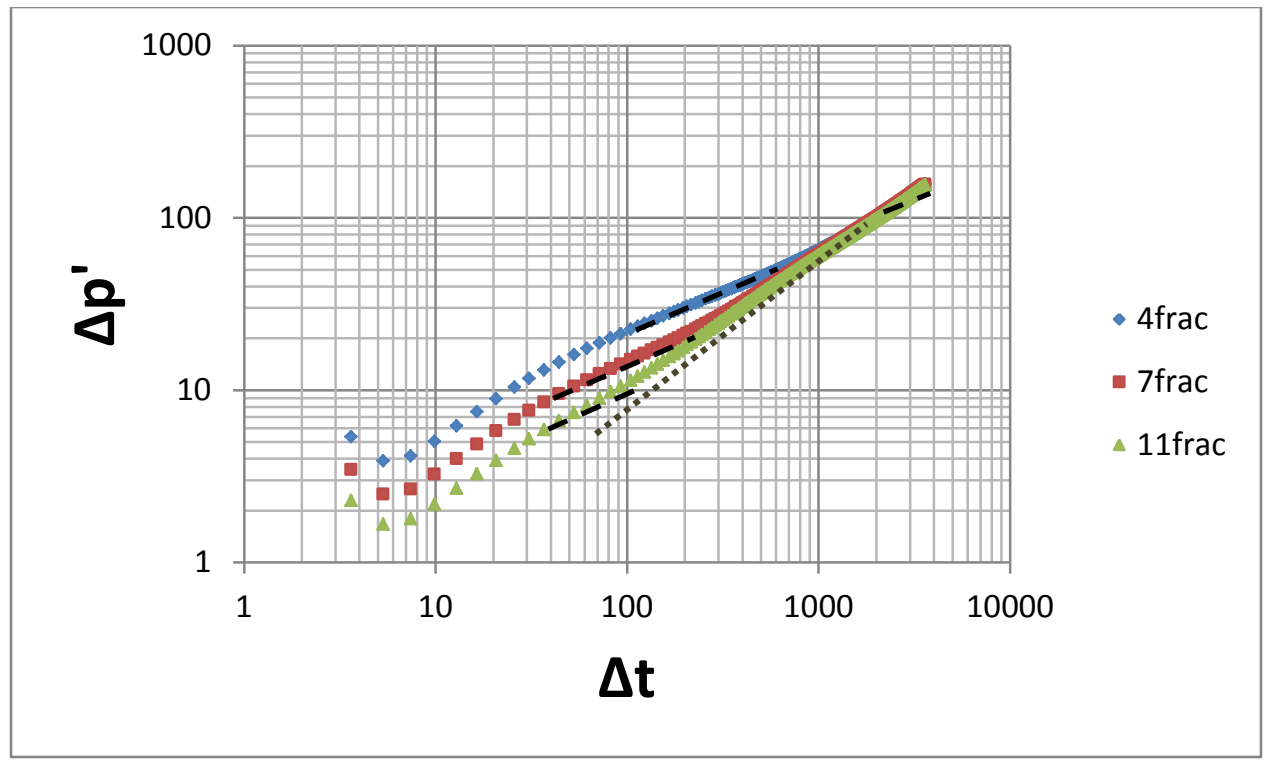

$\checkmark$ Case 3.10: $\mathrm{xf}=500 \mathrm{ft}$, width of fracture $=0.1$ in ,permeability of fracture $=10000$, porosity of fracture $=0.2$

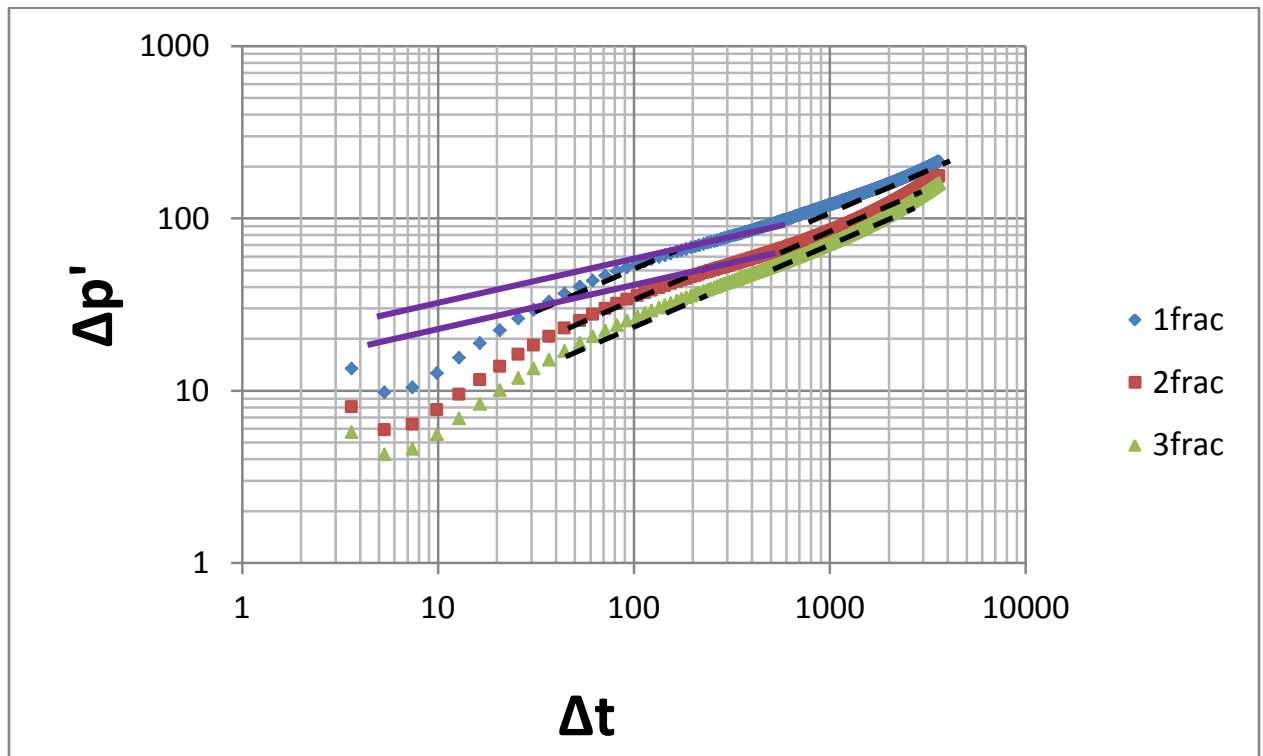




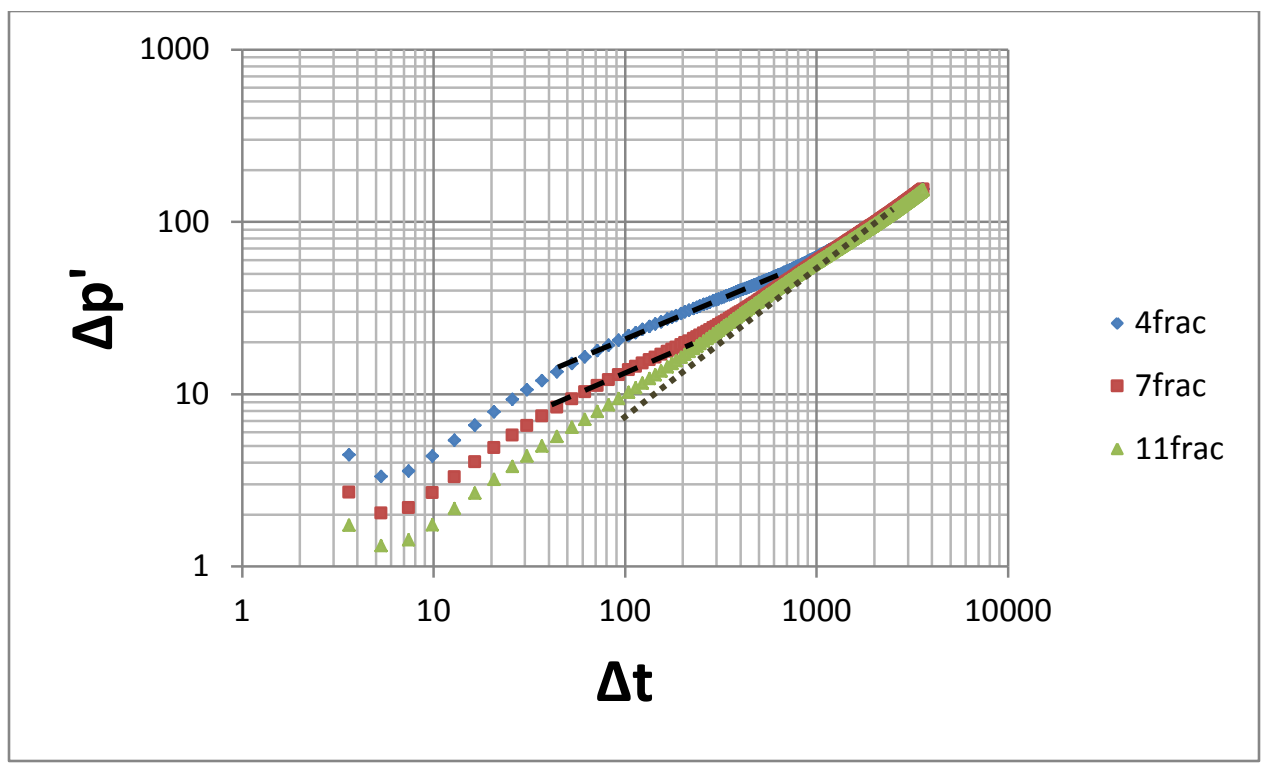

$\checkmark$ Case 3.11: $\mathrm{xf}=500 \mathrm{ft}$, width of fracture $=0.01$ in ,permeability of fracture $=40000$, porosity of fracture $=0.2$

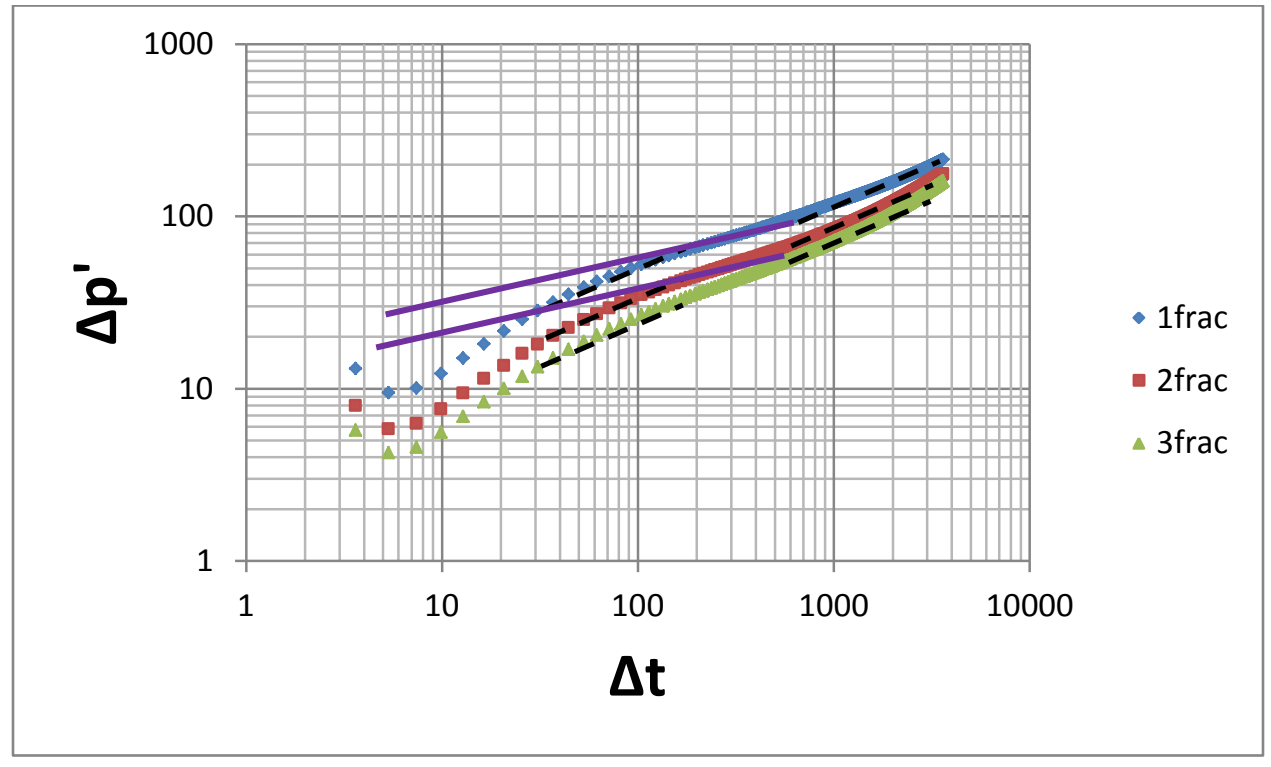




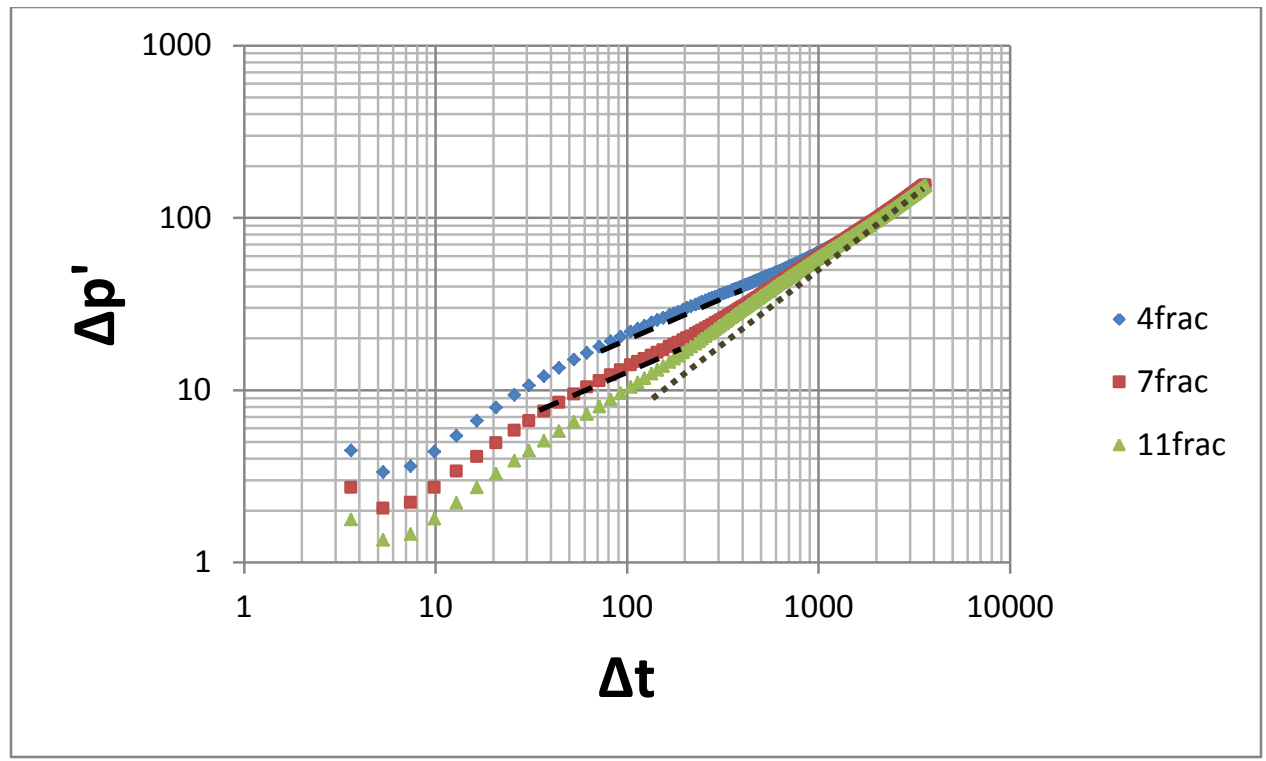

$\checkmark$ Case 3.12: $\mathrm{xf}=500 \mathrm{ft}$, width of fracture $=0.1$ in ,permeability of fracture $=40000$, porosity of fracture $=0.2$

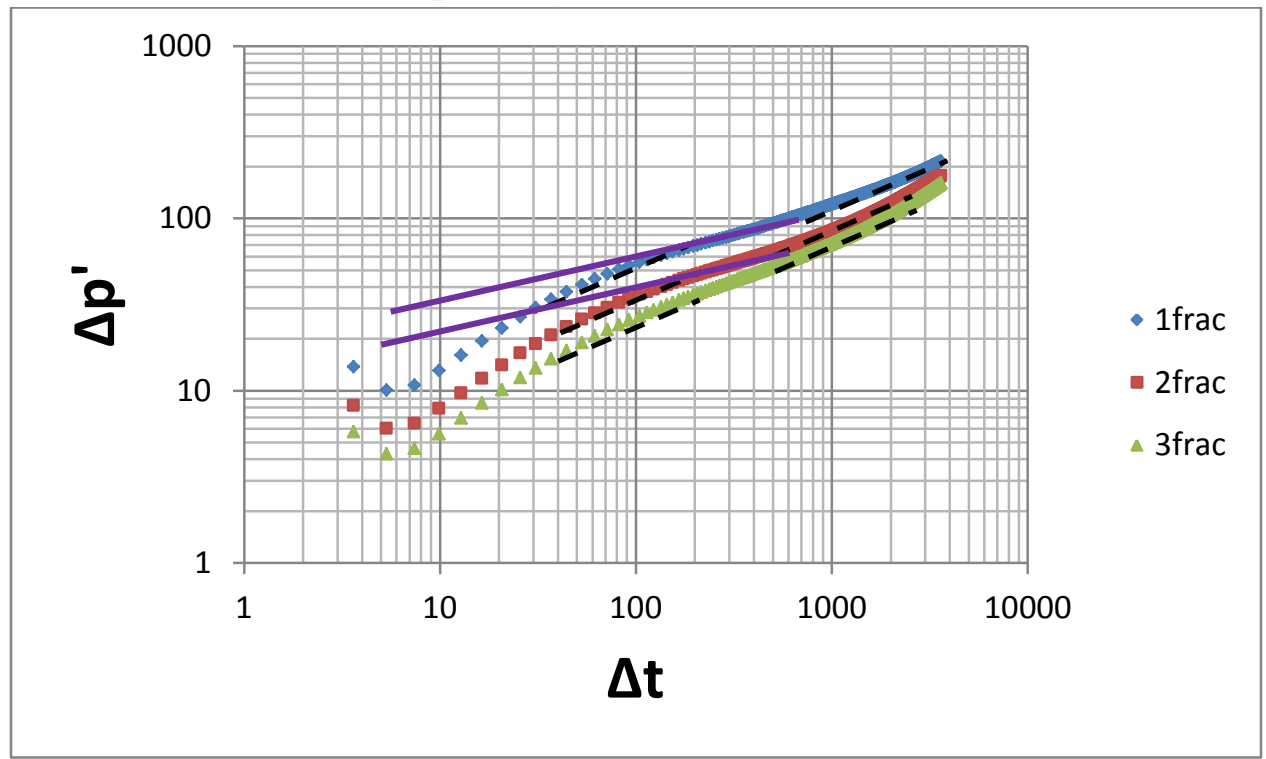




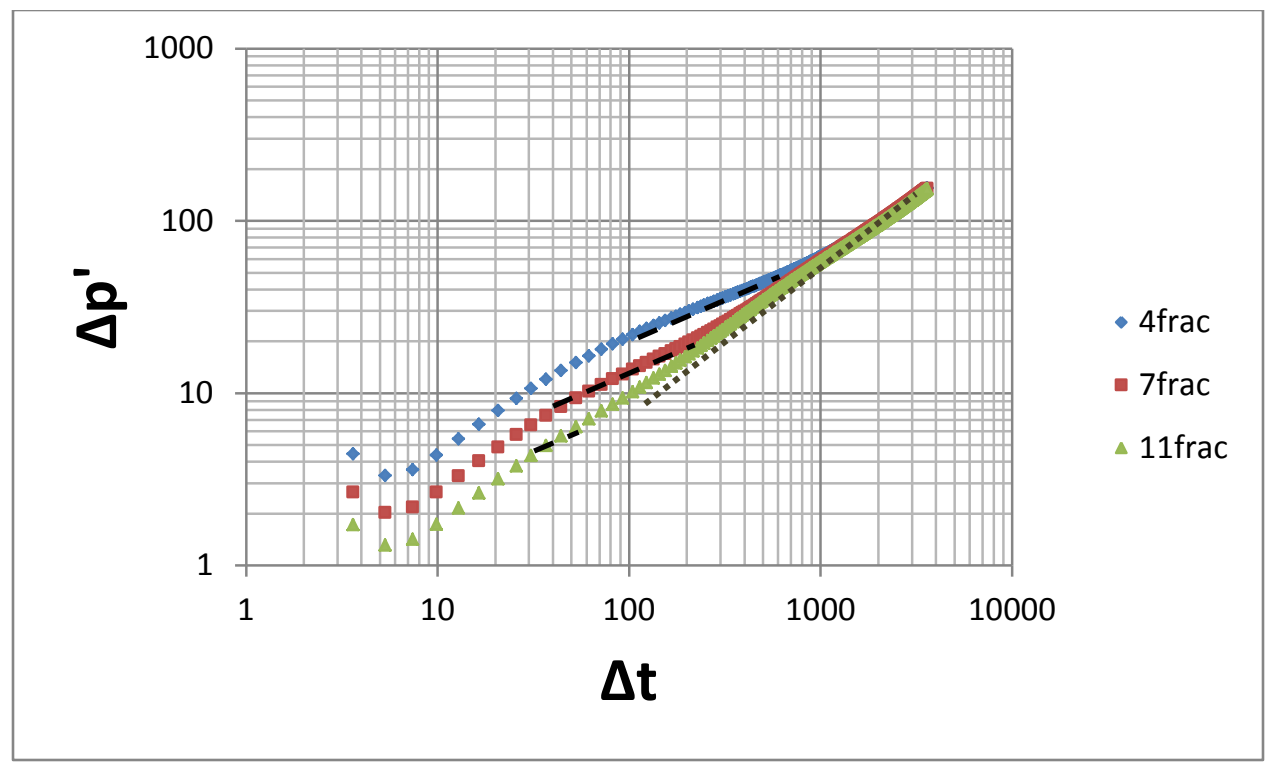

Horizontal well length $4000 \mathrm{ft}$

$\checkmark$ Case 3.13: $x f=500 \mathrm{ft}$, width of fracture $=0.01$ in , permeability of fracture $=10000$, porosity of fracture $=0.2$

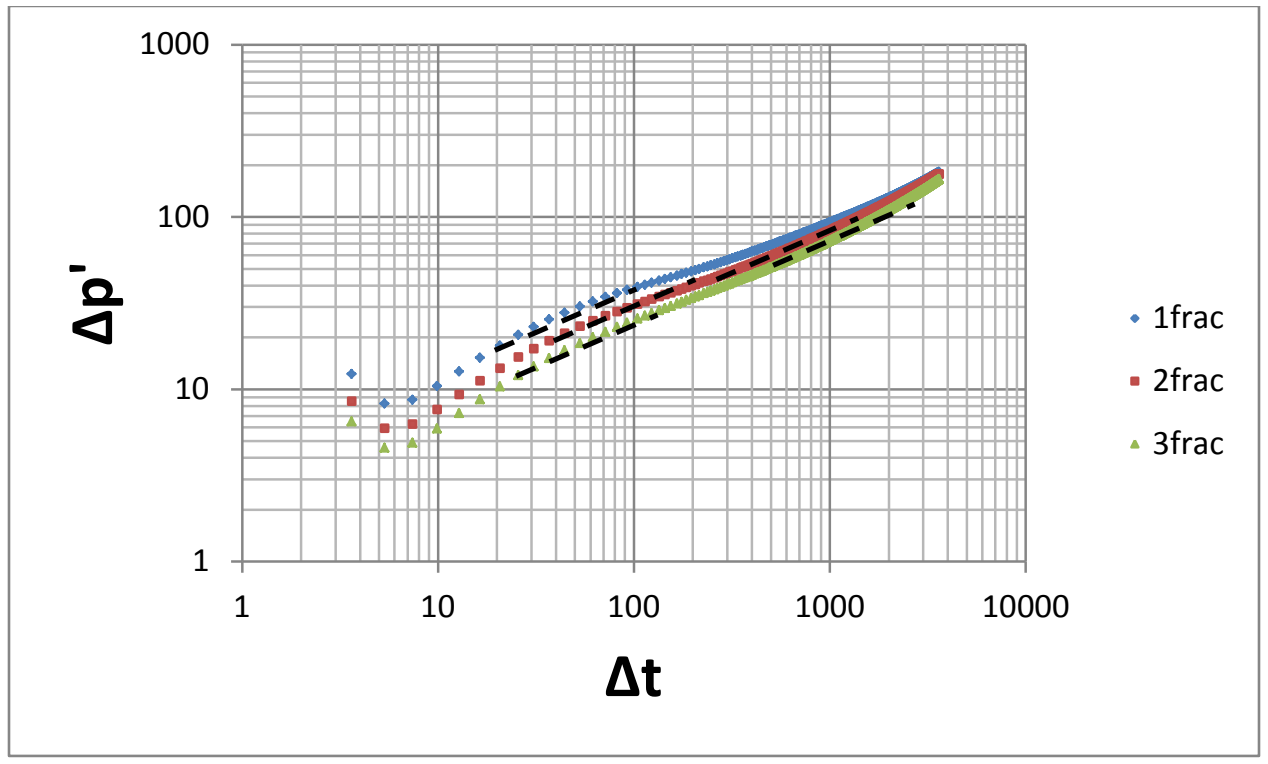




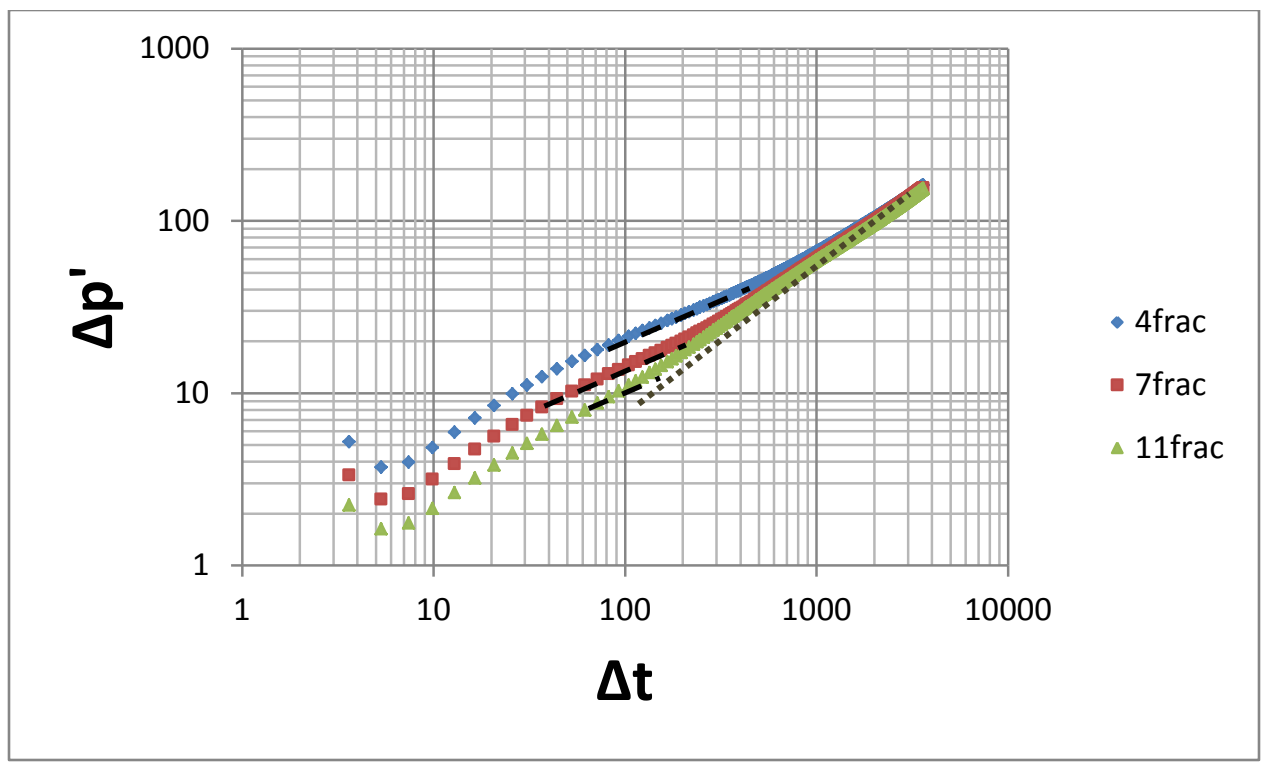

$\checkmark$ Case 3.14: $\mathrm{xf}=500 \mathrm{ft}$, width of fracture $=0.1$ in ,permeability of fracture $=10000$, porosity of fracture $=0.2$

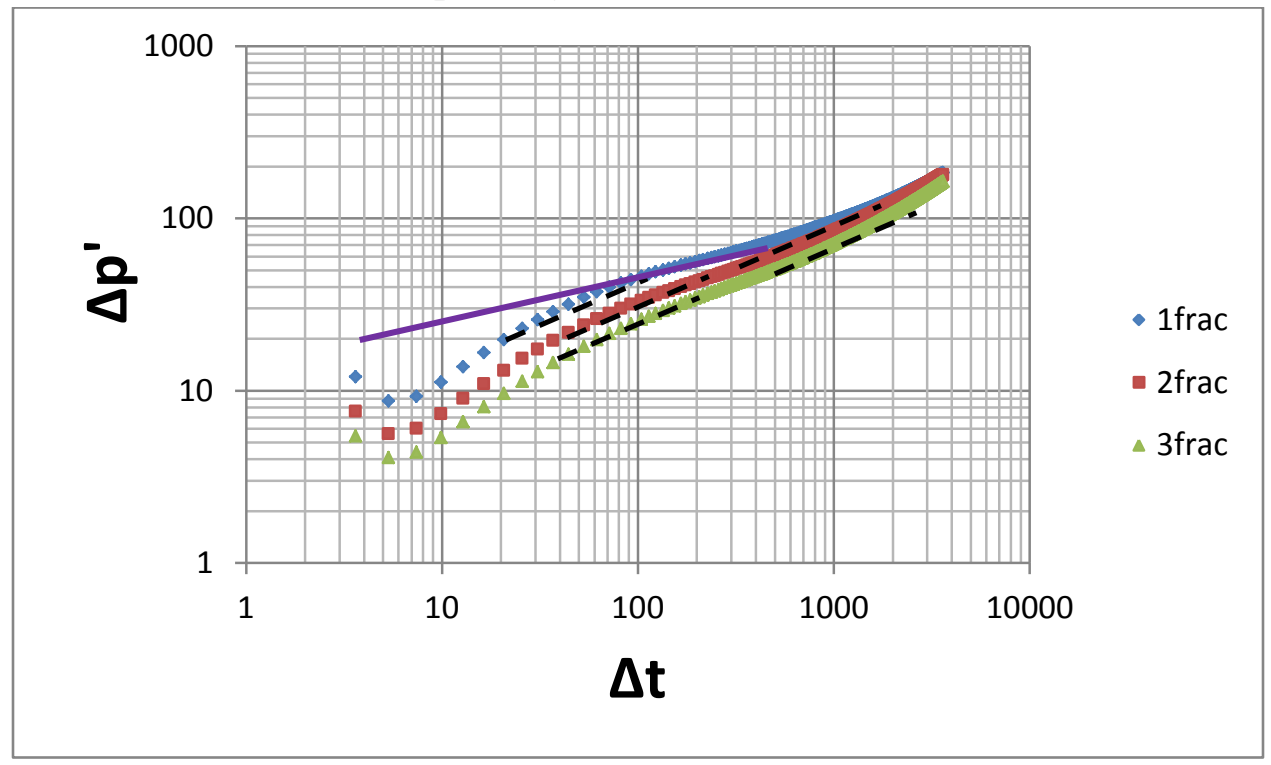




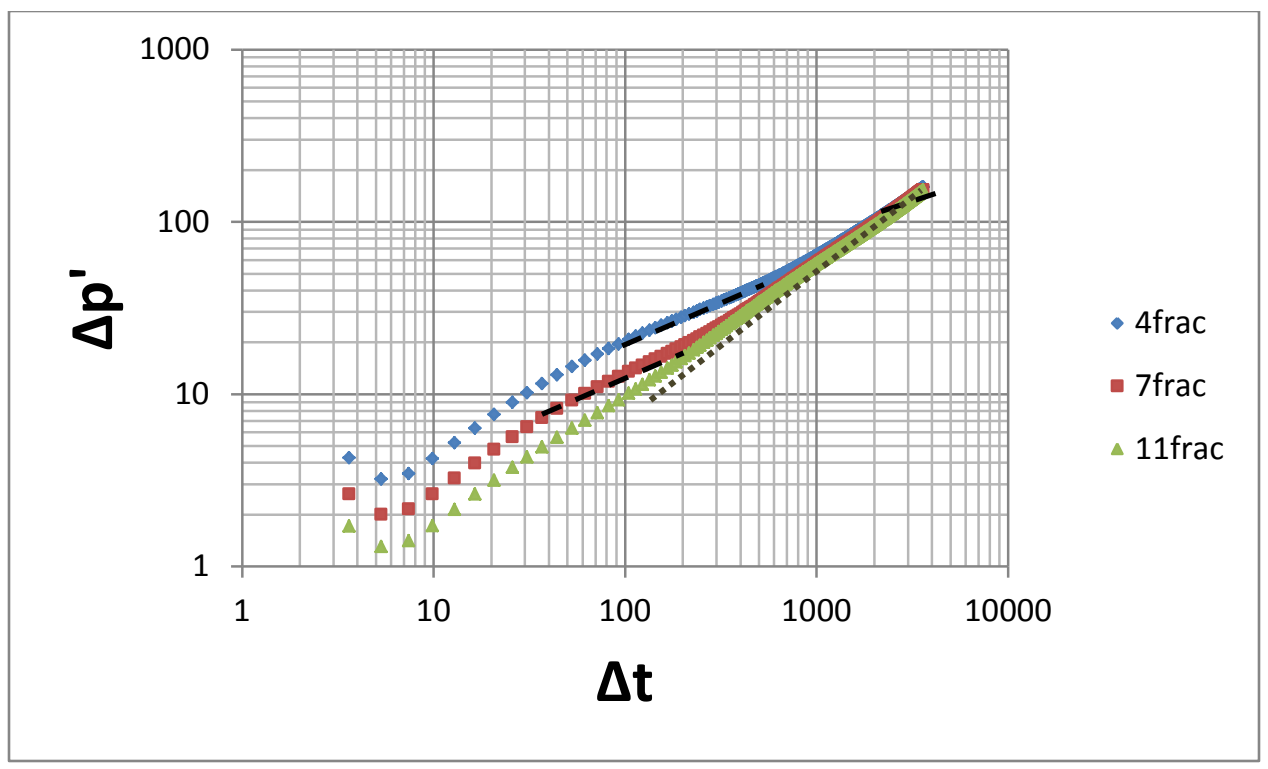

$\checkmark$ Case 3.15: $x f=500 \mathrm{ft}$, width of fracture $=0.01$ in , permeability of fracture $=40000$, porosity of fracture $=0.2$

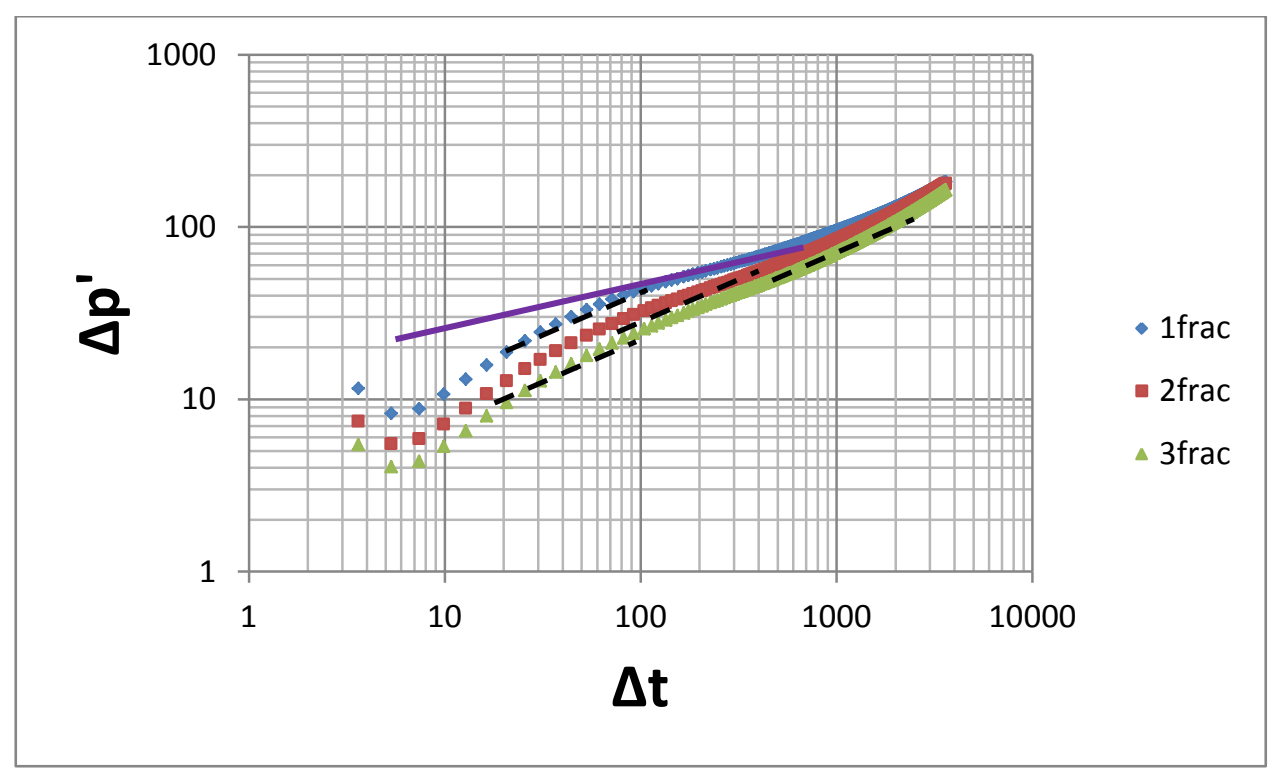




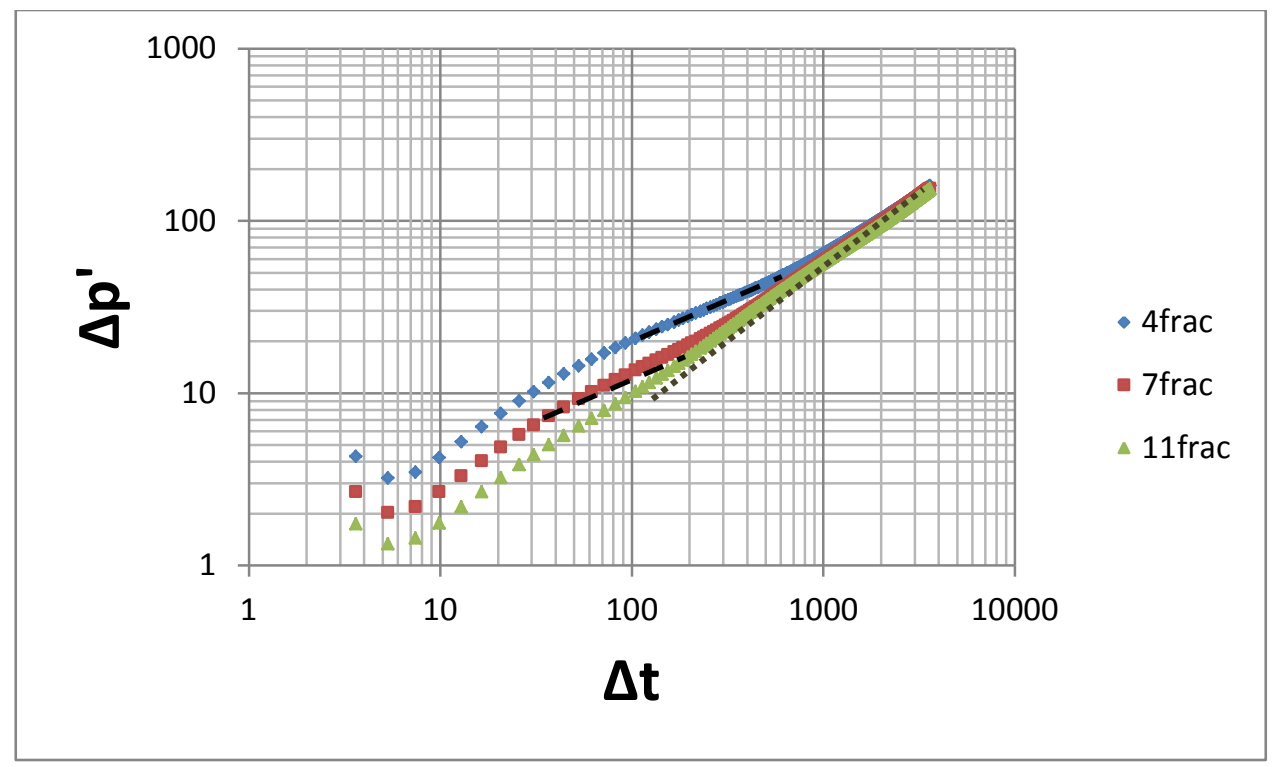

$\checkmark$ Case 3.16: $x f=500 \mathrm{ft}$, width of fracture $=0.1$ in ,permeability of fracture $=40000$, porosity of fracture $=0.2$

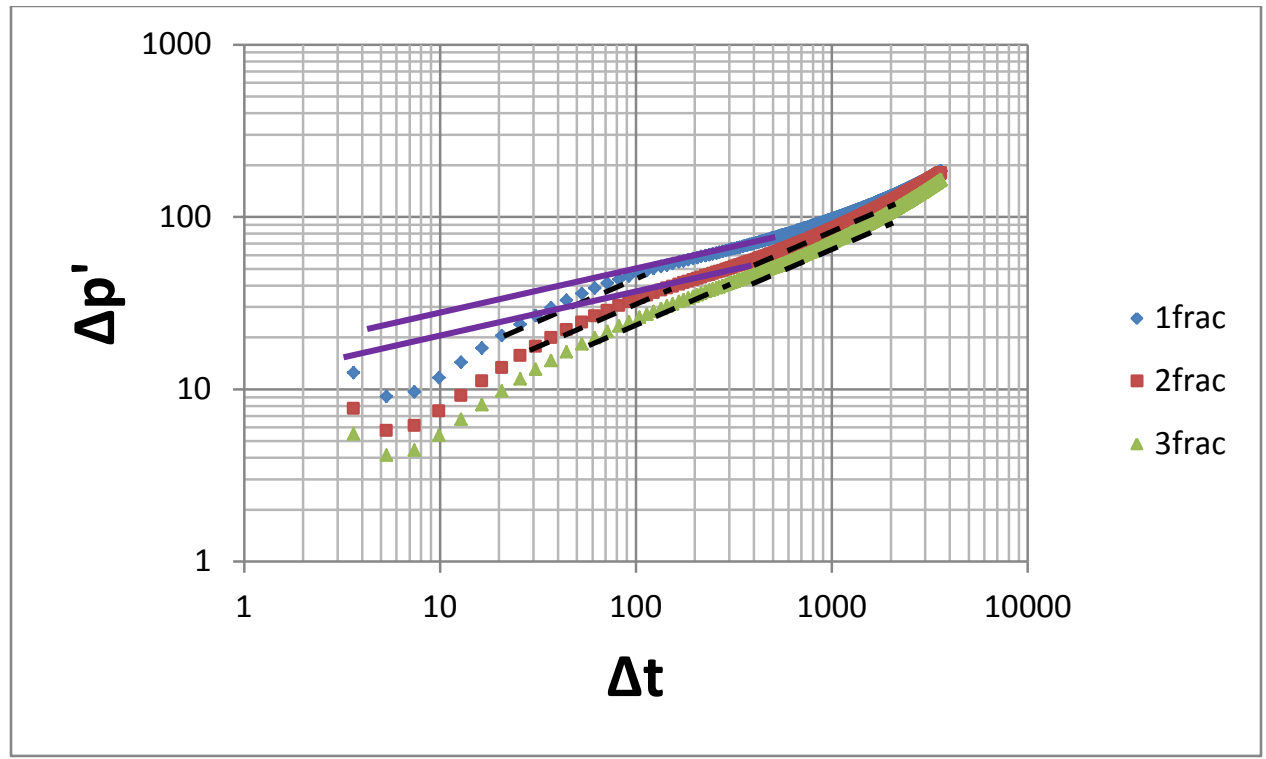




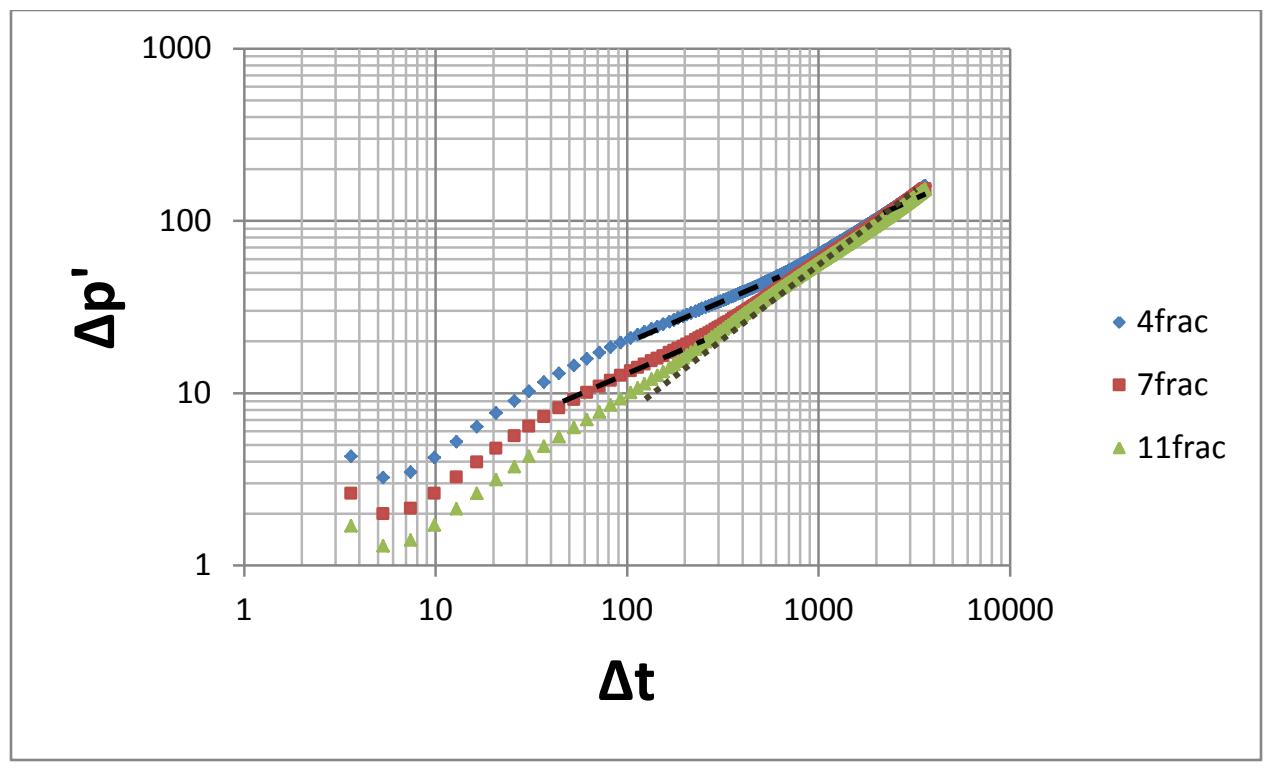




\section{Appendix 4}

Case 4: Fracture porosity fraction $=0.005$

Bulk permeability $i, j, k(m d)=0.003,0.003,0.0003$

Horizontal well length $4000 \mathrm{ft}$

$\checkmark$ Case 4.1: $\mathrm{xf}=300 \mathrm{ft}$, width of fracture $=0.01$ in ,permeability of fracture $=10000$, porosity of fracture $=0.2$

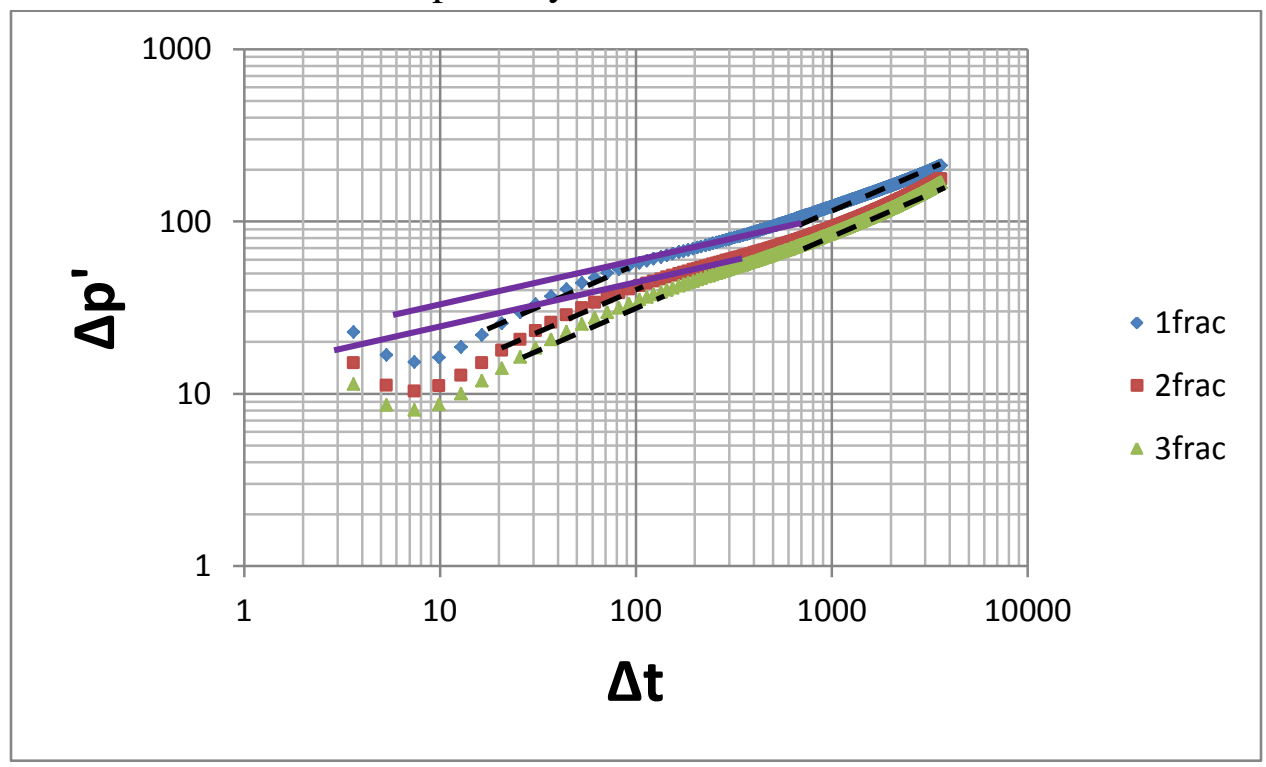




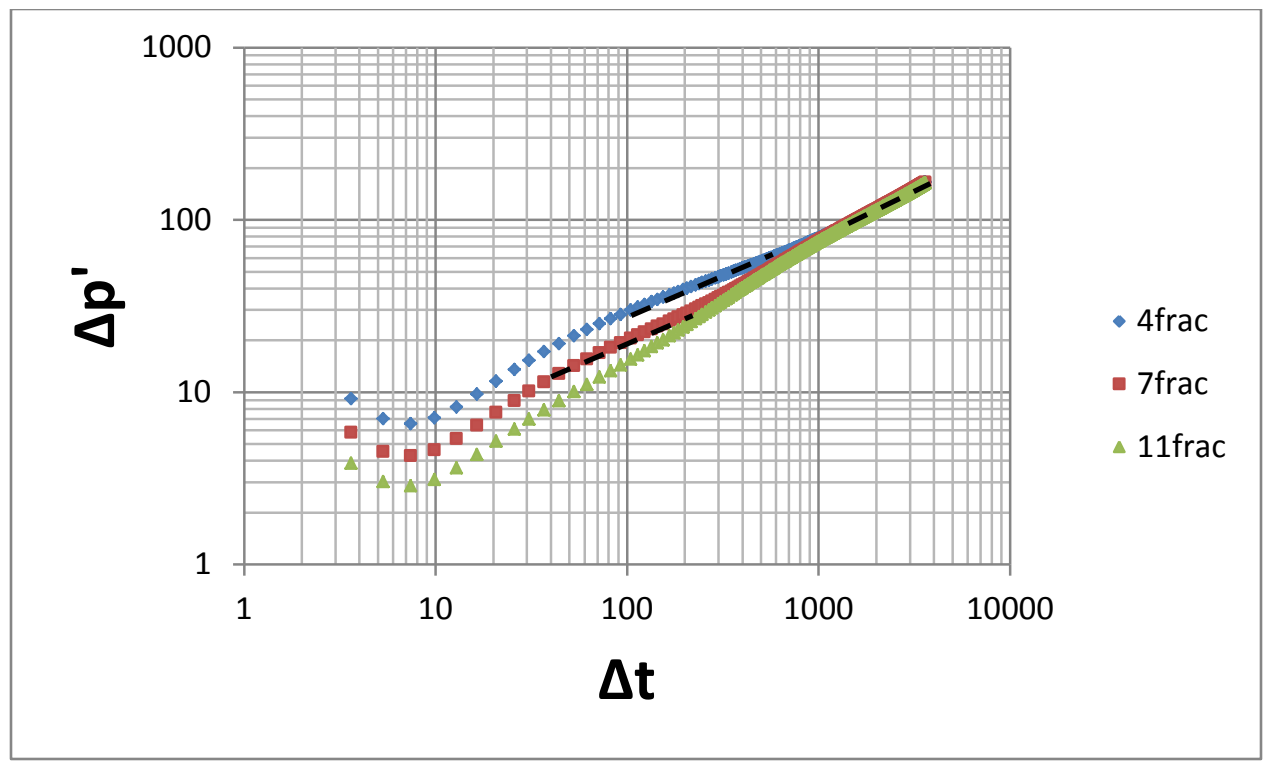

$\checkmark$ Case 4.2: $\mathrm{xf}=300 \mathrm{ft}$, width of fracture $=0.1$ in ,permeability of fracture $=10000$, porosity of fracture $=0.2$

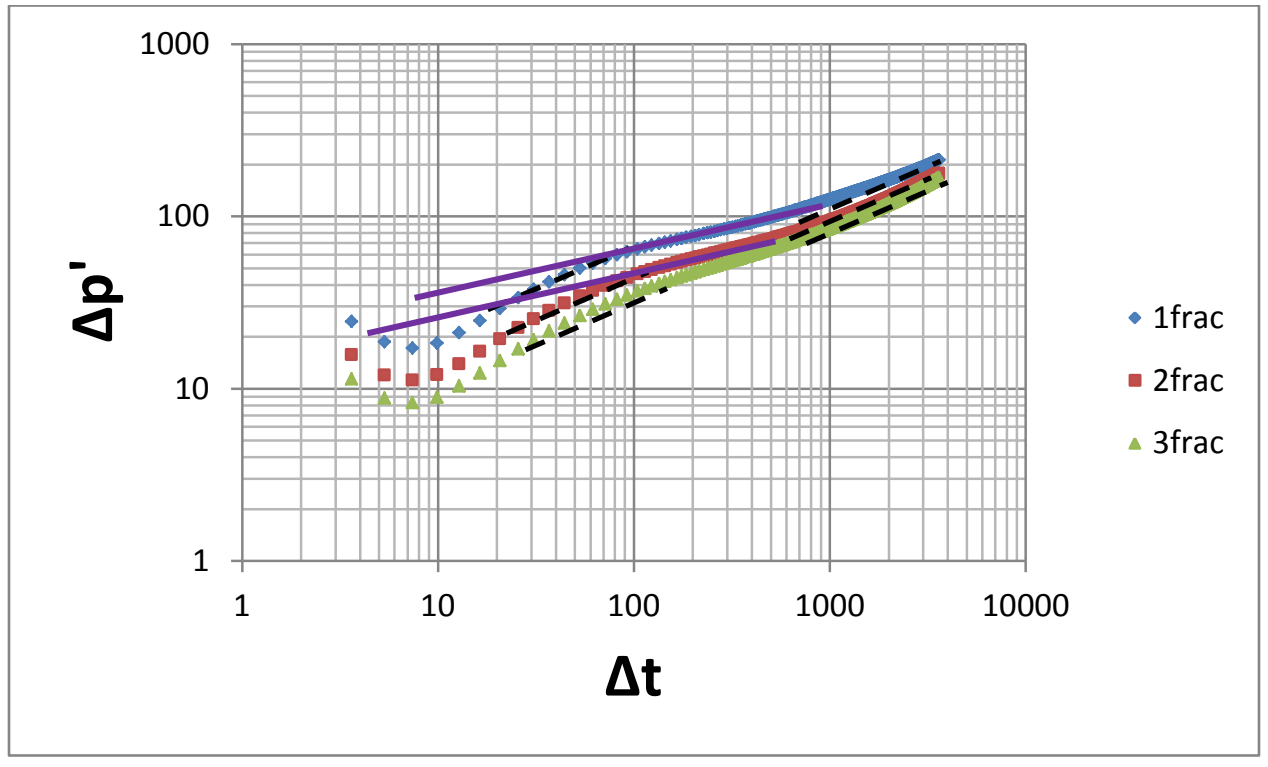




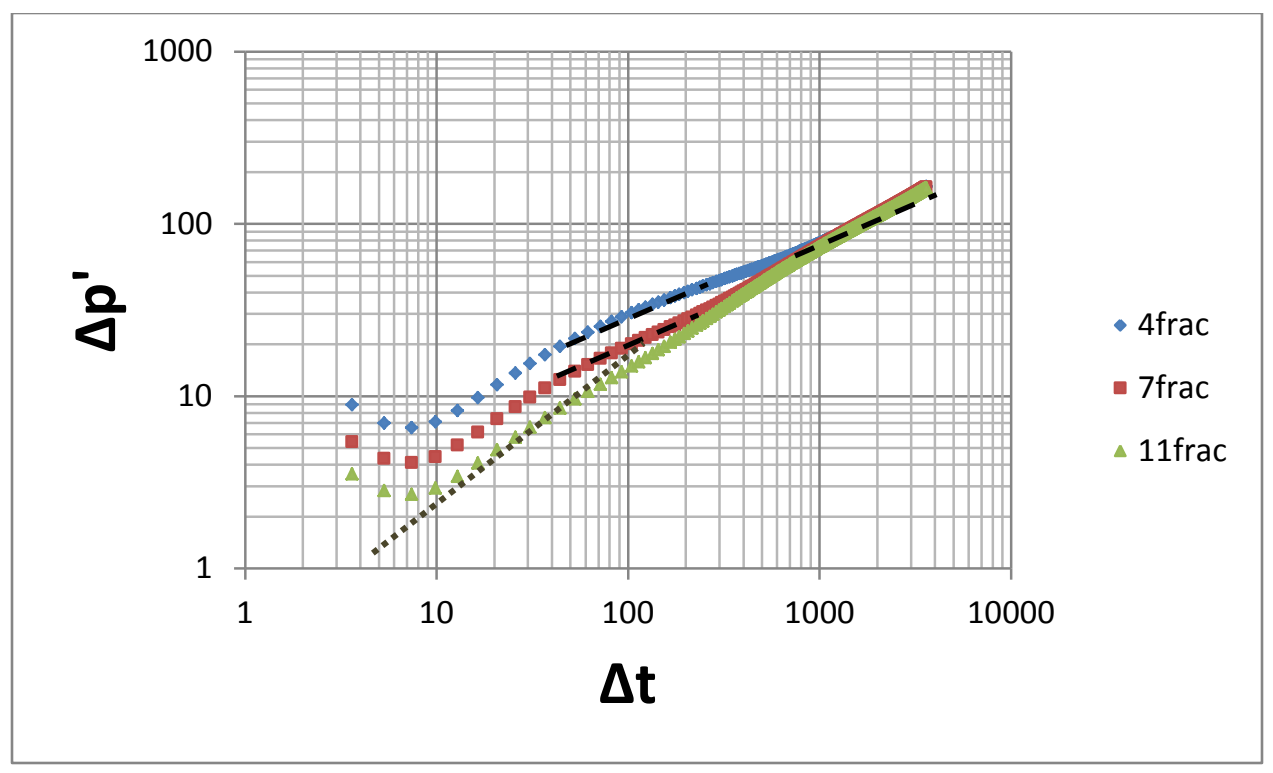

$\checkmark$ Case 4.3: $\mathrm{xf}=300 \mathrm{ft}$, width of fracture $=0.01$ in ,permeability of fracture $=40000$, porosity of fracture $=0.2$

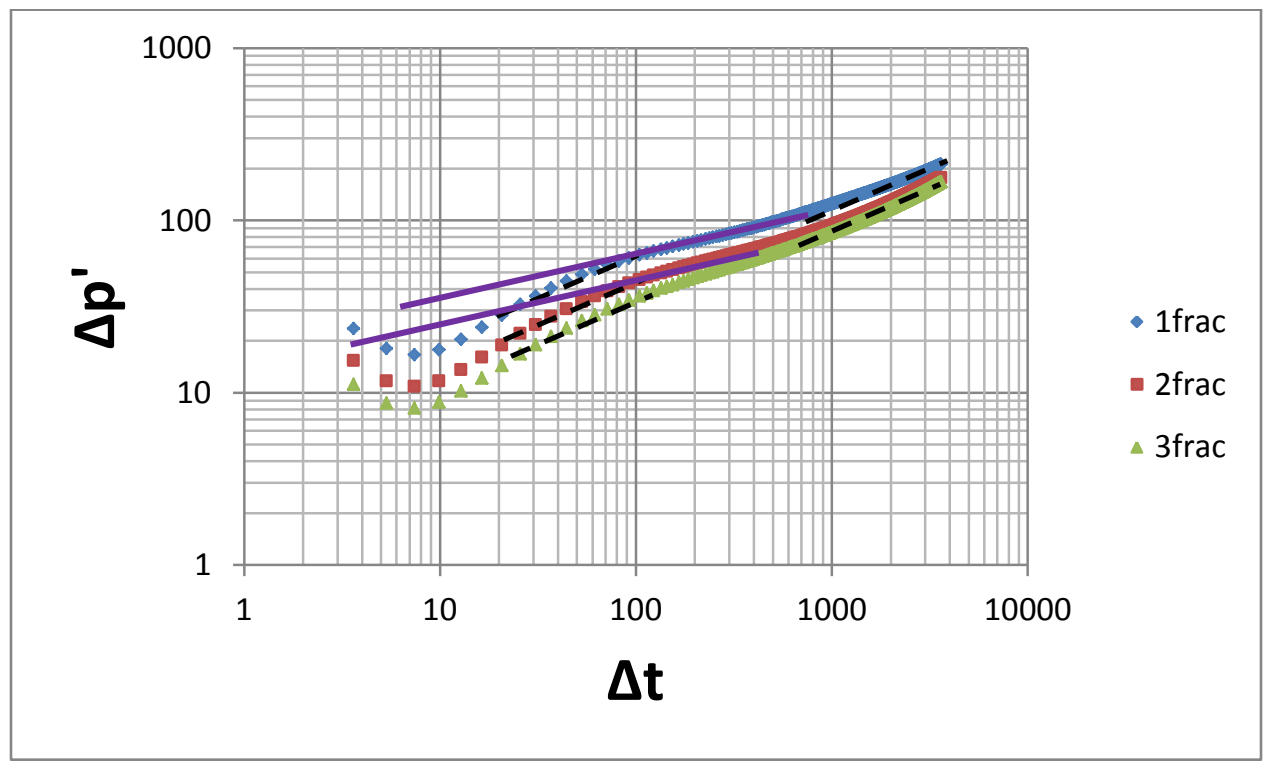




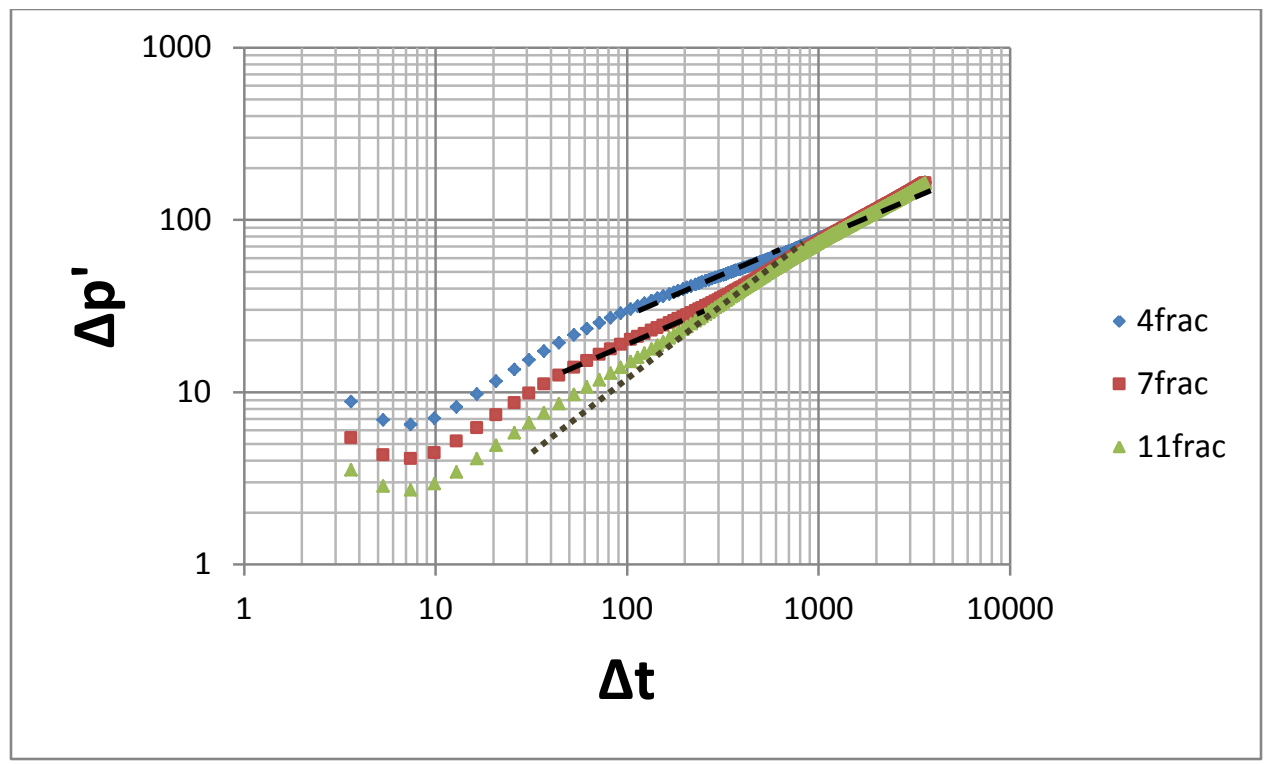

$\checkmark$ Case 4.4: $\mathrm{xf}=300 \mathrm{ft}$, width of fracture $=0.1$ in ,permeability of fracture $=40000$, porosity of fracture $=0.2$

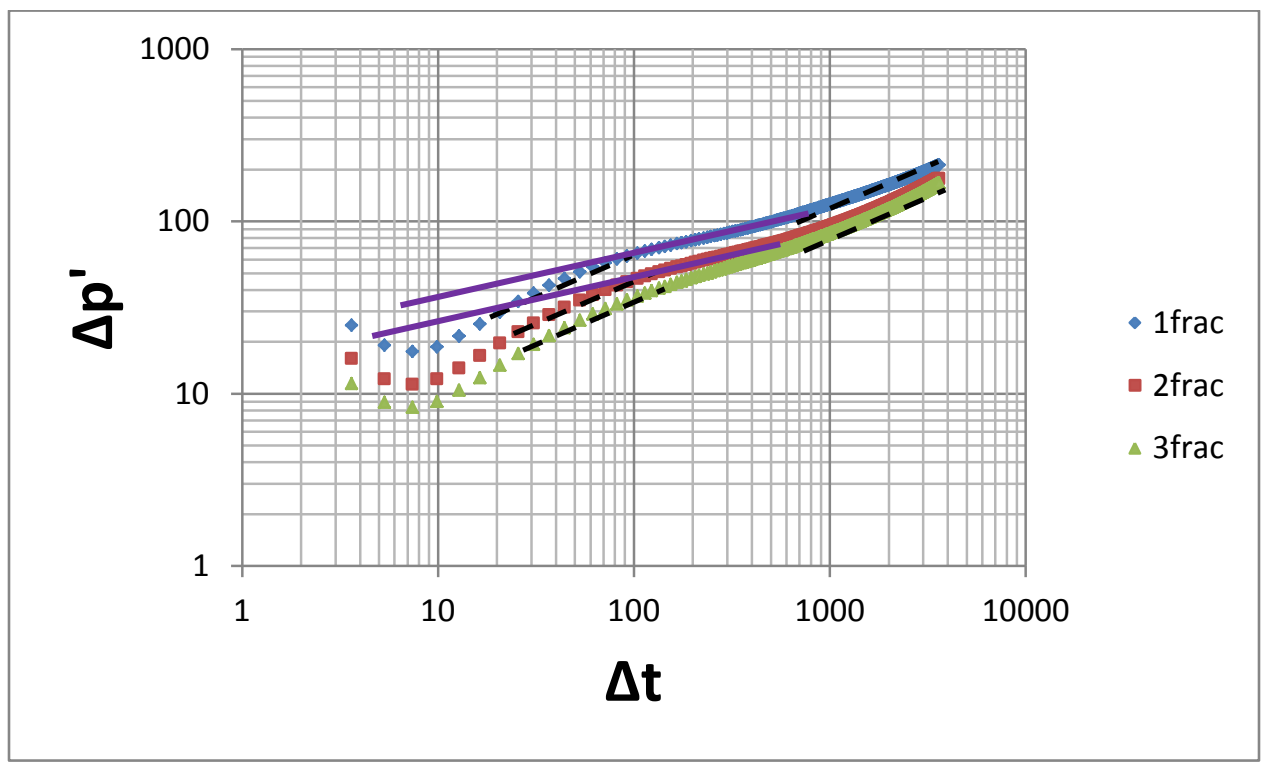




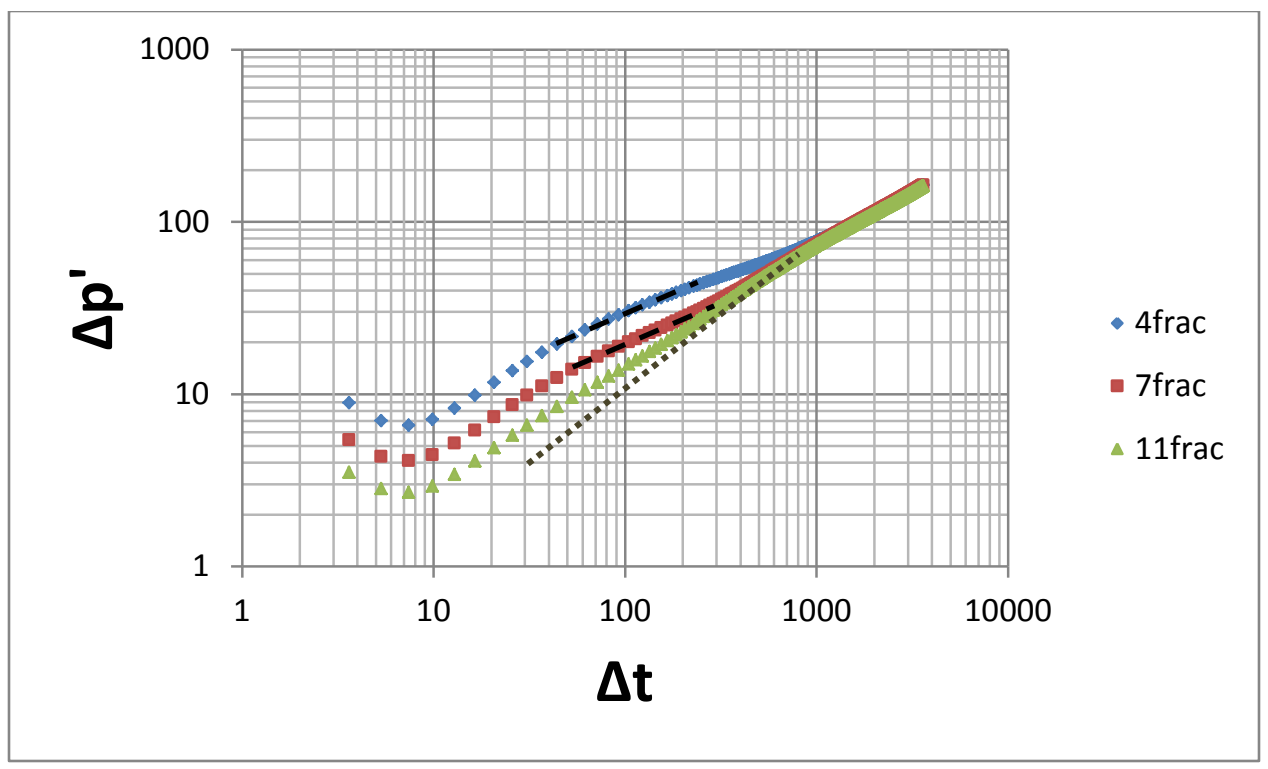

Horizontal well length $3500 \mathrm{ft}$

$\checkmark$ Case 4.5: $\mathrm{xf}=300 \mathrm{ft}$, width of fracture $=0.01$ in , permeability of fracture $=10000$, porosity of fracture $=0.2$

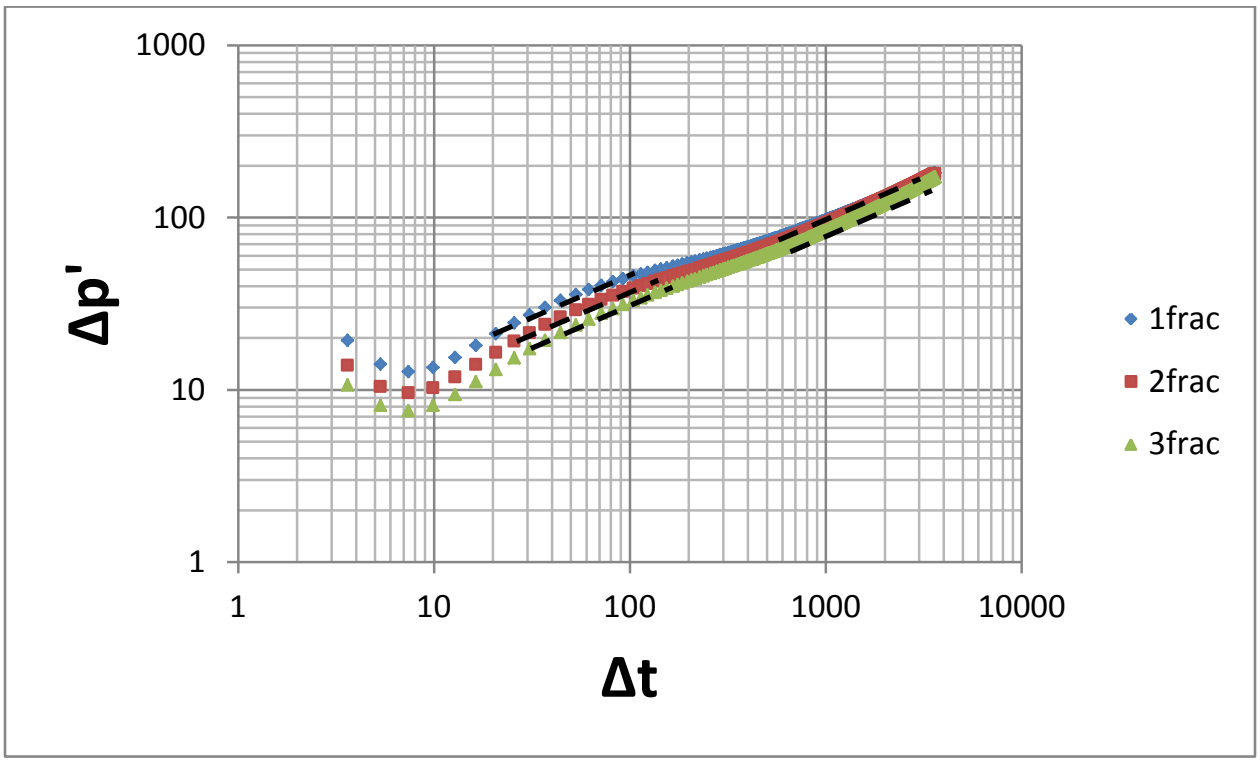




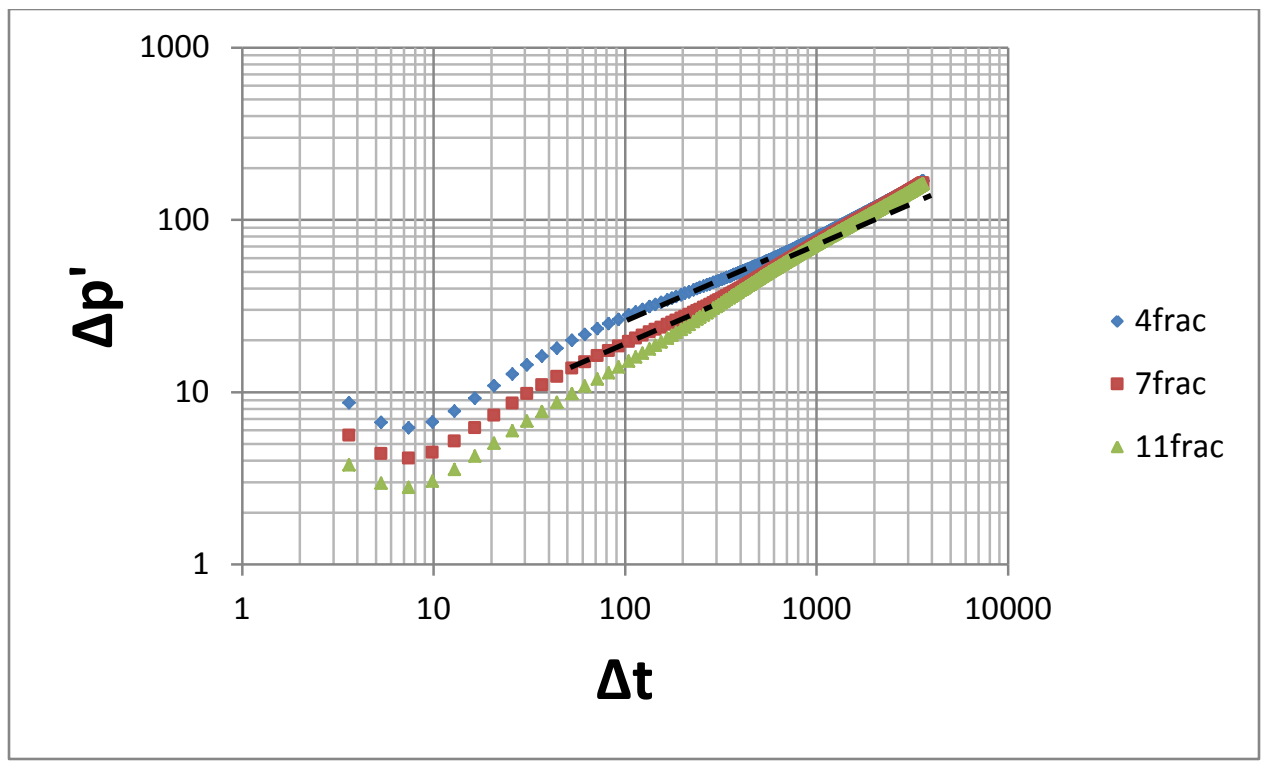

$\checkmark$ Case 4.6: $\mathrm{xf}=300 \mathrm{ft}$, width of fracture $=0.1$ in ,permeability of fracture $=10000$, porosity of fracture $=0.2$

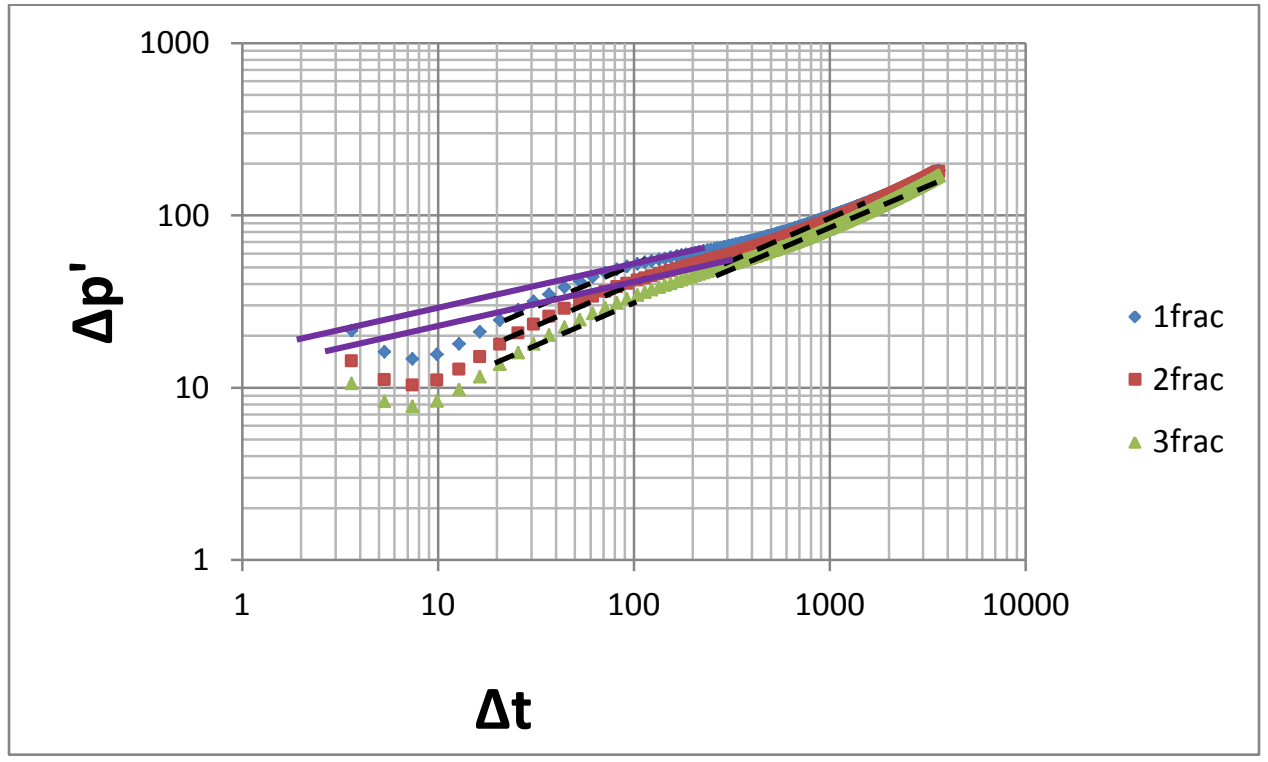




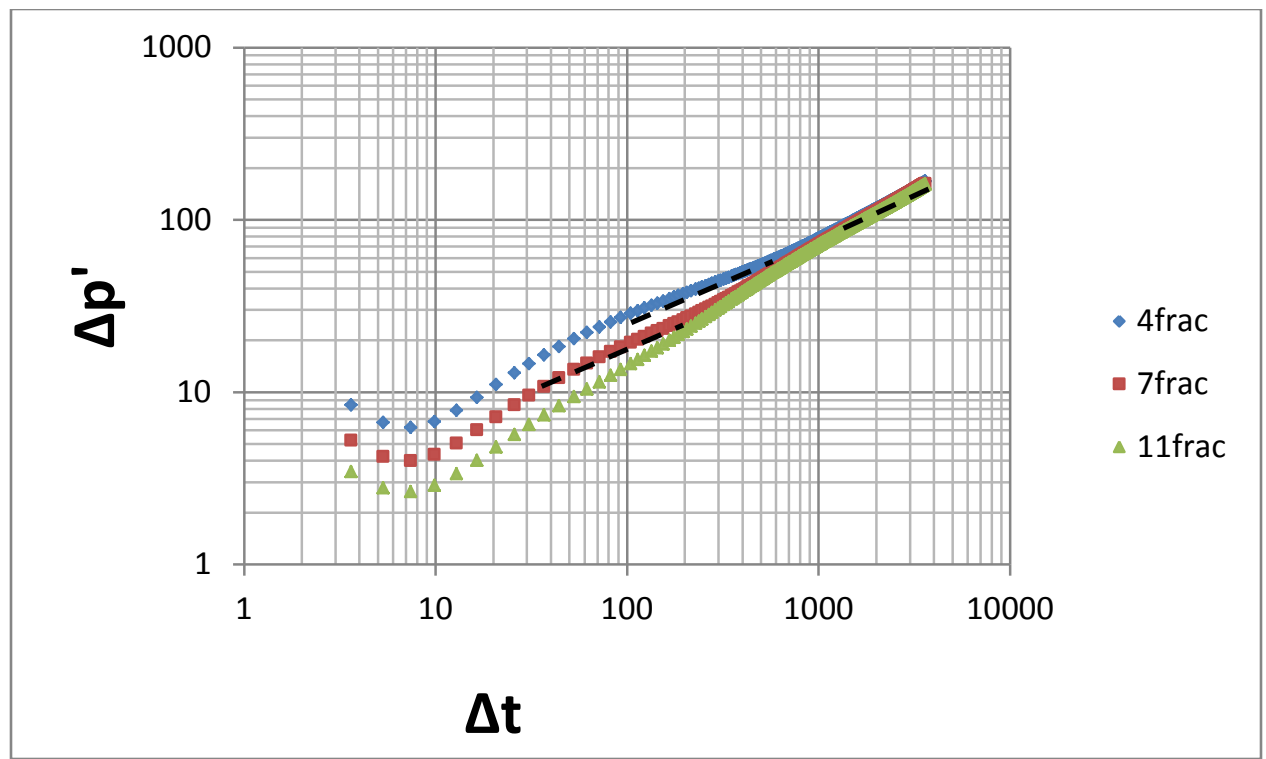

$\checkmark$ Case 4.7: $\mathrm{xf}=300 \mathrm{ft}$, width of fracture $=0.01$ in ,permeability of fracture $=40000$, porosity of fracture $=0.2$

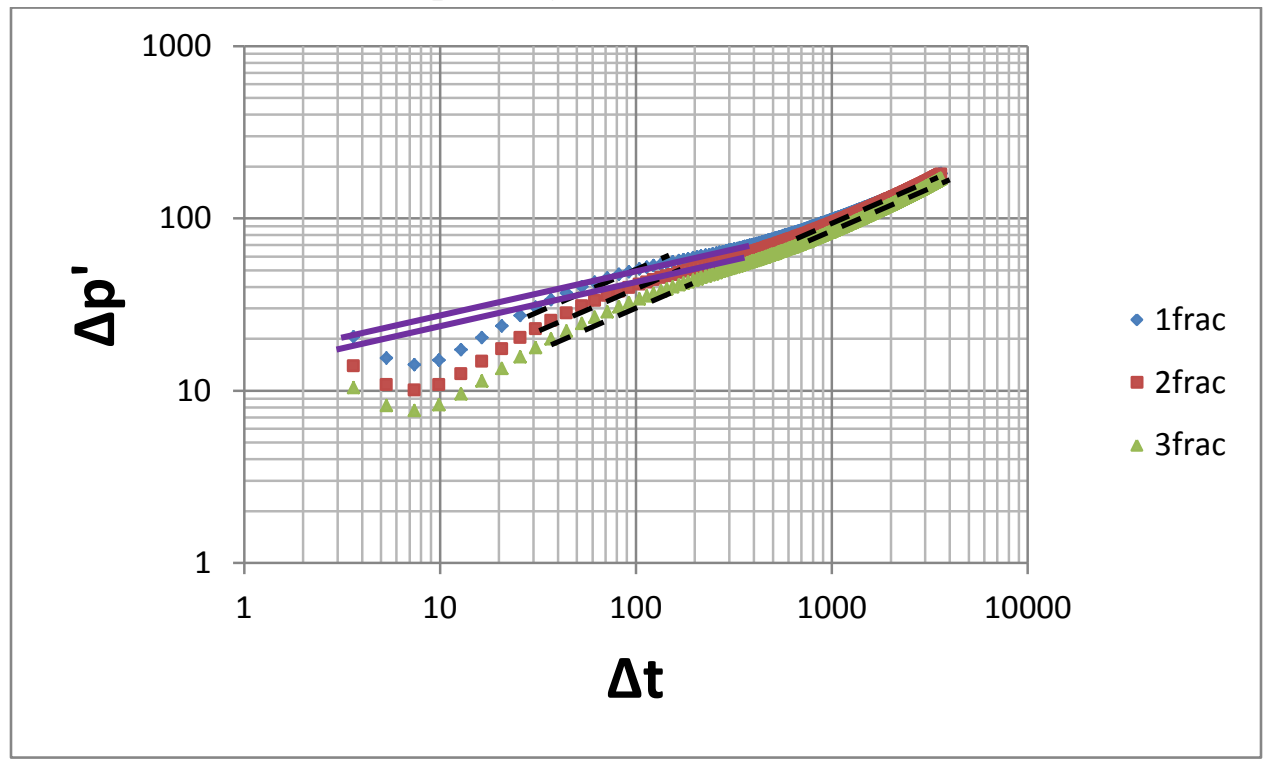




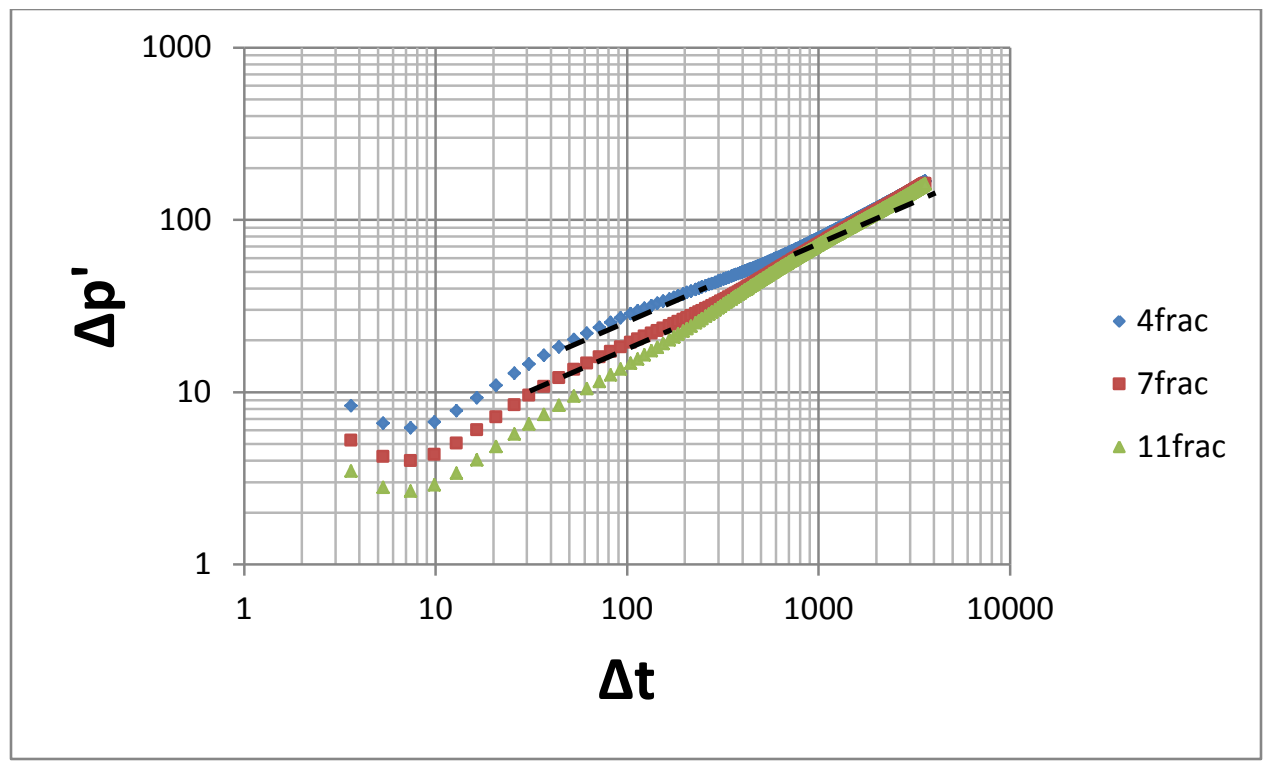

$\checkmark$ Case 4.8: $\mathrm{xf}=300 \mathrm{ft}$, width of fracture $=0.1$ in ,permeability of fracture $=40000$, porosity of fracture $=0.2$

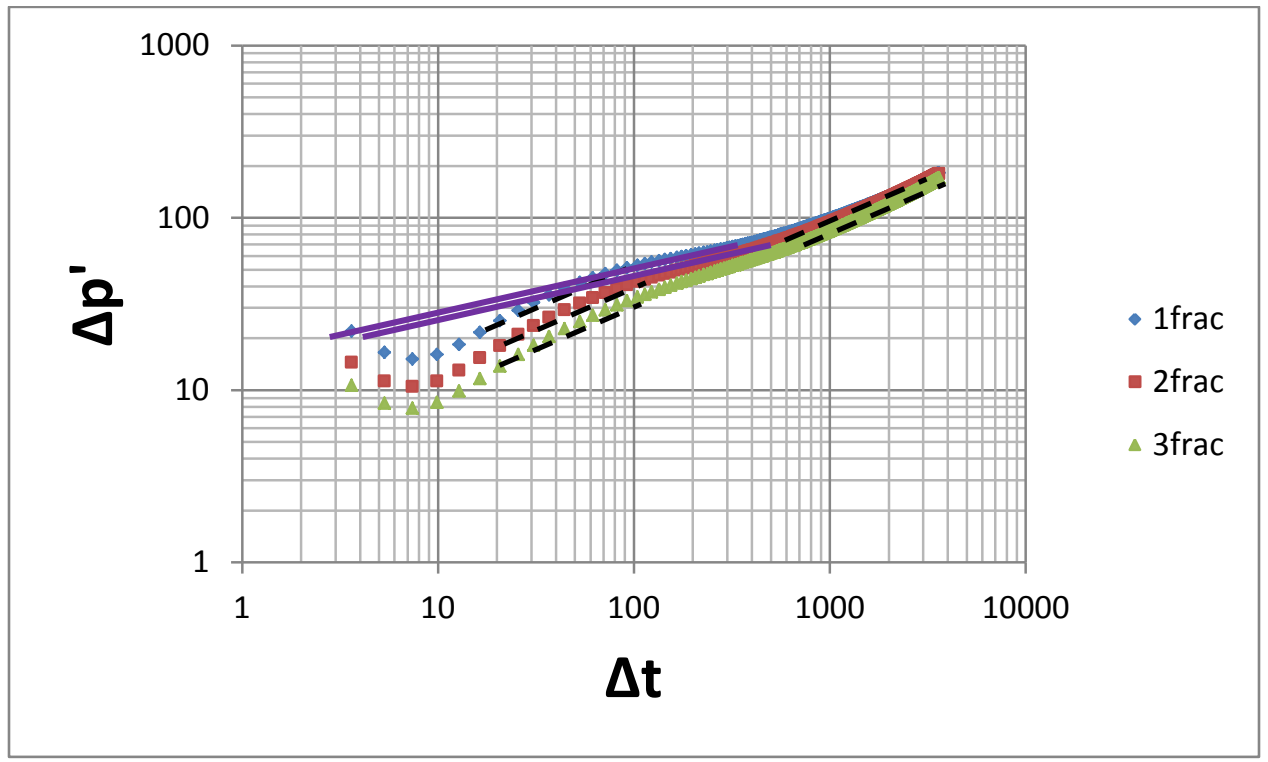




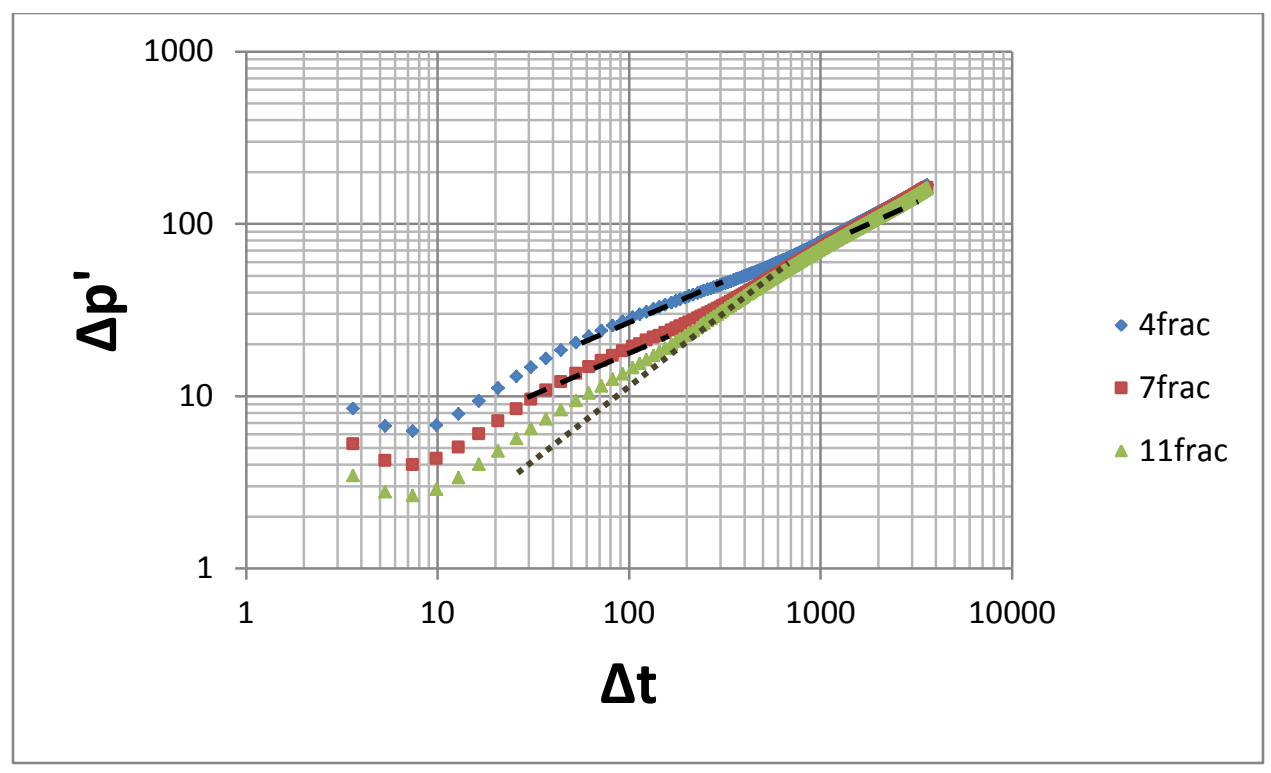

Horizontal well length $4000 \mathrm{ft}$

$\checkmark$ Case 4.9: $\mathrm{xf}=500 \mathrm{ft}$, width of fracture $=0.01$ in ,permeability of fracture $=10000$, porosity of fracture $=0.2$

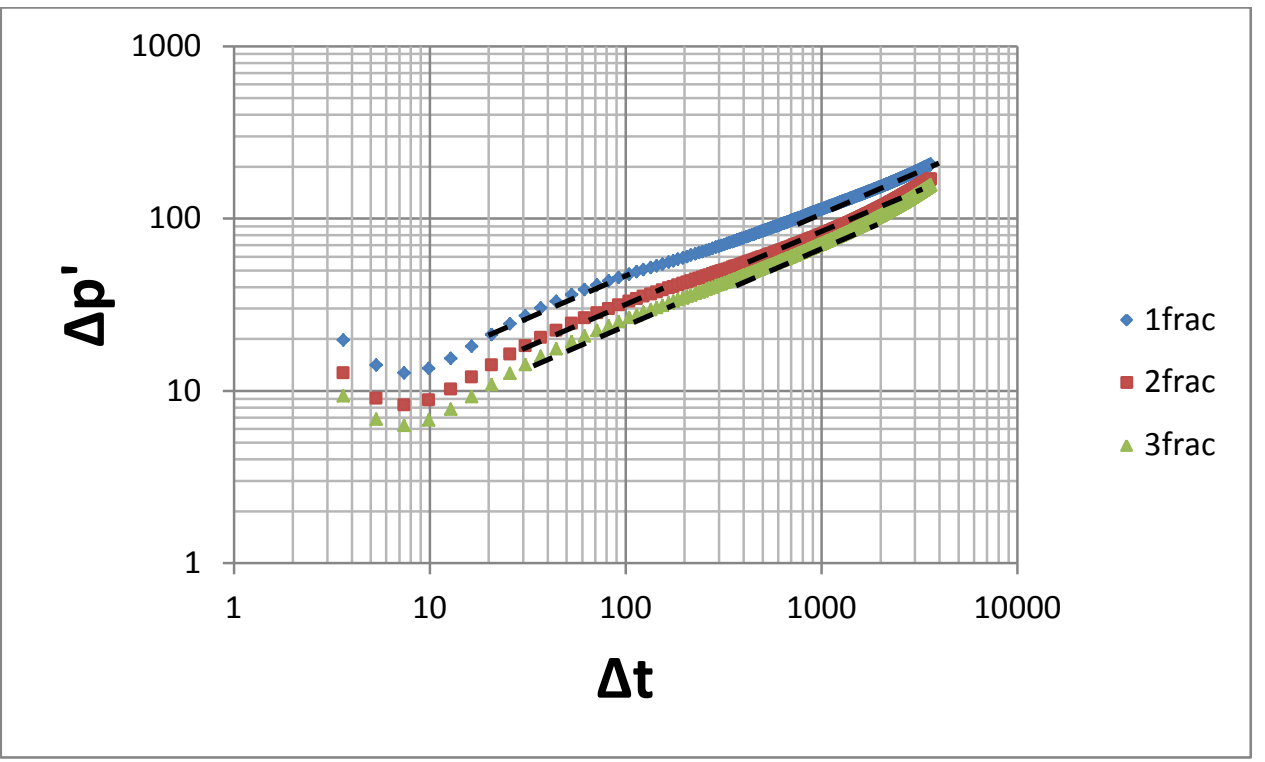




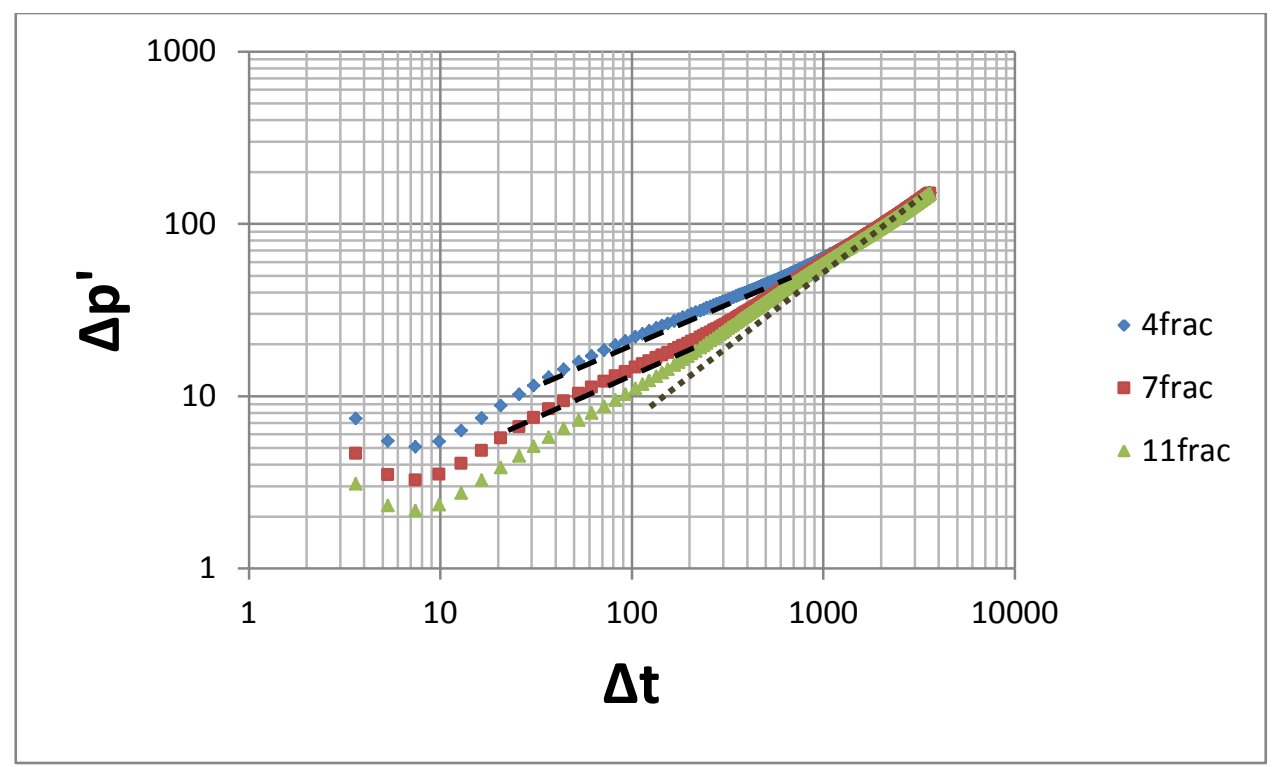

$\checkmark$ Case 4.10: $x f=500 \mathrm{ft}$, width of fracture $=0.1$ in ,permeability of fracture $=10000$, porosity of fracture $=0.2$

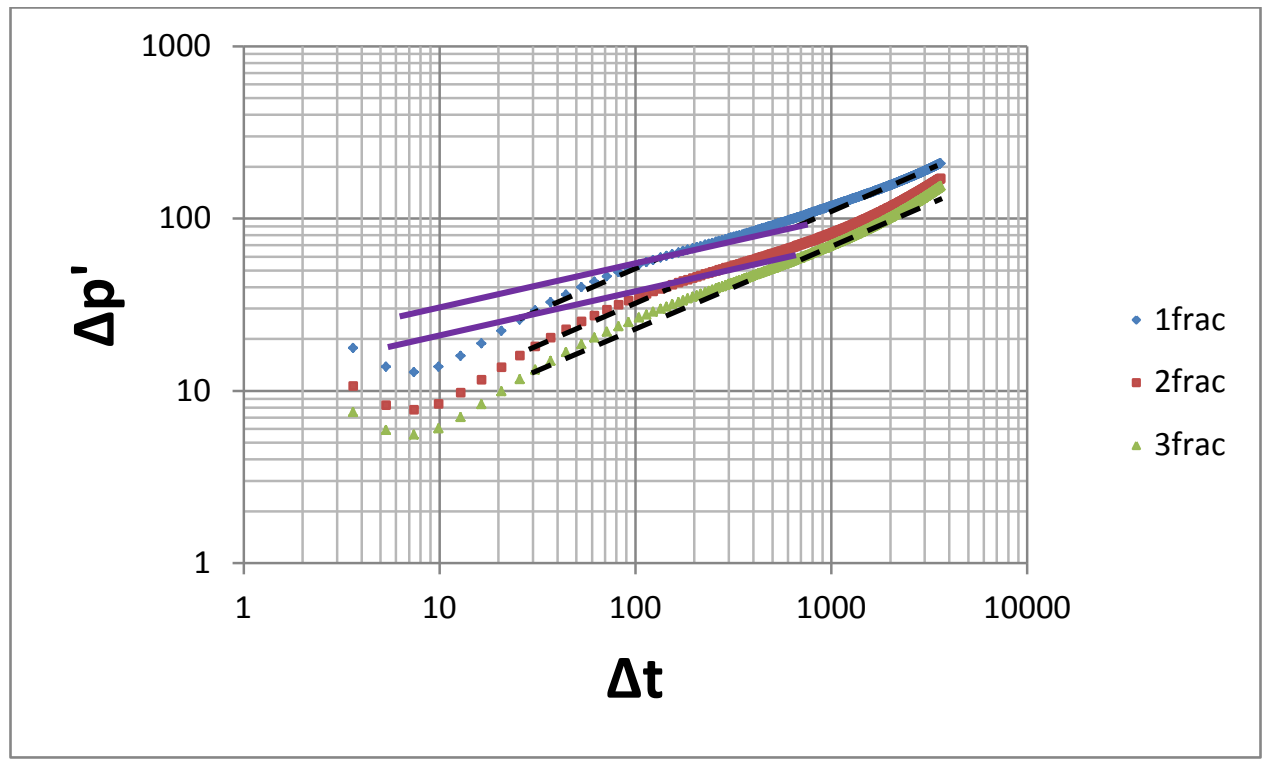




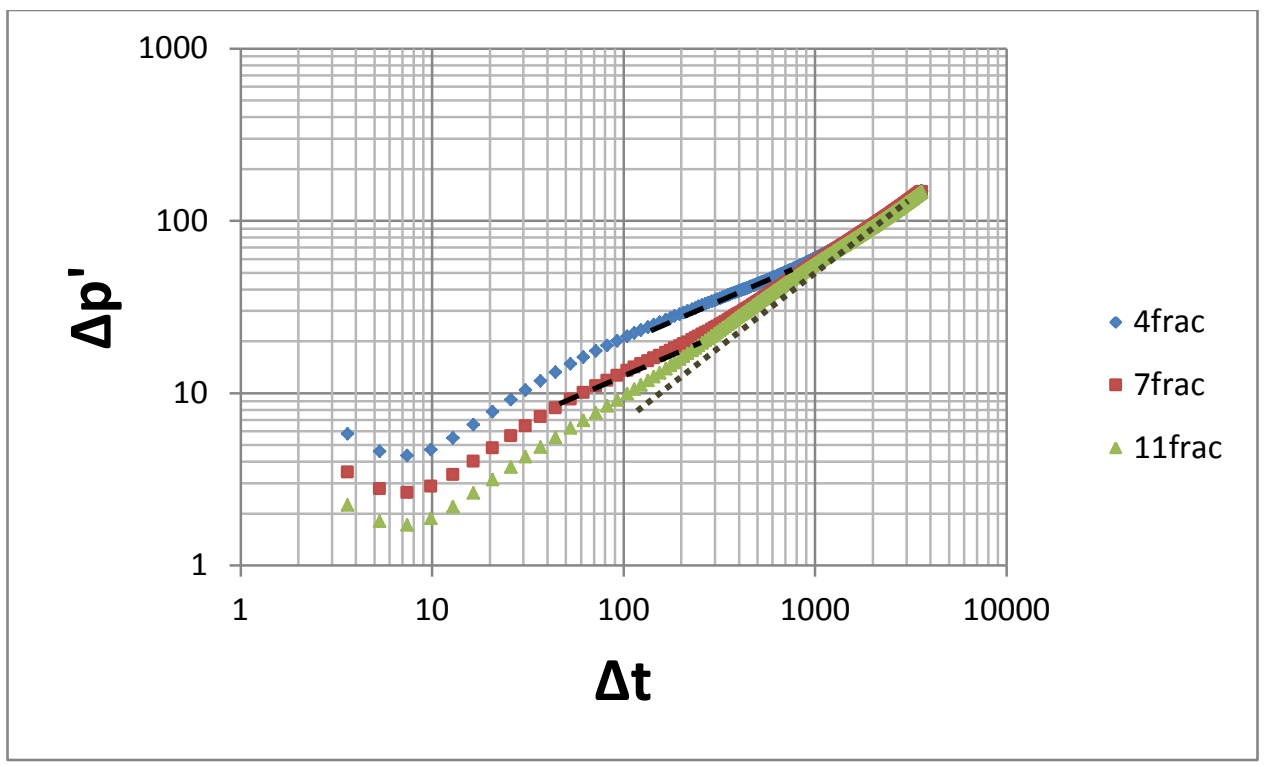

$\checkmark$ Case 4.11: $\mathrm{xf}=500 \mathrm{ft}$, width of fracture $=0.01$ in , permeability of fracture $=40000$, porosity of fracture $=0.2$

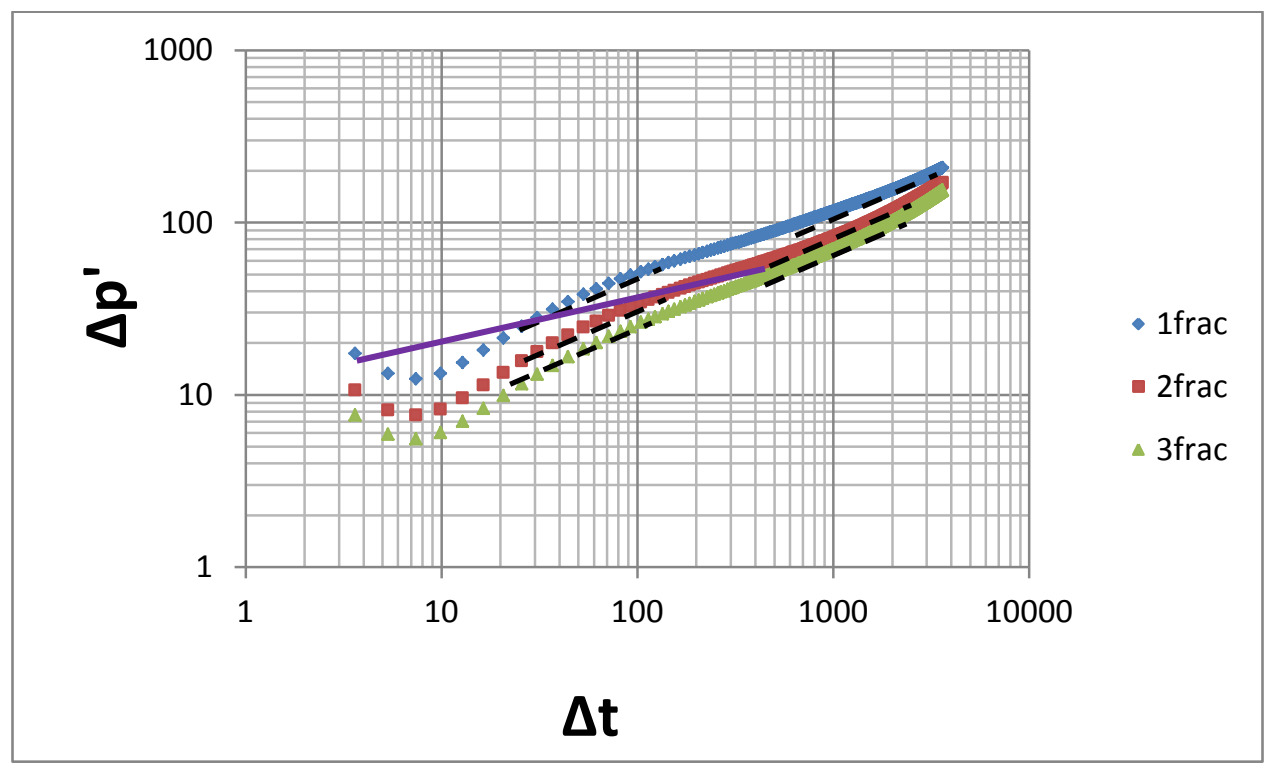




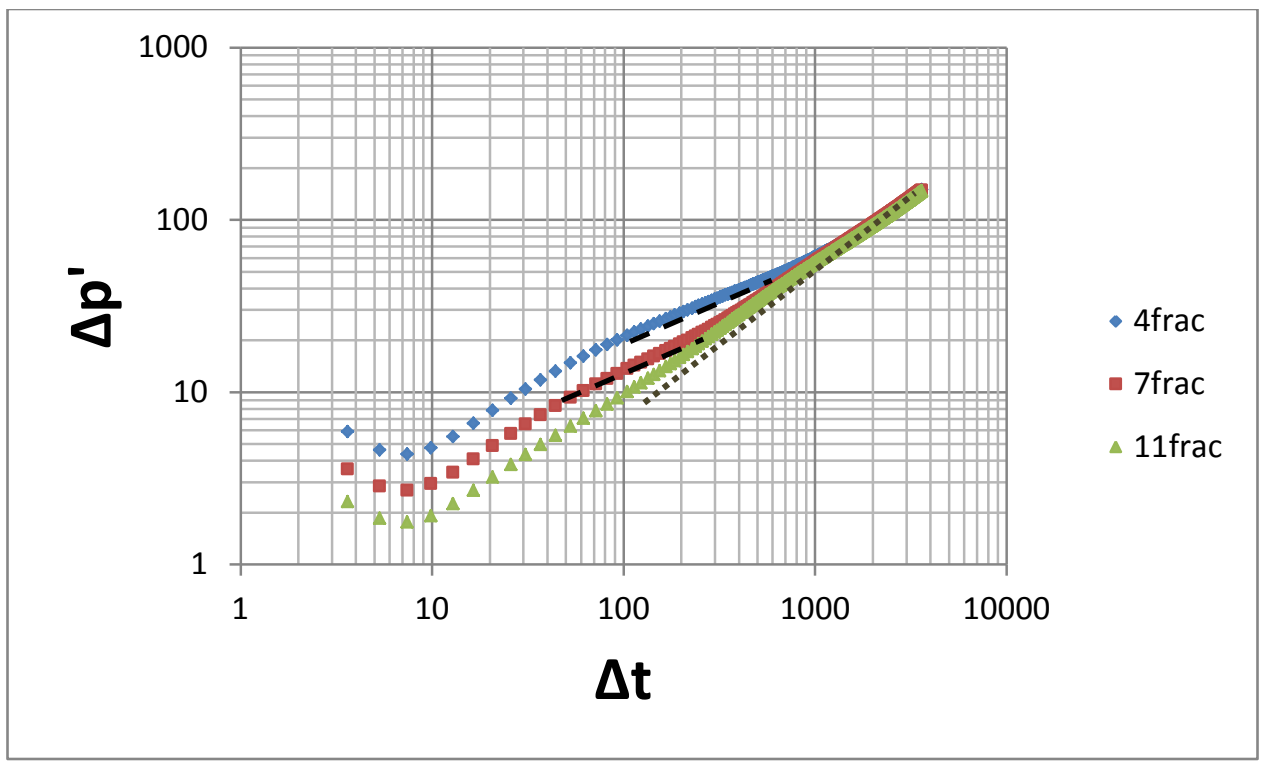

$\checkmark$ Case 4.12: $x f=500 \mathrm{ft}$, width of fracture $=0.1$ in ,permeability of fracture $=40000$, porosity of fracture $=0.2$

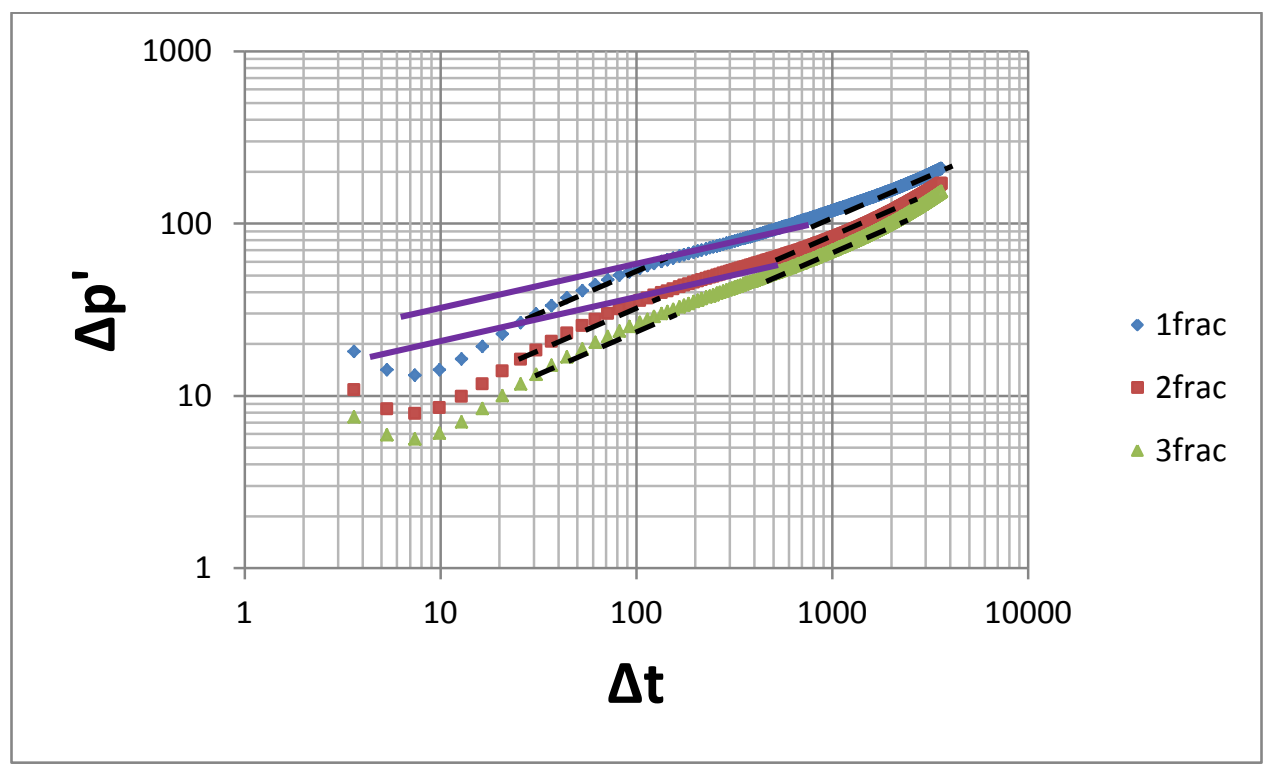




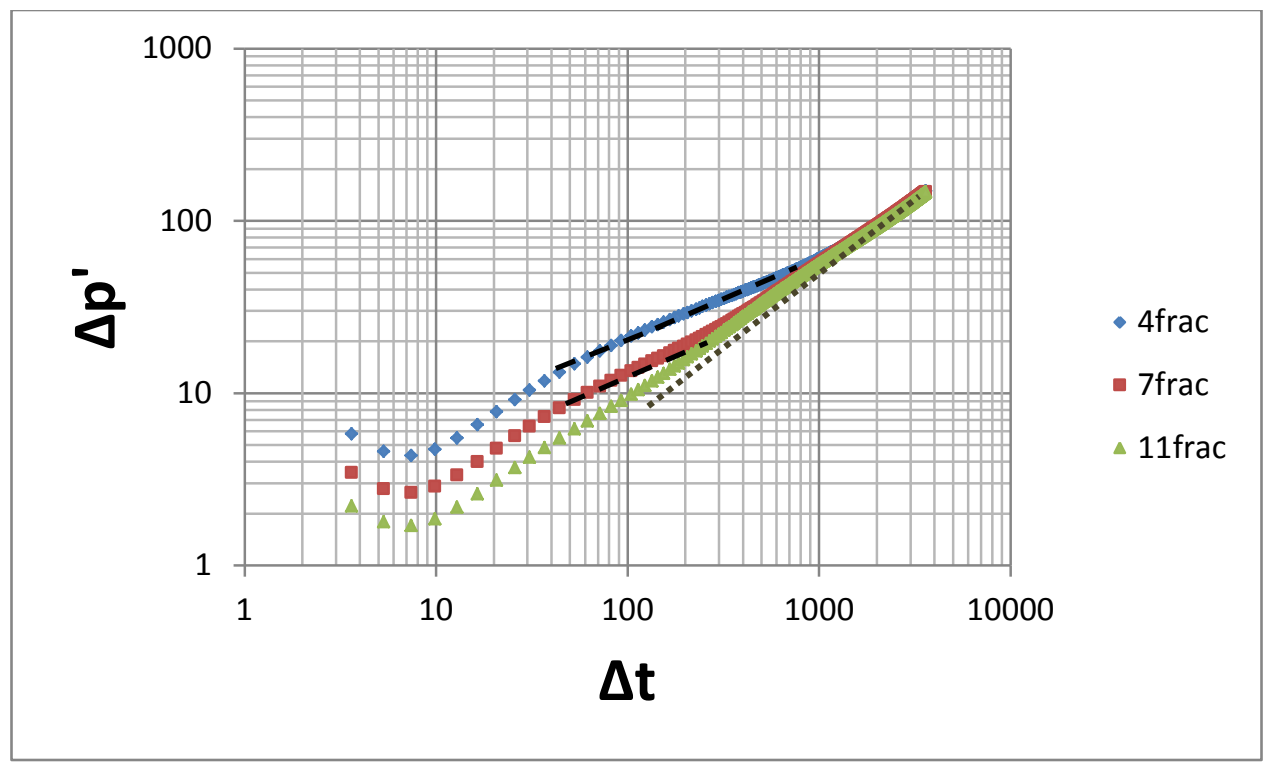

Horizontal well length $3500 \mathrm{ft}$

$\checkmark$ Case 4.13: $x f=500 \mathrm{ft}$, width of fracture $=0.01$ in , permeability of fracture $=10000$, porosity of fracture $=0.2$

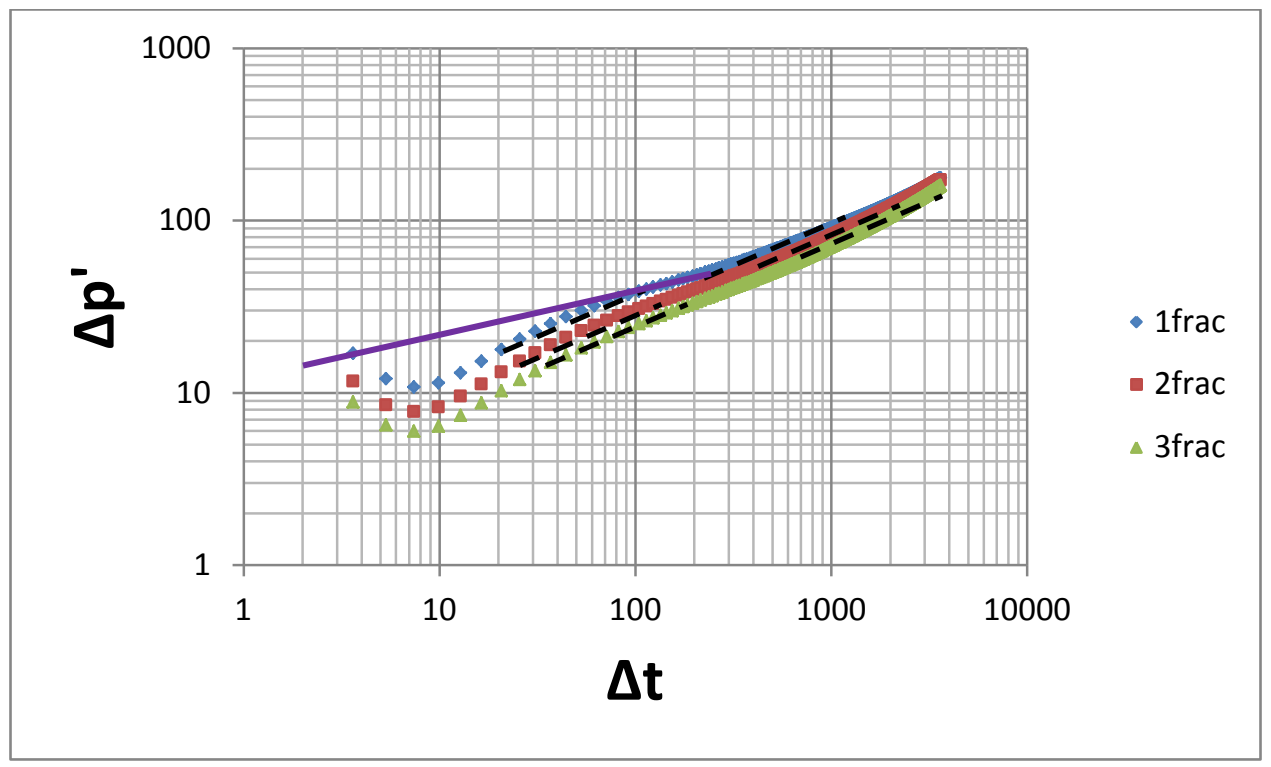




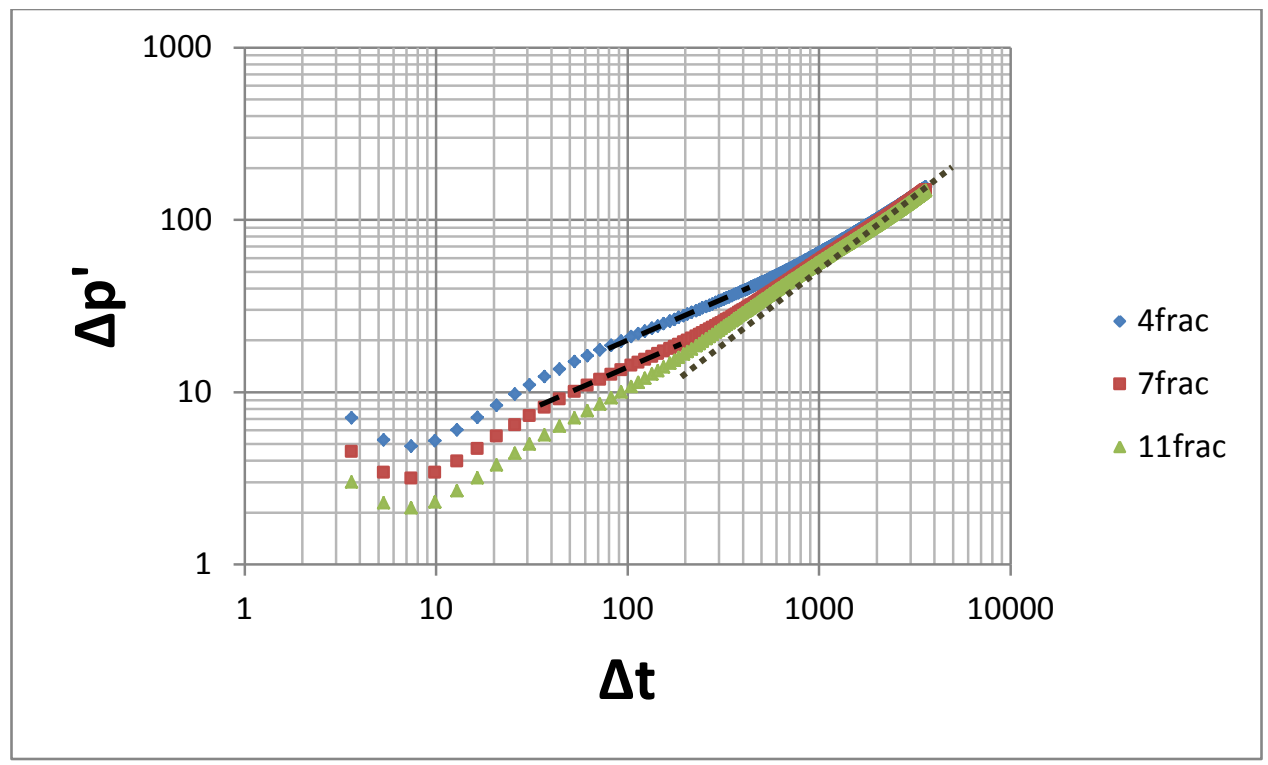

$\checkmark$ Case 4.14: $x f=500 \mathrm{ft}$, width of fracture $=0.1$ in ,permeability of fracture $=10000$, porosity of fracture $=0.2$

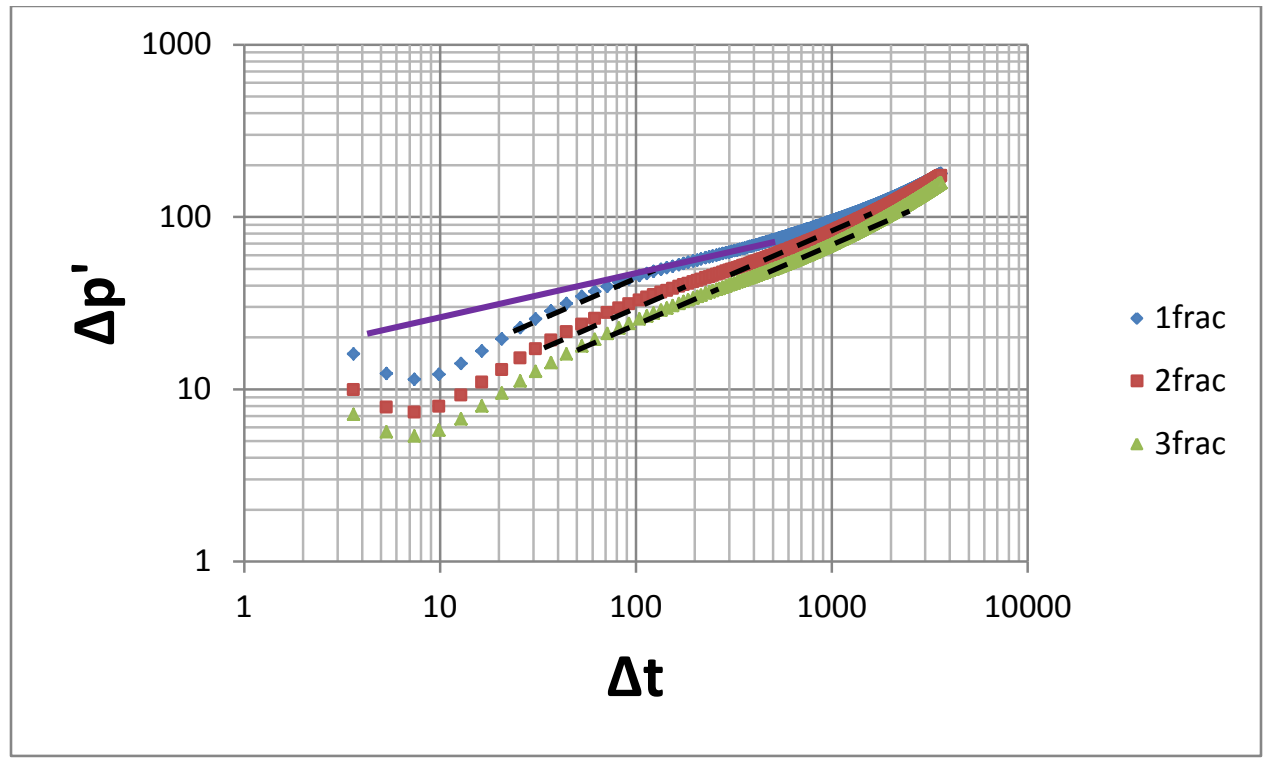




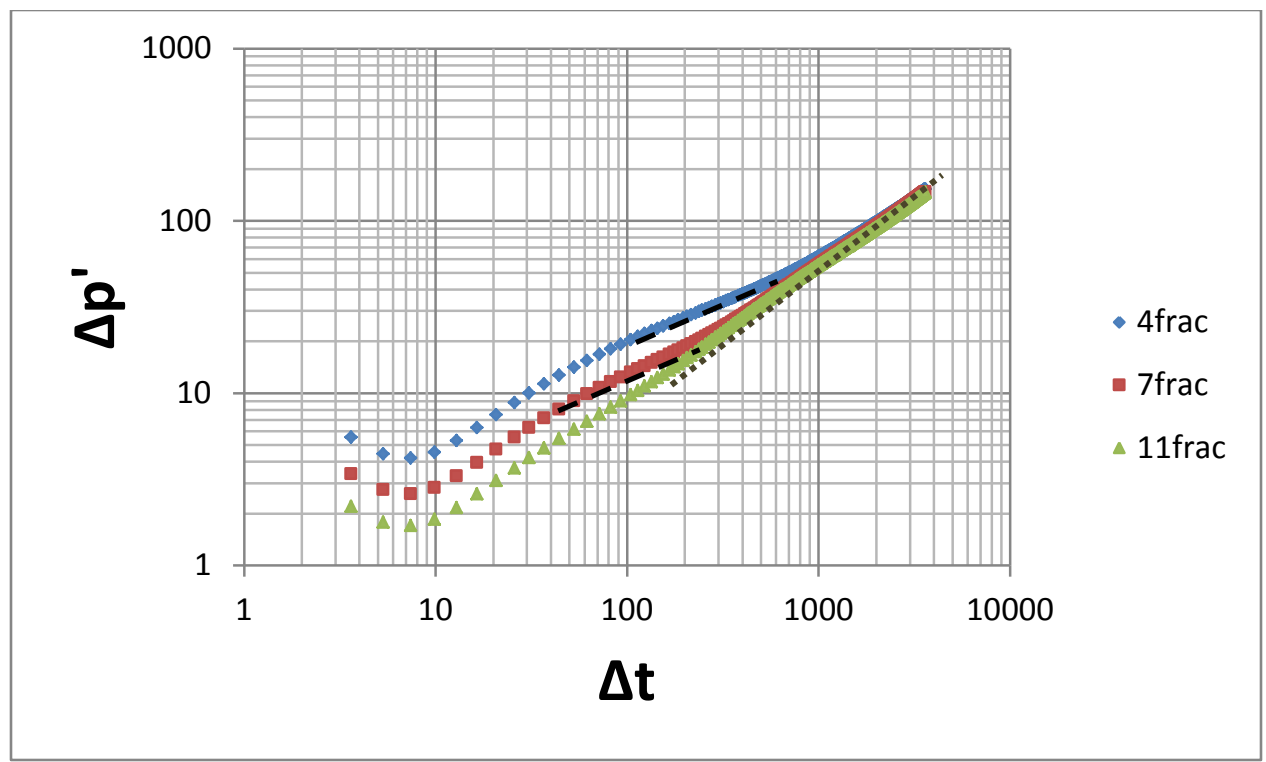

$\checkmark$ Case 4.15: $\mathrm{xf}=500 \mathrm{ft}$, width of fracture $=0.01$ in , permeability of fracture $=40000$, porosity of fracture $=0.2$

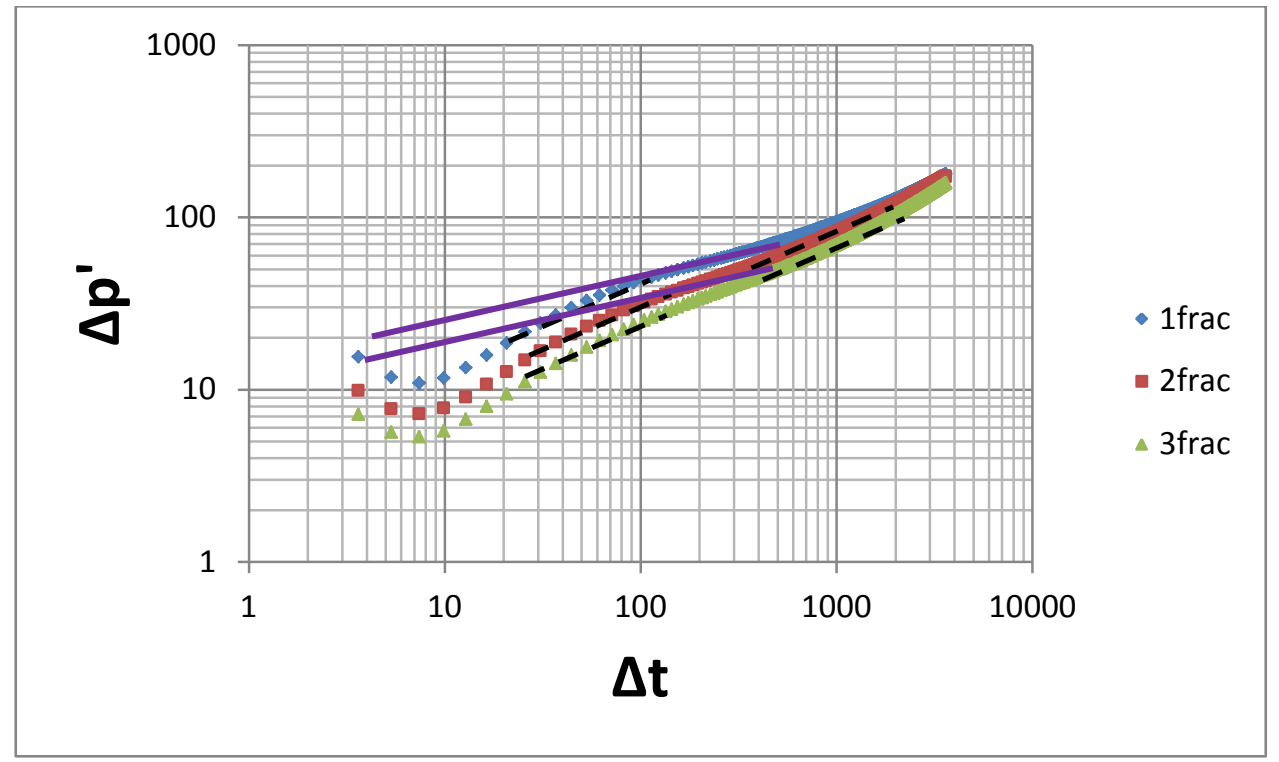




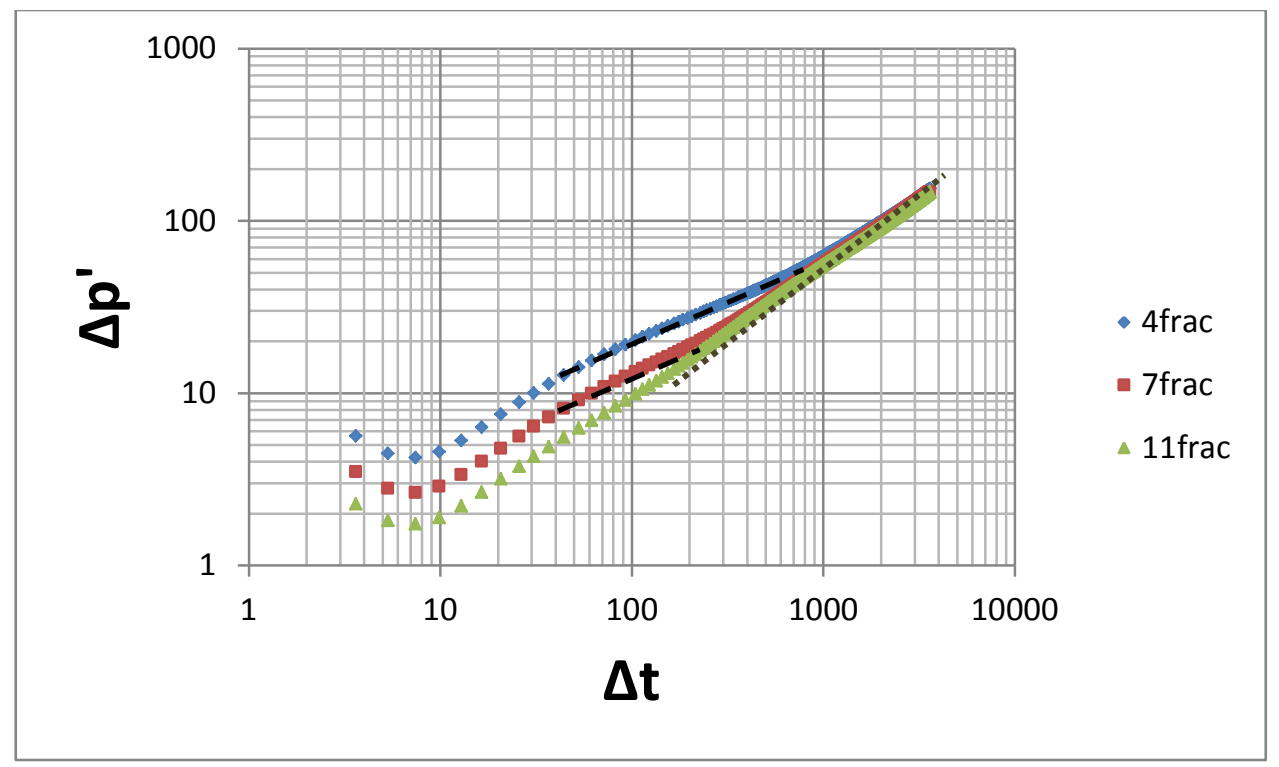

$\checkmark$ Case 4.16: $x f=500 \mathrm{ft}$, width of fracture $=0.1$ in ,permeability of fracture $=40000$, porosity of fracture $=0.2$

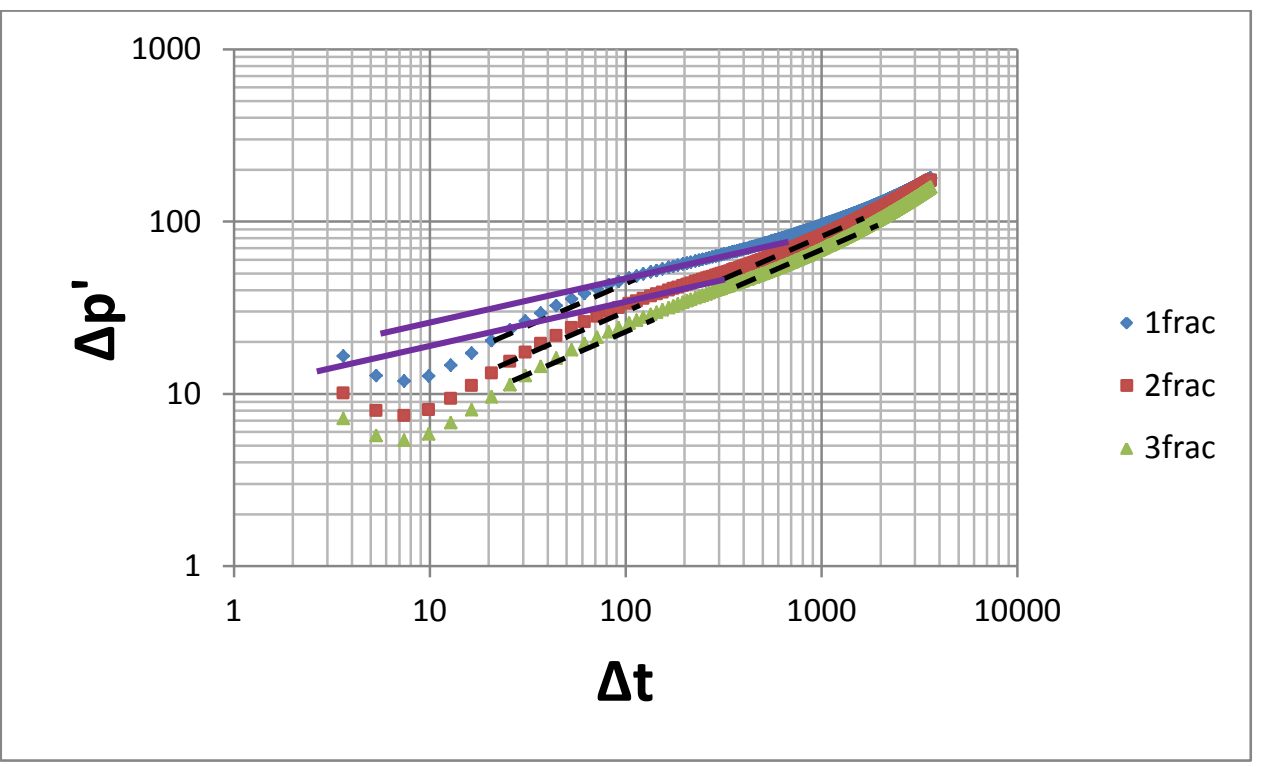




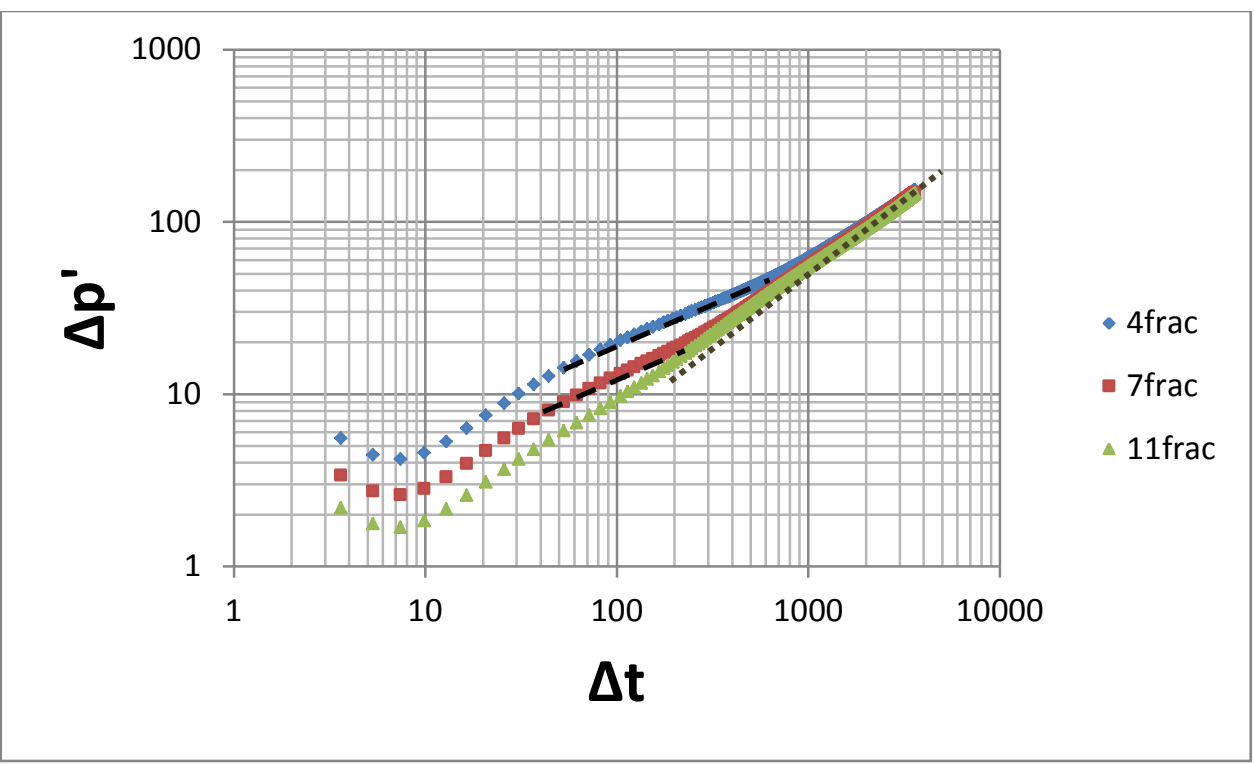

